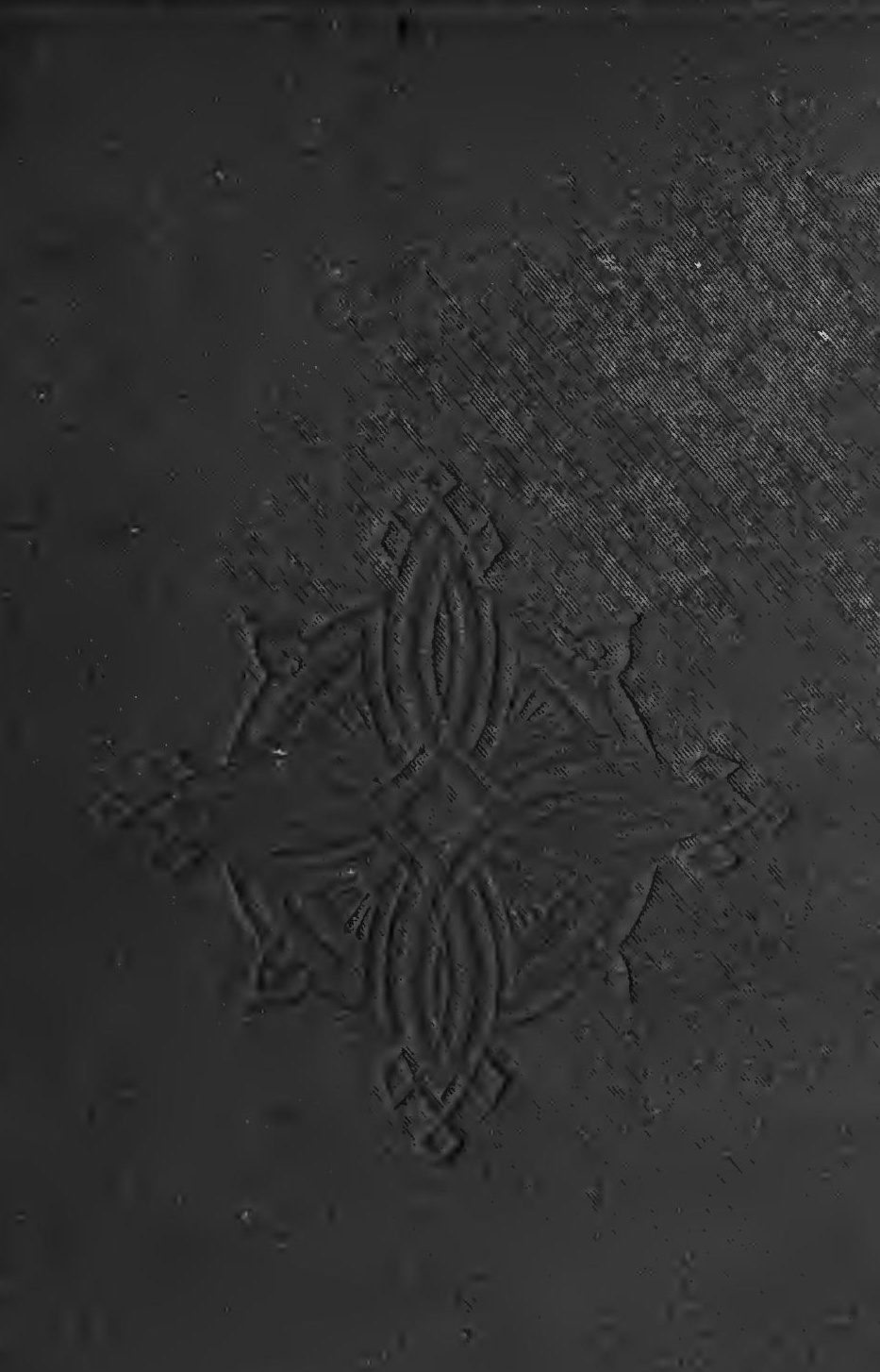




\section{LIBRARY \\ UNIVERSITY OF CALIFORNIA RIVERSIDE}



Digitized by the Internet Archive in 2007 with funding from Microsoft Corporation 



SIR: In the name and for the love of humanity, I implore you not only to accept the volume which $l$ have the honor to present to you, but to read witl prayerful consideration the appalling condition of the toiling and despairing masses; to note the wide-spread deterioration eating them up, body and mind; to consider the growing pauperism of our large towns from which all these evils spring, and to study the means of preventing this double bane of pauperism and deterioration.

Among the many subjects treated in this volume, I would direct your attention to the great waste of life among the laboring peo. ple, which crushes them, and hardens the hearts of those who wit ness this fearful loss unconcerned.

Early training in national infant schools, industrial education and suburban homes with garden plots, are discussed and recom mended as in keeping with the demands of science and humanity.

Look at our country-the people and its institutions-it is all a great field of labor and necessity, calling for action. Each is complaining and looking for help to the other, while each is guilty of selfish neglect and indifference, and our country is degenerating. The consumption of intoxicating liquors, of tobacco and opium and with it insanity, suicide, vice and crime, are increasing; wild speculation and disinclination to healthful labor are spreading among men; private and public corruption are becoming common, and our prisons are being filled with men of position, to whom the rising generation looked for an example of honorable usefulness. Our cicilization, like that of Ancient Rome and Greece, must end in ruin, unless we succeed in applying proper remedies against these social evils.

If I am not mistaken, honest labor is the NEED of the HouR, alike demanded by the physical, mental, moral and financial condition of the nation. Industrial education alone can bring about this change, by joining with labor, skill, dignity, and honor.

I call the attention of my countrymen and women to this book, because it accords with the better tendencies of the age and human nature; it is positive in its results, and shows more convincingly than any other work, that the needed reformation must be brought about in the Kindergarten, the Developing School, and the Manual Institute, all elucidated in the Eighth Part of this book, under the heading, "The Need of the Nation."

A favorable expression from the leading men and women of the world, the press and the libraries of America and Europe, in reference to the spirit and matter of this volume, will assist in the good which may be accomplished by spreading its contents.

Yours truly,

ElizABETH Thompson.

124 West 45th Strcet, New York City. 


\title{
DETERI.ORATION AND
}

\section{RACE EDUCATION.}

\author{
WITH
}

PRACTICAL APPLICATION TO THE CONDITION OF THE PEOPLE AND INDUSTRY.

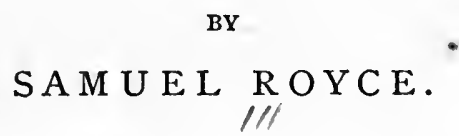

THE SACREDNESS OP HUMAN LIFE INCREASES WITH CIVILIZATION,

$$
\text { BOSTON: }
$$

LEE A N D HEPARD, PUBLISHERS. NEW YORK : CHARLES T. DILLINGHAM. 


\section{$\angle C 19$ I \\ R68}

COPYRIGHT, $1877, \mathrm{BY}$

SA UEL ROYCE. 
DEDICATED TO

MRS. ELIZABETH THOMPSON, THE PATRIO'T AND PHILANTIIROPIST, WHO DEVOTES HER ENERGIES TO THE ELEVATION OF THE MASSES THROUGH INDUSTRIAL EDUCATION, AND LABORS FOR THE IMPROVEMENT OF THE CHARACTER OF THE, MEN AND WOMEN OF AMERJCA

THROUGH THE KINDERGARTEN, BY THE AUTHOR. 



\section{P R E F A C E; \\ OR, \\ LETTER OF INTRODUCTION.}

My CHILD :-Amid the severe pressure of daily labors and cares I have tended you. Under deprivation and humiliation $I$ had but a cheerful countenance for you. Many a long winter's night I have watched over you, nursed and taught you until the sun rose, and my weary head without repose entered upon the struggle of the day. It is time you go forth and stammer your lesson to the world. Your dress is simple, for service and not for parade, but your armor shall make you strong in battle.

There is no loss of force. The life and spirit of my sweet little Julia, which floated away from her while I attended to you and your wants, will be with you; and however much you may be abused, never mind, if only thereby other children will be treated more tenderly, and will be kept alive and be made happy.

The perishing masses are the import of thy message; nothing can save them but an Education aiming in all its parts at the preservation of the individual and the race. Nothing but the solidarity of mankind, or, in more homely phrase, the 
feeling of mutual responsibility, can give stability to society tottering to its very base. Want almost general can only be allayed by industry as universal. Home, the school of great and small, health of body and mind, city and country, institutions, and whatever influences the well-being of individuals and States; the jail, the hospital, the battlefield, the shop and the bankinghouse, the past as well as the present, whatever touches man, is part of thy message-be brief, but hide nothing.

Proclaim the true spirit and principle of Education; when you will have done that, the people will know the rest, as Education embraces the whole of life, and ten thousand times ten thousand rules would leave the subject as incomplete as ever.

When your message, burdened with facts and figures, fatigues the listener, retire not unwillingly to the shelf, satisfied that the solidity of thy arguments will secure to your message another hearing.

And now, child of my riper age, of many labors and anxious hours, I trust you and your message to justice that never fails in the end.

May success attend you, not for my sake, nor for your sake, but for the sake of the Education of the Race, and the saving of the masses that perish to-day:

THE AUTHOR. 


\section{O NTENTS.}

Preface, .

Introduction,

Race Deterioration

Rate of Mortality,

Rate of Insanity,

Rate of Crime,

Blinduess and Deaf-mutism,

Unfitness for the Military Service,

Factory Population,

Consumption,

Scrofula,

Changes of Mortality Rates,

General Deterioration, .

Pauperism, . . . . $\quad$ • . . 449

Remedies, . . . . . . . 58

Education and Race Preservation, . . . $\quad 62$

Degenerated Tribes, . $\quad . \quad \ldots \quad . \quad . \quad .65$

Degeneracy in Tenement Houses, . . . 66

The Evolution of Education, . $\quad . \quad . \quad .67$

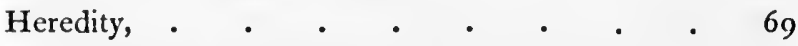

Race Education Defined, . . . . $\quad 7^{6}$

Race and Scholastic Education, . . . . 80 
Race and Scholastic Education compared, $\quad . \quad 82$

Systems of Education,. $\quad$. $\quad . \quad$. 90

Race and Individual Education, . . . . I .

Race Education further Expounded, . . . 105

Race Fducation and Division of Labor, . . . III

Woman's Work, • • . . . . • II2

The School and the Home, . . . . . II5

The Development of Education, • • . . II7

Our Civilization and Deterioration, . . . . I 9

Education and Individualism, . . . . I2I

Race Education and Hygiene, . . . . . 124

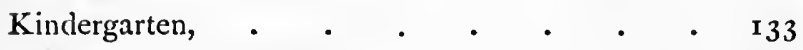

Education and Social Science, . . . . . 146

Industrial Education, . $\quad . \quad$. $\quad$ - $5^{2}$

The Progress of Industrial Education, . . . I6I

Industrial Education in the United States, . . I 70

The Progress of Civilization, . . . . . 185

The Progress of General Education, . . . $25 \mathrm{I}$

Cost of Education and of Crime, . . . . 26I

Does our Common Education Prevent Crime? . $\quad 263$

Does our Common Education Prevent Pauperism? . 263

Intellectual Pleasures, . $\quad$ - . . . $\quad 264$

Education and the State, . . . . . . . 265

Education and our Financial Crisis, . . . 266

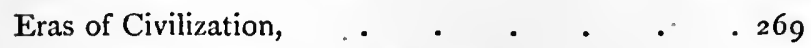

The School the Miniature of the World, . . $\quad 269$

The Period of Crime and of Education, . . . 270

The Half-time School System, . . . . 270

Our Wordy Education, . . . . . . . $27 \mathbf{I}$ 
Education and Industrial Labor, . . . . 272

Race Education Described, . • . . . 29I

The Education of the Old Greeks, . . $\quad 292$

The Education of Massachusetts, • • • 294

The Demands of Race Education, . . . 295

Race Education and a Rational Idealism, . $\quad$. 298

The Claims of Classical and Scientific Education, . 303

The Proper Employment of Time, . . . . $33^{2}$

Men and Women, and their Spheres, . • $\quad 334$

Industry, Health, Conıfort, and Happiness, - 335

The Science of Things, • • . . • 335

The Cultivation of Altruism, . $\quad$. $\quad$. $\quad$. 337

Laborers must make a Market for their Manufactures, 338

The People and their Homes, . . . 348

The Scourges of Humanity, . . . . 424

Our Resources and our Greed, . . . . . 460

The Need of the Nation, . . . • • 478

'The National Teachers' Association, . • . 486

The Massachusetts Board of Education, . . 488

The Worcester Free Institute, . . . . 49r

The Developing School and Manual Institute, • 493

The American Social Science Association, • 504

Public Action Demanded, . • . . . 514

The New Era and the Divine Law of Labor, - . 518

Pauperism Eating up the Nations, . . . 519

I abor and the Modern State, • • • • $\quad 5^{28}$

Channing on Manual Labor, . . . $\quad 53^{\mathrm{I}}$

The Dream of Philosophers, . • . . 532

The United States Looking to Massachusetts, . 533 
The Great Reformation we Need, . • • • 539

Industry Affecting the Character, . . $\quad 543$

Three Stages of Industrial Education, • • 544

Our Education without a Foundation, . • . 547

Industrial Education and Over-production, $\quad \cdot 55^{\circ}$

The Future, • • • • • • $55^{\mathrm{I}}$

The Threatening Danger, $\quad$ • $\quad$ • 554

The Duty of the Nation, . $\quad$. $\quad$ - 554

Conclusion, . $\quad . \quad$. $\quad . \quad$. 555

Index, . $\quad . \quad+\quad \cdot \quad \cdot \quad 5^{65}$ 


\section{INTRODUCTION.}

DETERIORATION is the foundation of our work, which we bring forward, that we may convince men of the necessity of aiming at race amelioration. Certainly, the gradual descent from the meridian of life to natural death is but an inevitable process of individual deterioration, and when, again, whole species and genera of plants and animals become extinct, as the geological strata attests, that is general deterioration. The whole of life, therefore, is a constant struggle of the individual and the race against a world of hostile forces ever tending to deteriorate them.

A healthy rural population crowding into unwholesome city quarters, and transmitting to an enfeebled progeny a constitution deteriorated by the conflux of adverse circumstances is not unworthy the attention of men.

The removal of the preventable causes of deterioration becomes the more urgent in this country, where a comparatively new soil and a foreign climate conspire against the exogenous white race, as has been noticed from Buffon down to our day, and is patent to every observer from the lesser development of the muscular system, the narrow chest, the pale face, the delicate constitution, the 
premature dental decay, the greater frequency of consumption, especially among the female sex, and the small fertility even of foreign born women after their acclimatization.

Society and the means of preventing ever present morbid tendencies from settling into abnormal and anti-social formations must be the chief study of the future teacher in our normal colleges.

We recognize the importance of the study of man, but, alas! look for it in musty chronicles instead of in the living present spread out before us like a feast. We might just as well seek the key to the enigma of life among rattling bones.

What a world of thought the structure of a prosperous society presents to us! and what lessons are to be compared in importance to those the morbid conditions of society offer us.

The application of physical, mental and social hygiene to the physical, mental and social degeneracy as manifested by an excessive rate of mortality, insanity, pauperism and crime is the great work of the teacher.

This truth is sure of finding acceptance at last, as we are beginning to be oppressed with taxes for the erection of hospitals, mad-houses, jails, poor houses, asylums for the blind, the deaf, the dumb, the idiotic, etc., etc., all the fruit of sin or our indiference for man, his happiness, or misery.

The very word Education in our day suggests the school, studies, hieroglyphics, and what not. The writer of this work sets out with an inquiry into the condition of the people, and from a vast 
array of facts relative to the increase of the rate of mortality, insanity and the deepening dye of criminality comes to the conclusion that the human race is threatened by degenerating tendencies.

The author next gives a rapid sketch of the opinions of the great thinkers of the world-past as well as present-concerning the cardinal principles of Education, and proceeds to establish his own doctrine of Race Education, or Hereditary Culture. He endeavors to prove that the preservation of the human race is the primary function of Education, He shows that a true Education must be organic and of a nature to become hereditary. $\mathrm{He}$ contrasts the proposed Race Education with our present scholastic tatooing. He sketches the history of general and industrial Education, as well as of civilization. The claims of classical and scientific Education are fully examined. The necessity of organizing kindergartens is dwelt upon; woman's work in society and civilization is shown, and Education exhibited as a social science. Pauperism is considered as the great deteriorator of the race, which must be combated by industrial Education.

The work concludes with the application of the principles of Race Education to the present crisis, and especially to the American people, to whom an appeal is made to do its duty to the rising generation, for whom to live it is our duty.

A hollow and self-seeking literary foppery fills the heads, empties the hearts, and weakens the hands of men. Work is the coördination of all the powers of man, educating them all, and developing 
in him the capacity and the will to serve mankind efficiently. The world, says Francis Bacon, has grown old with age, and goes to school to the loquacious childhood and puerilities of the boyish Greeks; this is trifling, contemptible, and degrading to modern civilization. Their science is but sophistry, and their history a fable; all idle, fruitless talk, without a single experiment to elevate or assist mankind. It is like the countenance of a virgin with monsters fastened to the womb, bringing forth barking questions and nothing else. Such is antiquity, in the words of the great Chancellor, and such is the Education of our youths, who should be trained to will and to do and to save a perishing race.

Climate, soil and mineral resources, or the country and its products, determine our wants and our character through industry, which leagues man with nature, and individuals with nations, making them free, rich, and powerful, or poor, miserable slaves. And yet while the masses cry for bread, instead of educating them into strong and active men who know how to extract wealth from earth, water, air, and all the elements and forces, we train them into mocking-birds, crazing the age with the broken notes of sweet songsters dead a thousand or more years, forgetting that the harmony of the soul springs from the harmonies of life, and that the lower elements are the soil in which the higher get their growth, lessons not to be set aside in an economic age, the law and order of which are the evolution of moral from material values. 


\section{DETERIORATION}

AXD

\section{RACE EDUCATION.}

\section{PART FIRST.}

RACE DETERIORATION.

WRITERS and thinkers, according to their standpoint or method of investigation, base their systems of Education upon religious or philosophical principles, as God-likeness, duty, humanity, usefulness, happiness, etc.

Most children are not educated at all. They are simply taught the three R's. Many are brought up to get along in the world, no matter how the world gets along; and a small minority is taught in schools devoted to the promotion of learning, but regardless to the advancement of humanity, while denominational schools care more for the propagation of their peculiar tenets than for anything else; and only the fewest children are educated upon anthropological principles.

Upon a careful study of the social condition of 
the people, we venture to advance the principle that the general tendency of human deterioration must be counteracted by Race Education aiming directly at race amclioration.

Statistics prove that a deterioration of the physical, mental and moral tone of mankind, induced by the present state of civilization, is undermining the race.

Many Utopian theories have been advanced against the various ills of society, but a race ameliorating Education alone can stop humanity in its downward career.

Pauperism, with all the misery and barbarity inseparable from it : drunkenness, crime and insanity, a growing morbidity, leading through heredity to race deterioration, and a fearful infant as well as adult rate of mortality, such are the tendencies that surround us on all sides, and must be combated by Race Education.

Maintaining, as we do, that the one great aim of Education must be to counteract the cause of human deterioration, the first step in our inquiry must be to prove the actual existence of such fatal agencies. Deterioration is contingent on our present state of civilization, as labor, especially in factories, is productive of metal, mineral, vegetable or animal dust and deleterious gases, all favoring phthisis. Not infrequently rank poison, such as 
copper, lead, arsenic, phosphorus, etc., have to be handled and are absorbed by the system. Many manufacturing processes require degrees of heat or moisture varying from what the human body can well bear; and often the posture of the laborer, attending one or another technical operation, interferes with the free action of one or more organs. Mines, barracks, damp and dark tenements, filthy lanes, crowded towns and factories, penitentiaries, want, commercial crises, epidemics, poverty, misery, degradation, drunkenness, tobacco, opium, and other influences too numerous for mentioning, contribute to this deterioration.

It would open too wide a field for discussion were we to enter upon these and kindred causes of human deterioration, the existence of which alone concerns us here, and which we shall prove by the rising rate of mortality as well as of insanity and by the nature of crime.

The profound Morel says: "My conviction is that in the majority of cases the insane are of a deteriorated constitution; suffering from a long line of hereditary degeneracy." Everywhere, the same writer continues, insanity increases, so does general paralysis, and a general collapsc diminishes the chances of curability. Hysteria and hypochondria, often accompanied with a suicidal mania or tendency, are becoming alarmingly common among 
the working people and even in the country. The increase of misdemeanors, crime against property, juvenile criminality, and a physically degenerated community that has not men enough fit for the service, are incontrovertible facts, alarming European governments and engaging their most earnest attention. A brigade raised among the weavers in England measured mostly less than five feet. At Spitalfields, the men are not good enough for camnon fodder. "The constitution of these degenerated men," says Dr. Mitchell, "does rapidly descend to the size of the Lilliputians; the old men among them surpass in strength the young ones."

At Birmingham the men cannot be said to be all sick, but neither are they all well. Among 6r 3 men, only 238 were approved for the service. The spinners and weavers are stunted and rickety. So they are in France and everywhere else. Upon investigation, scrofula, diseases of the digestive organs and inflammatory affections of the eyes are most common. Abortions and distortions of the spinal column are almost universal among the working people. Often the children manifest an early arrest of their faculties; they learn but little, and even of this they soon lose every recollection. Often three to four years are not sufficient for these degenerates to learn a little reading and writing. Their language, their morals, their conduct are all low, loose, 
and shameless. All about them is degenerate. Their pale physiognomies are mute, hard, showing nothing but resolution to persevere in evil. These types shock us; and well they may, for they are personifications of the degeneracy of our race, caused by evils which are more fraught with danger for modern society than the invasion of the barbarians was for ancient Rome. This degeneracy might be stopped if society would consent to be anything else but a machine, grinding humanity, even at the risk of conjuring up a revolution, to which the present state of affairs must lead sooncr or later.

Having described the symptoms of human deterioration among the English working people, Morel proceeds to trace the same symptoms in France, where he finds the masses to have lost the power and inclination for fixing their attention upon subjects of a higher order. Such is the imbecility of the young or their intellectual faculties that the priest has to defer their confirmation. In Rouen, as in most manufacturing cities of France, the population is born and develops under conditions favorable for the formation of phthisis, cancer, inflammation of the kidneys and of the digestive organs, hysteria, chlorosis, and general, progressive paralysis. The factory children are puny, their intclligence torpid; and most characteristic is the 
degeneracy which slowly, but surely, undermines the health of body, mind, and morals of the population, visibly nearing a fatal transformation into a fixed order of diseased specimens deviating from the normal type of humanity, in whom the average intellectual life is low; and the double characteristic of their moral and physical shortcomings is reflected in the form of the body as well as in the disposition of the mind. In the absence of regenerating measures these diseased specimens are bound to form progressive types of degeneration.

Having established the progressive hereditary deterioration of the normal type of humanity among the masses, and the necessity as well as the possibility of a complete regeneration by the removal of fatal causes, from the labors of Morel, we proceed to the still higher authority of a million statistical facts, and we shall set out with those of mortality rates as best studied, and the sure indicators of the vitality and the ameliorating or deteriorating tendencies of the world.

\section{RATE OF MORTALITY.}

To those who consider mortality rates a sentimental question, we would recall the words of Europe's greatest statistician: “The people themselves are by far the most important capital of the State; and the industrial capital stored up in the 
living generation surpasses the sum of all other species of capital. Every injury to the physical condition of the people is a loss of the noblest capital of intelligence and physical strength of the nation, and is an absolute destruction of capital."

Dr. Engel, to whom we have just referred, has established the average age at death in Prussia to have been as follows:

$$
\begin{aligned}
& \text { I } 82 \mathrm{I}-\mathrm{I} 830 \text {. . . } 28.39 \text { years. } \\
& 1831-1840 \text {. . . . . } 28.34 \text { “ } \\
& 184 \mathrm{I}-1850 \text {. . . . . } 27.23 \text { “ } \\
& 185 \mathrm{I}-1860 \text {. . . . . } 26.40 \text { “ }
\end{aligned}
$$

In Bavaria lived, after the first year, of

$$
\begin{array}{ccccccc}
\text { r,002 born, } 1841-1848 & \text {. } & \text {. } & 701 & \text { children. } \\
\text { “ } & \text { “ } & 1848-1855 & . & . & 697 & \text { “ } \\
\text { “ } & \text { “ } & 1855-1862 & . & . & 681 & \text { “ } \\
\text { “ } & \text { “ } & 1862-1869 & . & . & 673 & \text { “. }
\end{array}
$$

In Basel, Switzerland, survived the first year of

$$
\begin{array}{cccccc}
\text { r,000 born, } 1821-1840 & . & . & 879 & \text { children. } \\
\text { “ “ } & 1841-1850 & . & . & 830 & \text { “ } \\
\text { “ “ } & 1860-1865 & . & . & 802 & -“ \\
\text { “ } & 1866-1870 & . & . & 783 & \text { “ }
\end{array}
$$

Marc d'Espine shows the expectation of life for Geneva to have been as follows:

$$
\begin{aligned}
& \text { 1814-1836 . . . . } 47.29 \text { years. } \\
& 1838-1845 \text {. . . . . . } 43.62 \text { “ }
\end{aligned}
$$

In Wurtemberg lived, after the first year, of

r,000 born, $1846-1856$. . 697 children.

$$
\text { “ “ } \quad 1858-1866.0646 \text {. } 1866-1868.640
$$


In Muhlhausen lived, after the first year, of

$$
\begin{array}{lllll}
\text { 1,000 born, 1830-1842 } & \text {. } & 745 \text { children. } \\
\text { “ “ } 1860-1868 & \text {. } & \text {. } 670 \text { “ }
\end{array}
$$

In France lived, after the first year, of

$$
\begin{aligned}
& \text { 1,000 born, 1840-1851 . . } 834 \text { children. } \\
& \text { “ "1851-1860. . 826 “ }
\end{aligned}
$$

Neison shows in England an increased mortality, notwithstanding all sanitary improvements. It has been as follows :

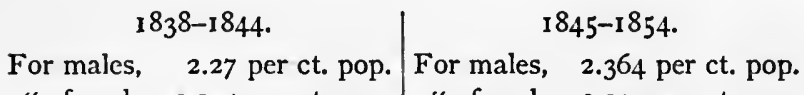
" females, 2.104 per ct. pop. " females, 2.209 per ct. pop.

This shows an increase of mortality of 4.141 per cent. in males, and 4.8 per cent. in the female portion of the population.

W. R. Gray, in a paper published in the Statistical Fournal of 1842 , says that the rate of mortality has increased in England since 1820 ro per cent. and probably i2.50 per cent.

Mr. S. Shattuck, in a paper on the vital statistics of Boston, says: "The average value of life is greater now than during the last century, but not as great as it was twenty years ago. It was at its maximum from $18 \mathrm{II}-1820$, and since that time it has somewhat decreased." He also says: "It is a melancholy fact, and one which should arrest the attention of all, that 43 per cent., or nearly one- 
half, of all deaths which have taken place within the last nine years, are of persons under nine years of age; and the proportional mortality at this age has been increasing."

The average mortality of children under five years in 1866-1870 amounted in the city of New York to 50.6 per cent., and but 4.4 per cent. of all who died during the same years reached seventy years. Of 492,262 deaths in the United States in I $870,7,986$, or 1.6 per cent., were of old age, while 69,896 died of consumption alone. Fully a hundred thousand children die annually in this country beyond what is natural, and with them twice as many hearts are broken. But hearts do not count in this matter-of-fact world. The loss of labor during gestation, lactation and the sickness of the child, medical attendance and funeral expenses foot up at least to one hundred dollars in each case, and in the aggregate to ten millions per annum, to a class generally in such precarious circumstances as to be crushed by this additional burden; and the fifty thousand adults, who die annually purely from degenerating causes, can we estimate them individually to be worth less than a thousand dollars? Or is the loss of the State in the citizen, or of the wealth of the country in the producer, and of the wife and the children in the husband and father, less than this paltry sum? This, then, is 
another loss of fifty millions per annum. But a hundred and fifty thousand avoidable deaths mean two millions of avoidable cases of sickness and their cost ; and, worse still, so much sickness means so much deterioration of the race, and multitudes of men, women and children decrepit in body and soul, fit inmates of all sorts of asylums and candidates for early graves-the last of which is not the worst for them.

But one glance more at the most degenerate. Among the most destitute at Manchester, of 21,000 children 20,700 die before they reach five years. In Lille, in France, 94 per cent. of the same sort of children die before this age. In very deteriorating trades, of $\mathrm{I}, 000$ born, but $\mathrm{I} 5$ reach the age of fifty. Without entering upon details and causes beyond the proper limit of our inquiry, we have established the fact of a rising death rate, which proves a degeneracy Education must protect us against, and this Race Education or Hereditary Culture only, and not school pedantry, can accomplish.

\section{RATE OF INSANITY.}

The daily increasing rate of insanity is another symptom of human deterioration.

Maudsley says: "In the hard struggle for existence, men of inherited weakness, or some other debility, break down in madness. Overcrowding 
deteriorates health, favors scrofula, phthisis, and faulty nutrition, all of which open the way to insanity; and whatever deteriorates mental or bodily health may lead to insanity in the next generation."

Galton says : "Social agencies are unsuspectedly working toward the degeneration of humanity, and it is a duty we owe humanity to study this power and to combat it to the advantage of the future inhabitants of the earth."

Griesinger, a great authority in Germany on insanity, decidedly believes in its increasing rate. He says: "Misery and privation are its chief causes. Bad nourishment, hunger, cold, fatigue and over-exertion, which of necessity accompany misery, are important physical causes of insanity, and, hence, of race deterioration. Typhus, intermittent fever, cholera, pneumonia, acute rheumatism, tubercular, constitutional diseases, and anæmic states-all scourges of the poor-induce insanity. The monotonous and hopeless condition of many factory hands, depriving them of all interest in a higher life, is favorable to dementia."

Such are the opinions of the leading minds of Europe on the spreading causes of insanity.

We shall now prove the terrible fact of an actual race deterioration by statistics, which, though sufficient to convince the earnest inquirer, do not begin to display all the facts of the case. 
Making every allowance, the following table of the number of lunatics and idiots in England and Wales and of their annual admissions, shows that the increase of want, worry, over-work, crowding, drunkenness, etc., has its effect on the mental condition of the people:

\begin{tabular}{lr|lc} 
Years. $\begin{array}{c}\text { Insxne and } \\
\text { Idiots. }\end{array}$ & $\begin{array}{c}\text { Admis- } \\
\text { sions. }\end{array}$ & Years. $\begin{array}{c}\text { Insane and } \\
\text { Idiots. }\end{array}$ & $\begin{array}{c}\text { Admis. } \\
\text { sions. }\end{array}$ \\
$1859 \ldots \ldots 36,762$ & 9,310 & $1868 \ldots \ldots 51,000$ & 11,213 \\
$1860 \ldots \ldots 38,058$ & 9,512 & $1869 \ldots \ldots 53,177$ & 11,194 \\
$1861 \ldots \ldots 39,647$ & 9,329 & $1870 \ldots .54,713$ & 11,620 \\
$1862 \ldots .41,129$ & 9,078 & $1871 \ldots \ldots 56,755$ & 12,573 \\
$1863 \ldots .43,118$ & 8,914 & $1872 \ldots \ldots 58,640$ & 12,176 \\
$1864 \ldots \ldots 44,795$ & 9,473 & $1873 \ldots \ldots 60,296$ & 12,773 \\
$1865 \ldots \ldots 45,950$ & 10,424 & $1874 \ldots \ldots 62,027$ & 13,229 \\
$1866 \ldots \ldots 47,648$ & 10,051 & $1875 \ldots .63,793$ & 14,317 \\
$1867 \ldots \ldots 49,086$ & 10,631 & $1876 \ldots .64,916$ & 14,386
\end{tabular}

The statements of Dr. Simon, the medical officer of the British Government, Maudsley, and Dr. Robertson, lead all to the same conclusion.

In Ireland, were in

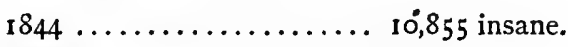

$$
\begin{aligned}
& 1863 \ldots \ldots \ldots \ldots \ldots \ldots \ldots 16,256 \text { " }
\end{aligned}
$$

In France insanity has most fearfully increased during the last ten years, though there were already in $1866,90,684$ insane and idiots, including those in private institutions. The following table is taken from the Report of the Inspector-General of the Insane, and takes only notice of the poor insane in public asylums : 
January 1,1835 , in the asylums . . 10,529 insane.

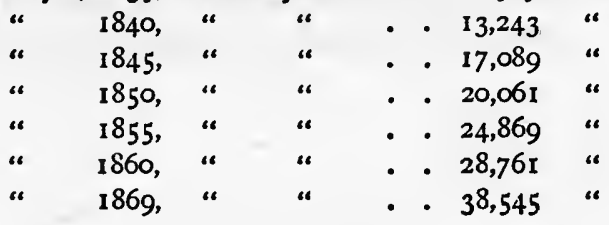

Belgium had in its asylums in

$$
\begin{aligned}
& 1852 \text {. . . . . 4 4,054 insane. } \\
& 1856 \text {. . . . . . } 4,278 \text { “ } \\
& 1860 \text {. . . . . . } 4,832 \text { “ } \\
& 1864 \text {. . . . . . 5 5,44I “ }
\end{aligned}
$$

In the Netherlands there were in the asylums in January I, 1844 . . . 837 insane.

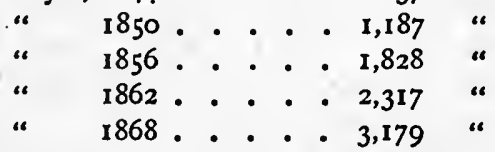

Norwegia had in

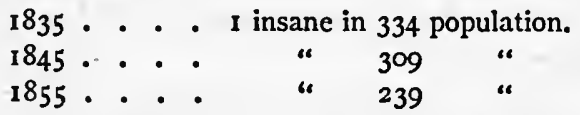

In the Rhenish provinces of Prussia the ratio of the insane to the population was in 1828 .. . I insane in 1,027 population.
1856 .. .

In Nassau the ratio of the insane to the population was in

$$
\begin{aligned}
& 1840 \text {. . . I insane in } 607 \text { population. } \\
& 1858 \text {... " " } 318 \text { " }
\end{aligned}
$$


In Wurtemberg insanity has increased since 1832 76.3 per cent., while the population has increased I3.5 per cent.

Baden shows in

$$
\begin{aligned}
& \text { I848 . . . . } 100 \text { insane. } \\
& 1851 \text {. . . . . . } 158 \text { “ } \\
& 1854 \text {. . . . . . } 187 \text { “ } \\
& 1857 \text {. . . . . . . } 231 \text { “ } \\
& 1860 \text {. . . . . . } 255 \text { “ } \\
& 1862 \text {. . . . . . } 306 \text { “ }
\end{aligned}
$$

The official reports of Berlin show an increase of cases of mental aberration or melancholia in

$$
\begin{aligned}
& \text { 1864 . . . . . . } 275 \text { cases. } \\
& \text { 1865 . . . . . . . } 337 \text { “ } \\
& 1866 \text {. . . . . . . } 377 \text { “ }
\end{aligned}
$$

Massachusetts had in 1870 in a population of I,457,35 I, 3,194 insane. Dr. Jarvis shows in the Fifth Annual Health Report an annual increase of fresh cases. In

$$
\begin{aligned}
& \text { I867 . . I for every I,546 population. }
\end{aligned}
$$

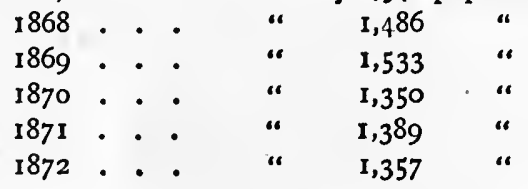

The intensity of this disease of degeneracy has equally increased, so that at Bicêtre, among 100 insane were afflicted with general paralysis, the very worst form and the most incurable, in 


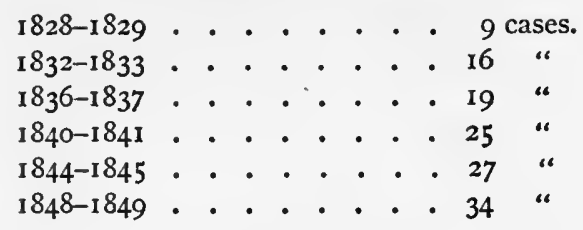

A glance at the following figures will show the disproportionate increase of the insane in the United States. In 54 asylums were in

\begin{tabular}{|c|c|c|c|c|c|c|}
\hline 39 & 1,329 & & wh & & & \\
\hline 849 & 7,029 & “ & “ & $2,96 \mathrm{r}$ & “" & “ \\
\hline & 13,696 & “ & “ & 5,342 & “ & “ \\
\hline & 22,549 & “ & “ & 8,769 & “ & “ \\
\hline
\end{tabular}

The State of New York had in its various institutions in

$$
\begin{aligned}
& \text { 1870. . . . . 4 4,761 insane. } \\
& \text { I871 . . . . . . . 5,073 " } \\
& 1873 \text {. . . . . . 6,003 “ } \\
& 1874 \text {. . . . . . 6,279 “ }
\end{aligned}
$$

What a commentary these increasing ratios of insanity form to Galton, when he says: "Our race is overweighed and likely to be drudged into degeneracy by demands that exceed its powers. With the deterioration of the condition of the masses, their organizations and functions, there will be plenty of idiots, but very few great men; and, hence, under the miscrable conditions in which the masses of the people live, the general standard of mind is but little above the grade of trained idiocy." 
The eager pursuit of wealth, says an eminent writer, as well as the dread of poverty, have their ill effects. Men are excited, anxious, absorbed in the state of the market, petty gains, meanness and dishonesty, until their moral nature and character are sapped, and their nature deteriorated. Overwork, depression, exhaustion, want of culture, poverty, drunkenness, licentiousness, are all favorable to the development of insanity; and the number of the insane is rising. The same author relates a number of cases of financial operators, whose speculative, selfish minds show their morbidity in the diseased minds of their children, who are either morally defunct or wholly insane.

The increase of insanity has been for a century steady, large and universal in the ratio of the spread of our present civilization.

Is this lesson not plain enough, when the universally educated Scandinavians have 3.4 insane in

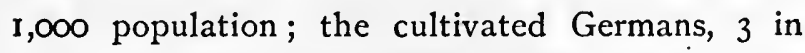

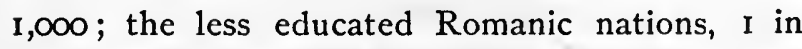
I,, 00 ; and the most barbarous Sclavonic races, 0.6 in $1, \infty 00$; and, again, when the ratio of the insane to the population is larger in cities than in the country, and the professionally educated, who compose 5.04 per cent. of the population, yield $\mathrm{I} 3.8$ of all the insane? If, then, our civilization and Education are especially productive of human deterio- 
ration and insanity, is it not reasonable to ask that Education should studiously avoid and oppose whatever degenerates mankind?

\section{CRIME.}

Crime may have decreased numerically but it has deepened in quality, and has become a low, permanent type of humanity. The crime of former times was rude force cropping out under other influences as stern virtue, and needed but the restraint of force. The crime of to-day is disease and insanity, and cries for help. Sporadic crime is individual, habitual crime is social ; for society engenders it by deteriorating humanity, though it denies the paternity and evades the responsibility. An English judge says, insanity and criminality are convertible terms. Plato and Aristotle held crime and insanity akin, and so do Pinel, Esquirol and Prichard in our own day. Morel says, we have hidden in us the germs of the fatal disposition of which we are the victims.

But our position that the criminal class is evidence of a deep-seated social deterioration, calls for more than a mere incidental verification. We shall, therefore, sustain it by the observations of Bruce Thompson, than whom none has brought greater experience and thoroughness to the treatment of this question. "Intimate and daily experience," says 
he, "have led me to the conviction, that in by far the greater proportion of offences, crime is hereditary, which tendency is in most cases associated with bodily defect, such as spinal deformities, stammering or other imperfect organizations of speech, club-foot, cleft palate, hare-lip, deafness, congenital blindness, paralysis, epilepsy and scrofula."

"The criminal class," says this great officer and observer, "has a stupid, sullen look, the complexion is bad, the heads and outlines are harsh, clumsy, and angular; the women are positively ugly in form, feature and action. The frequency of tubercular diseases among habitual criminals is proof of a low type and a deteriorated system. Most of them die before the meridian of life is reached, and hardly any see old age. The post-mortem examinations show a series of morbid appearances very remarkable; almost every vital organ of the body being more or less diseased; few dying of one disease, but generally worn out by a complete degeneration of all the vital organs. Everything indicates a deteriorated hereditary organization."

The low state of intellect among criminals shows them degenerate. One-third of the juvenile criminals are imbeciles. According to the reports of the English common prisons, one in every twentyfive of the males is weak-minded, insane, or epileptic. Of six thousand prisoners in Scotland, I 2 per 
cent. are mentally weak, imbeciles, suicides, epileptics, besides the fully insane. According to the official report of the Millbank Prison, of 943 convicts, 218 were weak-minded, 34 insane, besides many epileptics. One in 27 was insane, and the great majority had some inherited physical infirmity or defect of intellect. Out of 6,273 prison population in Scotland, fully I per cent. were epileptic, and, of course, enfeebled in mind and irritable in temper. Morel shows that crime and insanity lapse into each other congenitally.

Bruce Thompson further shows by the numberless recommittals returned to prison, not three, four or five, but thirty, forty and fifty times, by the utter remorselessness, grossest habitual lying, and total want of all self-respect, that professional criminals are hopeless imbeciles and hardly amenable to moral treatment. What else is this but a degraded organization?

The criminal classes are especially liable to brain diseases and insanity, and many of the great criminals died in lunatic asylums; and madness among criminals in prison is extremely frequent. In Scotland, of 2,690 criminals, 57 are insane, or $I$ in 47 of the criminal population, while of the whole population, $I$ in 432 is the common proportion.

In England, during 1860-1868, I,244 criminals were detained as insane. In 1857-1867, of 664 
homicides, 108 were declared by the courts of England as insane. Among the habitual female criminals, $I$ in 30 is the proportion of the insane to the sane.

Frederic Hill says: "Crime often proceeds from father to son in a long line of succession." Prof. Laycock says: "The line of hereditary transmission of mental and moral qualities is as inexorable in these moral imbeciles as in other men, and adds to the imbecile, vicious and degraded part of the population."

Dr. William Guy, upon a thorough research of the judicial record of the Millbank Prison during a period of thirty years, shows that of 5,598 criminals convicted of rape, arson, horse and cattle stealing, burglary, homicidal attacks or violence, and fraudulent offences, 232 were insane, weak-minded, and epileptic; 657 were scrofulous or lung and heart diseased; I,434 were deformed or defective, and 3,399 were sound.

The same great authority says: "We have at this moment at the Millbank Prison 200 convicts, who would be much more in their place at an insane asylum."

The late Governor of the Chatham Convict Prison declared: "I have known as many as 50 per cent. and more of the inmates of an Irish convict prison mentally affected." 
E. Gordon, the late Lord Advocate of Scotland, testifies to the great weakness of intellect among those placed at the bar of justice:

Dr. Wilson, in a paper read before the British Association, in 1869 , reported that from the examination of 460 heads of criminals, and from observations he had made, he had no doubt that cranial deficiency, associated with a real physical deterioration, is the cause of crime, and that 40 per cent. of all convicts are invalids more or less, and that the percentage is largely increased in the class of professional thieves.

Dr. Campbell found in 50 prisoners, after death, the weight of the brain 2 lbs. and $14 \frac{1}{4} \mathrm{oz}$., while the average weight of the brain in other men is over 3 lbs. The average height of 6,022 male prisoners, who passed through the Worcester Prison, was found two inches less than the average height of Englishmen, and their weight was lighter in proportion.

The physical aspects of convicts have become almost proverbial. Bullet heads, low brows, projecting ears, weasel eyes, and other bodily indications of deficiency, are but too general among them. In some of the most ferocious criminals there have repeatedly been discovered after death morbid conditions of the brain or other organs, as tumors, cancers, ulcers, or irritating secretions, 
which fully accounted for mental or moral deficiencies and for murders committed.

Dr. Wines cites many cases of congcnitally weak minds, idiots and insane, which came under his notice among our own criminals.

Miss Dix has in two years traced twenty-six persons convicted for crime in the Eastern Penitentiary of Pennsylvania, who were insane. Every month, she says, men are convicted and sentenced as if they were responsible, when, in fact, they were not.

Among 233 convicts, whose personal relations have been carefully studied under the auspices of our eminent sanitarian and prison reformer, Dr. Harris, 54 were found belonging to families in which insanity, epilepsy and other disorders of the nervous system are reported. Eighty-three per cent. belonged to a criminal, pauper or inebriate stock, and were, therefore, hereditary or congenitally affected; and, hence, nearly 76 per cent. of their number proved habitual criminals. Dr. Harris states, also, that the general observation in the counties of our State goes to prove that crime, pauperism and insanity, revert into each other congenitally, so that disease or insanity in the parent produces crime or pauperism in the offspring, or vice versa, crime or pauperism in the parent produces disease or insanity in the offspring. 
The progress of culture and civilization has certainly lessened the crime of unrestrained passion and rudeness; but has the criminal class, until quite of late, been reached?

In England and Wales were committed in

$$
\begin{aligned}
& \text { I805 . . . . 4,605 individuals. } \\
& 1815 \text {. . . . } 7,818 \text { “ } \\
& 1825 \text {. . . . . 14,437 “ } \\
& 1835 \text {. . . . . 20,73I “ } \\
& 1845 \text {. . . . . 24,033 “ }
\end{aligned}
$$

According to Potter, crime has increased in England and Wales since the beginning of this century to 1850 , to five times; in Ireland, from 1805 to 1849 , to twelve times; and in Scotland, since 18 I 5 to 1849 , to seven times. While the population has increased 79 per cent., crime has risen 482 per cent.

In France were committed for common offenses in

$$
\begin{aligned}
& \text { 1826-1830 . . 178,021 individuals. } \\
& 1831-1835 \text {. . . 203,207 " } \\
& \begin{array}{llllll}
1841-1845 & . & . & . & . & 195,542 \\
1846-1850 & . & . & . & . & 221,414
\end{array}
\end{aligned}
$$

Incendiarism has in $1826-1865$ increased in France over 200 per cent.

In London, the proportion of incendiarism to buildings was :

$$
\begin{aligned}
& 1845 \text {. . . . . . } 1 \text { in } 2,990 \text {, } \\
& 1850 \text {. . . . . . } 1 \text { in } 2,673 \text {, } \\
& 1855 \text {. . . . . . I in } 2,585 \text {. }
\end{aligned}
$$




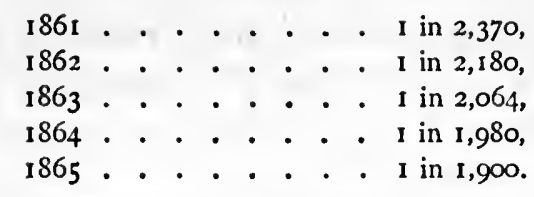

In Holland, according to Guringar, crime has in the last years increased 72 per cent., and the prisoners 34 per cent. Norwegia had in 1815,480 criminals, and in $1845,1,782$ !

And what progress have we made in the United States in lessening the number of the great and habitual criminals who crowd our State prisons? In $185^{\circ}$ the entire population was $19,553,668$, and the inmates of our State prisons numbered 5,646. In 1860 the population was $26,922,537$, and the criminals in the State prisons numbered 19,086; and at the last census, in 1870 , the population of the United States amounted to $33,589,377$, and the number of criminals was 32,901 .

We see here at a glance, that crime has increased beyond all proportion to population. Neither will it answer to lay it to the foreign element, the criminal rate of which has remained the same, or even lessened, while the native criminals have increased during $1860-1870$, from 10,143 to 24,173 .

We have proven that the criminal class is a deviation from the normal type of humanity, and is, therefore, an evidence of actual race deterioration. Statistics have shown us that no decided decrease 
of crime has attended our late general progress of civilization; and, in fact," the recommittals, especially of juvenile criminals, the frequency of female criminality, suicides, infanticides, prostitution and illegitimate births, show all a deep-seated human deterioration. Of course, illegitimate births mean a rich harvest for the grave, the jail, and prostitution, the latter of which avenges itself on society by insidious venereal deterioration, which inflicts upon its unborn victims blindness, idiocy, phthisis, scrofula and a most degenerate system in general. But we must forbear entering here upon this form of human deterioration though not to mention it would be a gross oversight.

The causes of human deterioration are vast and many, but the right sort of Education may conquer them all.

When the hero of Wagram, Austerlitz and Jena stood at the gates of Berlin, Fichte addressed to the German nation, in the midst of the thunder and storm which burst forth from the brazen throats of a thousand cannons, the potent word, Education, and the relative position of the French and Germans to-day proves the wisdom of the patriot and philosopher. Like an ancient, renowned legislator, he thought Education was the sole function of the Government; for, where the people are rightly educated, war, prisons, courts, asylums of all sorts, 
poor-houses, hospitals and other institutions of the same kind cease to have an existence.

\section{BLINDNESS AND DEAF-MUTISM.}

Blindness and deaf-mutism are common, fearful, expensive and preventable. Europe has 500,$\infty$ blind, Asia 2,000,000 and the United States 25,000. What a growing misery and public expense. Blindness, congenital in one in ten cases, and then the offspring of a deteriorated parentage, results in the main from causes accompanying misery. Scarlet fever, measles, smallpox, typhoid and other fevers, all preventable diseases, raging among the poor, give rise to this terrible visitation and great public burden; and so does scrofula. Ophthalmia is another disease of poverty leading often to blindness. The strain upon the eyes of tailors, dress makers, needle makers, watch makers, blacksmiths and other operatives causes much blindness; but lace making is the most fearful trade as far as blinding poor operatives is concerned.

Deaf-mutes, Europe counts 250,000, and the United States 20,000 . That congenital deaf-mutism is a deterioration of the system is obvious from the fact that whilst in Europe $I$ in 1400 is a deaf-mute, there are poor regions there in which I in 44 , and even $I$ in 20 of the entire population is a deaf-mute!

Of 644 deaf-mutes in Massachusetts, 350 are con- 
genital and traceable to a deteriorated stock, whilst 304 are post-natal, of whom II 2 are the result of scarlet fever, and the rest are the victims of other fevers, diseases and accidents peculiar to the tenements and condition of the poor.

The blind, deaf-mute, as well as the idiot, are but chargeable to removable causes and conditions of our half civilization. Inherent weakness is the cause of many a form of degeneracy. Under different conditions the local or general congenital weakness leads to blindness, deaf-mutism, idiocy, or other morbid formation, still-birth, deformity, general weakness, or death in early infancy.

\section{UNFITNESS FOR MILITARY SERVICE.}

Michel Lévy, the highest sanitary authority in France, cites the following facts as evidence of a general race deterioration: From 1816 to 1840 , of 7,321,609 recruits, $1,416,527$, or nearly one-fifth, have been rejected for being below the requisite stature or on account of infirmities. In comparing the exempted prior to 1816 with those of 1840 , the latter are twice as numerous, though the standard has been lowered from I metre 57 centimetres, to 1 metre 56 centimetres. There were rejected in

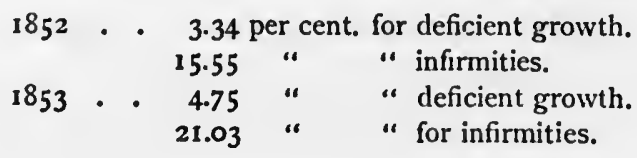


The steady deterioration of the people necessitated a continual lowering of the military standard, as the following table will show:

$$
\begin{aligned}
& \text { It was, I70I . . . . . . } 1.624 \text { metres, } \\
& \text { “ } 1803 \text {. . . . . . } 1.598 \text { “ } \\
& \text { “ } 1818 \ldots . . . .1 .576 \text { “. } \\
& \text { “ } 1860 \text {.... . 1.560 “ }
\end{aligned}
$$

and to-day of every 325,000 young men who survive their twenty-fifth year, 108,333 are rejected on account of low stature or infirmities.

According to the statement of Dr. Mayer, the average of nine years shows 716 out of 1,000 conscripts under the standard measure, and 399 unfit on account of bodily ailments. Berlin could not furnish its quota in men fit for service by 156 in 1856 .

If, on an average, $35^{2}$ in 1,000 men of the most favorable age are rejected by the recruiting officer, what must be the condition of the people at large?

Among 8,794,674 examined recruits of European countries between 1837 and $1856,1,576,8$ I 5 , or 17.9 per cent., were found below the standard measure, and 3,097,or 6 sickly, crippled, feeble and otherwise unfit for military service. What a condition!. About 53.I per cent. of men, at their best age, sickly or stunted in their growth.

The official report of the canton of Zurich shows, for the agricultural districts, 29 in I,000 young men disabled; for the industrial, 35 . 


\section{FACTORY POPULATION.}

The deterioration of the factory population in England is seen from the fact that, on an average, the measure of 1,000 factory boys aged 18 years, was 55.28 inches, of non-factory boys, 55.56 inches -a difference of .28 inches in favor of non-factory boys. The same official report shows 2,000 factory boys, aged 9-1 7 years, weighing 3 pounds less each than as many non-factory boys.

Upon examination

5I farmers' boys, old to y., 9 m., measured in height $5 \mathrm{I}$ inches. 5 I mining boys, of the same age, measured 47.3 inches.

An official examination of the health of 350 factory, and as many non-factory boys, showed of

\section{Factory. Non-factory.}

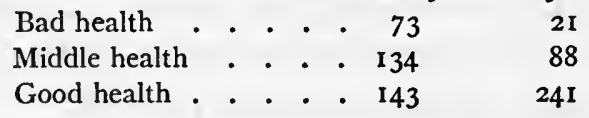

These examinations have been varied without any material change in the result.

The following official list of the diseases of the factory and agricultural population of the canton Zurich, in Switzerland, is suggestive. In each $\mathrm{I}, \infty 00$ population were found :

Fastory. Agriculturists.

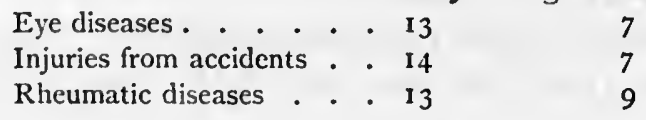




\begin{tabular}{|c|c|c|}
\hline & Factory. & Agriculturists \\
\hline Lung diseases & . 37 & . 10 \\
\hline 1 diseases & - 9 & 3 \\
\hline infirmity & . II & 5 \\
\hline Ulcers & . 8 & 3 \\
\hline
\end{tabular}

The deteriorating influence of the trades is only so fearful because they are divorced from science and Education, which alone can find the means of rendering them innoxious, and dispose the men engaged in them to be more on their guard.

Workers in white lead, arsenic and phosphorous compounds, who deteriorate most fearfully in most factories, suffer hardly any where the employers are highly intelligent and conscientiously disposed, and the government keeps a strict watch over the hygienic management of factories.

Nothing calls louder for the association of science and Education with the trades, than the present outrageous poisoning of humanity throughout more or less all the factories of the land.

\section{CONSUMPTION.}

As consumption shows more degeneracy and deteriorates humanity more fearfully than any-and we might almost say than all other diseases put together-we will just refer to its deteriorating influence in the trades divorced from science and Education upon the men engaged in them. In Berlin, the observation was made, that the whole 
population being taken, of 1,000 deaths of men over 20 years, 344 are caused by tubercular consumption, while among mechanics, 497 die from this fearfully deteriorating disease.

This observation is confirmed by the experience of Dr. Hannover, at Copenhagen, who found that upon 60 deaths from consumption among the people at large come 96 among the mechanics and laborers.

According to the observations of Benoiston de Chateauneuf, among 43,010 hospital cases 18 to 48.4 of every I,000 died from consumption, according to the nature of the different trades and the deteriorating influences, as dampness, dangerous fumes, dust, etc., accompanying them.

Lombard found that, while among men who live in perfectly healthy surroundings, 50 to 89 in a thousand die from consumption; men working in the close air of factories, as they are managed today, die in 138 cases in 1,000 ; those working in dust of any sort, die in 137 to 152 ; and those exposed to the evaporations of ethereal acids, varnishes, etc., die in 369 cases in 1,000 from consumption.

In the always reliable statistics of Geneva, we find among men living under the best possible conditions the death rate from consumption in 


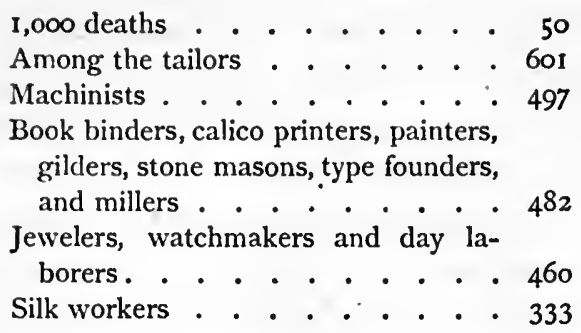

Fifty in a thousand we may, then, call the natural proportion of death from consumption to the deaths from all other causes. How loudly, then, do these high ratios of death from consumption call for bringing to bear science and Education upon these race-deteriorating trades, in many of which men grow gray before they live half their years. The dry-grinders die in the majority of cases before they reach thirty-six years; so do the manufacturers of watches and others exposed to fine, hard dust, like cutters of crystals, stone cutters, etc.

It is impossible to pass unnoticed this great cause of human deterioration; but to state in full the disease, deformity, death, and even hereditary corruption of body and mind entailed by each of two hundred trades deprived of the safeguards and thoughtful precaution of science, the school and Education, upon the producers of the wealth of the country, would fill many volumes. 
SCROFULA.

The tendency of the masses toward degeneracy is obvious from the character and spread of scrofulasignificantly called by some the people's malady-a constitutional, hereditary and deteriorating disease common among the poor. Mr. Phillips, the greatest authority in this field of inquiry, says that in the cottages of the poor we find the child with a scrofulous constitution, often pallid, puffy, insensible, listless; and, if it be not altogether deprived of force and energy, what remains is soon wasted by taxing it beyond its force.

In an extraordinary experience extending to the examination of 133,721 children, 24.5 per cent. presented a number of scrofulous symptoms; in 3.5 per cent. the disease was so marked as to be obvious to the eye. Among 95,586 recruits, 800 , or I in I I9, were rejected on account of scrofulous marks. At the examination of 660 persons, between 10 and 18 years, at the house of correction, 95 showed symptoms of scrofula.

Mr. Phillips sums up his wonderful experience as follows :

$11 / 2$ per cent. of the children of the poor show apparent scars; 3 per cent. show at a glance enlarged glands; $24 \mathrm{1} / 2$ per cent. show these enlarged glands under close examination; 8 per cent. of the 
adult poor show the same scrofulous symptoms; 3 per cent. of the population are under treatment for scrofula.

In some districts Mr. Phillips found only I I per cent. of the children of the poor scrofulous, and in other districts 72 per cent. were thus affected.

Barier found, upon examination of 166 strong children, 2 I tuberculous, or I in 8; I 14 moderate children, 27 tuberculous, or I in 4; 99 feeble children, 49 tuberculous, or $I$ in 2.

How closely want and misery in the parents and children are allied with scrofula, is obvious from the fact, that we find affected with this disease: 4 to 5 per cent. of all the sick in hospitals; 40 to 50 per cent. of foundlings; 50 to 60 per cent. of children received into orphan asylums.

-When we consider that insufficient or improper food, dark, damp and unventilated apartments, insufficient clothing, etc., engender scrofula, it becomes plain that, with the increase of poverty, scrofula must increase; and, as this disease is of a tubercular nature and akin to consumptioninto which it reverts hereditary-the impoverished masses must of necessity degenerate.

Scrofula, says a noted American author, that once was a rarity among us, has of late become quite common. 


\section{CHANGES OF MORTALITY RATES.}

Many causes contributed to improve the chances of life from the sixteenth to the beginning of the nineteenth century, as the growth of science, the spread of intelligence, the general prosperity springing up with the small trades, which brought with it improved dwellings, food, clothing, etc., the disappearance of periodical famines, the cessation of former ravages from smallpox through Jenner's great discovery; and, finally, another cause of the apparent great reduction in the old mortality rates, is to be found in the prudentially reduced modern birth rate, caused by later marriages, as the mortality is always greatest among infants.

But with the large industries, the former master has become again poor and dependent; large cities sprang up with all the unwholesome elements of thick populations, crowded tenements with their vices, drunkenness, worst of all, alcoholism, illegitimate births, the trade diseases of modern factories, and all contributed to swell of late the list of mortality. The ravages of our largely increased factory towns make up for the former victims from the smallpox, and our periodical business stagnations are as calamitous to the working people as former famines were.

There is none but will agree that there are ele- 
ments in our civilization tending toward the deterioration of mankind which must be combated; our position, therefore, cannot but be tenable that our Education must strive to preserve the race, which it can only by being physiological, scientific and industrial-making us healthy, intelligent and prosperous.

\section{GENERAL DETERIORATION.}

A picture of France of but a few years ago may serve us as an illustration of our civilization, which strives for perfection in art and literature, for accumulation of wealth and everything else, save the one thing needful-the amelioration of mankind. France, with a population of $35,783,170$, had

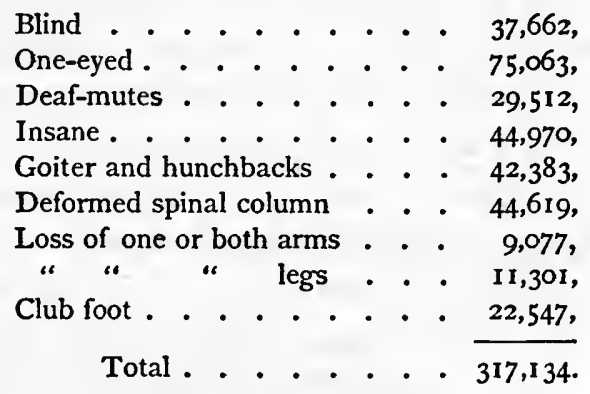

This picture of misery is far from being complete. The charity murder of tens of thousands of foundlings, the massacre of factory hands and miners, a fearful infant mortality, paupers, criminals, 
prostitutes, infanticides and suicides, should all be added as evidence that our pretentious age understands but little of the art how to prevent the deterioration of mankind.

What a picture the whole of Europe presents of what we call in this age civilization, with its 300 ,oo deaf-mutes, 500,000 blind, as many insane and idiotic, and as large a criminal class!!

\section{PAUPERISM.}

Pauperism, like insanity, does not exist in the natural state of man. Under the sweet influences of the skies, he is in the woods as quick and nimble as the bird or deer he pursues. Only in the atmosphere, thick with moral and physical poison of crowded cities, he degenerates into a pauper, robbed of all that elasticity and high potency by which man masters every resistance and subjects everything to his will. Pauperism being the parent as well as the offspring of human deterioration, forms such an entanglement of causes and effects as to render it difficult to hunt it down. Our poorhouses reveal at a glance the genesis of pauperism, for there we find the congenitally blind, deaf and mute, the insane, the idiotic, the epileptic, the deformed, the inebriate as well as the pauper; and they are not only inmates of the same building, 
but are members of the same family, united by all the ties of consanguinity. This idiot is that pauper's nephew; this deaf-mute is his own child; that inebriate is his brother; and that mount in view covers the bones of an old inmate, who found his last resting place in the pauper's field forty-five years ago-his uncle; what are we to conclude from all this but that the pauper is the child of a degenerate blood and family?

We do not mean to deny that poverty, with its harassing care, misery, squalor, crowded tenements and poor fare, with everything adverse to human health and development, is the generating cause of a deterioration that, deepening still more, settles in that apathetic state of the pauper, which is the beginning of a line of deformities ending in complete extinction.

If a pauper meant a man without money, we should not care about him. If it meant a man without pleasure, we would not care. If it meant a man of sorrow and much trouble, we might, perhaps, not care. But it means more than this, it means a man robbed of his very manhood; and even more than this, he is corruption and the deformity of everything that is manly; he is a disseminating mass of crime, insanity and disease; an infernal brood springing up from him and poisoning all around him; an avenging Nemesis get- 
ting even with society that mocked a brother in his deep fall and degradation.

Pauperism is, as a rule, attended by anæmic states of the blood, which make continuous exertion impossible, and dispose the poor to scrofula, subject them to a most frightful rate of infant mortality as also to a very high figure of adult death rate; and, during epidemics-as the black death, the cholera or typhus-the degenerate poor are the first and often the only sufferers, as the power of resistance is in these deteriorated men reduced to almost nothing.

In 1862 , among the 963,200 destitute or paupers of England and Wales, were 30,905 insane, which makes $I$ in 31.8 . If we consider that these insane are adults of from 20 to 45 years of age, which form but one-fifth of the whole population, we will find that one of six adults among the destitute and congenitally poor is insane. And in this frightful amount of mental disease 10,31 I idiots belonging to the same destitute poor of England and Wales are not included. And this fearful rate of insanity was gradually rising from 1852 to 1869 , until the ratio of the insane to the sane amounted, among the paupers of England and Wales, to $I$ in 25, and in the metropolitan district to nearly $I$ in 20.

In the United States it is not much better. In 1854 the legislature of Massachusetts appointed a 
commission on insanity. They reported: "We find the pauper class furnishes in the ratio of its number sixty-four times as many insane as the other classes."

Dr. Wm. Guy says, frequent as insanity is among criminals, it is still more so among paupers.

Epilepsy, that fearful malady, affecting and enfeebling the mind more than any other, is getting most common among the poor. Dr. Nattuck, physician to the Bradford infirmary, has searched the register of patients for more than thirty yearsfrom $1825-1859$ - and found the proportion of this malady to other diseases as follows :

$$
\begin{aligned}
& 1825-1835 \text {. . . . } 15 \text { in } 1,000 \text {, } \\
& \text { 1835-1845 ..... . } 18 \text { in } 1,000 \text {, } \\
& 1845-1855 \text {. . . . . } 24 \text { in } 1,000 \text {, } \\
& \text { 1855-1859.... } 34 \text { in } 1,000 \text {. }
\end{aligned}
$$

Balbi observed the same increase of epilepsy among the poor of Vienna and Milan.

These facts, together with the observation of the hereditary nature of pauperism-which congenitally reverts into insanity, disease or crime-leave no doubt but that pauperism is one of the worst forms of race deterioration, and that the paralysis of the human will and its energies is but the result of a fearful dissolution in progress. But, as we have already mentioned, human deterioration is also to a large extent the result of pauperism. 
Dr. Prichard, the famous author of the "Physical History of Man," says : "The conflict in England in the seventeenth century drove many of the natives to the mountains of Sligo and Mayo. Here they have been almost ever since exposed to the worst effects of hunger and ignorance-the two great brutalizers of the human race-gradually producing in their case open, projecting mouths, with prominent teeth and exposed gums; their advancing cheek bones and depressed noses bear barbarism in their very front. Five feet, two inches, on an average, pot-bellied, bow-legged, abortively featured, these spectres of a people that were once well-grown, able-bodied and comely, stalk abroad diminutive and deformed, while they are specimens of human beauty and vigor in other parts of the country where they have never been subjected to the same causes of physical degeneration. Such are the deteriorating effects of misery!"

Is the pauper condition of the world not a reproach to the nations, and will it not soon involve their very existence? To say, simply, pauperism forms in Germany, France and England respectively, 3,4 and 5 per cent. of the population, or that in these countries $30,000,40,000$ and 50,000 of each million population are paupers, gives no conception of the existing evil. We appreciate more truly the situation when we consider that at 
the slightest rise of breadstuffs or financial disturbance, this army of paupers swells to double and triple its usual proportion. So was in 1847 every tenth man in England and every eighth man in London a pauper. In 1852 every thirteenth man in Paris, every seventh man in Marseilles, and even double as many in Lille, in France, were paupers. In 1855 , every twelfth man in Italy, every sixth in Belgium, and nearly twice as many in Flanders were paupers.

In $1847,183,447$ individuals were assisted by the public authorities of Paris, and this number has gradually risen to 237,893 in 1866 . But how many hearts agonized in secret, and would not appeal to a public board of charities?

The following statement of Jules Simon gives us a full insight into the extent of public misery. $\mathrm{He}$ takes 1,700 francs to be the lowest possible sum a working-man can subsist upon a year with a family of two children. He further states that actually of 500,000 work-people of Paris earn per annum

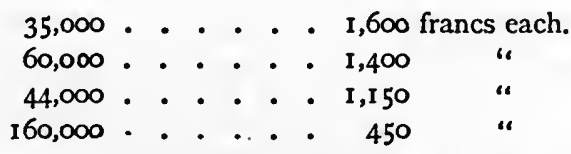

The remaining make even less. But, then, how do workmen fare with five, six and seven children on such scanty incomes? And the condition of this 
half million may fairly be taken as the average state of the masses.

But we are permitted to approach still nearer the problem of the actual condition of the people. In 1874 the tax roll in Prussia proved that 58.5 per cent. of the population earned individually less than \$100 per annum, and 34.I per cent. less than \$150. Here, then, we have more than nine out of every ten in the proud Empire of Bismarck struggling with poverty; and, in fact, less than I per cent. has an income of $\$ 1,500$, while the great wealth of the country is held by less than one-tenth of I per cent." of the nation.

The tax roll of England betrays the same sad condition of the people there. In 1865 , of a population of $24,127,013$, only 332,43 I were taxed on incomes, while the rest of the nation struggled with poverty, their incomes falling below three hundred dollars per annum.

In Belgium, in 1856 , of 908,000 families, lived

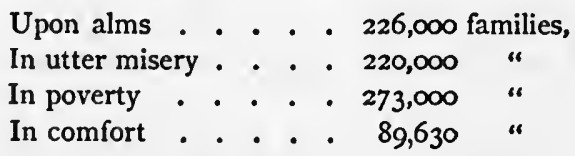

Of 100 Belgians, 49 live in utter destitution; 42 live very poorly; 9 live in comfort. That corruption and mortality are in proportion hardly needs being told; 44 per cent. of the children are illegiti- 
mate, and $I$ in every $I 50$ population is a prostitute.

The fact is, we have volumes upon volumes written by the conservative Le Play, Ducpetiaux, De Gerando and the like authorities, full of figures like Napier's tables of logarithms, about the wages of every trade for the last hundred years; the price of bread,-meal, cheese, meat, beans, onions, soap, rent, articles of furniture, clothing, and what not, the weight in grains of carbonaceous and nitrogenous food indispensable for the support of a man, woman or child at the different seasons of the year. Governments are turning pale at the ominous results of these accounts, all tending to establish in a variety of ways how the people are wasting away.

The Blue Books of the English government, in a lengthy and learned Report, officially advise the people of her British Majesty not to indulge in daily evacuations of the bowels, which are promotive of too vigorous a digestion. Two or three a week will do for people in straitened circumstances. . . . .

Do not the very heavens blush at such misery and insults? Poor humanity that calls for such official dissertations, and such royal philanthropy.

Calamitous as 40,000 to 50,000 paupers in the million are, the most desponding fact is the hope- 
less struggle of the whole million, save fifty or a hundred thousand who are well off. With the pauper-the degraded and ruined pauper-pity comes too late, he does not care for it, nor can he be bettered; those who have not yet given up the struggle against the stream, and are still to be saved, should most excite our sympathy.

What a mill that does such grinding, turning out to the million fifty thousand paupers of whom a couple of thousands go down in lunacy, and all end in total human brutalization, filling the world with bastards, prostitutes and sneaks, of whom England and Wales alone count I27,839.

The following table proves the deteriorating power of pauperism. Caspar showed that there are left of $I, 000$ born :

\begin{tabular}{|c|c|c|c|c|c|c|}
\hline \multicolumn{4}{|c|}{ tho } & \multirow{2}{*}{\multicolumn{2}{|c|}{$\begin{array}{l}\text { A mong the } \\
\text { favored. } \\
943\end{array}$}} & \multirow{2}{*}{$\begin{array}{c}\text { A moxg the } \\
\text { poor. } \\
598\end{array}$} \\
\hline I0 & ear & r & & & & \\
\hline 25 & “ & “ & & & - 852 & 553 \\
\hline 45 & “ & “ & 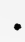 & & . 624 . & 396 \\
\hline 55 & “ & “ & - & 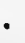 & - 464 & 283 \\
\hline 65 & “ & “ & $\bullet$ & & - $3^{18}$ & 172 \\
\hline 85 & “ & “ & $\bullet$ & ${ }^{\circ}$ & 29 & 9 \\
\hline D & " & " & • & - & 15 & 4 \\
\hline
\end{tabular}

Wherever, says a very able writer on medical statistics, pauperism with its want and misery prevails, there the mother is more likely to die in labor; there still-births will be more frequent; there the deaths during infancy will be more numerous; there epidemics will rage with more violence; there 
the recoveries from sickness will be fewer, and death will usually happen at an earlier period of life. All Education is thrown away on men in this condition, for you cannot engraft virtue on physical misery.

The advocates of the old regime claim for slavery that pauperism did not exist under it. But are we not to bear the sight of a brother with a square meal and a decent bed and shelter to rest him from the fatigue of an honest day's work without we own him like a sheep, a horse or a cow?

The rates of mortality of poor-houses are often higher than those of prisons, insane asylums and even than those of hospitals. Is this not proof enough that pauperism is one of the worst phases of race deterioration? That the county houses, in which the poor are collected, hardly harbor a man, woman or child with a sound limb, organ or brain, establishes only our proposition, that pauperism is evidence of a deteriorating humanity.

\section{REMEDIES.}

This tide of human corruption, wrong and infamy has ceased to be a subject for the consideration of curious students; the despairing millions are putting their hands to it; the very names of their societies and organizations and public organs all over the world, fill volumes. To prevent a war more bloody and desolating than the world has 
yet seen, what is proposed? Communism, public charity or co-operation.

Communism, destructive of liberty and individuality, is complete despotism. Besides, by destroying individual motives and responsibility, it decreases productiveness and increases poverty, want and misery.

Public charities were nowhere organized on so great a scale as in England, which raised a poor tax equal to the entire revenue of a kingdom, and they failed; for they are but an ill-concealed communism, and share in the same improvidence. But even co-operative societies would bring but little help, as with the present remorseless competition, societies would wage the same ruinous war against one another as now individuals do.

The world of the future is not to be a monster soup kitchen. The conception is poor, paltry and impossible. We want a more varied and higher productive power and moral energy. The world is becoming a school house, training the race for more efficient and more perfect work. Forty years ago the total value of the school property of the State of Massachusetts was half a million; to-day it is seventeen and a half millions. The school property of the State of New York amounts to thirty millions. This shows the direction we are marching in. 
Pauperism is want of energy, power, health and strength. We must, therefore, introduce into our system of Education the element of physical work to train the rising generation to labor and exertion. Better we combine work with Education, than build poor-houses and penitentiaries, and introduce work at that late stage.

When labor and intelligent reflection accompany each other in childhood and youth they will remain united through life, and the social problem will be solved. The productiveness of labor will increase then in more than one way; the laborer will lessen his expensive and injurious indulgences, while he will increase his substantial comforts and nobler pleasures, which add to his power and efficiency.

Nothing but Race Education, training all classes -capitalists as well as laborers-for accomplishing together the great work of saving, elevating and preserving the race, can deliver us from the violent revolution that threateningly overhangs the social sky.

Our present school system breaks a boy from any inclination he may have had for physical labor; it fills the country with seekers for clerkships and office hunters of all sorts; and the laboring people feel that the children who are to take up their work are not benefited by such schools. Through union with labor the school becomes the institution of 
the people, and renders Education common and universal, as the lovers of the race ever wished to see it, and solves every problem, as an active and intelligent people will ever be able to cope with the difficulties of their situation. Or does any one pretend that pauperism offers no problem for solution this side of the Atlantic?

Let us, then, just glance at the Empire State, and notice the progress of pauperism, which includes every other private as well as public vice and misfortune, and we will find its rate rising from year to year.

\begin{tabular}{|c|c|c|c|}
\hline & $\begin{array}{l}\text { Ounty Poor-house } \\
\text { Population. }\end{array}$ & $\begin{array}{l}\text { City Poor-house } \\
\text { Population. }\end{array}$ & Total. \\
\hline 1871. & - $\quad 18,933$ & 39,286 & 58,219, \\
\hline $\begin{array}{l}1873 . \\
1874 .\end{array}$ & $\begin{array}{l}20,193 \\
\text {. } 26,094\end{array}$ & $\begin{array}{l}41,737 \\
43,719\end{array}$ & $\begin{array}{l}61,930, \\
60,813\end{array}$ \\
\hline
\end{tabular}

But the army of the poor that had to be relieved by the board of charities was much larger than the one supplied inside the poor-house, and amounted in 1874 to 122,391 , which, added to the first, gives 192,204 individuals provided for by the public charities.

But to form a correct idea of the deterioration, that is partly the cause and partly the effect of pauperism, let us look at the 18,933 paupers inside the poor-houses of the State of New York in I87 I, and the causes which brought them there: 


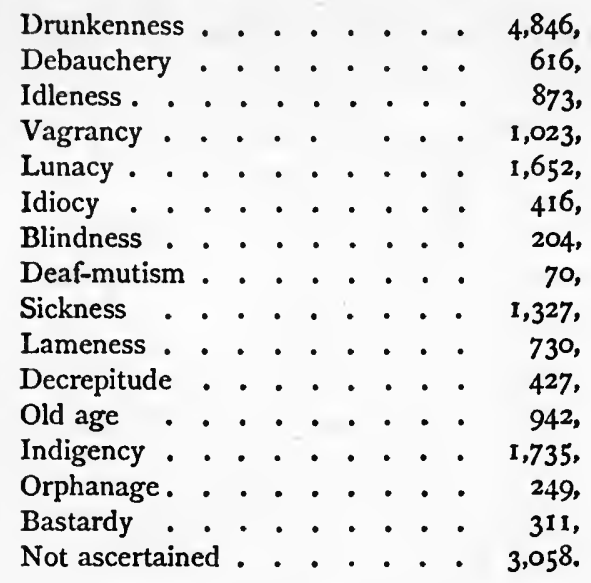

What a system of Education, life and philosophy, the fruitage of which is such a pandemonium compounded of hundreds of poor-houses, each teeming with prostitutes, bastards, drunkards, insane, idiots, epileptics, orphans, lame, sick, blind, deafmutes; and yet this queer medley of vice, misery and corruption is but a sharply drawn picture of the outside world.

\section{EDUCATION AND RACE PRESERVATION.}

We must organize schools which will make poorhouses, penitentiaries, insane asylums and the like institutions unnecessary. A school which cannot do this has no right to exist, and it will most assuredly fail to bring about such a consummation, if it does not strive for it directly, studiously and 
intelligently. Or has Education no higher aim than geography and grammar, and does it take no interest in the weal or woe of man, and in the calamities and misfortunes of life which develop from habits contracted in early childhood?

Race Education must lay a new and deep foundation in the heart, head and hands of the people. It must discard shams and illusions, restrain our selfishness, and set us to work for one another. It must stop our crime-creating society in its work of scattering broadcast the seeds of death and disease, of raising one crop after another of half a million of defectives and of undermining the health of all, as none can be all well in an atmosphere which breeds such a distemper. Necessity will force us at last to give heed to these lessons.

The capital absorbed in the State of New York in insane, blind and deaf-mute asylums, in poorhouses, houses for orphans and hospitals, amounts to $\$ 50,000,000$, and the yearly outlay on these institutions is fully $\$ 10,000,000$. Correctional institutions, criminal courts and penitentiaries, police force, etc., are not included in this sum. And as we cannot long continue the present barbarous fashion of lumping together all sorts of defectives in these sinks of wretchedness and misery we call poor-houses, and will have soon to put the blind, the deaf-mutes, the insane the idiot, the re- 
spectable but indigent old, and, finally, the children, into institutions their condition calls for, we shall have to double the sum presently expended upon them. To save the State from these burdens we must save humanity, and the prevention of human degeneracy must become the great aim of public Education.

Education is the natural function of parental aid extended to the undeveloped young for its preservation; and while among animals it stops at the individual, among men it takes in the race, the preservation of which is the only natural and sensible function of Education.

Our educators study to reduce the statistical figures of illiteracy, but look upon those of insanity, the blind, the deaf-mutes and the idiots as Godappointed social quantities. The high figures of these miseries are so constant, because our barbarity is ever the same, and we make no attempt at lessening them.

Noble men have plead for the bettering of the condition of the insane, the idiot, the blind and the deaf-mute; but what is wanted is an earnest effort for the prevention of these miseries, which are all the offspring of a constitution weakened by wretched living and other unhygienic conditions, under which mostly the poor degenerate.

In pleading for the tens of thousands of insane, 
idiotic, blind, deaf and dumb we plead for a hundred times as many outside the asylums; for nature tolerates no quick transitions, and we differ all but in degree from one another; and for every one who is all insane, idiotic or criminal, hundreds are partially so, and that just in proportion to their coming under the control of the same wide-spread causes.

To prevent human deterioration means to strengthen and purify the whole nation, and to defer its extinction a thousand years. And is such an aim unworthy of our schools?

\section{DEGENERATED TRIBES.}

Degeneracy, surrounding us on all sides, appears to us as the normal condition of mankind, which is not apt to lead to the disintegration of the race and the nation. But a little reflection and observation may convince us that the process of deterioration, though working by imperceptible degrees, brings about in the end fearful results.

The earth is full of kindred tribes, of which some are mean in body and spirit, brutal, lazy and stupid, by reason of the barren territory they occupy, and which starves and dwarfs them, while tribes of the same descent, but more favorably placed, are wellformed, active and intelligent.

Europeans, who, by their enterprise and valor, have made noticeable maritime conquests, have 
through unfavorable surroundings fallen behind the very savages their ancestors have subdued.

A most appalling illustration of the low type of humanity into which whole communities may degenerate from want of pure air, water, light and food, is afforded by the disgustingly deformed and idiotic cretins, found in great numbers at the base of great mountains and in deep valleys, with the air stagnant, in certain localities of Germany, Switzerland, France, Italy, Denmark, Norway, the Highlands of Scotland, Turkey, Russia, China, Sumatra, South America, etc.

\section{DEGENERACY IN TENEMENT HOUSES.}

But the crowded tenements of our large cities contain all the elements of the climatic influences which produce cretins, and we need not roam the world over to find illustrations of permanent types of a degraded sort of humanity. The pauper and criminal class show all the characteristics of a specific low type of humanity, and not only threaten our future, but are a burden to the present generation.

How unsound must be our general condition and how unsafe our future, with half our dead dying from unnatural causes, with three millions of avoidable cases of sickness per annum, half a million of habitual drunkards, criminals and pau- 
pers-not to mention an army of defectives of every description.

The duty of Education to counteract this degeneracy, and the system it must pursue to reach this important end, will form the contents of the following chapters.

\section{THE EVOLUTION OF EDUCATION.}

The catechism formed once the entire outfit of the school. Education meant then to believe. The reaction followed, and Education meant next to know. This, too, was found hollow, and Education was next taken for teaching us how and what to $b e$, which again ended in moral formalism and in a refined sentimental self-seeking. We expound Education as the art of preserving the race by training us what to do. To believe, to know, to be, to do, and, finally, the synthesis of all the four form the complete evolution of Education springing up in the order of the human faculties, perception, reason, emotion and the will.

The three distinct ages of childhood, boyhood or girlhood, and youth or maidenhood, indicate three phases of Education. In the first, our being is to be developed in the infant training school; in the second, the opening mind is to be furnished with knowledge in the common school, and in the third we are to be set to work in the school of 
industry preparatory to life we are about to enter. Our being, knowing and doing are to be determined at these three different ages. Our present Education plainly teaches by its practice, never mind what you are or what you do, if you only are knowing; and, hence, cunning rather than character and useful activity is fostered by our schools.

How long, oh! how long does the watchman of the night cry, When shall the blind see, the deaf hear, the dumb speak, the simple understand, the lame walk forth, the sick take up their bed, prisoners go free, and the people's dead rise?

How long, how long? does the voice of reason and experience respond to the voice of the watchman in the night, until the art of raising men will come to honor, and mothers will learn how to educate children, and children will be trained for virtue and activity in the infant sanctuaries of the nation, and young men will be prepared in temples devoted to art and manual skill for usefulness; until the body and its physical powers will be inured to active work. Not until then will men be healthy and honest, will the blind see, the deaf hear, the dumb speak, the simple understand, the prisoners go free, and the people's dead rise. 


\section{PART SECOND.}

\section{HEREDITY.}

HISTORY joins her testimony to that of statistics, and the decay of Egypt, Assyria, Greece, Carthage, Rome, the Byzantine Empire and the Saracens gives evidence of the deteriorating tendency inherent in human society.

Only an Education wisely directing its efforts toward counteracting this deterioration can delay the death of a nation.

Despotisms, aristocracies, democracies ; in short, distinctive forms of government have distinctive vicious tendencies, so have the different pursuitsas agriculture, manufacturing, commerce, or the different stages of civilization; and each of these varying conditions requires a distinctive system of Education for counteracting its peculiar degenerative tendencies.

As the masses live under conditions tending almost universally toward their deterioration, Education must directly aim to counteract this deterioration through measures leading to hereditary improvement. The principle of heredity or the trans- 
missibility of structural peculiarities from parent to offspring has already been recognized by Hippocrates, and has been fully established by Darwin and other naturalists. The principle of heredity has been fully discussed in regard to genius by Galton; in regard to psychological morbidity by Lucas, Despine and Mireau ; in regard to crime by Bruce Thompson; in regard to insanity by Morel. Maudsley and others, and in a more general way by Herbert Spencer, Ribot and others.

Nobody doubts but that the general nature of the parent is transmitted to the child. That less important peculiarities are transmissible is not so plain, nevertheless established. Many families have been known in which four, five and six generations had more or less than five fingers on each hand. Baldness, defective teeth, deafness, cataract, have been known to be congenital, and the gout, consumption and insanity are universally so; other affections are more or less so, and nervousness in parents generally appears in the children.

Singular habits are often formed through peculiar surroundings, and give rise to peculiar structural formations. Domestic birds that have no use for flying lose the power of the wing. Cave fishes, like moles, lose the organ of sight almost entirely. Domestic animals, which are not exposed to hostile attacks from other animals and do not raise their 
external ear in the act of spying the feared danger, lose the power of doing so just as man has lost it ; and, hence, the importance of fostering mental habits, as attention, reflection, self-observation, will, etc., as these habits condition corresponding structural peculiarities in the brain, become transmissible, and, after ages, permanent features of the race.

That even newly acquired habits are transmissible has been established beyond contradiction. It is maintained, with much reason, that merely the predisposition to disease and malformation, insanity, dipsomania, crime, consumption, etc., is transmitted and only developed under conditions favoring the formation of these peculiarities. This explains why often the peculiarity which appeared in the parent does not appear in all the children, and often shows itself only after two, three and four generations, when surrounding conditions conspire with the innate tendency they make actual.

Let the educator bear in mind that human deterioration can only be prevented by calling to his aid influences adverse to the development of undesirable hereditary tendencies, and that the improvement of mankind can only be secured by conditions favorable to the development of desirable hereditary tendencies.

It is not often that the one or the other set of 
qualities is so unalterably fixed in the mind of the child as to leave nothing to be done by Education.

We are the work of two factors-of innate tendencies, which are the work of nature, and of surroundings and habits, which are the work of man and of Education.

Heredity and human agency have each their limits, which it is well to bear in mind in order to avoid opposite, but equally dangerous mistakes. We cannot do all, but neither is our agency reduced to nothing. Only by realizing the power of heredity as well as the power of external conditions, are we sure to press both into the service of mankind and thereby prevent human deterioration.

We hold with Dr. Carter that the habit of exercising the judgment increases the power of this intellectual operation by stimulating the growth of its nervous organ, and that, as a general rule, a man's brain grows to the kind of activity most habitual to it-whether sensational or intellectual-and a tendency to the character thus impressed upon it is transmitted in some measure to his offspring. Or, as Darwin and Herbert Spencer show, external influences may considerably change functions which in their turn modify the organ which becomes permanent and fixed in the race through heredity.

Our mental powers have attained their present 


\section{Heredity.}

perfection through the cumulative or hereditary effect of a thousand generations, and are as capable of hereditary improvement in the future as they have been in the past.

It is high time the hereditary tendency of mental characteristics be intelligently applied in the Education of the race. The presumption is that, as the organ is hereditary, the function must be so, too. Thinking improves the brain under certain conditions, and with the improved brain the thinking is transmitted. Dr. Gall has maintained as much sixty years ago, and Auguste Comte recognizes the fact. Thomas Buckle was still in doubt, but observation has established the hereditary nature of our moral and intellectual faculties. Both Senecas were noted for their extraordinary memories. So were Annaeus, father and son; and in modern times the Porson family. The hereditary nature of the imagination is illustrated by the poetic eminence of the Greek poets Sophocles, his son and grandson; Aristophanes, the famous comic poet, and his three sons; Ariosto, of the "Orlando Furioso," his brother, Gabriel, and his nephew, Horace; Tasso, the renowned author of "Jerusalem Delivered," and Bernardo Tasso, his father, the greatest poet of his time, though eclipsed by his great son; music has descended through two centuries in the family of the Bachs. 
The family history of scientific men shows the intellect just as subject to the law of heredity as the imagination; an observation holding true from Aristotle down to Darwin, and of which we will cite a few instances. Jacques Bernouilli, a distinguished mathematician and scientist, had two sons, four grandsons and two great-grandsons equally renowned in one or another branch of science. Cassini, a celebrated astronomer, had a son, grandson, great-grandson and a great-great-grandson, all distinguished astronomers and naturalists. Euler, the celebrated mathematician, had a father and three sons, all great mathematicians. Gregory, the distinguished mathematician, counted fifteen members of scientific ability in his family. Sir William Herschel, the renowned astronomer, his son, John Herschel, his daughter and two grandsons, are among hundreds of illustrations of the principle of heredity.

The will-power, prominent in statesmen and soldiers, follows the same law, as is manifest from the names of the Adams, Colberts, Foxes, Guises, Medicis, Pitts, Peels, Richelieus, Walpoles, Charlemagne, Collignys, Gustavus Adolphus, Maurice of Nassau, and many other equally distinguished families.

It is not pleasant to dwell upon the shady side of human nature, or we could cite as many illustra- 
tions of the hereditary nature of drunkenness, theft, suicide, homicide and other crimes and vices. We shall illustrate this tendency by the sketch of one or two unfortunate families.

Jean Chrétien shows the following descendants by three sons :

Two grandsons condemned for life to hard labor for robbery and murder; one grandson condemned to death; one great-grandson transported for robbery; one great-grandson died in prison guilty of many robberies; one great-grandson died falling from a roof he was scaling in the attempt of robbery; one great-grandson died guilty of many robberies; two great-granddaughters died in prison, where they were sent for theft; one great-greatgrandson condemned to death for murder and robbery.

Bruce Thompson tells of 904 convicts at Perth, 404 of whom were recommitted. In a house of detention were rog convicts belonging to 50 familics, and 8 members of one family.

A most striking illustration of hereditary degeneracy offers the Thirtieth Annual Report of the Prison Association of the State of New York.

The Juke family, located in the State of New York, is descended from five sisters who were born I720-1740, and counts among its members 140 criminals and offenders, 60 habitual thieves and 50 
common prostitutes. Seven murders have been committed by this family, and one and forty years have been spent by it inside the prison.

The reporter of this case asks: "Do our courts, our laws, our almshouses and our jails deal with the question presented?" To us it seems, when once the problem reaches the court, the almshouse or the jail, it is already too late, and matters but little how they deal with it. The far more important query is, does our system of Education deal with this question? Shall we, by example, surroundings and judicious training, produce generations of Fénélons, Franklins and Aragos, or let heredity uncontrolled breed families and generations of the Chrétien and Juke style, and bankrupt humanity?

\section{RACE EDUCATION DEFINED.}

But Education to be hereditary must be something different than a mere cramming process. True Education is the constitutional improvement of the whole man. Man, and not scholarship, is the aim of Education. The constitutional improvement of man is effected by the training of the body, the senses and the functions of the brain to the highest degree of power and active use.

This training must take place in the formative period of earliest infancy, in order to improve the 
very organization, that it may work rightly and automatically through life.

Education must be functional and affect the organization of man, if it is to be hereditary.

Education, when hereditary, is not lost with the individual, but is what it ought to be-Race Education.

Education, when so constituted as to become hereditary in its effects, forms a truly National Education.

An Education that affects the constitution of man through habitual training in the formative period of earliest infancy, forms man's character; and if the training is of the right sort, it makes him a good man; and a like training of the whole people forms a noble national character.

The practical training of the eye, the ear, the hand, the intellect and the will in the formative period of earliest infancy makes an effective, industrious individual, and a like general training renders a nation industrious, inventive and prosperous. Our bookish Education keeps us from observing and using our senses with accuracy-a power of universal usefulness, and yet so rare.

The present bringing up called by a misnomer Education, neglecting the child in the formative, and, therefore, most susceptible and assimilative period of its carlicst infancy, fails to form its char- 
acter or to develop its powers; it fills the world with conceptions lacking execution, aspirations unsatisfied, promises unfulfilled, beautiful theories and poor practice, and, hence, the conflict between the ideal and the real, which constitutes the contradiction and the misery of the times.

Education must put the child to work; for by work man is perfected. And what he does not achieve, he never comprehends; and, hence, the barrenness of the word-learning of the schools. It profits but little the individual, and none at all the race or nation.

Habit and heredity, judiciously controlled, ameliorate man; left to themselves they deteriorate him.

We have to this day neglected to aim at the cumulative effect of Education through the principle of heredity, and have failed to secure as great an abundance of good and wise men, inventors, statesmen and sages as we might, while the vicious have even by the power of this principle spread themselves through generations until they threaten to curse the nation with a brood of criminals, paupers and imbeciles.

There is something of the infinite in moral obligation; and our duty toward the present, to be rightly performed, must take in the remotest future. The solidarity of mankind extends through 
all time as through all space, or as far as man's existence spreads. Only when based upon the principle of heredity we shall educate man for the future of the race, will the individual be blessed in his present relations; while an Education that ignores the future of the race sacrifices likewise the true interests of the individual and of the present, which are inseparably linked to the whole of humanity.

Only when national infant schools will watch over, cultivate and direct the growth of the bodies and souls of the dear little ones of the nation; and the future mothers of the race, instead of being unsexed in factories, will be trained in these national schools for their truly noble work in the nursery, will our homes be co-workers with our schools; and people and teachers will form one great educational association, joining heart, head and hand in the great national work of rearing up the rising generation.

Only when the principle of heredity will be made the foundation of a system-which will be the Education of the race and the nation as well as of the individual-will men of enlarged capacities of head and heart consecrate themselves to the work of Education, which under their hands will no more be a thoughtless routine, but science, life and practice. There was a heathen age, when it was the 
ambition of the great and the wise to guide and teach the young, who grew up to men worthy of their teachers, who were sages; that time must and will come again, and then humanity will be blessed.

Nothing but a thorough, consistent and welldirected Race Education will free the masses from the blight of pauperism, madness and crime, and remove from us the disorganizing selfishness and incapacity for good that sadden us on every side.

Education at public expense, directed by the nation, must be national, securing the perpetuity of the commonwealth, and the well-being of the masses, and that can only be achieved by hereditary Race Education, which is improving the quality and increasing the energy of every Godgiven power of the body and soul of man.

RACE AND SCHOLASTIC EDUCATION.

Race Education is the only solution of the great social problem arising from hereditary defectiveness and the consequent increase of pauperism, misery, crime and insanity.

While our routine Education is scholastic, exercising the memory at the expense of every other faculty and to the injury of the force of body and soul, Race Education, or Hereditary Culture, is hygiene applied to the physical, mental and moral nature of man. 
Race Education, by training the present generation, determines the condition of the next one; it watches over the first hours and days of man, when the foundations of his character are laid; it watches with unwearying solicitude over the waive in its charge, as a mother does over her babe.

Race Education makes physical culture the basis of its future operations; and, hence, gymnastics form an important part of its system.

Race Education, by its own hygienic tendency, inures the people to an habitual observance of the sanitary laws of body and mind, and secures thereby the health and strength of the nation.

Race Education, or Hereditary Culture, makes the practice of art and industry integral parts of its system; first, because activity is health, and, secondly, because activity transforms the physical world into things of beauty and use, which, in their turn, become means of a more perfect life; while the scholastic system has its eye fixed upon an artificial literary standard, unconcerned about life, health and power, and is entirely theoretical and notional.

Race Education, or Hereditary Culture, as it differs from scholastic Education in aim and method, so it differs from it in the objects of knowledge, or the subjects it gives prominence to in its course of instruction. It cultivates the study of hygiene, of 
nature, art, industry, economics and government, whatever concerns life and action, and looks to the future of man; while scholastic Education concerns itself about words, opinions, archæological lore, and looks to the past.

Race Education, or Hereditary Culture, considers function, organization, power, work and character, or a complete human existence, as the end, and knowledge as but one of the means for securing this end.

\section{RACE AND SCHOLASTIC EDUCATION COMPARED.}

Race Education, or Hereditary Culture, aiming at mental quality is averse to stuffing by lectures or text books. The mind must be exercised on the object of thought in the only natural and old Socratic way by dialogue, which alone develops the power of thought, and by showing the student how to find knowledge in and by himself, makes it part of himself and a possession forever.

It was not books, but the discourse, says Thornton, that developed the Grecian mind for the appreciation of Eschylus and orators of the metal of Demosthenes.

Race Education, caring above all for man, chooses subjects and methods of instruction suited to the age and the development of the faculties of judgment, reason, sensibility, invention or imagination. 
Race and Scholastic Education Compared. 83

The scholastic system, caring more for scholarship than for man, adopts methods calculated for the promotion of learning, unconcerned about the effect upon man, as it cares more about a complete body of rules of Latin composition or Greek particles, than about the body and soul of humanity.

Race Education, aiming at a harmoniously developed and happy humanity, recognizes the claims of the young to the happy days of childhood, which it will not sacrifice for the sake of producing intellectual prodigies.

Race Education, or Hereditary Culture, directing its efforts against human deterioration, guards against premature mental strains in infancy; it takes measures against the mental equilibrium disturbing predominance of one faculty over another; it aims at soundness and efficiency all over, which secure the present success and happiness of the individual as well as the health and strength of the race in the future: while our scholastic Education, which has only in view the individual and its accomplishments, cultivates the memory and imagination at the cost of the highest reasoning and moral faculties, and makes men selfish, proud and unjust; and, hence; the strife, ambition, disappointment, increase of insanity, suicide, premature death and social decay, so glaring in our day. 
Our chiefly literary Education stimulates mostly emotion and fancy, which are the life of the passions, and it secures the application of the student by working upon his pride, and thus nurses the flame which consumes us; for pride or morbid selfishness is half insanity, and passions uncontrolled are insanity complete; and pride and passion, as they disorganize the human cconomy, so they disorganize the social; and, hence, our charge against the doubly fatal tendency of our scholastic Education upon the individual as well as upon society.

However loyal schoolmen may be in theory to the principles of development in Education, do they recognize them in practice? Do they give due weight to the training of the physical forces, the senses, and, especially, to the moral faculties and the powers of observation, invention and practical execution or industrial skill?

Do they supremely aim at forming sound minds in sound bodies, which help themselves by efficient hands, restrained from working injury to others by fortified morals and habits of honesty?

As all evils tend to race deterioration, and not infrequently spring from it, Education, the great social preserver, has to be moulded in every particular, in aim, means, method, scope and surroundings, in keeping with the one great aim of race 
Race and Scholastic Education Compared. 85

amelioration or Hereditary Culture, to which every part of Education must tend as the radius points to the centre.

Our scholastic tattooing, with all its ornaments and accomplishments, is shallow patchwork, while Race Education recognizes no improvement unless it enters the blood and marrow of body and soul, and becomes, by its organic nature, hereditary.

Unless our partly ineffectual and partly selfish culture is given up to Race Education, Pariahs will spring up among us stunned in body, low in perception and defective in moral sensibility, who will drag the nation into the vortex of their own corruption; for the virtue and intelligence of a select few are too narrow a basis for a great nation to stand upon, and the few are absorbed by the many.

Upon the foundation we indicate here, physiologists, psychologists, statesmen and educators must raise a system, in which every step taken shall advance the race as well as the individual in very deed and forever.

The formation of desirable hereditary habits does not only call for infant schools, but also for longcontinued training. To render the association of occupation and virtue more permanent, we must make it continuous to the age of sixteen or eighteen years; this alone can deepen the better dispo- 
sition, render it organic and hereditary, and thus improve the race as well as the individual.

Theoretical knowledge has assumed vast proportions, and its power and efficiency are marvelous, where physical resistance is to be overcome by mechanical elements. More indefinite is the power of science in modifying organizations, which, growing from within and averse to direct external interference, yield only if put in surroundings, where they may-as if it were at will-seize upon the means which are to our purpose and assimilate them as desired. We know we have to adapt the medium a fauna or flora lives in to the qualities we wish them to develop; and yet, when we deal with the cultivation of man, we fancy that we can talk him into virtue, wisdom and efficiency, without adapting the conditions and surroundings to the desired end ; as if, like savages given to sorcery, we believed in the enchanting power of magic words and formulas. We forget that our actions very much depend upon our affective and passional nature, which almost wholly depends on the organic functions, in their turn determined by the nutritive condition of the entire state of the body and mind. Dejection, fear, grief, despair, uncertainty, anger, sorrow and the like affections, disturb the organic functions, which in their turn disturb the brain. And yet we consider the brain and its functions 
as if they were independent of all these affections.

But, if the outer world has to yield the elements for a healthy nutrition, the individual must, by an ever-active habit, contract such affections and mental tendencies as are most desirable for his own development and that of the race.

Only when we behold in our Education the Education of the race are we likely to see in our contact with men and nature and in our inner and outer experience, grand educational influences, the end of which is our own development as well as the culture and development of the race.

Men cannot be talked into living for the race; they must be trained and be brought up for the race, and they will live for the race.

Race Education, bringing up the individual for the race, develops the altruistic feelings, by which we feel the weal or woe of others as if it were our own, until conscience acts as an unerring and spontaneous force, and the religion of doing good becomes as hereditary among men as brute instinct among animals.

Does our position that the individual belongs to the race want a proof? Is there a power or faculty in him that has not descended to him from the race, and ought he not to make a faithful return for the trust with which he has been honored? 
Humanity has hitherto progressed from mere brutal strength to intellectual force, and must agdvance to moral power. Violence has but shifted the scene from muscle to brain. The three powers in man seem to have divided the rule of the ages among themselves. The first age of the world belonged to the brutal force in man. The second age belonged to reason. The empire of both these powers is equally remorseless. The third age of the world belongs to love, which rules only to serve.

God comes to us in humanity, and, above all, in helpless children, and calls upon us in their divine capabilities, which wait for our maturing them.

Education must not be a trade, but a worship; and the school must become a temple, in which the teacher officiating at the altar of humanity, makes a sacrifice of himself that the race may live a better and happier life.

Science pushes us to these conclusions. For every function has for its end self-preservation; and the function of Education must have for its purpose the preservation of the race, and, hence, the individual must be brought up not for ambition, wealth or power, but for the race. If we lived in isolation like animals, their brutal, individual Education might do for us as for them, but as we are by our families and states linked with the whole of hu- 
manity, the condition of the race determines our own preservation.

Not only the moral law with its sanctions of a sweet inner reward or remorse, but also the inexorable law of physiology, with its long catalogue of most hideous diseases, enjoins upon us Race Education, or Hereditary Culture.

The importance of plysical Education has been insisted upon by all great writers on Education, so the training of the senses, the development of the mental faculties, the formation of character and the strengthening of the will, so have the means of doing this great work been tried and studied; but, though the highest induction contains nothing but what lies in the scattered facts, it throws a flood of light upon them, and so will the principle of Race Education, or Hereditary Culture, give definiteness and union to the principles and practice of Education, which it will guide and direct by keeping in view the highest aim, by inculcating the subordination of the individual to the race, of which it is but a part and for which it must live and be educated.

The necessity of basing Education upon the principle of race amelioration was first suggested to us by the overwhelming evidence of an actual deterioration of race, forced upon us by a pathological study of labor. The study of heredity con- 
vinced us, in the next place, of the transmissibility of improved mental states, and, therefore, of the practicability of race amelioration through improved methods of Education.

Our doctrine is supported on every page of Carpenter's remarkable work on Mental Physiology, which must suggest our doctrine that the hereditary defectiveness of the masses must be corrected by Education and Hereditary Culture; that an Education that does not affect its subjects organically ana permanently-even as far as the race is concerned, and for future generations-is not deserving the name of Education.

This is our principle of Education, and all the means and appliances of study and training of mind and body must tend toward it as the planets do to the sun.

The great social problem of the condition of the masses, the latest development in biology, and the progress in the separate parts of Education, all point to the doctrine of Race Education, or Hereditary Culture, as the principle of gravitation of a strictly scientific system of Education upon which the whole science-in all its parts-is to be reconstructed.

\section{SYSTEMS OF EDUCATION.}

Others before us have laid stress upon Education; have singled out the various parts of Educa- 
tion; have, perhaps, seen in part the importance of our principle, as Spurzheim and others of the same school; none, however, have recognized in it the principle that contains all others and much more beside, and that alone is comprehensive enough to rear upon a complete system of Education.

Penn's first word to his colony was, "Educate," and Washington's last bequest in his farewell address to the people he so well lóved, was again, "Educate."

Education, says Rénan, is with modern society a question of life and death. It contains, as Laboulaye says, the solution of the problem that troubles the age we live in. But what is commonly called Education, makes of us, as Göethe expressed it, bags filled with words, figures and facts. What we want is men of vigor, action and character. "It is the early training that makes the master," sings Germany's great national poet. Strength, will, power, mental activity, work and a harmoniously developed humanity must be aimed at in Education-such are the utterances of our great thinkers.

Our higher reason is but the accumulated capital of the progress of the ages, says science. Thankfully we receive at the hands of the heroes of human progress the requisite material for our struct- 
ure of Race Education, and trace step by step our principle in their labors.

Already the Lacedemonians gave supreme attention to the physical condition of the parents.

The Old Testament almost on every one of its pages, lays stress upon the early training of the young.

The genealogical history of individuals and families proves the truth of the heredity of mental traits. Physiology teaches that systematic thinking enlarges the brain, and craniology establishes this principle by the exact measurements of the skulls of races and ages belonging to different stages of civilization. We acknowledge our indebtedness for these and other labors.

Happiness, truth, goodness, activity, reasonableness, virtue, God-likeness, etc., are unquestionably important elements, but they lack direction, definiteness, compass and scientific basis; they contain no principle that secures what they aim at, and each and every one of them considers only the individual, who, if he is to live for humanity, must be educated for it.

There is not a principle suggested by our system but has the support of the earliest thinkers of the race.

The divine Plato largely discourses how manners are implanted in early infancy, and virtue gathers 
strength from habit. He insisted upon bringing together children from three to six years of age for the purpose of being trained at their self-originated games. He already considered compulsory Education the safeguard of the State. Careful training in gymnastics, music and science he insists upon as the means for the attainment of strength and beauty of mind and body, so highly prized among the Greeks.

Aristotle, who furnished the world with its intellectual food for over two thousand years, like his great master, urges State Education to begin in early childhood, the very playthings of which should have a bearing upon the life and work of the man, whose ethical culture must be secured by early habits of right feeling and correct action, under teachers of political knowledge, whose aim must be not to form merely useful, but perfect men, by the means of art, science and discipline, the tools of Education.

Plutarch, in his inimitable essay on Education, tells us of Lycurgus showing the Lacedemonians in a public meeting the effect of early training on two dogs of the same dam, the one running to the platter, and the other starting after the hare; the one made voracious, and the other an excellent hunter.

Early exercise, says the same author, gives 
strength; good habits lead to virtue, and wisdom leads to happiness and a good old age.

Training of body and soul from earliest infancy, the solid things of science, the living example of parents and teachers, and upon the like topics, Plutarch gave us in these essays his thoughts with a freshness, which makes them delightful reading to-day.

Montaigne said: "Bookish learning is a poor stock to go upon." Again, he said: "Our understandings are no more formed by learning by rote what other men said than we learn riding, handling an axe or playing a tune, by discourses without practice."

Lord Bacon said: "Our speeches take after our learning, our thoughts after our inclinations, and our deeds after our habits, which are fixed by the force of early custom."

Milton indignantly descants against the waste of time in our schools with a miserable little Latin and Greek, and pleads for a virtuous and noble Education, consisting in studies, exercises, diet and music, likest to those ancient and famous schools of Pythagoras, Plato, Isocrates, Aristotle and others, and of whom were bred such a number of renowned philosophers, orators, historians, poets and statesmen.

John Locke held that a sound mind in a sound 
body - as already Juvenal aptly expressed it - is the chiefest happiness, and, hence, the chiefest care of Education. Education makes the man, and the commonest and weakest impressions in childhood have most important and permanent consequences for us. Morals and good habits come first, the knowledge of things next, and languages last. The treatment should be mild, natural and suited to the temperament, inclination and character of the child, which the educator has to study carefully.

Leibnitz, who, by the universality of his genius, has thrown out many ideas ahead of his age, advanced the teaching of the arts and trades in public schools as a matter of highest utility to the State.

Montesquieu said, Education has for its foundation the same principles as the State-fear under despotism, pride under a monarchy, and virtue under a republic. And since virtue is formed by carly habit, a republic must train children to simplicity and sclf-restraint. Attachment to the laws of the country demands a preference of the public good to narrow self-interest. Everybody participates in a free country in the government of the State, and must love to preserve it. Nothing but virtue and intelligence can save a republic from ending. in despotism, corruption and anarchy.

As the great Cominius, the Jolnn the Baptist of universal Education, was the apostle of the study? 
of method, to the spread of which all over Europe his agitated life has been devoted, so was Rousseau a hundred years later the apostle of the study of the child and its nature. According to him, the full activity of our senses and faculties and the skill of acquiring knowledge are the ends of Education and are to be attained by actual observation, but not by mere words thrust upon children, to whom they have no meaning and whom they 'can but stupefy. Like Locke, Rousseau insists upon the propriety of every child learning a trade, which not only bestows independence, but cultivates reflection far more than books do at that age.

Basedow, who first reduced to practice whatever was tangible in Rousseau's "Emile," insisted equally upon his pupils to engage at least two hours daily in the mechanical exercise of some useful trade.

None lived in deeper sympathy with the race, shared its miseries, loved it more truly, or worked more earnestly for elevating and saving it through life-long labor in the schoolroom, than Pestalozzi, and none has effectually more reformed our system of Education than he. He has clearly worked out the principles of developmental Education, object teaching and the whole modern system of primary Education; and he, above all, is the prophet of the school house and the schoolmaster of Europe.

Man's love of liberty, says Kant, is so strong that 
if he is not early subjected to discipline, he inclines, especially under a free government, to lawlessness, which is barbarity. To habituate the child to submission to reason is the first aim of Education, which must lead the race to its highest destiny, the development of its faculties. The great philosopher of Königsberg insisted that the child is not to be educated for the world as it is, that it may get along in it, but that it must be brought up for humanity and a better future; and that a bringing us up for the good of the world cannot injure us in our own life. Education is discipline or correction, culture or instruction, and exercise of the faculties of prudence and wisdom, and at last the formation of the moral disposition or of character. The child must learn to use its freedom and its powers, act upon principles and develop its character by order and steadiness. Work is the chief element in human life; the school should, therefore, train children to work, and as this requires strength and energy, physical exercise must form the prelude to Education, and is a chief part of it. So far the founder of the critical school of philosophy of Germany.

Mackintosh wisely says, Education is a proper disposal of all the circumstances which influence character, and of the means of producing those habitual dispositions which insure well-doing. 
According to Froebel, indolence, love of pleasure, want of sense and energy, lcad to vice and crime. He insists, therefore, upon work, as activity takes delight in its own creation, and develops intelligence and energy of will. Rousseau, Pestalozzi, and others before them, have seen that work develops virtue. None but Froebel has realized all the applications this principle is capable of developing in man. The Kindergarten is the door by which we re-enter the garden of Eden. As work was the first means in educating the race, when the soil was cursed with sterility that man might be blessed through work, so in the Education of the individual, work is the first means of blessing him; and the restless activity of the child is the foundation of the indefatigable enterprise of the man. Industry, which is the characteristic feature of the age, must be made the school of humanity. Life, energy and power, like wisdom, are not to be plucked from trees; they come only as responses to an earnest will, as the prayer which ends in work as its amen.

And in earliest infancy this training must begin. Spelling, grammar and arithmetic may be learned at ten or twenty years, or later. The man, the character, says Juvenal, is made at seven; what he is then, he will always be--in spite of a thousand teachers you may give him after that period has passed. 
Maudsley says, the true aim and character of Education are unhappily not yet understood. Man should understand himself and nature, of which he is a part; and with which himself, his thoughts and actions should be in harmony; that through knowledge of and obedience to the laws of nature he may represent the highest physical, mental and moral evolution. Our present Education must be revolutionized; for to-day, riches, position, power and the applause of men are the chief aims, and not culture, development and character; and, hence, anxieties, disappointments and jealousies break down the 'soul in madness, which nothing can cure more radically than a sound Education.

John Draper maintains, Education should represent the existing state of knowledge and not the pretended wisdom of past ages. He treats with deserved contempt the pretended training obtained through the study of Latin and Greek. The American political system is founded on the principle of public intellectual culture, and the organization of the intellect is to be the great work of this continent. The only method of ameliorating the condition of men is by acting on their intelligence. Our aspirations have been hitherto physical; they must and are now becoming spiritual and intellectual. Our personal ambitions must retire, that we 
may share in the development and accomplishment of a far higher result.

There is not a principle of Education but we may glean it from some ancient or modern writer; but Race Education, or Hereditary Culture, is a formula that embraces all the hitherto separated tendencies, each of which is but part of Education. It embraces the physical, mental, moral and industrial elements; it suggests the method, means and end, and sets before us humanity as the highest aim; it is above all practical, and looks to the solid welfare of the individual, nation and race, and indicates the necessity of a National Education, as none but the nation can educate the individual for the race and nation.

\section{RACE AND INDIVIDUAL EDUCATION.}

Man, standing on the border of the brute world, cares only for himself. He mounts the first step of civilization and lives for his family; the second, and he lives for the State. He is to-day called upon to mount the third and live for the race. Or, is it asking too much, after ages of spiritual culture and political Education, that man should feel his unity with, and his place in the race, from which separated he has no more life nor purpose than the eye, hand or foot has apart from the body? 
Is it not unscientific and leading to mischief, if the school treat man as a complete and unitary being that has its end outside of the race?

Should we not live, and, therefore, be brought up for the race? Or, are we to be brought up for ourselves, and be told afterward that we must live for the race? Does not this doing one thing and saying another, sow in us the sceds of hypocrisy and contradiction? Does not our every act bless or curse the race, ameliorate or deteriorate it? Why, then, should the preservation and amelioration of the race, which enters our every act, not be made especially the aim of Education?

If a decent regard for the rights of conscience keeps out of schools disputable points, what is there to hinder us from introducing into them the purest ethics of science?

The training of man for his place in a world of law, order and justice, that the race may be preserved and live, grow and develop in harmony with the conditions of being and universal progress and development, is the work of Race Education, or Hereditary Culture.

Everything serves a purpose outside its own existence; it is the law of nature in which everything is means as well as ends. Man, a conscious being, feels the void of a life that serves no higher purpose and ends with its own being. Race Education 
points out to us humanity or the whole as the end of the individual, who is but part of the whole, and is only possible in and through it.

The individual who, in passion or ignorance, silences this inner voice of nature, which pushes man to be means as well as end in a world of mutuality, will soon perish in his isolation.

Every great reformer of Education was a great lover of the race. So was every cxtraordinary teacher. The worst method in the hands of a teacher full of love to his race, is preferable to the best method in the hands of a teacher whose soul is dead.

The highest scientific induction places the spirit of saving, clevating and preserving the race, which has led all the great reformers of Education into the discovery of improved methods, and has strengthened and upheld their hands in the performance of their arduous work, as a constructive principle, at the very head and front of Education, and builds upon it a system in keeping with the great end to be attained.

Of course, routine pays no attention to the aim or principle of the teacher, whom it considers a tool working well with the method, books and charts furnished by the man of genius who has a soul for him.

We deny the proposition. Man is not made of 
wood or leather, and cannot be manufactured machine-like. A man must have a higher life in his soul, or he cannot kindle it in others. In every department even this is the mischief, that forms and methods so useful supersede the life and spirit which generated them; and, natural enough, lose their efficiency with the spirit that departed.

The highest generalization alone can teach us the proper means and methods, and put into them life and efficiency.

Civilization will not long tolerate the barbarism of our present poor and mad-houses or killing jails. The care of our defectives is becoming very expensive; the lessening of public burdens, therefore, by lessening public miseries, is the rightful domain of public Education, the sphere of which is the public weal and not fashionable accomplishments, leading to fashionable vices and corruption, and ending in human degencracy-the very thing public Education is to prevent.

If we are to succeed in stopping race deterioration or lessening defectiveness, we must aim directly at it and work hard for it; sailing at large on the wide ocean of Education will not do it.

Theorists may dream; still the indications are the world is not to be improved by being turned into 
a vast monster kitchen, but by being made into a grand school house, where the present gencration will train the next one, that every man may live in harmony with the laws of his own individual being, of society and of the entire universe ; that all discord may disappear; vice, misery and crime may only live in name as sad memories of the past, and men may no more imbrue their hands in each other's blood, nor may be driven annually by the half a million to madness or unnatural self-destruction. The common consciousness of the nation and the world at large is, that its future salvation is Educa. tion. Of course, we ascribe such potency, no more than Herbert Spencer does, to mere ciphering, or spelling, or geography, or algebra.

Make the individual the end of Education, and his partial culture will be taken for his full development ; make individual development the means and the race the end-as nothing else is-heredity becomes then our great ally and human degeneracy our great adversary, of which the one can only be secured by early infant training and discipline throughout the whole of Education, and the other can only be combated through industrial training, the only sure preventive of pauperism, the main source of misery which upens the flood gates of human degeneracy. 
RACE EDUCATION FURTHER EXPOUNDED.

Physical, intellectual, moral, scientific and industrial Education have each attracted more or less attention. We deal with Education as a social science and with the chief end of Education. Men of mere routine care not about ends, but the sight of the end of the journey keeps us on the right track. The end once clearly perceived, and the means and method for obtaining it are clear. The putting of the problem right is half the solution; and, hence, our solicitude for ascertaining the great end of Education and for finding the formula, which embraces the whole of Education.

Race Education implies that Education has its tangible foundation in the physical nature of, and its moral purpose in devotion to, the race. And we must lay stress upon the moral element, which is crowded out of Education by the multiplicity of modern studies.

Virtue, says Locke, is to be aimed at in Education, and not forward pertness or any little arts of shifting. The teacher should know that Latin and language are the least part of Education, and that virtue and a well-tempered soul are to be preferred to any sort of learning.

Lord Kames says: "Our teachers direct their instruction to the head with very little attention 
to the heart. And yet, surely, a man is intended to be more an active than a contemplative being; and right action is infinitcly more important than rare scholarship." Bacon and Milton, like all great leaders of the race, speak in the same strain.

But this right disposition can only be formed in the mind while it is in its very making, by our stamping devotion to mankind upon every exercise of the school, be it gymnastics, music or industry, and that we can only effect by engaging in every cxercise for the purpose of enlarging the capacities, efficiency and happiness of the race.

The whole of Education must be a consecration of the individual to the race, in which it is to be merged, and life from the cradle to the grave has to be a sacrifice of the present to the future, and of the individual to the race. Still, this sacrifice is only one in appearance, as we can do nothing for the race, which does not further our own individual growth and true happiness.

Race Education, or Hereditary Culture, renders the adaptation of the Education of every individual to his own peculiar organization only the more imperative, as no permanent improvement is possible which is not based on physiological conformation; and, hence, the development of the race and the individual is best secured when the one is treated as the end, and the other as the means. 
The gala or state morality, or moral mask and prudery, of a lesson or two a week in a moral text book, would not be worth pleading for. The whole of Education and every act of it must be permeated by a spiritual element, which is at the same time the last and most sober word of science, without cant or weakness, and in which science and religion are wedded to each other-and that word is Race Education.

In the multiplicity of means and methods for doing this, that and something else in the mechanical routine of our crowded school houses, the physical basis, and the moral purpose of all true Education can only be kept in view by the magic word of Race Education.

A teacher cannot develop hereditary culture or build up a desirable national character, if he has not risen even to the bare conception of Race Education. He, who aims may hit; he, who does not even aim is sure to miss.

Only national infant schools moulding the character and organization of a people by habit and training, and nothing else can build up a desirable hereditary national character. Every peculiarity of the skin, muscles, bones and nerves is hereditary, and so is that of the brain, especially when the whole of the nation is trained and educated in the same direction, and the surroundings are made subservi- 
ent to the same common end. It is almost beyond the power of the individual to dispose the forces of nature and of society in a manner as will develop his character in the right direction. This requires the almost infinite means and power only at the disposal of a nation, which, to say the least, largely shares in our individual responsibility, which it controls mightily in its right or wrong development. And, hence, the duty of our public Education to use all the powers at the command of the state for the elevation of the character and efficiency of all.

Race Education, or Progressive Hereditary Culture, has a double function to perform-the correction of physical, mental and moral morbid tendencies and the developing and strengthening of the normal activities of man in the most susceptible and pliable period of infancy and youth.

Enlightened thinkers insist that a criminal should not be treated as a blank, but as a collection of hereditary tendencies; and, certainly, the school and the teacher should not be behind the prison and its keepers in scientific method and treatment. Let the school correct some of our hereditary tendencies and cultivate others, and there will soon be no call for prisons and the like institutions. Better the teacher study the hereditary tendencies of the child than that the same study be forced upon us in the end for the purpose of correcting pauperism, insanity and crime. 
The constitutional deterioration of the masses induced by want, misery and neglect, begins its destructive work in the mind with the highest functions, the moral sensibilities, or the conscience, spreading to the will, the seat of the character or energy, until it reaches at last the power of thought; and, hence, the increase of crime, pauperism and insanity.

The physical powers may seem unabated, but the decay is apparent in the higher functions and the moral sensibilities are defective, rendering men hardly accountable. With the progress of deterioration the function of the will is attacked, and the man is no more to be blamed for his lethargy, than the idiot for his obtuseness.

The corruption of our time and its general confusion, as our lack of organizing capacity, are all symptoms of deterioration not likely to be met by Latin grammar.

We over-estimate in our scheme of Education the ideas of other men which, coming to us without thought or observation, are but half understood words, adding nothing to our real strength. Knowledge, like wealth, looks tempting; but only when obtained by long and hard labor do they develop the power of employing them wisely. Our thirst for knowledge is as morbid as our greed for gain. Wealth and knowledge are both but means of which humanity is the end; knowledge, however, 
instead of developing humanity by being assimilated into character or incorporated into institutions, is left by us unapplied. We hurry from idea to idea, like images in a phantasmagoria; one gives way to the other; all solves itself into relativity; and, hence, the apathy and anarchy of the age in which truth and goodness have ceased to serve as standards of life and action.

Ideas are so far ahead of the actual condition of mankind that the application of the one to the other is almost out of question; the one advancing at high speed, the other lagging lazily behind at a great distance, until hardly anything but violent revolution can bridge over the chasm between the actual and the ideal; a contrast too painful long to be borne and which must have its adjustment.

Race Education strives for a strong, healthy and normal humanity; scholastic Education sends its literary firework up into the clouds, unconcerned about the benighted masses of mankind below.

Religious men feel the defect of the position of men, who cultivate science and literature unconcerned about man. We have applied science to almost everything and have made it pay, save to humanity itself, which has become almost worthless. It was otherwise with the Greeks. True, they knew but little of machinery, but their men were, Godlike. The realism of science may become as dan- 
gerous to humanity, and even more so, than the dogmatism of past ages, which it replaces by the worship of wealth it develops.

Spain, doting upon the gold mines of the New World, neglected the richer treasures of her own soil and got poor. We get rich by trade and commerce, and neglect the cultivation of humanity, more rich in treasures than even the bosom of mother earth under our feet. Poor and paltry, indeed, are our richest possessions compared with the material wealth of the future, and this is but as the dust of the balance to the power and the resources of the mind, which creates it all.

Science in its most perfect form leads to the highest evolution of humanity, and is more truly religious than anything else, because it is most humane.

We believe with the great positivist, that the re-organization of Education must precede the reorganization of society; as all legislation is but a dead letter as long as public opinion is unimproved.

RACE EDUCATION AND DIVISION OF LABOR.

Race Education leads to a proper division of labor, the chief part of a proper organization of society.

For National Irfant schools, a chief feature in Race Education, train young women for their fu- 
ture work and dutics as mothers and educators of the race. The children are kept first in the infant, next in the elementary, and, at last, in industrial schools; and grown men alone are to work in factories. Herc, then, is a most simple and natural division of labor initiated, resting upon the differencc of sex and age, decidedly restricting the present murderous competition of labor. All the vast interests and the very existence of humanity call imperatively for this step in the re-organization of society, a step supported by public opinion and meeting with but little resistance, everybody feeling the need and naturalness of this measure.

We shall not lose by this division of labor, for we produce values in proportion to our efficiency; and, if we are better educated, the production of material values will be enhanced, besides that the more perfect and normal man is the chiefest wealth of the state.

\section{WOMAN'S WORK.}

Woman holds her commission from God; her natural sphere is the nursery and the Infant Training school, where she continues her work of gestation, which is not completed until she has formed the character of her offspring.

The factory is not woman's place, as Gladstone says: "He who will free woman from labor in the 
factory will be a benefactor of the family ;" still, as we cannot afford to lose the labor of half the race, woman must work for the race by working upon the race, fashioning and developing its character; and that she only can do when Kindergartens cover the land in which she is prepared for her work.

Why were the Romans during the better ages of the republic the model citizens of the world? Because they had model mothers for their educators. Fill the land with Kindergartens, training women for their future duties as mothers; and, as we shall have then more than Roman mothers, we shall also have citizens who are more than Romans.

Woman in the barbarous state of society is the slave; in the semi-barbarous she is the toy and the tyrant, and in the perfect state of society she is the educator.

When women will be educators of the race they will be its saviors; to-day, show, pride and vanity make them its destroyers, leading on men by their extravagance to corruption in private as well as public business, until confidence in men and institutions is to-day fairly gone, and the downfall of the nation almost inevitable.

To let a woman speak about her own sex, we will quote the well-known and competent Emilie Davies, who said before the National Association for the Improvement of Social Science: "Is it 
not true that to amuse themselves and other people is the great object in the life of women; and is it possible that their sedulous devotion to this one object can fail to react upon the men with whom they associate? Who gives the tone to what we may call lax and luxurious homes? Who teaches the boys that hard work is foolish self-torture, that an easy life is more to be desired than the fine gold of intellectual attainment? Not their fathers. What is the ideal presented to young girls? Is it anything higher than to be amiable, inoffensive, always ready to give pleasure and to bc pleased? Could anything be more stupefying than such a conception of the purposes of existence? As long as women live only for trifles, men will only live for making money."

Only when women will be brought up to be the educators of the race will men live for great purposes, and every family will be a centre from which saving influences will go forth to bless the race.

Women have infinitely more tact for developing character than men, though they may have less fitness for teaching Aristotle's metaphysics, which, however, are best not taught at all.

Pessimists may stamp every thought of an upward tendency as an idle dream, but we cannot believe men, women, the government and our whole civilization hopelessly corrupt. 
Race Education, or Hereditary Culture, aiming at the prevention of race deterioration, insists upon fitting woman for her domestic duties, upon the proper performance of which many lives depend. She has under her supervision the home, the food, the clothing, the exercise, the rest, sleep and the entire habits of the family. She nurses them in sickness, and by her economy or lavishness brings comfort competency, and general improvement, or poverty, with all its want, misery and deterioration.

For the children, the home and the school are the place, and not the factory.

For men and their powers the factory and the workshops of art, science and industry furnish opportunities, according to their aptitudes.

Reactionists may force upon the world revolution; thinkers work for normal development; and the soul must be dead that does not feel that there is a divinity in reason that shapes the progress of the race.

THE SCHOOL AND THE HOME.

Race Education interests itself in the homes of the people, without the co-operation of which its own success is utterly impossible.

The school can at best do but half its work with children housed like swine. 
The cry of the educators of the land must, therefore, be: "Homes for the people and schools for the children."

Race Education, in which training predominates, exercises more the will, the central faculty of the mind; and by moulding the heart and character of man leads through correct feeling to sound thinking.

Race Education antagonizes in the pliant state of the young organism all vicious hereditary tendencies, physical or otherwise, and corrects the passions which unbalance the mind.

Race Education improves the race by fostering individual skill and aptitudes, which increase the effectiveness of the race as well as of the individual.

Race Education does not consider man as a separate being, divorced from the past, present and future of the race. Man exists only in, through and for the race, and can only be understood and prepared for his destiny in harmony with the race.

Race Education, aiming at the improvement of the race, seeks to elevate the masses; while scholastic Education, aiming at literary excellency, the prerogative of but few, sacrifices to this small minority the many.

Education, fitting man for all his functions in society, must take council with social science. The teachers of Greece and Rome were social and moral 
philosophers, hence their great influence upon their disciples and upon the lives of the men of their times.

The characteristic morbid tendencies of the minds and morals of individuals and communities, the vices and miseries peculiar to the age, their spread, cure and prevention deeply interest the educator.

\section{THE DEVELOPMENT OF EDUCATION.}

The Education of modern Europe began with the catechism, or belief, progressed to the study of the languages of Grecce and Rome, and is thought to have reached its goal in our day in aiming at knowledge, which, we maintain, must give way to Race Education. Belief, language, knowledge and humanity form the complete cycle or cvolution of Education. We begin with instinctive hope and assurance, the prophecy of future realization; and, hence, belief, or the catechism. As language is the first step and mark of growing intelligence in the child, so it is with the race. Language, the instrument of thought, must be brought to some degree of perfection before men can think with precision and advance to scientific knowledgc. Language, having the full impress of reason, is the best means for developing the mind; and, being the storehouse of the intellectual acquisitions of the race, 
acquaints us with the labors of those who preceded us before we advance to original research. But even knowledge is not the last word, for ideas must become things, leading to the improvement of man and the elcvation of the race.

We are far from undervaluing knowledge; still nothing less than the preservation and improvement of the race can be the aim of Education.

We object to the display made of a showy sort of learning in our higher institutions, while the people are refused in their elementary schools the solid instruction of science that would assist them in the use of the tools they are to handle in their future practical pursuits in life.

Our histories, with their royal pedigrees, political intrigues and battles, must give way to the study of the rise and development of cities and states; and physics, chemistry, physiology, botany and the other sciences must be taught in the common school chiefly in their applications to life and industry. Our common schools better teach a little less geography and a little more of Youmans' Physiology and Hygiene, a little less grammar and a little more of Youmans' Household Science. The subject matter of our Education is not life, but literature, the heroes of which we worship, while we neglect the only true hero of the world-toiling humanity. 
Race Education, or Hereditary Culture, implies progress, a power by which we are striving for an excellency not yet attained, and which assists us more in our endeavor to work up to the high destiny of man than any other idea or principle.

Race Education, improving the masses, lifts all to a higher plane of common sense, where all see at a glance what the interminable discussions of former ages could not make clear even to the wise surrounded by general darkness.

OUR CIVILIZATION AND DETERIORATION.

The whole of our civilization is a series of lifedeteriorating processes. The producing classes degenerate in mines and factories; adulterations and artificial wants do their work on the consumer; luxury deteriorates the one, and want and misery degenerate the other. The records of the nobles of Venice, of the old aristocracy of France and England, prove the almost general disappearance of families living in great affluence after a few centuries; while our factory and poor laborers in great cities, left to themselves, die out in three to four generations.

There is not a relation in life but tends toward race deterioration; and, like past nations and civilizations, we dig our own grave if we fail to oppose to this degenerating tendency an Education, which 
is a persistent system of race amelioration, inspired by the spirit of altruism, the saving genius of the race, and the only possible correction of an age selfish to the core.

Race Education cultivates in the teacher, who brings up the child for the race, devotion to humanity, which from him spreads and imbues all. The system in vogue appeals to the scholar's pride -a passion that stirred up the first rebellion in heaven; a passion fierce and anti-social underlying one-half of all mischief and oppression in the world.

Are men never to be brought up to work for one another? Is the kingdom of heaven never to become a fact and a truth? Are justice, peace and good-will among men but a dream and not a prophecy as well?

Individual Education means selfishness, which, winding its way from the school room to the cabinet, creeps down thence to the lowest shop, and involves the nation in ruin.

Not without mighty reasons, and the testimony of the universal facts of history as well as the judgment of the best of mankind, has Rousseau denounced civilization as the mother of the chiefest of our woes, which denunciation falls still justly upon the culture of to-day, that often is but another name for refined selfishness, considering itself the highest end instead of serving and improving 
the race. Within reasonable limits this terrible indictment of all past civilization is more than a mere morbid fancy of the over-sensitive Jean Jacques. The clear-sighted Lessing, than whom none loved truth more ardently, moaned over the displacement of the practical wisdom of Socrates by the dreams of Plato and the syllogisms of Aristotle-for both these men were but toying, the one with philosophy and the other with science-while none of them cared for humanity, at least not in the great style of the master, who discarded the high-sounding philosophy of the schools and set about teaching men how to live.

Other sages spoke words of love, equally drowned by the jargon of the schools, which ever preferred what pedants call scholarly accomplishments to humanity, which they left to perish.

Words cost less than deeds, and learning is cheaper than goodness; and, hence, scholarship is more popular than humanity.

This evil, therefore, is not of yesterday, nor is its denunciation new; but, as the lesson is not heeded, men must not complain if it is dinned in their ear over and again.

\section{EDUCATION AND INDIVIDUALISM.}

Neither the promotion of the individual nor the establisliment of any truth or principle, but solely 
the preservation and improvement of the race are the aim of the new Education.

Or do we aim too high, when we are asking for the masses of the people a sound body and a wellbalanced mind, the first requisite of Race Education?

Nothing but the bringing up of every child for the race can bring those better times, the belief of which is implanted in every human breast.

Race Education, with heredity, its foundation principle, impresses parents and all with the sense of the responsibility arising from the knowledge that by any imprudence, which deteriorates the race, we may give the world maniacs, criminals, paupers and idiots, filling individuals and communities with sadness and decay, and even lead to a degeneracy which may seal the doom of our country.

Individual happiness as the aim of Education, and, therefore, of life, is mean on the very face of it ; and yet the aim of individual perfection leads invariably to the same selfish end and defeats its own better purpose.

Considering the culture of the select few of our own class as the sole aim of humanity, we reduce mankind to beasts of burden in order to subserve our own selfish purposes, call it culture or what you may, and thus we find that neither the divino 
musings of Plato nor the scicnce of Aristotle discovered to the one or the other the inhumanity of slavery, which they deemed the necessary condition of their own culture.

Race Education, setting up the claims of the race above those of the individual, makes universal benevolence, the sum total of all morality, the foundation of our Education and of our conduct in life.

In our endeavor to be unsectarian we become inhuman to piracy. But humanity will not always be cheated out of the great principles springing from the eternal relations of the individual to the whole of humanity and the Cosmos, advanced by every founder of religion and adhered to by a sound philosophy. Every man who sacrifices the interests of humanity to his own narrow advantage, or who is proud, oppressive and inhuman, has not risen to the high plane of humanity, and is a brute. Education must be organized on the highest principles of humanity, or society will break up into fragments. A half a million of men have fallen as if it was yesterday, before the violated majesty of the higher law, and if it cannot be done otherwise, millions more will fall-but the higher law of the subordination of the individual to society will be vindicated. Men sneer at patriotism, honesty and honor, and confess money their deity. Wealth takes off the ugly looks of vice, and poverty de- 
prives virtue of its charm. Ostentation makes riches a necessity at any price, and all at war with one another chase for gold. A nation may live for ages under traditional slavery, but a state, in which all deliberately violate the known laws of nature, cannot long continue to exist; and that this is our condition is the open secret of the nation to be read on every countenance. And are we to be told by pedants that this condition of affairs matters nothing to the school?-perish the state, literary culture is the thing!

Since, then, nothing but subordination to the higher law, or the subordination of the individual to humanity, and general regard to the good of mankind can preserve a state or government, Educators must rear their whole structure upon this foundation, and, hence, the necessity of Race Education, or Hereditary Culture, which subordinates in every particular the individual to the race.

Under the system of Race Education self-culture is not a debt we owe merely to ourselves, and which we may slight-if we so please-it becomes rather a duty we owe to others, and which to neglect is a crime against the race.

\section{RACE EDUCATION AND HYGIENE.}

Race Education does not trust to the power of mere words; it looks to material conditions, from 
which ever ideas and principles spring, as effects do from their causes; for folly or wisdom, and vice or virtue, are but the inner aspect of the outer condition of man; and air, bread, clothing and shelter are full of moral significance.

Do we expect to pluck figs from thistles? Why, then, should we look for sound principles in an unsound body? We treat the mind and take no account of the body-the common vice of the quack, who treats the symptoms and leaves the deeper seat of the disease untouched.

Race Education studies its subjects in their homes and in connection with their hereditary family relations.

Plants, to be understood, must be seen in the soil in which they grow; and children can only be understood in the home in which they are rooted with their vices and their virtues.

The scholastic system injures body and soul by the cramming process; the æsthetic system cultivates unduly the imagination and the passions; the moral system, relying upon precepts, neglects the material conditions of what it aims at; the practical system makes time-serving men, and even the harmonious development of the faculties of the individual is defective in principle, as man must be brought up chiefly in harmony with the race and the future of humanity. 
Race Education lays its foundation in the body, watching the physiological formation, in which are the beginnings of the higher development.

Emotion, will and perception originate in sensations, and these depend upon the state of nutrition; and we might just as well try to transplant the flora of the tropics to the rigid zone as try to inculcate noble conceptions into children, whose nerves, suffering from want of proper nutrition, give rise to vicious sensations.

The school often debilitates children by mental overstrain, physical inactivity, too long hours of study, want of pure air and ozone, seats and postures interfering with the natural functions of one or the other of the organs, overheated rooms, depression arising from fear or dislike of the teacher or the school restraint, envy of the more gifted and preferred students, self-distrust, want of cheerfulness or lack of harmonizing physical and moral surroundings.

With so many drawbacks to health, strength, working capacity and good-will, what wonder that the funneling system of the schools interfering in so many ways with individuality and energy, furnished so small a quota of the great men of the world.

Sir Isaac Newton ranked very low in school until the age of twelve. Sheridan was pronounced an 
incorrigible dunce. Goldsmith was dull in his youth, and Shakespeare, Gibbon, Davy and Dryden have given at school not the slightest evidence of their future success. The character given to the great Swedish chemist, Berzelius, in his school certificate, is "Indifferent in behavior and of doubtful hope." Walter Scott passed for "the thickest skull in the school." Milton and Swift were justly celebrated for stupidity in childhood.

That our schools look more to geography, grammar and spelling than to life, health and strength of the rising generation may be seen from the last report of the Commissioner of Education, in which Dr. Thomas F. Hunter, of Buffalo, is quoted to have said in his inaugural address before the Medical Society of the State of New York: "In the primary department little children have hardly room to breathe and stretch out their little arms. The United States hospitals allow from 800 to r,200 cubic feet of air to the individual. The British India jails give the prisoners 648 cubic feet of air. Some of our schools give our (growing?) children 56 cubic feet! No wonder that scarlet fever, diphtheria, typhoid fever and blood poisoning of every sort are more or less prevalent. A large proportion of these dread disorders are generated and propagated in our public schools. But acute diseases are not the only results of this criminal 
crowding. Tuberculosis, scrofulous and brain affections, developed at various periods, are generated in our schools. Better for socicty and better for themselves would it be that these infants were not educated at all than at such risk."

And such schools may be found in every large city of the land!

The average number of cubic feet to the scholar in the schools of Philadelphia is 143 . The proportion of carbonic acid to the air is 500 per cent. larger in these crowded rooms than in the normal atmosphere, and cannot but vitiate the blood. Every individual, says Dr. Bell, requires 2,000 feet of fresh air every hour, and if only 300 feet are allowed to the scholar, the air must be changed every twenty minutes, and with less provisions contamination is sure to follow; the sensibilities are blunted, the intellect is obtused; stupidity, idiocy and physical deformity are promoted. The depressed condition of the children in our schools predisposes them to epidemics, from which they suffer also more intensely than others.

An examination of the public schools of Brooklyn, in 1874, showed 50, 49, 30, 29 and even as little as 24 cubic feet of air to the scholar. Such is the condition of the schools in Brooklyn. It is, as we have seen, not much better in Philadelphia, and very much the same all over the country. 
Dr. Howard shows that our present system of Education, treating alike all scholars, is injurious to many, weakens body and mind, and is one of the causes of the increase of insanity.

Is it not time, then, that our schools be put under the sanitary supervision of competent physicians, as advocated by the Social Science Association?

Theory and practice have both established the hygienic effect of gymnastics, never more indispensable in childhood or mature age than under our present division of labor, which affords hardly to anybody the harmonious exercise of all the parts and organs of his body. Still our schools are criminally indifferent about this reform, alike necessary to the health and development of the human system.

The one-sided mental culture of our seminaries leads to mental degeneracy. The criminal pride and foolish vanity of the world, the excess of imagination and passion, and other disturbing elements cultivated by our literary schools, prepare the way for insanity, to which students thus deteriorated fall an easy prey in after-life.

But it is not necessary to enter upon a hygienic analysis of our present scholastic system. Dr. Ray, a most eminent observer, sketches in a few lines the future mothers of our physically enfeebled race, as sickly young women, daughters of healthy moth- 
ers who went to school hale and hearty, and returned with an enfecbled constitution, the face pale and the spine not infrequently curved, to give existence to children as weak as themselves.

The examination of a noted physician proved the fact that there was not one girl out of forty who have spent two years at a boarding-school that was not more or less crooked.

Horace Mann said: "Degeneracy must not only be considered as one of the greatest calamities that can befall a people, but it must be entered on the catalogue of its greatest sins." Again, the same eminent educator says: "As the inevitable consequence of unhealthful habits, debility or sickness ensues, old age is anticipated, feeble parents are succeeded by feebler children, the lineage dwindles and tapers from less to less, the cradle and swaddling clothes are frequently converted into the coffin and shroud, occasional contributions are sent off to deformity, to idiocy and insanity, until sooner or later, after incredible sufferings and abused and outraged nature finding all her commands broken, her admonitions unheeded, her punishments contemned, applies to the offending family her sovereign remedy of extinction." The same veteran says : "On the broad and firm foundation of health alone can the loftiest and most enduring structure of the intellect be reared." 
Nervous diseases are daily becoming more frequent, and our mad houses, though of the size of towns and daily increasing in number, are overflowing with their unhappy tenants.

We, therefore, insist upon Race Education, or Hereditary Culture, which clearly implies a humanity, sound in body, vigorous in mind, skilful in performing, inventive in conception and well-balanced all over.

Our definition of Education excludes both extremes, the past ineffectual formalism as well as the anti-ideal or unethical realism, which would fain press Education into the service of a selfish industrialism.

Health is the first condition of success and happiness, and, hence, hygiene and gymnastics are the first steps in Education. Gymnastics direct the organic activity of the body from the great nervous centres to the muscular system, and lessen thereby an excess of sensibility, which, among other baneful influences, counts also that of a premature and morbid sexual development, ending in that terrible vice which destroys the youths of the land by the tens of thousands. Our onesided Education, failing to combine physical with mental exercise, is greatly responsible for this racedeteriorating pest.

Too many lessons lead to evening studics, an 
excited brain, an unsound sleep, dreams and selfpollution. Muscular exercise and fatigue induce a sound sleep and a clear head for morning study.

Germany is following in the traces of ancient Greece, and gymnastics form a part of its common schools, of which it is fast reaping the benefit.

Prof. Tyndall, like others, strongly condemns our one-sided culture. "Few persons," he says, "are aware how great a promoter of study labor is. Those whose occupations are of the intellectual kind, frequently become brain-weary, and this sort of weariness is very exhausting. The brain needs rest, gets it most effectually in muscular toil, and returns to study with a keen appetite." Tyndall recommends alternation of farm and shop work with study, and concludes, "This habit of work should be formed early in life, if we would have it a source of pleasure. Work is the greatest educator and blessing that we have or are likely to have." And this initiation in the mechanical arts, horticulture or agriculture, while affording relaxation from mental exercise, would prepare us for the active duties of life, and add greatly to our material wealth. 


\section{P A R T T H I R D.}

\section{KINDERGÄRTEN AND INFANT EDUCATION.}

For hundreds of years universities absorbed all the care of governments ; to-day the vaster importance of common schools is conceded. But we venture to say, the foundation must be laid deeper and lower still-in infant schools, where the senses are developed, moral and industrious habits are formed, the taste is improved, and the finer feelings, which give fibre to the will, are cultivated.

But while the highest interests of humanity demand the formation of national infant schools, the immediate material interests of the industrial classes call for them as an opportunity for early art training, the development of the faculty of form, combination and invention, as they can only compete with machinery in art and ornamental industry.

The daily increasing temptations of all classes convince all of the urgency of moral training, the want of which has not a little to do with our almost universal loss of trust and confidence, and the consequent crisis we are passing through. 
Through the inactivity of our intellectual faculties in early infancy we become more apt to imitate and form habits good or bad, and, hence, the importance of training-schools at that age.

Our sensations and their gradations, even those of touch, smell and taste, and especially those of sight-which suggest form and magnitude and lcad to the perception of order and beauty-and those of hearing-which imply a succession of time and harmony-are all elements of thought and lead to the formation and development of the mind. This cultivation of the mind begins, then, with the exercise of the senses, and especially of the eye, best cultivated by Kindergarten training adapted for the purpose and by the art of drawing continued in after years.

From the very birth of man, sensations deepen into perceptions, perceptions by repetition form memory, memory develops into imagination; the absent object is imagined and calls forth desire, which grows into passion; impressions force a comparison and give rise to judgment, which again develops into reason; and, hence, the importance of coming in contact with living nature and her grand living realities, the source of all healthy sensation and perception, the fountain-head of all higher mental life, and the necessity of feeding the minds of children through their senses and not to blur 
their minds through words - the imperfect shadows of things. It is from the freshness of the sensations and perceptions, derived from the constant intercourse with living nature, that the self-made man obtains his vigor and success in life.

When character and individuality and the cultivation of virtues, like order, steadiness, neatness, industry, wisdom and love, and, in general, a better and happier humanity will be aimed at in Education, Kindergarten, in which the development of these traits is the only business of the teacher and his young pupils, will be assigned the first place in the rearing of the race. As long, however, as the cramming down of the fragments of half-digested knowledge is taken for the proper work of the school, the race will be uneducated and suffer severely and variously, in spite of our boasted institutions of learning, and in proportion to the undeveloped nature of its positive elements of physical, mental and moral strength.

The words of Lord Brougham are always worth considering, and he dwells upon it as a weighty matter in connection with national infant schools, that a child can and does learn more before the age of six years than it does or can lcarn after that age during his whole life, however long it may prove to be. Children, he says, with curiosity, frankness and candor, become soon unwilling to 


\section{Kindergartens and Infant Education.}

learn, turn stubborn and sullen, and even full of base fear and falsehood, from want of early Education and infantile tuition.

If colleges and universities turn out men full of fine speeches and sermons, only Kindergarten schools can turn out men and women of fine moral dispositions and such sterling mental parts as will make them citizens of solid worth.

Kindergarten sounds very poetic, though its origin is deeply realistic. Froebel's heart sunk within him at the misery of the masses, whose children are pining away within the dingy walls of dark and damp tenement apartments. He longed to see men free and happy, which they cannot be without activity; but to be active they must be healthy, and, hence, he insisted that the pale little prisoners of the poor should be congregated in schools connected with gardens, that heaven's free air may have access to them and give them strength to act and to live. Next to bodily vigor, mental activity is requisite to a perfect life. The dwellings of the poor offer but little variety of impressions and yield but little food to the perceptive powers, the imagination, the will, the æsthetic faculty; and the social virtues have no chance at all in the isolation of the dwellings of the poor, where the dear little ones are not infrequently locked up as brutes in cages, while the parents are out to work. 
That in England 408,46I infants of the ages between three and six years attend infant schools, or, according to the report of the Commission of the Duke of Newcastle, 12.I7 per cent. of the population under 5 years, and in France 418,768 infants of the same ages are in public halls, proves sufficiently the practicability of infant schools, and that they could be made beneficial to the highest degree to the race by the training and direction given to the physical and mental activities of the young before they take the wrong direction, into which they are often pushed by vicious hereditary tendencies.

The progress of the Kindergarten schools in the last few years is a guarantee of their ultimate success. There were but twelve in the United States in $187 \mathrm{r}$. The following table, taken from the Commissioner's late report, shows their growth in the last few years :

\begin{tabular}{|c|c|c|c|c|c|c|}
\hline & & & I 873 & 1874. & 1875. & 1876 \\
\hline Kindergarten, & , . & - . & 42 & 55 & 95 & 130 \\
\hline Teachers, . & - & • & 73 & 125 & 216 & 364 \\
\hline Pupils, . . & . & . . & 1,252 & 1,636 & 2,809 & 4,090 \\
\hline
\end{tabular}

St. Louis has made a lively beginning of incorporating the Kindergarten system in the primary department of public instruction. Boston has entered upon the same experiment.

The Kindergarten demands the highest capacity 
in the teacher, shows clearly the object of Education, and how to reach it; the teacher studying and developing the pupil, as books do not step in between the two and defeat the true object of Education.

Once the presence of the father assisted the mother in the government of the children; to-day the factory or the business house calls him away from his home; and the mother, burdened with additional cares and labors in and out of the house, can impossibly attend with an even temper to the difficult task of properly training her children. The generality of mothers have to do their own work, their cooking, washing, sweeping, mending, nursing and taking care of babies; and shall they be made also to train and educate our little children? 'Is it a wonder that women are weakened, break down in body and mind and transmit their feebleness to their children?

We insist upon it that the father's absence and the increased responsibilities and cares and labors of women to-day, together with the irritability of our excited nerves, make it a necessity-both for mothers and children-that the latter are managed by infant schools, which would thereby much improve the health of overburdened mothers, and, in consequence, improve the race.

As the house is dead and empty without the 
presence of the blessed little ones, so is the nation without its public nurseries, in which alone our children can be properly trained.

Oh! what bliss is in store for the race, when juvenile processions of sweet children will on festive occasions brighten the careworn brow of the workers of the nation. The lamb-like innocence, beaming from the angelic little faces, will do more toward purifying the moral atmosphere of the land than all opposition parties.

Far from being an innovation, we find that Boston had already in 1823 an infant school of 130 children.

The growing difficulty of attaining success in the complexity of our modern relations, the advantage a cultivated intellect bestows, and the continuous exercise of this faculty, render it superfluous to dwell upon the necessity of mental training at school.

In proportion as men will be expected to do something well in life, the development of their faculties and encrgies, and, hence, their early training will become more important. The infant school, therefore, must be something different from a mere play or singing school; and, least of all, must the children be crammed.

Infant schools cannot but become worse than useless when children are taught in them in the manner of : 
G, is for Goshen, a rich and good land,

$\mathrm{H}$, is for Horeb, where Moses stand.

I, is for Italy, where Rome stands so fair.

$\mathrm{J}$, is for Joppa, and Peter lodged there.

$\mathrm{K}$, is for Kadesh, where Miriam died,

$\mathrm{L}$, is for Lebanon, can't be denied.

Froebel's games must not be allowed to become monotonous, but the individuality of the teacher and the pupil must endow them with a daily freshness, which renders them a delightful exercise to the minds and bodies of the children. The teachers of infant training-schools do a most noble work and must have warm hearts and active minds.

Race Education, aiming at permanent qualities and fixed tendencies in the race, cares more for infant training than collegiate teaching. The latter may give us masters or commanders, who have neither the will nor the disposition to practice the laws they lay down for the regulation of others; it may make diplomats disposed to take advantage of the ignorance of the multitudes; but infant training makes men who are a law to themselves, and who succeed not by the folly and faults of other men, but by their own skill and industry.

It is a sort of malign providence in the state to educate the citizen just sufficiently to make him responsible for the law which he may be able to read, without developing in him the power to conform to it. 
The culture of the disposition in the young, which is mostly effected by living example, is a grand school for the adult generation. But, alas! just here is the rub. It costs little or nothing to lecture. To give the example, we have to become learners and workers ourselves, and, hence, the preference of barren teaching to fruitful training.

If a person well trained in childhood strays from the path of rectitude, he is easily redeemed from his error through the early instilled sentiment, which, as it were, waits but for an opportunity to be aroused from its dormant state into full power, swaying again the life and action of the soul and purging it from vice and crime.

Race Education lays most stress upon the cultivation and development of a sound body, for where health and vigor are wanting, nothing great or good can be achieved, neither intellectually nor otherwise, and nations as individuals lose their hold upon success and pre-eminence with the loss of physical energy.

Still, though our main care in dealing with infancy is the attainment of bodily health and strength, we may and must lay the foundation to intellectual greatness already in the nursery. It has been observed by Beale that fixing the attention steadily upon one object, or the complete concentration of mind, makes the Newton or Leib- 
nitz. And this faculty may be cultivated in the nursery by riveting the attention of a child to whatever he is doing, until he comprehends as much of it as his age permits before he passes to anything else. Children are so apt to fly from one thing to another with too much rapidity to thoroughly acquire a knowledge of one thing before they begin to examine another.

By a wise control over the appetites and propensities of our children the foundation is laid to that self-command in them, without which no real happiness in life is possible.

Let children observe and learn facts, storing their minds with material for a later age when the higher faculties will begin to combine and compare ideas.

We take only notice of what a child learns by set lessons, forgetting how much he learns by observation of innumerable facts and the acquisition of language.

Premature decrepitude and death are often the fruit of forcing the mind and neglecting to strengthen the body.

Proper digestion, perspiration, exercise and respiration are requisite to the proper action of the brain. Lessen the quality of the blood by impure air, or the quantity by insufficiency of food, and the brain lacks its proper stimulus.

Race Education aiming at permanent effect 
through organic improvement seeks to ascertain in the nursery the temperament, constitution, idiosyncrasies of the various organs and their functions, morbid affections, hereditary tendencies and habits of those trusted to its charge. It being ascertained that the child we are to manage is of a bilious, sanguine, nervous or lymphatic temperament, of a weak or powerful constitution, scrofulous or phthitical, with a hereditary tendency to insanity, habits, surroundings and a mode of living are to be chosen opposing the development of the evil tendencies feared.

It is in the nursery that the habit must be cstablished of conforming to the hygienic laws of our being, a habit that determines the whole of life, and is positively of itself sufficient to insure our success and happiness in life; and punctuality as regards food, sleep, temperature, evacuations, clothing, etc., affords a constant opportunity for the establishment of this habit of conforming to the hygienic laws of our being; and this opportunity begins with our existence, and will do more for us than all later precepts and exactions.

The brain of the young, soon over-worked, disturbs the functions of nutrition and produces indigestion so common among us, as we over-task our children at school and ourselves in whatever enterprise we may be engaged in. 
It is the excess that injures. A proper amount of physical and mental activity promotes the nervous activity requisite for the healthy functions of the human system.

Temperance and exercise of body and mind must be insisted upon, without which health of body and mind are impossible and life becomes a torment.

Though all faculties are to be trained, still they are to be subordinate to the intellectual powers, which must, above all, be called into active exercise, especially as we are naturally prone to yield to our animal propensities.

As the formation of regular habits, self-control and order are of the highest importance, a good nurse will lay the foundation to all these habits, and secure at the same time the health of the child by invariable order in the periods of feeding and in all other matters.

Much can be done for the future happiness of the child by a cheerful nurse, who avoids harsh tones. A discordant voice and ill-tempered mother are sure to beget moroseness in the child, and lay the foundation for future misery. Gloom and depression, says Taylor, during childhood debilitate body and mind. A sorrowful child, full of unkindness and misfortune, develops among the lowest class a ferocity, which startles from the commission 
of no crime. An unhappy childhood is often the cause of a wrong life, for it perverts the judgment and natural feelings of man; depression impairs the functions and lowers the tone of body and mind.

Bearing in mind all the time that the physical growth and development is at this tender age important beyond every other consideration, we still say, more can be done for the future mental development of the child in the first two years, than at any future period, for the child's powers of observation can be steadied and its curiosity strengthened, while we can weaken the one by discouraging the other, in order not to be annoyed by the child questioning us and exposing our ignorance besides trying our patience.

As light, air and exercise are the first requisites of the young citizen, we will remark that the fading of the carpet must not be allowed to interfere with free access of the rays of the sun, neither must the possibility of soiling clean garments stand in the way of free and easy out-door play, and as a properly warm and active skin is the foremost preserver of good health, we will add here our protest against children's bare arms and legs.

It is a shame, our factories interfere even with infant schools. But can we not by stringent factory laws, like Switzcrland, keep little children out of factorics? Or are our western prairies not as 
fertile as the ice-fields of Helvetia, and can the American republic not as well provide for the future citizen, as the mountainous land of Tell does for its children?

EDUCATION A SOCIAL SCIENCE.

Providence, that gives the bird its beautiful plumage and teaches it to sing, that joins suppleness to strength in the tiger, gives antlers to the stag and fleetness to the hare, will it not provide for the suffering masses a way of escape from their miseries? The physician studies but one side of human life-the physical-and that in its abnormal state. The lawyer considers man in his legal and hardly in his moral or physical relations. The divine is almost wholly absorbed by the world to come, and the suffering masses themselves, and their hungry leaders, are too much in the thickest of the fight to direct with judgment the details of the battle.

May we not look reasonably to the teacher for the deliverance of humanity from its present troubles?

Great educators are not mere cipherers. They are lovers of the race, and sorrow with its sufferings. Luther, Franke, De la Salle, Rousseau, Basedow, Zinzendorf, Pestalozzi, De Fellenberg, Oberlin, Wichern, in short, all who have revolutionized old barren systems, or applied well-known principles 
on a grand scale, were deeply exercised about the social miseries of the people they yearned to relieve from the burdens that were pressing upon them. Vehrli, in Switzerland, was so strongly convinced of the necessity of the teacher's sympathy with the people, that at his normal school at Constance the future teachers had to work as hard and live as poorly as the commonest of the people, with whom they were to be united in heart and feeling; and the success of this system had become so manifest, that it has been copied in numerous normal schools all over Europe, and especially in those which had the good of the people at heart as the great and good Vehrli.

The teacher is no theorist, but a practical worker. $\mathrm{He}$ has the best opportunities for observing human nature and for acting upon it when it is most susceptible and least prejudiced. He has but one desire - the good of the race-and the world trusts and confides in him to-day more than ever. Who, then, of all men is more suited for the priesthood of social reform than the teacher and educator?

The proper division of the sciences and the assigning to each of them its proper work is the very foundation and beginning of their successful cultivation. Medicine was for long ages but a part of theology and was practiced by the miracle working and healing divine, and astronomy was left to 
the fortune-telling astrologer; while the chemistry of society, or social philosophy, like the chemistry of nature, was left to the goldmakers, and shared the same fate of never rising in such hands to the dignity of a science.

Remove social science from political economyvulgarly speaking, the art of making money-to Education or the art of improving man, and social philosophy will experience the same change as the science of the heavens did when removed from its ancient quackery to the serene science of astronomy, or chemistry from the goldmakers to the schools and laboratories of the Berzelius and Rose.

As long as social philosophy was made the adjunct of political economy, man was made subservient to wealth, just as wealth will be made subservient to man when political economy will be made an adjunct to social philosophy.

Like law, medicine or theology, social philosophy must be put in keeping of some working profession ; and there is none, as we have seen, more proper for the cultivation of this noblest of all departments than that of the educator, who has in his hands the formation of humanity almost from the very cradle, and whose work is the improvement of man. Of course, the educator will make man and his improvement the centre and circumference of social philosophy. But is there any serious objection to this? 
Only in the union of social science and Education lies the success of both and the future of humanity.

Like the mills of the gods the educator grinds slowly, but surely, and equals all in the end. $\mathrm{He}$ does not convulse society with revolutionary measures; but neither are counter revolutions possible where he has prepared the ground for the onward movement of a progress in keeping with the conditions of time and place.

Race Education puts a new emphasis upon Lord Brougham's celebrated "the schoolmaster is abroad," and endows it with the force of an almost new inspiration. The suffering masses, humanity, need not despair, the schoolmaster is abroad. He is intelligent; is in daily contact with the children of the poor; his labors and aspirations are for the poor; their welfare is his success; his worldly prospects are modest; the prosperity of the poor is all he works for, and this is the highest reward of his most ardent labors. To the teacher the poor must look as to their most trusty friend, who will yet conquer for them the sphynx, answer her queries, and solve the problem that presses hard upon a suffering world to-day.

To fill this, his mission, the teacher must study the whole of man. Hc must understand the genesis of physical debility, morbidity and of excessive 
rates of mortality; he must understand the genesis of pauperism, of drunkenness, of insanity, of vice and of crime; for Education is the dietetics by which all these abnormal developments are to be prevented, and the race and the individual are to be prescrved and improved.

But if Education is a social science, it certainly cannot teach, as it does to-day teach, everything save the principles of this science, which is the most useful of all to man.

Horace Mann has successfully ukged upon com. mon schools the study of human physiology. But is the physiology of society or political economy less essential for our social existence than common physiology is for the animal economy?

Ignorance cannot interfere with the motion of the stars, but it does with the movements of industry. Passions and narrow interests blind us as to the facts and principles of social science, and make an impartial study of the same a double necessity.

How natural it is for a laboring man to believe that labor is the only factor in production; that wages can be raised or lowered at option; that what is gained by capital is taken from wages, and that to curtail capital is to improve wages, and the like sophisms, which form the stock in the conflict between labor and capital and which sound economical teachings must help to clear away. 
England,with its extreme centralization of wealth, real and personal, would not enjoy to-day the peace and prosperity it does, had not its Broughams, its Robert Peels, its Chalmers, its Chambers, Charles Knights and Chadwicks worked as assiduously for the spread of sound economical doctrines as for the improvement of the condition of the masses.

Education, or race preservation, cannot overlook the laws of production, exchange, currency, distribution and consumption, which can no more be violated with impunity than any other laws of nature.

The aim of Education, says Mr. Blyth, before the National Association of Social Improvement, is not to make reading and calculating machines, or manufacturers of Greek and Latin verses, but steady, intelligent and thrifty men, practicing regular industry, beneficially to society, and, therefore, profitable to themselves; men who possess self-restraint to abstain from wasting or misusing the product of their industry; forethought to store a portion of that product against sickness or old age ; honesty and trustworthiness, the prevalence of which qualities in society enables confidence to be felt that their savings will be enjoyed, and a sense of parental duty inducing them to seek to implant in their children a disposition similar to their own.

There are plenty of opportunities in school life 
to follow up the lessons of industry, self-restraint, forethought, equity and the like duties with their practical application.

The mischief caused by the economical ignorance of the merchant class can only be imagined when we consider the universal calamity of our financial crises, which are as periodic and destructive as the pest formerly was.

If men of science do not teach at school correct principles of social science to the advancement of social order, peace and general prosperity, disorganizers will spread doctrines subversive to society and civilization.

Whoever will succeed to arouse the nation to a proper realization of the danger that threatens our future, from the neglect of the duty of teaching the people sound principles of social science in our common schools, will prove himself a public benefactor.

\section{INDUSTRIAL EDUCATION.}

The preservation and improvement of the race requires a certain degree of general well-being, which depends to-day chiefly upon the productiveness of the industrial arts, which, therefore, must form the chief concern of the school. Our whole course of instruction looks to general culture. The adding of practical science and industrial training, 
far from materializing the schools and rendering men machines, would only join practice to theory, and executing to planning, which humanizes us by the inter-penetration of thought and action. Science and industry are both gainers when they are united. Once the soldier held the scholar in contempt; today the-school and the scholar avoid the contact with the workshop and the mechanic; and yet, if Lord Bacon is right, the workshop is the vestibule to real knowledge, and its methods are safer than those of Plato or Descartes.

The school should omit nothing in theory or practice to make men more productive, saving, forethoughted, just and moral. Science, in its practical application, the history and description of raw materials and the fashioning them into articles of industry, the management of tools, domestic and political economy and social science, form all-important parts of the workingman's course at the industrial school. The industrial colleges of the United States should graduate annually a thouand mechanics and artisans, models of skill, efficiency and reliability. How much more such graduates would be worth to the country than the graduates sent out by our Latin and Greek schools, the relics of the middle ages.

We are no more satisfied with verbal alterations. The abstract formulas and rules of science are of 
no more practical use than the fine points of the schoolmen of the middle ages. Our infant schools must build us up by their training; our common schools must use us to experimental ways by their constructive method of instruction, and our industrial schools must give us opportunities for applying that spirit to the practical arts of life.

A sensible people will as well submit to compulsory industrial training as to spelling and grammar, cspecially as many trace their miseries to the want of such training. One-half of the people are out of work, because the other does not know how to work, and has nothing to give in exchange for the labor of the other.

Or is this idea of compulsory industry a dream? If it is, it was sober enough a dream for the eminent jurist Lieber to have dreamt it forty years ago.

Against the spirit of the age Education is impotent. Joining with it, Lieber remarks, it yields a permanency of results attested by the stability of the Chinese Empire, in which the Education of the schools and the spirit of the country are of a piece. Wild speculation and industrial activity are the double tendency of this age; the school may reinforce the first and lead to extravagance and ruin, or it may sustain the latter and promote universal well-being.

In antiquity, lessening human wants was lessening 
the double barbarity of slavery, which supplied labor, and of war, which furnished the markets of the world with slaves. In modern times, the increase of human wants is the foundation of a civilization in which labor is supplied by brains, directing machinery. Only when labor will be coupled with intelligence and taste, and will be efficient, and the capacity for consumption will be universally increased by the enhanced productive power of the masses, will over-production cease to be a periodic calamity, distressing alike to labor and capital, and, hence, the necessity of associating art instruction and industrial training with the common Education of the people.

Or must the children of the industrial classes be pauperized before they can get into industrial schools?

Is it just or wise to make industry the exclusive feature of pauper schools? Is not this degrading labor and sliding back into the foul spirit of slavery and indolence, and the contempt of poor humanity? Is it not undermining the foundation of national wealth and public morality and manhood?

There are two sorts of culture, a traditional, occupying itself with the opinions of the past, and a common, acquainting itself with men and things as they are. The first is as barren as endless, and inaccessible to the masses, for whose wants public 
Education ought to be suited. The second is suited for the people, whose Education must be such as will make them healthy and well balanced men, gaining a comfortable living by their skill and industry; and with health of body and mind, and industry, comfort and manly culture will not long be missing. To be plain, our schools are not to furnish us with young ladies and gentlemen shining in society, but to fit men and women for useful work in a world of toil and labor.

Our encyclopædic Education makes of everybody a superficial judge of everything; thorough universal elementary art and technical training make men skilful performers of useful things. We want workers and not everlasting talkers. We are all critics, but where are the artists?

Once schools were only attended by the clergy; and, hence, they were engrossed by Latin. Later, they were frequented by the wealthier classes and became commercial in character. To-day, when the working people crowd them, they must become essentially industrial. Drawing, geometry, science applied, technical instruction and industrial training must develop taste, skill and inclination for a variety of mechanical pursuits. As long as five millions of, youths are annually unfitted upon our school benches for the plough, the shop and the factory, neither this, that or any 
other administration will relieve us of the misery of our times.

Who can count the direct and indirect victims of a half a million of dens of iniquity in the land? Who can measure the depth of their misery and degradation?. What an army of paupers, drunkards, criminals, insane and idiots! What sorrowful batallions of the blind, deaf and dumb, who come into the world loaded with other men's sins. And the vicious, the proud, the avaricious, slaves and oppressors greatly swell this sad list.

When men have once been saturated with sin and shame, benevolent societies may pitying follow them to the grave.

The common schools must bring up the people for work; and a gentleman who thinks his children above such an Education, must have the dancing master come to the house.

Education alone can safely guide us through life. But Education must start us on the very way we are to travel through life. It must make us, when children, feel, think, live and act as we are to do through life. To pass our young years upon school benches entirely, prepares us for passing our lives in the school and not in the world. There are hours enough in the day for exercising a child in all the parts of life.

William Penn, the founder of the commonwealth 
that bears his name, framed the following provision, which was adopted by the Provincial Council in 1683 : "That all children within this province of the age of twelve years shall be taught some useful trade or skill, to the end that none may be idle, but the poor may work to live and the rich-if they become poor-may not want."

Our Education, says the State Superintendent of Pennsylvania, seems faulty in this, that too many young people are seeking a livelihood without working with their hands. Of 240 convicts, received at the Eastern Penitentiary of Pennsylvania, only twelve had a regular trade, and of the criminals of 17 prisons in the United States in 1868,79 per cent. were without a trade.

Mr. Edward Winslow, of Boston, insists upon joining mechanical and industrial training to our common school exercises. So does Prof. J. W. Burns, of Philadelphia. Commissioner Eaton decidedly uses all his resources to direct the minds of the teachers of the United States to the want of a more practical Education; and aptly quotes, in introducing the subject of Education and Labor, the words of Humboldt : "The time is not far distant when science and manipulative skill must be wedded together, that national wealth and the increasing prosperity of nations must be based on an enlight. ened employment of natural products and forces." 
Man's whole make of body and soul, his wants, and the whole structure of society, call for the perfecting of our industrial occupations, especially today, when the competition among unskilled laborers is so great, and the power of steam takes the place of muscle. But under our system of division of labor, when a man, making a twentieth part of a thing, can earn however scanty a living and doing it all the time, does it expeditiously and to the satisfaction of the employer, technical schools become a necessity, in which apprentices are taught every part of a process, and the theory as well as the practice, in order to become superior workmen.

Neighborhoods and countries blessed with such industrial institutions have distanced in the great markets of the world all the competition of the imperfect products of other countries, which by this sad experience have been awakened to their commercial danger.

Muhlhousen, Creuzot and Besançon, with their celebrated industrial schools; Belgium, with fifty such institutions and fifteen thousand apprentices, who have attended these schools with great satisfaction to themselves and the manufacturers; France, with its twelve thousand of industrial scholars; and Germany, with its 52,127 apprentices in fourtecn hundred and fifty industrial schools, are sufficient proof of the practicability of such institutions. 
Scott Russel shows the actual cost of the technical Education of a workman is no more than \$125, and the surplus earning of educated over uneducated labor of one single year amounts to as much.

England is almost carrying on a crusade against the ignorance arising from want of like institutions for the technical training of her people. It recognizes the utter failure of a general Education, that is not followed up by a special Education and training in some particular industry.

A practical Education for useful life is hereditary; for, as it is all work and training, it enters the very make of body and soul, while superficial scholarship profits very little at present and nothing at all in the future.

Modern governments are expensive; and if they do not assist the pursuit of industry, especially when the scientific information and the technical skill necessary for the complete mastery cannot be secured without the assistance of public institutions, they will soon find empty the pockets of the people they so often rifle.

Why should the government not as well provide for the highest mastery of the occupations of the work-people as for the learned professions?

Solon freed children from all obligations toward their old parents, who neglected to teach them a trade. 


\section{The Progress of Industrial Education. I6I}

Massachusetts made this duty obligatory upon parents by statute laws as early as 1642 , and Connecticut in 1650 .

Almost forty years ago, Lieber said in his "Ethics of Politics," that all his investigations lead him to the conclusion that modern crime is very much due to the want of fixed occupations. Among 358 convicts in one prison he found but 52 , or one in seven, who had a trade.

In Belgium, in districts in which industrial schools are in operation, vagrancy, the hotbed of crime, has entirely disappeared, and at Creuzot, in which industrial instruction has been in vogue since $184 \mathrm{I}$ though a city of twenty-five thousand inhabitants, crime, and even misdemeanors, have almost disappeared, and three policemen form the entire force sufficient to give the people the feeling of perfect security.

Education, without industrial training, starves the masses, breeds mutiny and ends in national suicide.

Race Education most stringently insists upon industrial training as the most effective preventive of pauperism, vice, crime, insanity, and, in fact, of every wrong from which society suffers to-day.

THE PROGRESS OF INDUSTRIAL EDUCATION.

The progress in the industrial arts in England, France and Germany is not by any means the re- 


\section{The Progress of Industrial Education.}

sult of mere manufacturing routine, which has but slowly advanced the arts, until the government has, by the creation of schools of design, of art, and practical science, spread the taste and the principles requisite for the advancement of a higher industry:

If we are to advance in the industrial arts for the sake of our commerce, our hungry masses, the purification of taste and the delights of a higher civilization, we must likewise found industrial schools. Our late national exhibition entitles us to say that with the same art and industrial training, France, England and Germany possess already for many years, we would soon be more than their equal in the manufacturing arts.

As far back as 1835 the House of Commons has appointed a parliamentary committee for ascertaining the state of art in England and other countries, the best means for extending a knowledge of and a taste for art among the manufacturing classes, and the state of the higher branches of art and the best mode for advancing them.

The want of instruction in design and the absence of public and open galleries containing approved specimens of art was pronounced by this committee the chief cause of the difference between the artistic feeling of the English manufacturing districts and that of similar districts of France and other countries. A normal school of design was, therefore, 
determined upon, and the Government School of Design opened at Somerset House, in 1837. Every student had to devote himself to the advancement of the interests of manufactures and ornamental trades. The course of study embraced-

1. Elementary instruction, as outline drawing of ornaments and of the human figure, shadowing, drawing from plaster, modeling and coloring.

2. Instruction in design for special branches; the study of fabrics and of such processes of industry as admit only of the application of design under certain conditions; the history of taste in manufacturing; the distinction of styles of ornamentation, and such knowledge as was calculated to improve the tastes of the pupils and acquaint them with art.

In 184I the first common local schools of art were opened at Spitalfields, Sheffield, Manchester, Birmingham, Coventry, Nottingham, Norwich, Stoke, Hanley, Leeds, Huddersfield, Newcastle, Glasgow and Paislcy, with 2,24I pupils.

Technical art instruction was given; museums were established; artistic anatomy, practical construction, wood engraving, painting on porcelain, decorative art in all kinds of woven fabrics, paper staining, furniture and jewelry, all were treated with the grcatest attention.

In 1863 these schools of art have, through the continued care of Parliament, and the central insti- 


\section{The Progress of Industrial Education.}

tution, the Chamber of Commerce, and the general interest of the public, risen to 90 with 16,480 pupils under instruction, and 79,305 children of poor, and other schools were taught through their influence; and to-day II 7 schools of art give instruction to 20,3 to pupils, with 309 night classes, having I I,747. pupils and 148,256 scholars in poor-schools all over the country under instruction in design.

That these establishments have materially raised the character of the designs in all descriptions of English manufactures nobody doubts.

The opening of the trade schools at Bristol, Worcester and other places, in which building, mechanical and engineering trades and chemical manufacturing have made great progress since 1852 , has been successfully followed up, until in 1870,799 have been in full operation with 34,283 pupils. And it is universally admitted that these science schools had a lasting effect upon the scientific Education of the working people throughout the country.

In I 861,82 classes submitted to public examination, such as entitles to government support; in I 870, 2,204 science classes were examined not only in mathematics, mechanics, drawing, physics and chemistry, but in practical work, testing the power of using the ax, saw, plane, chisel, file, forge; smithwork, turning, pattern making, moulding, ctc., the. 
The Progress of Industrial Education. $\quad 165$

rule being that unless fully one-half of the science students are practical workmen the school has no claim upon the government for support. What an excellent example for our imitation. A school that does not aid the world in its work has no claim upon its assistance.

The following table will best illustrate the importance attached by England to these practical institutions. Industrial instruction was given in

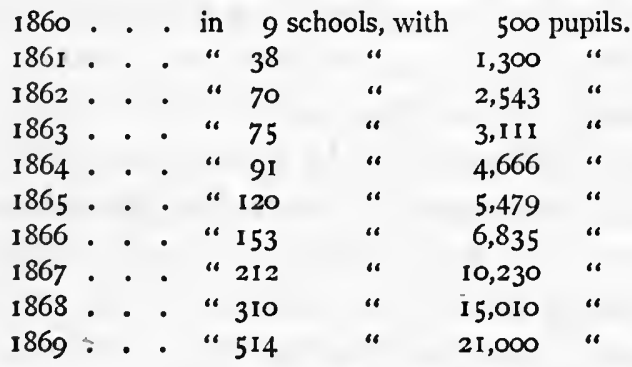

Enough has been said about the industrial, art and science schools of England, which have made it great in the industrial arts, to show how much can be accomplished in a few years by a government, which has at heart the commerce of the nation and the welfare of the masses.

In France, national schools of art and common industrial schools have been fostered with the same care as in England and with the same results. The schools of arts and trades at Chalons, Angers and at Aix sent out every year 300 young men perfect 
in theory and practice in a number of trades. Paris, Lyons, Muhlhausen, Rouen, Nimes, Dieppe, Rocliclle and other places, have excellent practical schools of industry. In 1862, 79 cities had industrial schools, attended by 32,000 pupils.

France has two great national agricultural colleges, seventy farm schools, practical schools for draining, etc.; three mining schools, the central schools of arts and manufacturing at Paris, also the famous Conservatory of Arts and Industry, three national schools of arts and manufacturing in the provinces; in Savoy, a famous school for watchmaking, the renowned Polytechnic School at Paris. In 1867 , there were in France 250 special smaller technical schools, 21 schools of design, 12 of arts and trades, 5 of hydrography, 4 of the technical sciences, 4 of design for textile arts, lace, wallpaper, furniture, etc.

Germany, which ranks high in the industrial pursuits, swarms with thorough practical technical schools, of which Austria has 45, Bavaria 36, Saxony 76 , Baden 50 , among which are some for watchmaking, weaving and straw plaiting. Switzerland has, besides its great polytechnic institutes, 29 industrial schools. Belgium has 15 technical schools and 68 national workshops.

Enough has been said to show the necessity of organizing industrial schools for our success in the 
practical arts, commerce and the self-support of the masses, who must live by their labor. We have done more; we have shown by the example of the foremost nations in art and industry that these institutions are not only possible and thoroughly practical, but do actually exist in great numbers and fulfill all that is expected of them.

Every lover of America cannot but look with pleasure at the following table, which shows the growth of schools of science in the United States:

$\begin{array}{lrrrrrrr} & 1870 . & 1871 . & 1872 . & 1873 . & 1874 . & 1875 . & 1876 . \\ \text { Schools, . . } & 17 & 41 & 70 & 70 & 72 & 74 & 75 \\ \text { Teachers, . . } & 144 & 303 & 724 & 749 & 609 & 758 & 793 \\ \text { Students, . . } & 1,413 & 3,303 & 5,395 & 8,950 & 7,244 & 7,157 & 7,614\end{array}$

These schools of science are an almost infinite improvement upon the old Greek and Latin schools, which in the vast majority of cases do more injury than good; and as these schools of science grow older, they will become more practical and teach more science applied than pure science, with which a graduate leaving the college cannot profit the world sufficiently to get in return for his services a modest meal. We have hardly any schools of industry; and drawing, as useful, and even more so than writing, to every artisan, is but slowly making headway in our common schools, the only ones the masses are able to attend.

It is often expressed that technical pursuits hard. 
ly merit the attention of men seeking a comfortable living. If this was really so, and an efficient artisan could not make a decent living, communism, incendiarism and every disorganizing scheme against a society, which refuses men a living for the labor it requires of them, would find almost an apology in such an unjustifiable condition. The fact is, we live in a crisis, in which a fat bank account or even plenty of real estate is no more security against want than labor is. An average importa-. tion of $\$ 500,000,000$ to $\$ 600,000,000$ worth of manufactured goods is evidence that we want more skilled men. The association of industry with the school and science, will raise it to the character of art and infinitely vary it. No matter how much. machinery produces, as long as men work and exchange their products, they are benefited. But that they may all have work, industry must take the character of art, which admits of an almost infinite variety and demand; for, of course, with a gigantic producing machinery, men cannot find employment in a few rude manufactures. An Arabic enameled glass lamp set up in the Louvre, became the support of hundreds of artisans modeling after it.

An industry raised to the character of art not only gives bread to the masses, but in purifying the taste of the people it improves their morals, for the beau- 
tiful and the good are but different expressions of the same thing.

Congress has manifested great wisdom in initiating the practical and scientific tendency of our higher institutions by its munificent grants for the establishment of agricultural colleges. That it put foremost agriculture and mechanics next, is eminently proper, as the promotion of agriculture is every way more to be desired in this country than the cultivation of manufacturing industry.

The National Bureau of Education, under the able superintendence of John Eaton, contributes its full share to rendering the educators of the land more practical. It does all in its power to show the need of the organization of infant schools. It acquaints us with the progress of technical Education abroad. It makes plain by statistical investigations the bearings of Education upon the various relations of the nation as well as of the individual. It brings face to face the theories and practice of the great educators of the land, which are thus corrected or supported one by the other. The influence of the National Bureau of Education is immense, and forms an epoch in the educational activity of the United States. It lifts the educator to a plane where he discerns all that is advanced the world over by the leaders of thought in his line, and where he beholds Education in connection with all the great interests of humanity. 
170 Industrial Education in the Unitcd States.

The prospected delineation of our centennial history of Education by the National Bureau is simply stupendous.

INDUSTRIAL EDUCATION IN THE UNITED STATES.

In the beginning of the century, before the full tide of emigration had set in, when land was new and cheap, work hard and plenty and help rare, the farmers' sons had to do the work; and when they had grown into manhood and felt the want of an Education, the colleges and seminaries were glad to give it to them in exchange for their labor. Thus the condition of the country prepared for manual labor schools, and here, as everywhere else, has theory perfected what practice has roughly initiated.

Between 1820 and 1830 public opinion had taken a decided stand on the utility and feasibility of manual labor schools, which were introduced everywhere at the end of this period.

The democratic men who cleared the woods, broke the ground and made this country and government, did a good deal of hard working and hard thinking; and they thought their children most likely to do the same if they handled at college as many tools as books. They wanted their sons to work for their Education, and work while they were at it, as they deemed thought only valuable when work rendered it effective. They did not want 
Industrial Education in the United States. I I I

polish got at the expense of health and vigor, which labor alone can give and preserve. Neither did they want the poor, who could not pay, but could work for their Education, to be excluded from the schools. But, above all, were they unwilling that their sons should lose at school their taste for working, while they acquired a taste for thinking. And, then, they believed nothing was gained when independence was lost ; and so, again, they wanted their sons doubly to work for their Education, that they might feel independent while they worked for it, and feel independent after they got it; as they could live by the plow or the anvil-if they could not by their profession-and be true to their convictions.

The eminently industrial people of Pennsylvania took the lead in this matter. The Manual Labor Academy near Philadelphia, opened in 1829. "The hours of recreation are employed in useful bodily labor, such as will exercise their skill, make them dexterous, establish their health and strength, enable each to defray his own expenses, and fit him for the vicissitudes of life," the record reads.

In 1830 every invalid student, who resorted to the Manual Labor Academy and spent there about a year, was restored to health. "When thought shall need no brain," the report continues, "and nearly four hundred organs of motion shall cease 


\section{Industrial Education in the United States.}

to constitute the principal portion of the human body, then may the student dispense with muscular exertion."

The House of Representatives of the State of Pennsylvania, by a resolution passed in December, 1832 , directed a committee on education to inquire into the expediency of establishing at the expense of the state a manual labor academy for the instruction of teachers for public schools. The committee made out a report as the result of a very careful investigation, of which we will briefly state the following points:

I. That the expense of Education, when connected with manual labor judiciously directed, may be reduced at least one-half.

2. That the exercise of about three hours' labor daily, contributes to the health and cheerfulness of the pupil, by strengthening and improving his physical powers and by engaging his mind in useful pursuits.

3. That so far from manual labor being an impediment in the progress of the pupil in intellectual studies, it has been found, that in proportion as one pupil has excelled the other in the amount of labor performed, the same pupil has excelled the other in equal ratio in his intellectual studies.

4. That manual labor institutions tend to break down the distinction between rich and poor, which 
exists in society, inasmuch as they give an almost equal opportunity of Education to the poor by labor as is afforded to the rich by the possession of wealth; and

5. That pupils trained that way are much better fitted for active life, and better qualified to act as useful citizens than when educated in any other mode; that they are better as regards physical energy and better intellectually and morally.

This report was accompanied with an act to be passed by the Legislature establishing a State Manual Labor Academy.

New York City had a Society for Promoting Manual Labor in Literary Institutions, the principles of which were expressed by Mr. Wild, the secretary, in the report of 1833 , in so solid a manner, as to command our attention even to-day. Our muscular system and bony structure, he says, does not look as if we were made merely for reading and writing.

The influences which body and mind exert upon each other are innumerable, incessant and all-controlling; the body continually modifying the state of the mind, and the mind ever varying the condition of the body. Not the body alone, not the mind alone, but both united by mutual laws make man. The mutual laws form the only rational basis for a system of Education. A system based upon 


\section{Industrial Education in the United States.}

anything elsc is wrong. The body is the house, the instrument, the reflector and the servant of the mind; and if it is rendered dark, dull and crippled, what is it worth, and of what use is it to the mind? And what is then the state of the mind?

The body and the mind must be educated together. We must preserve the body in the condition which will most favorably affect the mind. As the best condition of the mind always attends the best condition of the body, must not a system of Education, which expends all its energies upon the mind alone and surrenders the body to chance, be fundamentally defective? Is not a system false, which aims solely at development of mind and yet overlooks those very principles which are indispensable to produce that development, and transgresses those very laws which constitute the only groundwork of rational Education?

The mental part of Education has been vastly improved. But what has meanwhile been done for the body? What provision has been made for the daily wants of its muscles and nerves? What aids have been furnished to the organs of digestion, secretion and circulation? What means have been provided for preserving the body in its best condition, or for giving healthful energy to its functions, best securing to the mind that permanent vigor which results from such a condition of bodily 
organs? We have neglected the Education of the body, and with the sound body the sound mind has become rare. This is no new discovery. Milton has, two centuries ago, urged the connection of physical and mental Education. Locke has done the same. Jahn, Ackerman, Salzmann and Franke have done the same in Germany, and Tissot, Rousseau and Lond in France.

As far back as the end of the last century, Dr. Rush, of Philadelphia, recommended at length the connecting of agricultural and mechanical labor with literary institutions, saying, "The student should work with his own hands in the intervals of study."

President Lindsley, of the Nashville University; Professor Mitchel, of the Medical College of Ohio; Professor Harris, of the Medical Institute of Philadelphia; President Fisk, of the Wesleyan University, and Professor Hitchcock, of Amherst College, have all earnestly advocated the union of manual labor with intellectual culture.

Mr. Wild closes his very, able report with the apprehension that the want of the element of physical work in our system of Education will make of us just as degenerate and sinking a race as the higher classes in France were before the great revolution, or as the noble families of Spain are to-day. But reports and speeches were the small- 


\section{Industrial Education in the United States.}

est part of the work. Manual labor schools sprung up North and South, and East and West.

The Society for the Promotion of Education of the Episcopal Methodist Church organized a number of manual labor schools. The Baptists were not less active in the cause of establishing like institutions.

The Governor of Pennsylvania recommended in his message the adoption of the system of manual labor in seminaries for teachers. The Governor of Georgia recommended the introduction of manual labor schools. The Legislature of North Carolina has passed a bill incorporating the manual labor schools of the State.

In the United States Senate, in 1836 , the resolution was offered proposing the Committee on Public Lands to be instructed to inquire into the expediency of making a grant of land to our colleges in each State for the Education of the poor on the manual labor school system.

We may, by way of illustration, mention but few of the many manual labor schools which resulted from this discussion of principles and legislation. Connecticut had manual labor schools at Suffield, at Worcester and Haddenfield. Georgia had manual labor schools in Camden county, at Lawrenceville and Covington. These institutions were in successful operation, and paid the students at the 
end of each term, \$14 to $\$ 30$ for the work done in three hours per day.

In Kentucky, Cumberland College, at Princeton, was conducted as a manual labor school. Another labor school was at Lexington.

In the State of Indiana manual labor was introduced at Wabash College; and at the Teachers' Seminary at Madison the students paid entirely by their labor for all necessary expenses, without being put back in their studies.

Dr. Blyth, President of South Hanover College, in the same State, and organized on the same principle, says: "Such schools give birth to enterprise, create or perpetuate habits of industry and economy, generate and keep alive a feeling of self-support and independence, preserve health and create genius."

Massachusetts introduced a manual labor schaol at Lexington and at Andover Seminary.

In Missouri, Marion College required every student to work in the shop or field three hours daily, which enabled the student to pay a considerable part of his expenses.

In New Hampshire, at the manual labor school, straw-plaiting was carried on as a trade.

In New Jersey, we find manual labor introduced at the Stockbridge Academy, in Madison county.

In the State of New York, we find the manual 8* 


\section{Industrial Education in the United States.}

labor schools practically introduced by the noblest of her sons, Gerrit Smith, at Peterboro.

In North Carolina, the Donaldson Manual Labor School gave poor young men an opportunity of getting the best Education by paying for it in labor.

Ohio seems to unite the industry of the East with the snap or go-aheadativeness of the West. It had a manual labor school at Granville, prepared teachers on the same plan at Marietta, and had another manual labor school at Dayton. At Lane Seminary, on Walnut Hills, near Cincinnati, the committee state that the combining of three hours daily labor in some useful and interesting employment with study, protects the health and constitution of our young men; greatly augments their physical energy; furnishes to a considerable extent or entirely the means of self-education; increases their power of intellectual acquisition; facilitates their actual progress in study; removes their temptation to idleness; confirms their habits of industry; gives them a practical acquaintance with the common employments of life; inspires them with independence of character and the originality of investigation, which belongs peculiarly to self-made men. Printing was followed. The students got sufficiently skilled in three weeks' practice to earn $\$ 2.54$ per week, working daily three hours. They 
Industrial Education in the United States. 179

followed also cabinet making with the same good results.

The Western Reserve College, at Hudson, had shops and tools provided for those who wished to engage in labor. Some have gained, says the college report, only health of body and vigor and elasticity of mind, enough to pay, one would think, for two or three hours daily labor, while others did much toward defraying their expenses. Oberlin was never backward in the spirit of genuine reform, and required the students to do daily three hours of manual labor, with marked results as to the health of the students, which was made an object.

The Keystone State has already occupied our attention. The manual labor school near Pittsburg had 440 acres of land and a three-story building sixty feet long. Chester county was the seat of a very active association for the adoption of an improved system of Education, recommending the establishment of a model school combining agricultural and mechanical labor with literary and scientific instruction.

At Bristol College, in the same state, manual labor in school was found highly useful as well as economical, and the Episcopal Recorder, at Philadelphia, says, with reference to this institution : "We hope to send forth trained and strong men, 


\section{So Industrial Education in the United States.}

no diluted manhood, who associate vulgarity and meanness with all manual labor, or young men blighted with college diseases. Sedentary invalids of every description demand that systematic and regular labor be incorporated in the very framework of our new institutions. Manual labor and mental culture ought to go together, for, as Plato says, "A good Education imparts to the mind and to the body all the power, all the beauty and all the perfection of which they are capable."

In South Carolina the report of the Manual Labor School at Pendleton says that the manual labor system in South Carolina has been fairly tried, and that it is decidedly the most advantageous mode of Education which has ever been introduced into this or any other country.

Alabama, Michigan, Tennessee and other states have interested themselves equally in this cause, but enough has been said to show what our fathers have thought and what they have done for manual labor schools.

About the time of the agitation of manual labor schools, I820-1830, the population of the United States, all told, was not 10,000,000. Labor was then mostly native and respected. The American laborer wanted a higher Education he could not pay for nor find free of charge. The pupil, who came from the plough or the shop, felt more the bene- 
fit of manual labor, which, indeed, all appreciated in all its blessed bearings, as the young republic was still full of democratic inspirations. With the change of these conditions manual labor schools lost in popularity; but physical labor is so fundamental a condition of human existence, that these institutions will never be superseded without detriment to society, though their methods may have to be varied to meet new wants and purposes. Our cities have in the last thirty years grown to the size of the largest cities of the Old World; land has become rare, and the foreign populationespecially under the present system of manufacturing-is flocking more and more into these hives of human beings. In these days of steam and machinery, these masses must be aided and sustained to maintain themselves by an industry, skill and knowledge have elevated to the character of art, or we all end in chaos brought on by idleness, misery, vice, crime and a turbulent and despairing mob.

Enough has been said to show that our fathers have thought the union of labor and study at school eminently wise and practical as well. We do not ask to make of every school a workshop, but we insist, the most important years of man in which his character and habits are formed for life and the many millions which are spent on Education in 


\section{Industrial Education in the United States.}

this country, must have something greater, better and wiser to point to than a little grammar, spelling, arithmetic and geography. Industrial Education is not a new crotchet. It had many years ago a most tangible existence in this country; it is today organized on a great scale in Germany, France, Belgium, Switzerland, and is making rapid progress in England. It has been urged upon the teachers and legislators of the land by most practical men for the last twenty-five years; and the modern apostle of Education, Pestalozzi, held it sufficiently important for the school to help the pupil to sustain himself in the world, that he combined manual labor with school instruction.

We plead for practical scientific instruction, with full application to the industrial arts and life. We plead for drawing that shall give the scholar full exercise of the eye, hand and imagination, and develop his taste and skill; for more geometry, the science of form and color, and the history of industry and technology. We plead for technical gymnastics in every school, which, besides promoting physical development, shall give the scholar the use of the common implements of the trades. We plead for special industrial schools of a nature to assist in the progress of the trades peculiar to certain localities and districts. We plead for the organization of industrial institutions of all grades 
into one great system, with a national industrial university at its head, that shall inspire our hands with great and useful works. We plead, in fine, for the cultivation of the industrial spirit in every normal college, which is to send out into the world teachers for the people, whose success as well as the success of the country depend on the cultivation of industrial habits.

In our pleading for industry we plead for agriculture-the noblest of all industries, and the most useful as well as the most elevating of them alland the one in which more than in any other we have great nature as an especial ally on our grand and unequalled prairies and in the variety of our climes, which produce whatever will bless man.

How long still will teachers set before them with indifference of mind the vacant task of making children read and write, and, perchance, know a little geography, arithmetic and grammar?

It is time we spread the practical facts and principles of science, which would make of every laborer, mechanic and manufacturer a thinker and an inventor; a man, who by his skill would largely contribute to the pleasures and adornments of life, and add to his own happiness as well as to that of mankind. The capabilitics of art and science for making of earth a heaven will not be known until pervading the masses, every child in the land will be tremu- 


\section{I84 Industrial Education in the United States.}

lous with sensibility, and love of order and beauty. With the energy of thought peculiar to practical science and the sensibility attending art, every home will be the blessed abode of peace and plenty, of love, order and beauty, in which sadness and sorrow will be unknown, as all will be industrious and live in natural simplicity, hardly ever visited by sickness, want and misery.

Such is the future the union of science, art and industry is to usher in. But who has the heart to dwell upon the picture of the misery of the laborer of to-day, who, unaided by art and science, plods along in the old beaten path with but a poor return for his toil, and lives in squalid quarters made darker and more miserable still by the sight of cheerless, sick and dying children and a poor mother borne down by labor and care?

Industrial Education for the people is no theory. It is with them a question of life and death. It is a question of civilization. It is a national question, and touches the existence of the state. And the rich are as well interested in it as the poor, as the time is near when only capital turned over by laborers, skilled through the knowledge of art and science, will yield a return to its owner. 


\section{PART FOURTH.}

\section{THE PROGRESS OF CIVILIZATION.}

THE history of the world is the Education of mankind, and every step in the onward march of civilization is full of lessons and suggestions to the educator who aims at the preservation and improvement of the race.

Schoolmen take the wit and wisdom of books for civilization. They do not know what effort it has cost humanity to develop the industrial arts, which have made life possible and even pleasureable in a world that harasses man at every step.

Industry, or human activity applied to the arts of life, has changed us, and is changing us every day; and if Education is to become a civilizing power, it must improve and advance industry to a science and instrument for the mental and moral improvement of the people who are ever engaged in it.

Industry is the mother of the inductive method of reasoning from enlarged experience, and of the utilitarian philosophy, and both these, her daughters, are fast changing the life and mind of mankind. 
It is a maxim recognized and acted upon by practical statesmen, that general progress is not influenced by abstruse principles or reasonings, which never penetrate the masses. Only as far as science mingles with the trades and occupations of the people does it become the property of the world and civilizes the age.

The decorations of a building are not the building, nor are they as important as the foundation laid solidly deep down in the ground. It is so with literature and the common arts of life, which sustain life. Civilization existed before prophets, poets, philosophers and statesmen appeared.

Long and laborious was the way industry had to travel before the present stage was reached.

Not only civilization as a whole includes many changes, but, as Tylor conclusively shows, there is not a tool, a garment or any other object of art, but it is the survivor of a thousand changes; and as every pebble is an epitome of all past geological changes, and mirrors the cosmos to him who understands its language, even so it is with every object of human ingenuity, as each is a volume of the world's history, stretching back from this our Age of Steel to that of Iron, back to the Age of Bronze, and the Flint Age, when man was the companion of the mammoth and the woolly rhinoceros.

Yes, the whole world of human objects is a library, 
and nothing in it is so trivial, be it a spade, a knife or a hatchet, but it has to tell wonders of the thousand sires that preceded it, and whose history is closely interwoven with the history of the race.

Pedants see civilization exclusively in schools and books which exist but since yesterday, while the mechanic arts date back a hundred thousand years, and their remains are found to-day buried under thick strata, the work of myriads of years and in company with a fauna that shows the very skies and climate as well as the earth have changed, and are no more what they have been when the hands of men have formed these débris of another age and world. Such is the cycle" of ages that was required to bring the mechanic arts to their present maturity.

Well says Gibbon, “The poet or philosopher illustrates his age and country by the efforts of a single mind, but these superior powers of reason or fancy are rare; many may be qualified to spread the benefits of government, trade, manufactures, art and science, but even this requires the union of many, which may come to naught; but the simple practice of the mechanic trades stikes an everlasting root into the most unfavorable soil; under all changes and restrictions these inestimable gifts have been diffused; they have been successively propagated; they can never be lost. We may, 
therefore, acquiesce in the pleasing conclusion, that every age of the world has increased and still increases the real wealth, the happiness, the knowledge, and, perliaps, the virtue of the human race." Thus with the practice of the mechanic trades the progress of the race has begun and continued through unnumbered ages, and through them alone what has been acquired in the long struggle will be maintained and descend to new races and civilizations, when all else will be lost and become unintelligible.

Thousands of years the race roamed about before it stole the thunder from the clouds-learned how to kindle fire and how to keep it up. The Egyptians, the Phœnicians, the Persians, the Greeks and the Chinese have all preserved the tradition of the invention of this art by their ancestors, and to this day we meet with tribes who miss it.

To pluck fruit from trees was the first method of sustaining life. A long time passed before man made the first tool or instrument, the first step in his civilization-the arrow and the bow-which made the chase possible. Only as men multiplied, and the chase fell short of sustaining life, would men consent to tend flocks of sheep and herds of cattle.

When man succeeded in domesticating animals and throwing the burden and slavery of his work 
upon the horse, the ox and the ass, a great stride was made in the civilization of the race. In China and India but until a very recent date men were used instead of animals for transporting goods over roads; and an embassy from Holland to Peking required the service of a thousand men to carry the baggage. In the taking of Mexico by Ferdinand Cortez, fifty thousand Indians were employed in doing what five hundred horses might have accomplished.

It was no small matter when man discovered the chestnut and the like preservable fruits; and the cereals, as rice, wheat, maize, were still later discoveries, and became each the foundation of a peculiar civilization - rice in Asia, wheat in Europe and maize in Peru and Mexico.

Hunting, fishing, pastoral life, mining, working of metals and tool making had all to precede the plow, without which the proper cultivation of the cereals was impossible. It certainly is hardly deserving the name of agriculture when plowing was done with horns, the rib bones of cows were used for cutting the grain, and threshing was done by driving wagons, or rather sleighs, through the grain, or the wheat was gained and at the same time prepared for eating by burning the straw.

We find still, tribes not only preparing the ground for receiving the seed in such a rough way, but 
wholly ignorant of seeding. The plow is a great stride in the civilization of the race; for, by increasing food and making man secure against hunger, it gave him leisure to provide for his higher and nobler wants.

Bread, the first necessity of life, most aptly illustrates the slow and laborious progress of the arts of civilization. After the discovery of the cereals, seeding, and cultivation by the plow, the cereals were for long ages roasted and thus eaten. Next came the improvement of pounding them, and not until long after, were they ground on hand mills, and made into flat and brittle cakes, whence the Scripture expression of breaking bread. Bread, properly speaking, was a much later invention, and wholesome light bread raised by ferment, belongs to a still later period.

Let none think that these first steps toward pro- . viding for the race belong to the fabulous ages. Wheat bread was in England but a very few hundred years ago a luxury indulged in by the higher classes; fruit and vegetables are there but of a very late date; and even the consumption of fresh meat was restricted to the fewest.

Next to food is clothing. Here humanity had to learn curing or tanning of skins, spinning and weaving of wool. The preparation of flax cannot have been learned but slowly and is due to woman's 
fine observation and painstaking; and language has preserved the history of this art in the etymology of wife, which means literally a weaver. How inefficient was man before he understood the working of metals and the use of tools. It was the plow that by a proper cultivation of the soil turned nations from cannibalism.

The first houses were caverns, not as perfect as the dwellings constructed by beavers. Ages passed before the cave was improved by a hole at the top for the smoke to escape.

The first implements of war were clubs, spears, darts and arrows, and the latter were headed with brass as early as the siege of Troy. The battering ram was first used by Pericles. The first cannons were made of iron bars held together in the shape of a concave cylinder by rings of copper, and the first cannon balls were stone.

The first vessels were beams joined together; next trunks of trees were cut hollow, and at last planks were joined in the shape of a boat. The ship with a prow and a stern with a movable helm and sails came after thousands of years.

Burning wood was anciently the only method for lighting the house; torches came next; and even at the time of Homer lamps and candles were unknown among the Greeks, so were spoons and forks. Neither had their houses chimneys. Locks and 
keys were unknown, and bundles were secured with ropes intricately combined; and, hence, the famous Gordian knot. Shoes and stockings are a late improvement; so are shirts, which came into use in the last days of Rome; and in modern Europe shirts were not common before the eighth century.

Hardly any commerce was possible before the discovery of the wheel, the wagon and the ship, which were rendered more effective by steam and the compass.

A new epoch dawned upon mankind with the discovery of letters, which, again, took thousands of years, and is not by any means perfect as yet.

The Egyptians used hieroglyphics. It was a divine inspiration that first permanently fastened on any material the idea of gentleness by the picture of the lamb; strength by the picture of the bull, or magnanimity by that of the lion. The Chinese use to this day sixty thousand arbitrary signs representing as many words, the greatest scholar can hardly master in a long life, a method that much retarded their progress and made them stiff and conservative. Our alphabet is the evolution of hieroglyphics and shows the outlines in its letters of the things from which they are derived. The representation of the simple elements of sound by visible signs or letters was a wonderful process and one that had to pass through many stages; and writing 
was most probably but little known in Greece at the time of Homer. Charlemagne could not sign his name, neither could many of the bishops at his time. Books were still rare at the time of William the Conqueror. The Countess of Anjou gave for a collection of homilies two hundred sheep, a quarter of wheat, another of rye and a third of millet, besides a number of marten skins.

To encourage the art of reading in England, capital punishment for murder was remitted if the criminal could read, which was expressed in law by the phrase of "benefit of clergy." An English edition of six hundred copies of the Bible, when first printed, was not wholly sold in three years. The Emperor Rudolphus, in $128 \mathrm{I}$, ordered all public acts to be published in German instead of Latin, as formerly. In France all public edicts were still published in Latin in 1539 , and in Scotland and other European countries the practice continued to the last century to the damage of the language of the land and the common people, who were thereby kept ignorant of the public law and cut off from all contact with the higher classes, who werc jabbering hog Latin among themselves.

We find tribes who cannot count beyond five. Our decimal system has early been learned from our digitals. The Peruvians used knots of various colors to designate numbers. Our ciphers wcre 
invented in Hindoostanee and were brought to France in the tenth century by the Arabs, who are also the inventors of algebra or the science of solving mathematical problems by representing numbers by the common letters of the alphabet.

Money was certainly a vast improvement upon barter. Cattle were the first general medium of exchange, as they could be driven from place to place, and as men bought their wives, a virgin was, for instance, held worth a dozen heads of cattle. The Lydians were the first who coined gold and silver money after the Trojan war, at which barter was still the common method of exchange.

Money is one of the mightiest instruments in the rise of civilization, as it encouraged industry by facilitating commerce through a universal standard of value and a portable and preservable instrument of exchange, which could be used as an equivalent for the greatest as well as for the smallest values.

It set man free; he could at any time liquidate his property and go where he pleased and thus escape tyranny, but it made man also greedy for so desirable an article, rendered him more selfish and also powerful for ill as well as for good.

The useful arts lead to the fine arts; and sculpture, painting, architecture, and, at last, gardening, rose into prominence one after another already in antiquity. 
We have already remarked that civilization followed everywhere the introduction of the cereals. The Egyptians and the Chaldeans were the first cultivators of the cereals and the first civilized nations. The civilization of Europe dates equally from the introduction of the cereals, iron and the plow.

How much has common industry done for humanity by the cultivation or introduction of the cereals, the plow, iron, steel, the loom, steam and machinery, each of which marks a new epoch of civilization.

Little has the school achieved hitherto in comparison with this, neither will it in the future, except it makes its object the improvement of industry and effects thereby civilization.

Without iron, man is impotent, for he is then without tools. A hatchet, a knife, or even a nail, will buy almost anything among tribes who have not the use of iron, as they feel their power infinitely increased by it. Copper, brass and the precious metals have all been earlier discovered and used on account of their brightness and state of purity in which they are often found on the very surface of the earth, and as they are softer and easier worked. It is all otherwise with iron. . At the time of Homer iron was still thought precious enough to rank with gold and silver as the price 
of the conqueror. Every step in the improvement of the working of iron and the manufacture of steel is an improvement in civilization affecting humanity far more than the smoothest rhymes or the most acute system of metaphysics.

Herodotus mentions Glaucus of Chios as the first who smelted iron. It was not before the Middle Ages that iron entirely took the place of brass. Think for a moment we lost the use of iron; without a plow or a tool we should soon sink into utter barbarity; and but few could maintain themselves even in that condition, but would perish.

Erasmus describes England at the time of Henry VIII. as a land of filth, every room full of "grease, fragments, bones, spittle, excrements of dogs and cats and everything that is nauseous." Madrid had not a privy as late as I760, and the royal mandate to build such raised a storm of opposition. Iron brought the age of industry, which cast men into a new mould, and made of the English a people loving cleanliness.

In $156_{3}$ knives were first made in England. Pocket watches were brought from Germany 1577 . In 1580 coaches were introduced. A saw mill was erected near London 1633. Coffee houses were opened 1652 . Steam flouring mills began as hand mills, horse mills, water mills, and, finally, became what they are to-day. Striking clocks were not 
known until the end of the thirteenth century, and, hence, the custom of watchmen calling the hours of the night. Paper was first made in the fourteenth century. The eggs of the silk-worms were first introduced in Europe under the reign of Justinian from Hindoostanee.

With the progress of industry, food, clothing . and all other means of comfort and luxury so increased, that the poorest man to-day has a greater quantity of them than fell to the share of kings or nobles but a few hundred years ago.

Queen Catharine could not command a salad for dinner until the king brought a gardener from the Netherlands. About the same time the artichoke, the apricot and the damask rose made their first appearance in England. Turkeys, carps and hops were first known there in the year 1524. The currant shrub was brought from the islands of Zante 1533. In the year 1540 cherry trees were brought from Flanders to Kent.

At the time of Henry•VIII. there were but fow chimneys even in the capital towns of England, and the smoke issued at a hole in the ceiling, the door and windows; utensils, forks, spoons, etc., were of wood. The pcople slept on straw with a $\log$ of wood for a pillow.

Henry II., of France, at the marriage of the dutchess of Savoy, used the first silk stockings that 
were made in France. Elizabeth, the great queen of England, had her reception room strewn with rushes or straw-as in our days half decent stables are; she received in the third year of her reign a present of a pair of black silk stockings. The first stone bridge over the Thames was built in 1213 , and over the Seine in the beginning of the sixteenth century. The first silk factory was built in Lyons in 1536 . Glass windows were still rare in private houses in the twelfth century. King Edward III. invited three clockmakers from Holland.

Gunpowder, firearms and artillery, with the new art of war, called forth standing armies, while the rest of the people remained at home and devoted themselves to the trades, which gained thereby such importance that they ruled the state and pretty much ended the old régime, which was one of constant war, and, therefore, barbarous.

The Saracens have spread a taste for chemical manipulation and the observation of nature and mechanical improvements. Roger Bacon has trod into this path, and prepared the way for the great Bacon of Verulam.

Men have never paid attention enough to the importance of the industrial arts. Glass was introduced into Britain $67 \mathbf{1}$; still it was not applied there for windows until the thirteenth century, was but in the sixteenth century manufactured there 
and did not enter into general use until the middle of the seventeenth century. Country houses in Scotland were not glazed until r66I. The manufacture of silk was more than a thousand years traveling from the shores of the Bosphorus to England.

Henry the Great, king of France, and his distinguished minister, the able Sully, have laid the foundation to France's eminence in the manufacturing arts. Under the great Colbert, the minister of Louis XIV., the since famous manufactory of Sevres china was established, the manufacture of glass brought from Venice, wall paper invented in France, the manufacture of fine cloth introduced from England; until, in 1685 , the revocation of the edict of Nantes had driven away the Huguenots, the best artisans of France, with whom a great part of the manufacture and civilization of France have wandered to England, Germany, the United States and other countries.

In the Middle Ages all arts were debased through the spirit of feudalism, and all labor was considered slavish. Hence the slow progress in manufactures and civilization. All articles of furniture were rare, the same room was used for cooking and eating, and the ox often lived under the same roof with the farmer. Lords, even at the time of Elizabeth, would, like other movable furniture, take with them 
the windows of their castle on leaving for I.ondon and the court. Forks were unknown until James I.

Barley bread was the usual food of the poorer classes in 1626. In some portions of England, as late as I 725 , even a rich family used but a peck of wheat in a year, and that about Christmas. Dry bran bread, mixed with rye meal, was commonly used by servants and laborers. Corn was mostly ground at home by the hand mill, even at the time of Elizabeth. Holland provided London with vegetables, and at the time of Henry VIII. not a cabbage, carrot, turnip or other edible root grew in all England. Natural enough, in proportion to the want of industry, barbarism and crime abounded, and 70,000 thieves were hanged under this prince in England.

Spectacles were introduced in the thirteenth century; needles were brought from France to England in 1543 , and first made there in 1626 . Umbrellas made their appearance in England in I 768, and their first use excited the jeers of the vulgar. The land was one waste and the mines poorly explored.

Take the quantity of iron smelted in the Middle Ages. It amounted to fifteen pounds at most, per hand. Using coke instead of charcoal in making iron, a furnace produces in our time thirty tons a day, or four hundred pounds of a superior quality 
per hand. A man accomplishes, therefore, thirty times as much as before.

When grinding flour was done by hand mills it took one grinder for twenty-five consumers. In our improved flouring mills one man turns out flour enough for 3,600 , so that one man does the work of one hundred and forty-four formerly employed. Fourteen large mills, employing two hundred and seventy-eight hands, do to-day the milling of a city of a million population. In Rome and Athens the hand mills kept going 40,000 hands for an equal population.

In the manufacture of cotton one man does today what seven hundred could do before recent improvements were made. John Kay, of Bolton, introduced the fly shuttle in 1750 , so that one hand can attend from ten to twenty shuttles. Mr. Hargreaves, of Blackburn, first introduced the spinning jenny in I770. Mr. Arkwright built his machinery for carding and roving in $177 \mathrm{I}$, and Mr. Crompton's mule was introduced in 1780 ; and about the beginning of the century Mr. Watts' steam engine came into use, the power loom began its work, and from that day the modern factory system dates. About the middle of this century 250,000 power looms were in operation.

The muslin exported from England in 1833 measured ten times the circumference of the globe. In 
I840 it was equal to thirty-five times the same length, or one milliard and three hundred and eighty-three millions of metres, and the whole export of cotton manufactures amounted to one hunhundred and sixty-three millions of dollars. The cheapness has increased with the supply, so that it was in 1853 five times as cheap as twenty-five years back, and twelve times as cheap as fifty years back.

In 1740 England produced 17,000 tons of iron, in $1840,1,500,000$ tons, and in $1856,3,000,000$ tons.

But in transporting power we have gained perhaps most. One man with an efficient locomotive can carry 500 tons of freight. It would take 50,000 men to do the same carrying in the same time. All this was accomplished by the hard struggle and ingenuity of industry, hardly aided by the school.

Let the reader notice that we traced the progress of the arts before an earnest attempt of introducing universal Education was made. Solely by the natural force of circumstances, by a continually spreading division of labor, and the devotion of the whole attention of the laborer to but a small field of labor, skill and invention have made rapid progress, comforts have been increased, taste has been improved, and leisure has been gained, which has called forth the literature of the day, of which the arts and trades are the cause and not the effect. 
Slavery in all degrees gave way in England in I 35 I to the arbitrary power and stipulations of legislation, which settled the price of labor. And the trades were so backward that four-fifths of the people were agriculturists, and yet, as we have seen, the land was a waste.

The discomfort of the people may be seen from the fact that from the year 1075 to 1575 the population of England and Wales has but doubled. From 1600 to 1700 , the increase was about 30 per cent.; from I 700 to 1750 , the increase was 25 per cent., and in 1800 to 1850 , the population of the United Kingdom doubled, besides furnishing a constant stream of emigration for this and other parts of the world.

Commerce had anxiously explored the sea to find a new way to the East Indies; and the maritime discoveries which were constantly making, kept the world agitated and enterprising.

The first attempt of manufacturing in the United States was made in 1608 , only one year after the first effective English settlement at Jamestown, in Virginia. So early has the spirit of industry developed in this country.

In 1776 the first attempts of raising cotton in the South were made, and the cotton of 1790 , I79I and 1792 together, made one moderate cargo. At the end of half a century the cotton crop amounted 
to two millions of bales; and to-day it reaches the figure of four and five millions.

In 1812 the first glass works were erected in Pittsburg. The first iron works were built in the United States in Pennsylvania, in Newcastle county, in 1726 . In 1805 the population of the United States was 6,I80,000; its manufactures amounted to $\$ 30,000,000$, and its agricultural productions to $\$ 85,000,000$. In 1870 the population of the United States amounted to $38,558,37 \mathrm{I}$, and there were counted 252,148 factories, with 40 , I9I steam engines and 51,018 water wheels, with a total of 2,346, 142 horse power, and 2,053,996 hands, yielding a net product of $\$ 1,743,898,200$, or, including the raw material, $\$ 4,232,325,442$.

These sums are too large to realize their amounts. We will, therefore, take some of the great industries separately :

$$
\begin{aligned}
& \text { Iron industries . . . . \$346,952,694 } \\
& \text { Cotton goods . . . . . 177,903,687 } \\
& \text { Woolen goods . . . 178,064,453 } \\
& \text { Boots and shoes. . . . 181,644,090 } \\
& \text { Clothier goods . . . . . 147,650,378 } \\
& \text { Leather. . . . . . 137,480,097 } \\
& \text { Furniture . . . . . 57,926,547 } \\
& \text { Mining products . . . . 152,598,994 }
\end{aligned}
$$

The agricultural productions of every sort amounted in 1870 to $\$ 2,447,538,658$.

The United States had in $1873,70,178$ miles of 
railroad, at a cost of $\$ 3,436,638,749$ for carrying on its internal trade.

The foreign trade of the world amounts to \$10,$\infty 00, \infty 00, \infty 00$ per annum, and is carried on in $200,-$ ooo vessels plowing the ocean with a cargo of $20,000,000$ tons.

Of 2,500,000 tons of sugar-the yearly consumption of the world - the United States consume 500,000 tons.

How slow, uncertain and laborious was the progress of industry, feeling, as it were, her way in the dark for thousands of years, and how glorious and rapid was her march since she has caught sight of the rising sun of science! Let science, then, fully join her, and the effect on her as well as on her children will be immense, and a new era will rise for humanity.

But industrial progress does not merely mean so many bales of cotton and so many tons of iron or coal ; it means the progress in the condition of the slave, serf or villain, and the free laborer; it means the moral progress of the chieftain or successful bandit to the privilege of birth; and, at last, to personal capacity and useful enterprise. With the increase of production the laborer gained in personal and political influence as well as in a material víew. As slaves, laborers were crowded together without reference to health or decency; as free mechanics 
and small masters they occupied small properties; they became possessed of all the virtues and advantages attaching to property and well-regulated homes.

But, alas! the great industries under the régime of steam and machinery have centralized capital and population; and, again, laborers are crowded in tenements without regard to health and decency, ending in the formation of a permanent low, shortlived, stinted type of degraded humanity.

We cannot separate from our present form of industry the sanitary and moral relations of the people; they are all eminently questions of - civilization, and find their solution in Education. Associate industry at all points with Education, and mind will control matter, and reason will bring order into the present social chaos.

The Education of the industrial masses into thinking men once achieved, further steps will best suggest themselves to the men most concerned, and who are the best judges of their condition, wants and means of relief.

But this Education must embrace the industrial, economical, domestic and social relations, and increase their efficiency as producers, their intelligence, their moral power, their health and their social consideration. Our all-absorbing great industries can find their only justification in the 
union with art and science and in the spread of taste, sensibility, fine feeling, knowledge, wisdom and well-being among the masses engaged in them. Industries which had no other end than the production of a million of trifles to satisfy the vanity of their consumers, and left their producers unimproved and miserable, would be a most degrading materialism, which could only end in universal brutalization and in the downfall of the nation.

Every field and every factory throughout the land and the wide world is a laboratory, and every laborer producing profitable results is an experimentalist.

Where the hand and the brain work in unison and shape nature's elements into angels ministering to the well-being of man, most is effected for human civilization.

Schools, hardly organized for half a century, have as yet done little for industry, which has progressed by its own unaided exertions, until its advance has aroused practical men to found polytechnic institutes and industrial schools, which promise to lead industry to still higher development.

The unaided success of the industries is plainly to be read in the greatness of the Italian republics, the Hansas, Flanders and in France prior to the persecution of the Huguenots; or in England in our own day, where Education has been organized but of very late. 
We do not deny the importance of the school; but to advance civilization, it must prepare the people for their work-nice essays are for the philosopher. The nature of the civilization of an epoch is determined by the character of the people, which, again, depends on the work they are engaged in and on the manner in which they perform it. The tens and hundreds of thousands of fabricates they manufacture are their volumes; and, hence, the more intelligence and science is brought to bear upon them by an industrial and technical Education, the more the people will think and improve, and the higher a civilization will be attained. Industry has advanced to a science, and its theory must be taught as well as its practice, if it is to progress with the rapidity peculiar to all the movements of the age we live in. All the appliances of human ingenuity are to be set in motion to increase the quality as well as the quantity of our manufactures, to make the workmen consumers as well as producers, and to restore harmony between labor and capital.

With every new step industry increased the happiness of mankind, and made us wiser and better in proportion as the common wants were satisfied and the higher ones awakened and cared for.

How vast are the numbers engaged in the industries of the world and how great is the capital 
- the whole earnings of the past-engaged in them. Can Education do anything worthier and more fruitful of precious results than by improving the industries, improve the great majority of mankind engaged in them, and by doubling the wages of labor and the profits of capital, and satisfying all, fill all with peace and concord, wiping out the sorrow and woe attending the present state of want, madness and crime?

In very deed science owes all to industry, and it is time it serve in its turn industry, that it may the surer serve humanity and the moral progress of the race.

The beautiful arts of architecture, sculpture and painting, clocks, spectacles, telescopes, air pumps, chemical manipulations and printing, were all developed before universal Education was introduced, and are all the results of the progress of the industrial arts, which furnished the tools and often the entire mechanism and the very observations which led to the principles some claim for the school.

When we consider the innumerable host of technical arts and trades furnishing the necessities, comforts and pleasures of life, providing science with her tools and developing the taste, mind and morals of the great mass of mankind engaged in them, the infinite observations, facts and combinations of 
ideas stored up in them as displayed in the great industrial exhibitions of the world, and especially in the magnificent one we have just witnessed in our own country, what an infinite world of mental activity they present to us.

And right here, speaking of the indebtedness of the world to past labors, we will express our obligations to scores of laborers who have preceded us in our ficld of inquiry, and especially would we mention the noble author of the "Sketches of Man," upon whose resources we have freely drawn. Little can man in his few days see with his own eyes; past labors are the genuine source of inspiration, and their honest recognition is the most befitting invocation.

In almost every trade qualities and relations hidden from the superficial observer, are made the basis of operations and applications. How mighty small is the sum of our little school learning compared with the thought and experience treasured up in a thousand skilful trades, each of which manufactures often a hundred different articles. The most complicated technical arts require as much mental force as any of the branches of school learning, which were only injured by metaphysical subtlety.

Bishop Heretius remarked that all the learning 
down to the beginning of the eighteenth century could be put into six to ten moderate folios, to which we may add ten or even twenty volumes for our late scientific acquisitions. What a library, on the other hand, would it form, if every observation and every manipulation in every trade and art was written down! And, yet, these practical observations are unquestionably founded in truth, and useful much more than most of the learned trash of the schools.

Industry, more than science, has worked in the past under the guidance of practical observationthe main instrument of genius and the source of all invention-until Bacon has got his philosophy from the shop, which has done the world more good than the philosophy which Socrates has brought down from heaven.

The knowledge of the schools or abstract philosophy has done infinite mischief, by fostering religious prejudices and false political theories sustaining despotisms, false moral systems and standards; in short, it has caused much physical, moral, political and religious mischief, while technical inventions have saved and preserved mankind from much physical harm and have assisted in the moral and intellectual culture of the race.

The technical pursuits, by cultivating physical 
and mental activity, developed the body and mind of the people, and thus materially increased their health, efficiency and well-being.

Industrial progress is continuous in its development; theoretical knowledge and literary. culture are often inactive and dead for ages.

The labor of the world may be historically divided into the following epochs: The time of the first rude labors; the trades, with division of labor; industry, combined with science and art, or ornamental industry; and, at last, the highest technic, or union of strength and beauty. In the first days of the race, the same man was hunter, fisher, smith, carpenter, cabinet maker, tailor, etc. This sharpened his wits; but, of course, he brought it to perfection in nothing. However, as everybody was his own customer, he was easily suited.

As mankind increased and formed towns, each man was able to dispose of his surplus, he devoted himself, therefore, to one trade, produced a great quantity of articles of better quality, and got in exchange for his fabric a greater number of articles of higher quality than he could have made himself.

This division of labor led to almost scientific exactness and perfection in the trades. Competition among the producers led to ornamental industry.

At last, use, beauty and strength, with the great- 
est possible productivity and cheapness in articles of manufacture, were aimed at ; and what formerly seemed to be the work of individual skill, is now performed by a mechanism which replaces the dexterity and intelligence of the laborer.

In Greece as well as in Rome the trades were despised as fit only for slaves. In the world of to-day they are the very beginning of freedom, universal liberty and civilization.

It is the tradesmen who formed in the Middle Ages fortified towns and founded modern liberty, maintaining their rights against a fierce nobility and often against kings.

The Florentine republics, the Hansa League and Flanders have achieved wealth and liberty, not by their arms, but by their industry; and to-day, the greatest of all modern states, as Germany, France, England and the United States, are founded upon industry, as the ancient states developed their strength in war.

How productive of great and noble qualities is industry by the independence it procures and the opportunities it gives us for developing our talents. Wealth develops power and dignity and health and well-being among the masses.

The industrial laborer is the soldier of the nineteenth century, making daily more conquests for civilization and humanity. 
Industry creates commerce and new sources of maintenance, lessens idleness and vice, and improves morals by employing men. It was the want of industry that made the people of Rome and Grecce accessible to the tricks of the demagogue and rendered them turbulent.

To the rise of the industrial classes and the consequent development of wealth, Europe owes its liberty and civilization, as the third estate, grown powerful, forced royalty and nobles as well as the clergy to respect the rights of the people.

Industry, through commerce following in its wake, gives rise to intercourse among men and nations, to interchange of ideas, mutual liberality, and peace and good-will among men. Commerce, which rests upon industry, is one of the main sources of modern civilization. Industry constitutes our superiority over the ancients.

Slavery and contempt of labor form the centre of the civilization of the ancients and of the military life in which their activity found the only outlet. Among the Bootians, men who defiled themselves by commerce, were for ten years excluded from all state offices; and Augustus condemned a senator to death because he took part in manufacture.

The slave system engendered ferocity. Slaves had to imbrue their hands in each other's blood as gladiators, and to engage in deadly combat with 
brutes almost as ferocious as their masters. They were often mutilated with atrocious cruelty; they were tortured on the slightest suspicion and crucified for trifling offenses. If a master was murdered, all the slaves were put to torture; and if the per. petrator was not discovered, they were all put to death. Tacitus relates a case in which not less than four hundred were thus slaughtered. Ladies of fashion amused themselves by the repeated infliction of painful flesh wounds on their lady maids with their own hand and dagger, and by ordering others to be crucified. Old and infirm slaves were exposed on an island of the Tiber, where they were left to die from starvation.

As a man's children could not be considered less his own than his slaves, and his wife is but part of his household, he had also over them the power of life and death; and as a man is not likely to be more tender with strangers than with his own wife and children, savage barbarism characterized all the relations of man with his fellows. Such was antiquity and such the models classical Education would force upon modern civilization.

Industry, or application to the arts and trades, led to the development of the spirit of observation and to facts; it led away from drcams, sophistry and dogmatism to genuine enlightenment and reasonableness; it led to the discovery of the inductive 
philosophy, or, rather, declared working the only true philosophy and the shop the best school, and thus laid the foundation to genuine progress and improvement.

It led to the development of the principle of utility, which is the safest test of truth and goodness. It led to peace and good-will among all men, as they all work for each other and exchange with each other the products of their labor.

Industry cultivates enterprise and caution, two qualities Hume calls the most important for success in life.

Industry, says Buckle, makes us conscious of our power. It is averse to superstition, as we daily feel that all depends on our own resources and how we manage them. It is the mother of wealth, and, hence, of civilization, and seeking for markets it leads to maritime discoveries. Industry gives men with competency and independence dignity and respectability, and thus cultivates a higher regard for humanity.

Industry, assuming the character of art, develops the taste for the beautiful, and, hence, the cultivation of industry and art leads to virtue and good manners, as the good and the beautiful are akin.

Industry strengthens the physical and mental capacitics of man by constant exercise; increases 
his self-restraining power, the basis of moral excellency, and thus renders man better and nobler.

Industry, says Leckey, by providing the world with refining comforts, undermined the asceticism of the Church, its monastic spirit and ecclesiastic power; it secularized Europe and made it tolerant.

Industry led from dreamy philosophy and metaphysical speculation and dogmatic theology to the cultivation of science and the formation of a practical code of natural ethics for the regulation of man in his intercourse with his fellow, nature or with himself.

All the gold in the world flowing into a state cannot save it if industry leaves it ; witness Spain.

The main idea of Adam Smith's "Wealth of Nations" is industry, which all his measures tend to promote as the pillar of a nation's greatness. Labor, according to him, is the basis of value. Adam Smith employed his whole genius to show that industry must be freed from all its former shackles.

A new lesson we must learn-inasmuch as industry makes a nation great and prospcrous-the school as well as the state must chiefly direct its efforts toward the promotion of manufactures and industry. For, as skill and excellency are only attained by habitual exercise, we must be trained to industry from early childhood. 
Liberty, industry and peace are indissolubly linked together. Nothing but the enlightened self-interest of industry and commerce will eventually abolish war among nations.

But industry and commerce, which cement foreign nations, should they not draw closer to each other the different classes and conditions in the same nation by showing them the identity of their interests?

Industry, says Leckey, while it disposes nations for peace, makes them strong in war.

Under the industrial régime production gives rise to new wants, and wants to new exertions, and exertions to wealth, which again gives rise to refined tastes, finer perceptions of beauty and intellectual aspirations.

Industry produces capital, which gives opportunity for higher pursuits.

Slavery, war and despotism, all recede before industry. A law-abiding spirit, sobriety, integrity and a steady character, are all in the wake of industry.

The old ascetic spirit destroys with human nature human energy. Industry strengthens human energies and unites all by an enlightened self-interest.

Human industry has connected oceans separated by continents; has drained lakes in low lands and created others in high places; has pierced moun- 
tain chains; has planted gardens in the wilderness; has built cities upon the waves of the ocean; has laid low ancient forests; has changed climates; has turned rivers from their natural course and has altered the face of the whole earth by changing its vegetable covering. St. Helena, when discovered in 1505 , produced about sixty vegetable species, including but three or four known to grow elsewhere, also. At the present time its flora numbers seven hundred and fifty species. The flora of tropical America has been found by Humboldt and Bonpland to have been greatly introduced after the discovery of the New World. At the time of Aristotle the peach, that ripens to-day in England and Germany, could but imperfectly be raised under the Grecian sky; and many of the fruits that in the days of Pliny thrived but poorly in sunny Italy, do well to-day in northern Europe. The mulberry tree was introduced in southern France in 1500 , and to-day it does well in much more northerly climes of Europe.

Who dares to deny but that tropical plants may ultimately grow in the temperate zone, by industry transplanting them gradually into countries more and more removed from their tropical home?

The changes effected by human industry in the animal kingdom are not less extensive than those in the vegetable world, and these changes multiply 
each other by their mutual bearings, until the final results assume a universal aspect.

Not to speak of the changes effected by the introduction of birds which live on insects-the agency of which is important in fertilizing plantsthe ox, the horse, the sheep, the swine, so useful to man, have all been transplanted to the New World by human industry, as hardly any of the quadrupeds of the Old World were found in America. And in our own day the Cashmere or Thibet goat was brought but in 1850 to South Carolina and the camel to Texas and New Mexico, where they promise to do well.

The monumental buildings of the world are its true public libraries, seen and read by all, spreading in one or another style lessons of severe and chaste beauty or of spiritual grandeur, and imparting the spirit and civilization of one age to another; and this, too, is the work of industry.

With the increase of pleasure and refinement arising from the beauty and delicacy of an industry daily more assuming the character of art, human sensibility and kindliness of heart spread among men, and brought with them a higher state of civilization. As laborers, mechanics and manufacturers obtained wealth, they gained importance and achieved freedom, consideration and influence; the courts and the law had to do them justice, and 
thus changed all together; governments had to consult them and became representative and constitutional; and now, at last, schools have to suit their course to the practical needs of the laborer.

We best learn the nature of Education by studying it in the great style of Providence or universal history, which is the Education of the race. The Education of the individual must be in kind the same as the Education of the race, and must end in it. If educators find nothing in the history and development of the race that concerns them, the worse for their system; as for us the Education of the individual must begin the very work the Education of the race will complete.

Draw closer the connection between the school and industry, science and the trades, and spread sound economical knowledge, and a humane disposition among employers and employees, and you reduce the mortality of the laborers of the land by at least 50,000 , and the number of cases of sickness by 750,000 per annum.

There is hardly a department of science but its fundamental facts have been furnished by the observation of the practical men of industry. But how many of these observations are lost through the want of scientific knowledge in the practical workers of the world, and who can set a limit to 
future progress and improvement when practical workers will be scientific observers?

As long as labor is a drudgery, leaving the mind and the heart vacant, men will rather scheme than work. Join to labor science and art, and the venerated high priests of human industry, ministering in their laboratories to the comforts and necessities of mankind, will find their work a delight and a pleasure, they would no more exchange with the leisure of the elegant trifler than the toiling chemist or physicist would.

Labor is the physical aspect of moral power, and a nation cannot be free, powerful and truly great without being eminent for its industry. Rome and Greece possessed no industries, neither were they great, for their masses were slaves.

Industry, through constant exercise, bestows the freedom of the power of using our faculties for our own good as well as for the good of the race, and this freedom constitutes true liberty.

As long as war is tolerated, the spirit of rapacity, inhumanity and domination will pervade every sphere of private and public life, and men and nations will be barbarians. As long as men are fools and knaves enough to butcher one another, it is simply ridiculous to talk of civilization, which only can begin where war ends. War deteriorates a nation physically as well as morally. After every 
great war--in Sweden and Germany after the thirty years' war, in Prussia after the seven years' war and in France after the great Napoleonic war-the number of diseased, crippled and weak men had increased to an extent that interfered with the recruiting office. For, as the able-bodied men have been taken from their homes, and have fallen in the field, the weak and the sickly formed families and humanity necessarily was physically deteriorated.

So, for instance, do we find in France exempt from the service-aside from causes of sickness, low stature or of being crippled-for constitutional weakness, in

$$
\begin{array}{llllll}
1816-1820 & . & . & . & 51.05 \text { in } 1,000 & \text { recruits. } \\
1831-1835 & . & . & . & 79.04 & \text { " } \\
1865-1868 & . & . & . & 96.90 & \text { " }
\end{array}
$$

In Prussia were exempt for all causes of sickness, for being crippled, constitutionally weak and of low stature, in

$$
\begin{aligned}
& \text { I831 . . . } 345 \text { in } 1,000 \text { recruits. }
\end{aligned}
$$

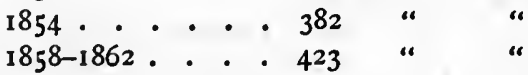

In Saxony, were exempt from the service for all causes in

$$
\begin{aligned}
& 1832-1836 . . . . .33 \text { in } 100 . \\
& \text { 1850-1854 . . . . . 5 } 50 \text { “ }
\end{aligned}
$$


The steadily diminishing number of long-lived persons is another incontestable proof of a deteriorating humanity. There were in Sweden over 90 years of age in

Women.

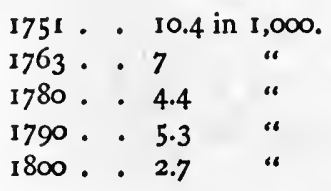

Men.

6.6 in $1, \infty 00$.

4 " (1766)

3.4

2.7 " (1775)

-We dare not enter upon a recital of the social, moral and economical disorders which follow wars, neither is it necessary, as we all keenly feel them just now.

Our armies are slaughter houses. The killed in the field are the least. The barracks and the camp do the work of destruction. Though the soldiers are picked men, the mortality among them is double that of the entire population.

Balfour shows the mortality in England in a $I, \infty 00$ population at the age of

$$
\text { 20-25. 25-30. 30-35. 35-40. }
$$

$\begin{array}{lrrrr}\text { Civilians . . . } & 8.4 & 9.2 & 10.2 & 11.6 \\ \text { Soldiers . . . } & 17.0 & 18.3 & 18.4 & 19.3\end{array}$

The mortality of colonial troops in warm climates is a real slaughter, and amounts among the English troosps in 
The Bermudas . . : to 52.1 in 1,000 .

St. Helena . . . . “ 33 “

Jamaica . . . . . “ 128 “

The Small Antilles . . “ 82.5 “

Ceylon. . . . . " 75 “

In the Russian army the regular mortality is 38 in $I, \infty 00$, almost four-fold what it is among the common people at the same ages.

$\checkmark$ In Algeria, during the war, the French lost 100,-

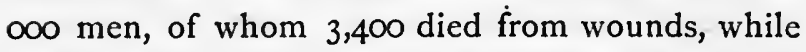
more than nineteen out of every twenty were the victims of camp diseases.

During the first seven months of the Crimean war 38.5 per cent. of the English troops died from camp diseases.

In the great Russian campaign Bonaparte lost two-thirds of his magnificent army, before he reached Moscow, in camp diseases. The great Russian army of 209,800 men that opposed him counted, after five months, 40,290 men.

In our own great war we had from June I, I86I, to June I, 1863, 53.2 deaths per annum for every I,, 00 men in the field, of whom 8.6 died from wounds and 44.6 from camp diseases.

We know the slaughter in the battle field was great, and yet the slaughter in the camp was more than five times as large as that by ball and powder. The slaughter from suicide is not less remarkable 
in the army, and compares with the number of suicides among civilians in

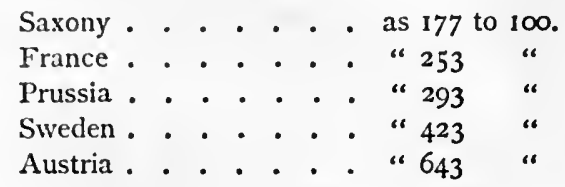

And Christian governments foster military organizations and parade with them on occasions of great religious solemnity. Russia is carrying on a war of aggression against Turkey with a prospect of another war fifty years hence for the enslavement of the whole of Europe. Has the press a word against it? Is our plea, then, for the sacredness of human life out of season? According to an article in the Lancet of April I0, I84I, the mortality in the English work-houses was 207 in 1,000 !

But we need not go so far back. It amounted in 47 work-houses in

$$
\begin{array}{llll}
\text { London, } 1851-55 & \text {. . . } & \text {. } & 227.2 \text { in } 1,000 . \\
\text { Berlin, } 1852 \text {. . . . } & \text {. } 142.8 \text { " } \\
\text { Massachusetts, } 1861-67 & . & 133.7
\end{array}
$$

The wantonness of these mortalities among the state poor appears in its true light when we consider that even in hospitals, which only take in the sick, the mortality averages in the smaller 150 in 1,000 and in the larger 100 in 1,000 , and that on an average there is but one death for fifteen cases 
of sickness, so that a sick man entering a hospital has a better chance of life than a poor man entering the almshouse. Among prisoners averaging 3040 years, $30-50$ in a thousand die per annum, while in the outside world the mortality among men of the same ages is but $10-20$ in 1,000 .

If the mortality in our public institutions, right under the eye and control of the government, surpasses the general mortality - which already includes all sorts of vicious and criminal classesmust we not conclude that sacredness of human life has not as yet the supreme influence it ought to have even with the guardians of public order and safety?

Or is this fearful mortality in our public institutions due to the deep-seated deterioration in the classes gathered in them? We do not deny it partly is, and this establishes our position of the prevalence of deteriorating tendencies in society, which, again, have very much for their basis a general disregard for human life, which allows causes unfavorable to human life to accumulate and gather strength until they settle in a permanent deteriorated type of humanity.

No, the sacredness of human life does not as yet find the recognition it calls for. We occasionally suspend hostilities to give a chance to the natural increase of population and to the industrial savings 
of a few years of peace to fill the gap made in the ranks and in the pocket by Krupp's eighty-ton guns, the improved implements of destruction of an advanced Christian civilization.

War organized and carried on openly by governments established mainly for the protection of the lives of the citizens, is the most flagrant outrage upon God, man and nature; and, as long as it is tolerated, justice among men will be but a mockery. For, if governments indulge in direct murde- for the sake of self-aggrandizement, why should not individuals commit indirect murder for the same purpose? And they do, as the slaughter of factories, railroads and tenement houses proves.

Dr. Parne finds scrofula prevalent in the industrial district of the department of Aude. Bossard ascribes the physical debility of the inhabitants of the Ardennes to their industries. In Haute Rhin, Muller tells us that the agriculturists are fine men, while the operatives are pale and sickly. Poter finds in the department of the Rhone the people, exclusively devoted to manufacturing, physically degenerated and furnishing the greatest number of exempts from the service.

Dr. Engel showed for Saxony in 1852, I853 and I 854 unfit for the service,

In cities. . . . . 56 in roo.

In the country . . . . 5I “ 
Repeated recruiting gave the following results as to unfitness for the service :

\begin{tabular}{|c|c|c|c|c|c|}
\hline Farmers & & . & . 46 & in $\mathrm{I}$ & ecruit \\
\hline Cabinet-makers & & & $5 \mathrm{I}$ & “ & “ \\
\hline Operatives . . & & & 57 & “ & “ \\
\hline Artists . . & & & 63 & “ & “ \\
\hline Merchants & & . & 70 & “ & “ \\
\hline Scholars . & & . & 80 & “ & “ \\
\hline Domestics . & & & 83 & “ & “ \\
\hline
\end{tabular}

A higher civilization must protect us against the insiduous attacks upon life growing out of the conditions of a lower state of civilization as well as against the open violence of the savage state. It must deal with causes, and not with isolated flagrant acts, which like weeds spring up from the old stock.

The higher civilization is greatly hygienic and improves the race in its highest aspects by improving its physical basis and its very genesis.

Our industries create a new sort of barbarism in the very midst of our much boasted civilization by their stolid indifference to the physical and moral condition of the millions engaged in them.

Several years ago the average age at death in the weaveries of Leicester was eighteen years! For every one agriculturist, who dies from lung diseases, 2.63 die from the same diseases in the manufacturing town of Manchester. Of women engaged in lace making 617 die from the same terrible mal- 
ady to every $30 \mathrm{r}$ men otherwise occupied in the same district. At the age of thirty-five to fortyfive the mortality of the London tailors is 57 per cent. and the mortality of the London printers I 7 per cent. higher than that of the agriculturists. At the age of forty-five to fifty-five London tailors have twice and London printers more than twice the mortality of the agriculturists.

The enumeration of the various pests making havoc among the workmen in many industries, and against which a higher civilization must protect the masses, would fill not one, but many volumes.

Of 1,078 children who worked in English spinneries 22 reached the fortieth year and but 9 the fiftieth. Of 824 young hands in six spinneries 183 enjoyed good health, 240 were in delicate health, 256 were sick, 43 were puny, 100 had tumefactions of joints, 37 had curvatures of the spine. Trades with excessive labor cause inflammations, curvatures, ruptures and hemorrhages.

According to Dr. Friedlander one-fourth of the workingmen of England and one-eighth of Germany are ruptured. France, England and Germany keep an exact inventory of the work-people reared with the treasure of the nation. The time is coming when we shall have to raise our laborers, and then we shall at least take as good care of them as we do of other chattel; but until 
then the friend of humanity can study only abroad the effects of modern industry upon the lives and health and morals of the work-people.

Considering the army of martyrs among the hands engaged in the manufacture of fine clothing, Ruskin says of the wearers of these articles: "They have literally entered into a partnership of . death and dressed themselves in his spoils. Yes, if the veil could be lifted not only from your thoughts, but from your human sight, you would see-the angels do see-on those gay white dresses of yours, strange, dark spots of crimson patterns, that you know not of-spots of the inextinguishable red that all the sea cannot wash away; yea, and that among the pleasant flowers that crown your fair heads and glow on your wreathed hair, you would see that one weed was always twisted which none thought of - the grass that grows on the grave."

In our chase for gold we have become reckless as to human life, and so various are the ways in which men in our day are got out of the world that fully half the people die by a brother's hand. This murderous spirit so perfectly possesses this age, that men snap the cord of life before their sands are run. The increase of suicide has been fearful in the last hundred years. There were committed in 
Paris, 1794-1804, . . . 107 annual suicides.

\begin{tabular}{|c|c|c|c|c|}
\hline “ & $1804-1823$ & . . & . 334 & “ \\
\hline “ & $1830-1835$ & . & - $3^{82}$ & “ \\
\hline Berlin, & $1758-1775$ & . & - 45 & “ \\
\hline “ & I784-1797, & & - 62 & “ \\
\hline “ & 1797-1808, & & - 126 & “ \\
\hline “ & $1813-1822$, & . & . 546 & “ \\
\hline
\end{tabular}

The average annual suicides in France were

$$
\begin{aligned}
& \text { 1826-1830 . . . . . . 1,739 } \\
& 1831-1835 \text {. . . . . . 2,263 } \\
& 1836-1840 \text {. . . . . . 2,574 } \\
& \text { I } 84 \text { I-I845 . . . . . . . 2,95I } \\
& \text { 1846-1850 . . . . . . . . 3,466 } \\
& \text { 1851-1855 . . . . . . 3,639 }
\end{aligned}
$$

While during $1826-1856$ the population has risen from $31,858,937$ to $36,039,364$, or in the ratio of 100 to I 13 , suicides have risen in the ratio of 100 to 209 , so that while the population has but little increased, suicides have more than doubled.

In Denmark the annual number of suicides were

$$
\begin{aligned}
& \text { 1835-1839 . . . . . . . 261 } \\
& \text { 1840-1844 . . . . . . . . 300 } \\
& \text { 1845-1849 . . . . . . . } 330 \\
& \text { 1850-1854 . . . . . . . . } 389 \\
& 1855-1856 \text {. . . . . . . 414 }
\end{aligned}
$$

The proportion of suicides has thus risen from 219 to 392 in every million of population.

In Prussia suicides have increased in $1823-1858$ from 5 10 to 2,180 . 
In general, suicides have increased, taking most European countries, 3 to 5 per cent., while the average increase of population has been 1.64 per cent.

The proportion of suicides in

\begin{tabular}{|c|c|c|c|}
\hline Denmark . . & is 388 & $\infty, c$ & \\
\hline Saxony . & “ 215 & “ & 6 \\
\hline Scandinavia & “ 126 & “ & \\
\hline Germany . & “ 112 & “ & \\
\hline France . . & “ 105 & “ & $\because$ \\
\hline Spain and other & & & \\
\hline Romanic nations & “ 80 & “ & \\
\hline Slavonic races . . & 47 & “ & \\
\hline
\end{tabular}

The annual ratio of suicides to every million population is for

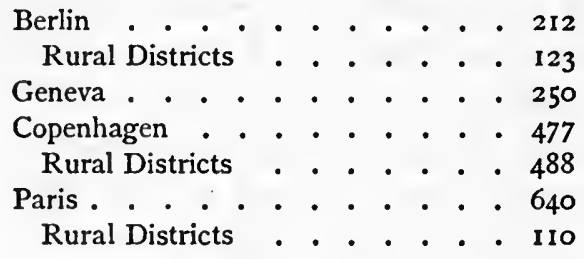

According to Legoyt the proportion of suicides in a million population is in France among

Farmers . . . . . . 90

Industrials . . . . . . . . ${ }_{128} 28$

Liberal Professions . . . . . 218

The Poor . . . . . . 569

These figures speak volumes. For only a deteriorated humanity can act contrary to the natural instincts of self-prescrvation, and the increasing 
ratios of a suicidal mania prove, therefore, a progressive deterioration of the race. And as like insanity suicide is most prevalent among civilized nations, in the large centres of the world, and among classes of men who are mostly drawn into the vortex of civilization, the falsity of this very civilization is the unavoidable conclusion.

The social relations of a people are the main factors of the prevalent suicidal mania, the amount of which is the guage of its prosperity, health and soundness. In our extravagance, luxury makes of the one a blasé, and misery crushes the other, until both lose their mental balance, and neither the one nor the other cares for living. This demomalized condition loudly calls for a more solid Education and training in our youth, and for an industrial system and laws in consonance with the physical and moral elements of our nature, which only a government based upon hygiene can give us.

Pauperism, crime and human degeneracy in its various forms, treated in other parts of this work, lead by various routes to self-destruction, the final judgment of nature, events and of the irdividual upon himself.

Murder, insanity and oppression beyond endurance culminate in suicide, the most tragic catastrophe in life in which man wrecked in his mind and all else makes the fearful plunge. Yes, suicide 
is but one of the many forms of social murder, which must be stayed, that something may be sacred beside gold - and that is human life.

Do we give an uncertain sound? We trace on every page of the history of our age the spirit of social murder and insist upon an honest regard for human life. We insist upon an unflinchingly sanitary government, that will protect the life of the poor and his children as much as the property of the rich.

The ages of war have not slain more men than this age of industry has. The ages of war have spared at least women and children. This age of industry has fastened its fangs deepest even in the flesh of women and children.

The stolid indifference with which industry sees the life of the poor waste away, nurses among the masses an apathy that must become dangerous to society.

In the name of God, humanity and the future peace of the world, let industry lesson the people in other sentiments than contempt of life and a disregard of humanity.

The adjustments of an infinite Providence may turn to profit the slaughter of wars and revolutions, and death may feed life in decaying organisms, but it is madness still to destroy life that out of its ashes it may risc again. 
Already Pinel noticed the immense points of contact between the diseases of men and the world's history. Let statesmen study less politics and more pathology. They will thereby prevent diseases physicians vainly endeavor to cure. By acquainting themselves with the special tendencies of certain classes and ages to suffer from leading diseases, statesmen learn how they may preserve the health and strength of the nation. That there are general social relations under which death and disease single out whole classes and ages for their special victims we have established by facts, reasonings and authorities.

The diseases of a people and the degree of their sufferings are the truest index to the culture, the moral and social condition as well as the prosperity of a nation. "History," says Virchhow, " has more than once shown that the destiny of a nation depends upon its condition of health and energy, and it is plain the pathological history of a people is inseparable from its civilization. Fearful rates of mortality are writings on the wall in which the statesman of capacity can read the disturbing element which has invaded the life of the nation, and which even a careless government cannot afford to overlook."

There was a time when the wrath of the gods was looked upon as the source of disease; later the 
stars had to bear the blame; to-day it is the occult forces of nature and what not, instead of tracing the main cause of disease in the food we eat, in the water we drink, in the air we breathe, in our occupations and their deleterious influences and cares, anxieties, over-exertions and ensuing debility.

Civilization is the conquest of nature and of ourselves through obedience to the laws of being. And, certainly, a people cannot be said to be civilized which is greatly wrecked and diseased, body and soul, by slavery, want and misery.

We understand the significance of prevailing rates of mortality. We know they greatly vary in the different industries and may be swelled or lowered by measures taken or neglected; and still the government, which alone has the power of enforcing such measures, takes no notice of this matter, involving as it is the lives of tens of thousands. England has long ago shown its wisdom and humanity by its factory legislation, which is being imitated by every other government, as local legislation is too much under private influence, and the self-help of the work-people is liable to run into excess.

Moses, Lycurgus and Numa have knitted together slaves and brigands into nations loving liberty, order and virtue, through institutions embodying immortal principles; and to-day great nations are 
threatened with dissolution through the all-disintegrating selfishness of a self-seeking age. There is a mutinous war of the masses the world over, in Germany, France, England, Belgium, Holland, Italy, Spain, Scandinavia, Russia and in America. This is no more a prophecy. It is history for all who can read.

Never were the conditions more favorable for the building up of a great and beautiful humanity than to-day. Prejudices of race are dead, and we are all brothers; slaves no more work for us, but we delight in industry and live by it; the ignorance of former days has passed away, and science illumines and directs us all.

Humanity, industry and science incorporated into public institutions, established for the preservation and the improvement of the race, and based upon an unflinching regard for human life and whatever touches man and his rights, duties and entire nature, may still give rise to a grand and beautiful humanity, such as the past has neither known nor conceived of, and this consummation will be achieved when hygiene, the law of life and health, will control the individual as wcll as the nation as the supreme law of a grand and a complete humanity.

It is not bread for the stomach, but regard for humanity, the life, the mind and the position of the masses the age demands. 
But the right of the masses to this regard implies their duty to exercise it themselves toward others, which unless they do, can never become a universal sentiment, as is desirable for the good of mankind.

Self-sufficient capital may delight in the strife of competition, which by itself would reduce the social world into conflicting atoms; and labor may consider paramount association, by which it sustains itself in its weakness. We acknowledge both these principles as necessary and natural complements to each other; still neither competition nor association are the highest elements of civilization; they are both but means to an end, and this end is humanity itself, and the highest principle is, therefore, regard for human life or the preservation of the race.

The oddity of our position does not escape us. Setting aside the high considerations of philosophy and literature, we treat the life, health and well-being of the masses as the question of civilization. And this our subject not suffering us to turn from it for the sake of making apologies, we will only say what needs no further proof, that the health and well-being of a people are its wislom and its virtue, and its honor and its greatness among the nations, as its weakness and its poverty are its folly, and its crimes and its downfall and its shame among the nations. 
It is clear to every historical student who casts his eye observingly over the world, that a most fearful revolution is imminent, one not to be put down with the baton of the police nor with the bayonet or cannon of the regular army. We would, therefore, inspire a sacred regard for human life, such as would lead to peaceful reformation and improvement. But if the fates, or, better, the folly and inhumanity of man, have decided upon revolution and violence, may the lesson of the sacredness of human life, repeated on every page and almost in every line of this volume, help assuage the wrath of man, and stay in some degree the fratricidal hand of man raised against his brother man.

There is no other foundation for peace, prosperity, freedom, concord and equity among men than the sacredness of human life; it is our only security against oppression, injustice and grinding rapacity. The sacredness of human life means educational opportunities for all; it means the integrity of the family, the bulwark of civilization against its dissolution and moral chaos; it means sobriety, temperance and moderation against all that leads to drunkenness, madness and human decay; the sacredness of human life pleads for the fallen criminal, who is after all a man, and against his further brutalization and the gallows; the sacredness of human life pleads for the good of all, 
be they rich or poor, strong or weak, wise or foolish, aye, be they good or bad, as all are men and all are more or less erring and all in want of more light and more love.

The sacredness of human life alone is the harbinger of the reign of justice, love and peace and of God's kingdom among men. But there is a new school of reformers who, discarding every noble sentiment that dwells in the human breast, feign to make us believe that might is right and brute force is the highest divinity. These selfstyled Darwinians say the struggle for existence is nature's method for weeding out the weak and improving the race. The old practice of destroying feeble children is approved of ; hospitals are discarded; wars are deemed useful as mowing down the less vigorous; no quarters are given to the weak, and the gospel of war and selfishness is preached in the name of Darwin and his principle of the "survival of the fittest."

Humanity revolts against this slaughter-pen civilization, which is not less false in principle as it is cruel in practice. Though the law of heredity is true, still the law of the dissimilarity of children and parents is not less true than the law of similarity, and the law of deterioration is often corrected by the natural tendency of reverting to the normal type, which is effected by children taking 
after the healthier organized of the two parents or even after a remote ancestor; and, hence, a father mean in body and soul has often children of finest quality. We must not push inferences to an unreasonable extent and preach in the name of Darwin indirect murder, already too prevalent.

We are not to join the blind elements against a brother, but rather avert from him their fury. We must instruct the ignorant, strengthen the weak, lead the fallen back to virtue's ways, and thus use all gentler means for the improvement of the race ; and if death and destruction are to come, the earth has her volcanoes and the skies are armed with thunderbolts. But let not man volunteer to be a minister of death to his brother man, directly or indirectly, either by what he does or by what he omits to do.

Only when the sanctity of human life will determine our Education and industry, will our progress in civilization be genuine. The history of the world is as yet but the history of humanity suffering death under a thousand forms at the fratricidal hand of man.

The Spartans hunted down their slaves, occasionally, as if they were the meanest animals, to keep down their numbers.

The Greeks butchered in war in cold blood, sparing neither age, sex nor station. 
The Romans, as we have seen, were no less cruel at home than in war. Cicero, having been beheaded by the order of Antonius, and his head having been brought, Fulvia, the wife of Antonius, struck it on the face, drew out the tongue and pierced it with a bodkin.

The delight of the Romans in the combat of wild beasts with slaves shows their bloodthirstiness. Turkey never showed such barbarity.

Clotaire, King of the Franks, 559, burned alive his son with all his friends, because they rebelled against him. Queen Brunehaut, being condemned by Clotaire II., was dragged through the camp at a horse's tail till she gave up her ghost. The Goths were extremely prone to blood. The Scythians made use of the skulls of their enemies to drink out of. The Gauls deposited the heads of their slain, brought from battle, in chests as trophies. The scalping of enemies by Indians is too wellknown.

The French peasants, in the civil wars in 1358 sorely oppressed by the nobles warring against each other-hung a knight, after they had violated in his presence wife and daughters, whom they forced to eat of the flesh of the husband and father they had roasted upon the spit, and terminated that horrid scene by murdering the whole family and burning the castle. The nobility treated the peasants no 
better. The Dutch, in Amboyna, deprived the natives, if they were found guilty of theft, of their ears and nosc, and William Funnel, who was there in 1705 , reports to have seen 500 of such ear-andnoseless wretches in one gang.

Poisoning and assassination were most commonly perpetrated as late as the seventeenth century in England. For a scorc of trifling offenses people were hung in England as late as this very century. For treason or lisping a word against the King of England the prescribed punishment was to cut up the criminal alive, to tear out his heart, to dash it about his ears, and to throw it into the flames.

The torturing and burning of the Jews, the knight templars, heretics and witches are well-known.

The treatment of the Mexicans by the Spaniards shocks us; so does the infecting of the Peruvians by the Portuguese with the clothes of smallpox and scarlet fever patients, or the shooting of the Tasmanilians by the English to feed their dogs on the flesh of these unfortunates, or the poisoning of wells with strychnine by the

to get rid of the redskins. Of course, we would not do these things, and yet we are but a refined set of anthropophagi and let but exceedingly few of our fellows die a natural death, and the victims of indirect or social murder are more than a thou- 
sandfold the number of those who are cut down bluntly by the armed hand of the undisguised homicide.

The story of Madame Lapouchin has but too often repeated itself. She was the most admired at the court of the Empress Elizabeth at St. Petersburg. - Suspected of plotting against the government, she was condemned to undergo the punishment of the knout. As she appeared at the place of execution, every feature in her face plead for her innocence. Her youth, her beauty, her life and spirit pleaded in vain for her; she was deserted by all and abandoned to the grim executioners. Her cloak being torn off, modesty made her start back, she turned pale, and burst into tears. One of the executioners stripped her naked to the waist, seized her with both hands, and threw her upon his back, raising her some inches from the ground. The other executioner, laying hold of her delicate limbs with his rough fists, put her in a posture for receiving the punishment. Then laying hold of the knout-a sort of whip made of a leathern strap -he, with a single stroke, tore off a slip of skin from the neck downward, repeating his strokes till all the skin of her back was cut off in small slips. The executioner finished his task with cutting out her tongue; after which she was dispatched to Siberia, the land of Russian mercy. 
Our theme is humanity, and were this the history of an individual only, we should not have told it here; but it has repeated itself so many times that it has become the history of humanity, and we have no apology to make for its recital.

Not only pagan Rome was profuse in shedding human blood in constant party strife; as the names of Marius and Scylla, Cinna and Octavius will call to everybody's memory. Not only religious fanatics have caused human blood to flow in torrents, but even in the name of liberty and human rights men have been butchered.

According to good authority, 18,613 persons have been guillotined in the madness of the first French revolution. In the Vendée have been killed:

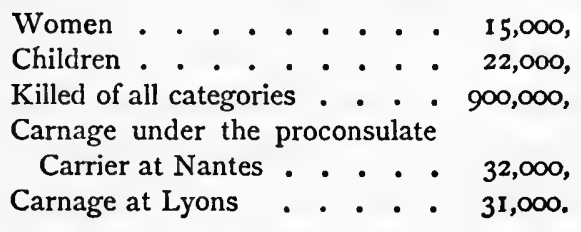

Neither does the great French revolution form an exception to the rule.

Has the French government not fusillated forty thousand citizens in the name of order as it was but yesterday?

And what is every war organized by' we care not what government, but public murder sanctioning 
the killing of our fellow-men in one or another way under one or another pretext, whenever it suits our own private advantage or public cupidity, national glory or what not.

The murdering of wives, husbands, children, slaves and old men, the avenging of imaginary offenses in the duel, political assassinations, have all been sanctioned in their turn, and the want of the unconditional recognition of the sacredness of human life has marked every century with another form of bloody mania. At one time husbands trembled for their lives as women could not resist the temptation of poisoning their natural protectors. At another time tyrants were smitten with fury, and every free thought was expiated on the gallows. Priests have more raged than all other madmen put together, knights challenged and fought everybody for their love's honor sake, red republicans did their part, and when there was none against whom to turn a bloody hand, men ran in companies to drown themselves, and laws prescribing the dishonorable treatment of the dead bodies had to be passed to stop the suicidal mania.

Give but one page to the sad story of every unfortunate individual, who fell a victim to fratricidul rage of one or another sort in the last-five thousand years, and they would fill volumes out- 
numbering the books of all the private and public libraries of the United States.

The lesson for which more than ten thousand times ten thousand have paid with their dear lives can be nothing else and nothing less than THE SANCTITY OF HUMAN LIFE.

Men, nations and periods have excelled in religion, poetry and philosophy, and have at the same time been inhuman in their dealings. Herein, even, has the past failed. It has treated humanity as a circumstance, but not as the corner-stone of civilization.

None of the civilizations of the past has declared man sacred and inviolate by any and every power, under each and every pretence, be it of a private or public nature, in the name of justice, religion, God, country or anything else.

It is time man and his well-being are declared the paramount object of the state and civilization. Wealth, science, philosophy, religion, were all made for man, and not man for them.

Some put knowledge above man. But most of the knowledge of our age is only the present error that replaces the error of the past age, to be in its turn replaced by that which is to come. In Education as well as in religion, the good of mankind has hitherto been sacrificed to barren opinions. We plead for man, his life, his bread, his freedom, 
his happiness. His civilization will take care of itself.

In spite of the prophets, poets and philosophers of the past, ignorance, misery and injustice have cursed and oppressed the race. There is but one principle, that proclaimed in all its absoluteness, can save and bless the race, REGARD FOR HUMAN LIFE, FOR ALL THAT PRESERVES, PROLONGS AND SAVES HUMAN LIFE, AND AN ABSOLUTE CONDEMNATION OF ALL THAT WORKS DESTRUCTIVELY UPON HUMAN LIFE, WEAKENS, SHORTENS OR RENDERS IT BURDENSOME.

No man, or government, or institution has a right to sap directly or indirectly human life, the very foundation of all rights and duties, and whatever is sacred in human rights and institutions.

As the sanctity of human life is the foundation of civilization, so it is also the cardinal priniciple of Education, which must aim at the preservation and improvement of the race through the preservation and improvement of the individual.

We maintain civilization means something different than a little gloss here and a few sophisms there. It means a people at work for its own good and doing well; a well-to-do people; the foundation of a free and perfect manhood, that will in its own way work out the problem of civilization.

Industry will do more for mankind than all the I I* 
Iliads. Greece has excelled in philosophy, Rome in jurisprudence, and the Middle Ages in religion, and each has oppressed the masses. Human life, despised by them all, must become the corner-stone of a new and aitogether different civilization, philosophy, jurisprudence, religion and industry, such as will usher in a better and happicr age than the world has yet seen.

A straggling piper, fiddler, rhymer or dreamer are but poor evidences of a high civilization. A good government patterns after nature; it builds up the body, and the mind will take care of itself; it looks after the seemingly trivial things of to-day, which bear in them the germs of the great things of to-morrow; it sees the future culture of the masses in their health and strength and bread and butter of to-day, and goes for it with a will. This is civilization. 


\section{PART FIFTH.}

\section{THE PROGRESS OF GENERAL EDUCATION.}

The progress of Education in the United States, as everywhere else, establishes our proposition that it is the tendency of the age to improve the condition of mankind and to solve the great social problem by making the world a schoolhouse, in which humanity is not taught letters, but is taught and trained in the art of living and acting.

At the close of the last century we had but twenty-three colleges and thirty-seven academies and no common school system in the United States. In 1813 , the State of New York appointed the first superintendent of common schools. Normal colleges, school journals, high schools, and, at last, the erection of agricultural and industrial schools, are all of a late date, and the National Bureau of Education is still more so. To-day the common school property of the United States amounts to $\$ 173,838,545$, the yearly expenditure of the common schools reaches the sum of $\$ 88,6$ r 8,950 , and the teachers number 249,262 ! The entire property of all sorts of schools, exclusive of orphan 
asylums, houses of correction, etc., amounts to $\$ 340,601,7$ I 8 .

The following table of the Commissioner shows how deeply and rapidly the conviction is spreading that through the school we are to solve the great social problem, and, hence, the erection of normal colleges, which shall provide us with professional teachers devoted for life to the art of educating men :

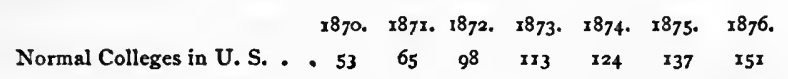

As the world relies upon the school, the school must study the problem it is to solve. The teacher must understand the cause of every deviation from the normal type of humanity in the pauper, the criminal and the insane; he must strive to lessen human misery and weakness as far as physical, mental, moral and industrial training enable him, and that will quite suffice to regenerate the world.

It is but a couple of centuries when the doors of the better institutions in England were slammed in the face of the common people, who had the impertinence to aspire after a gentleman's Education. It is hardly a hundred years when in Scotland, foremost in Education, the usual deficiency of the schoolmaster's budget had to be made up by cockfighting displayed in the school-room-the victims of the feathery tribe being adjudged the teacher's- 
who was sure to put into the field a most valiant fighting cock.

It is not yet forty years that the schools of the people in England had to be provided for by all sorts of charitable tricks, of which one pretty common was clubs meeting every Saturday at the beer houses and taking up collections to pay the schoolmaster, who was a member of the club and was bound to spend part of his dues in beer. The teacher was very frequently drawing pauper rates, and by teaching for the consideration of four or five shillings a week kept out of the working house.

No wonder teachers did not feel sweet-tempered, who, as Friedrich Richter informs us, had in Prussia an average salary of two hundred dollars per annum, while many had but from five to ten dollars, and some got one cent per week for each scholar, upon which they could but poorly subsist, but recuperated during the half of the year when they drove out to pasture their bovine friends, whom they treated to less blows than the scholars who kept them lean. John Jacob Häuberle, more punctual than the rest, kept a School Flogging Journal, in which he informs us of having administered during his schoolmastership of fifty-one years and seven months, 911,527 strokes of the cane and 124,000 of the rod; also 20,989 blows with the ruler; not only 10,235 boxes on the ear, but also 7,905 tugs at the 
same member; and a sum total of 1, I I 5,800 blows with the knuckles on the head. He imposed besides 22,763 fines in the shape of chapters in the Bible and catechism and parts of grammar to be learned by heart. He threatened 1,707 children who did not receive it, made 777 kneel upon round hard peas and 63I upon a sharp-edged piece of wood, to which are to be added a corps of 5,00r riders on the wooden horse. Such was the treatment of scholars by John Jacob Häuberle, who thought the floggings the children received of sufficient importance to keep account. What must have been the treatment of helpless children at the hand of less scrupulous teachers?

To Lord Brougham belongs the glory to have aroused the Parliament of England by his position, his learning, his eloquence, his humanity and statesmanship to the danger that threatened the country from the gross ignorance of its population; and mainly through his exertions a Committee of the House of Commons to inquire into the educational condition of London, Westminster and Southwark, was appointed in 1816 . In $1818 \mathrm{Mr}$. Brougham's Committee on the Education of the People generally, was appointed. In I820 his first bill was brought before Parliament. In 1834 the first Parliamentary vote for Education was passed, and a select Committee of the House of Commons ap- 
pointed to inquire into the means for establishing a national system of Education. In 1836 the first Parliamentary vote was passed for the erection of schools of design, and from this time one Parliamentary act after another laid vividly hold upon general, industrial, scientific and art Education, until the most comprehensive of all, the Elementary Act of Education, passed in 1870 .

As late as 1850 half of the people of England and Wales were illiterate, and half the children were without school attendance. The teachers were poor, miserable men, not to be trusted with the commonest work. The schools were kept in unwholesome cellars and garrets, without maps, blackboards, books, apparatus or playgrounds, and, of course, without rooms for classification. Many parishes were without any schools at all. Among the teachers we find blacksmiths, tailors, colliers, cooks, hatters, hucksters, some of them continuing their trade.

The noise in these school rooms was usually such that a person could not hear what was said. These wretched, miserable schools, with a few worm-eaten benches and tables for their furniture, were often hovels in ruins or over stables, with small windows, poorly lighted, with damp earth for their floor; and among 692 of these schools, 364 had not as much accommodation as anything in the shape 
256 The Progress of General Education.

of a privy. Parliamentary grants for Education were for the primary department in

$$
\begin{aligned}
& 1833 \text {. . . . . . . \$100,000 } \\
& 1840 \text {. . . . . . . . } 150,000 \\
& 1850 \text {. . . . . . . . } 900,000 \\
& 1862 \text {. . . . . . . 3,873,715 } \\
& 1870 \text {. . . . . . . 4, 473,605 } \\
& 1872 \text {. . . . . . . 7,757,800 }
\end{aligned}
$$

In France, of 38,000 communities, 14,000 were in 1833 without schools; in 1870 only 800 very small communities were without schools. In 1832 onesixth of the French people were educated. In I 856 almost one-half of the people were educated. Upon 10,000 in the army of France could read in

$$
\begin{aligned}
& \text { 1828 . } 3,518 \text { men from } 21-40 \text { years old. }
\end{aligned}
$$

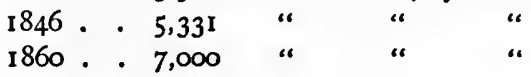

The primary department in France counted in

$$
\begin{array}{lllllllll}
1830 & . & . & . & . & . & . & 1,000,000 & \text { scholars. } \\
1848 & . & . & . & . & . & . & 3,530,135 & \text { “ } \\
1850 & . & . & . & . & . & . & 3,784,710 & \text { “ } \\
1868 & . & . & . & . & . & . & . & 4,442,421
\end{array}
$$

The appropriations for primary instruction in Paris were in

$$
\begin{array}{lllllllll}
1852 & . & . & . & . & . & . & . & 1,300,000 \\
1859 & . & . & . & . & . & . & . & 1,700,000 \\
1866 & . & . & . & . & . & . & . & 5,207,000
\end{array}
$$


In 1862 , France had I,833 school libraries, in 1866 it had 10,243!

Belgium had in $1830,293,000$ children in the primary department; in 1848 it had 462,000 in the same department.

The progress of Education in the past and present is very much the same everywhere, and not only proves that the world came to the conclusion that its improvement must come from the school; it also shows that if the misery of the masses has been very great hitherto, so has been the neglect of their Education. It further proves that scholars and philosophers, while they indulge in the delights - of the intellect and the imagination, are, as a rule, to their own reproach, unconcerned about the brutality, ignorance and misery of the masses. But the weightiest lesson of all is that private means and efforts are insufficient to provide for the Education of the masses. England, with its state church, and mutually jealous sects and its publicspirited men of wealth, proved by the miserable failure they made of the Education of the people, that the power and wisdom of the state alone are to be trusted with this great work and responsibility.

The more the masses equal in moral and intellectual grasp the rest of society, the more it must be admitted that they are the most important fac- 
tor in the production of wealth, and are, therefore, entitled to the best wealth can give-a good and substantial Education; and this is also all they can claim from the state without detriment to themselves and without confusion of ideas and principles; and whoever endeavors to deprive them of that, under whatsoever pretext-public economy, or what not-his name ought to be loathed as that of Arnold, the traitor.

Reforms should commence so imperceptibly as to be sure to escape the opposition of opinions and things, and the capital invested in them should only grow with our experience in managing them. We should then be sure of meeting with success and of finding imitators. "Do not pitch your improvements too high," is the instruction of the Prussian Minister to his Commissioner of Education.

Connecticut feels the necessity of combining industrial training with school Education, as the people in many localities visibly suffer from want of occupation, and she refuses $\$ 100,000$ of a testator, bequeathed for the purpose of inaugurating that improvement, as the committee appointed for the investigation of that matter reports an industrial school requires a capital of $\$ 500,000$.

We should open our industrial school with two dozens of needles, a half a dozen spools of cotton and sixty yards of muslin; and if, in an evil hour, 
we should allow our ambition to run away with us, we might open in two branches at a time, and put into the students' hands two dozens of knives, and commence wood carving with a stock of 200 square feet of walnut lumber. Anyhow, we should begin with a capital of not over $\$ 50$, and be sure of success; but the Connecticut industrial school cannot start on less than $\$ 500,000$ !

Our philosophy as how to open industrial schools applies to infant schools, obligatory evening schools and every new movement.

Train the children to profitable employment, and every parent will hurry his children to school and keep them there, until the morals of the school accompanying the work of the muscles will become assimilated, fixed, organic and hereditary.

The cultivation and improvement of the few favorably situated for a time is lost with their opportunities in the unimproved masses in which they soon sink back; only the culture and improvement of the whole people can become hereditary; and, hence, Race Education, or Hereditary Culture, implies universal culture.

Luther, the reformer of the schoolhouse as well as of the Church, and Pestalozzi, are beginning to tell on Germany.

After the Austrian defeat at Sadowa, a high Prussian official having been asked, "Who was 
your biggest general?" answered, "The schoolmaster."

It was the lack of this sort of general that beat France. The Polytechnic Institute of France is the best in Europe-its primary instruction is the poorest.

The Protestant leaders, as early as 1560 , asked for an obligatory school law; they were crushed; and to-day, after three hundred years, the French government is still wrangling over such a law. Germany, having taken possession of Elsace and Lorraine, March I, I87I, introduced compulsory school attendance the 18 th of the following month, and made an annual school appropriation of $6,562,427$ francs. The French government, under the Restauration, made an annual appropriation of 50,000 francs for the primary Education of the whole of France.

That England appropriated for' primary instruction in $1841, \$ 150,000$, and in $1872, \$ 7,757,800$, and France, in 1828 , for the primary instruction of the nation 50,000 francs, while Paris appropriated for the primary instruction of its own population in $1873, \mathrm{II}, \mathrm{I} 32,046$ francs, is a guarantee of progress and gives us faith in the future of humanity.

Prussia, with $12,256,725$ population, had already in $1825,21,623$ primary free schools, with 25,000 teachers and $\mathrm{r}, 664,2$ I 8 scholars under attendance, 
while England, as late as $\mathrm{I} 84 \mathrm{I}$, had an annual appropriation of $\$ 50,000$ for the primary schools of the whole country; and, as a natural consequence, expended during the same period for the suppression of crime, $\$ 3,224,845$.

COST OF EDUCATION AND OF CRIME.

An Education that trains, teaches and fits us for usefulness from our earliest childhood may be expensive. But is a quarter of a million of drunkards, as many criminals, paupers and defectives, less so? A half a million of men consume, waste, depredate and not only produce nothing, but absorb the labor of one army watching them, and of another that is administering to their vicious propensities in a hundred thousand haunts of vice, shame and drunkenness! The wages of these idlers, at the low rate of $\$ \mathrm{r}$ per day, would amount to \$150,$\infty 0, \infty 00$ per annum. But the difference between the production of a nation of forty million industrially and morally trained and one that is without such influence, does not count by the hundred, but by the thousands of millions; as the result of every producer would be enhanced by increased efficiency and economy.

The habitual criminals, of whom we have about 40,000 in our state prisons, cost the state each, for detection, apprehension, conviction and mainte- 
nance, $\$ 500$. The depredations of each, during an average criminial career of five years and a half, amount to $\$ 2,750$, which gives a total cost to society of $\$ 130,000,000$. Drunkenness costs the nation four and five times as much, and the same may be said of the idle pauper class and the defectives. For pauperism and its misery nearly double the rate of death and disease in the land. But we may multiply tenfold the damage to the nation from pauperism, drunkenness, crime and every sort of defectiveness, and these miseries assume vaster proportions still, as they are hereditary and multiply with every generation in a geometrical ratio.

The Juke family thus yielded in seventy-five years in

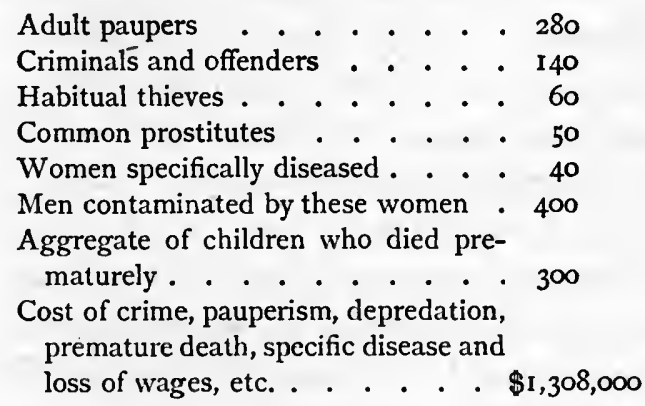

This is the fruit borne by the cheap Education of a family of four sisters in the State of New York during seventy-five years. 


\section{Does Every Education Prevent Pauperism? 263}

Charles L. Brace has proved the wholesome influence of industrial schools on crime. But does our common Education prevent crime?

The criminal class is, naturally enough among other things, also illiterate ; but, certainly, reading and writing have in themselves but little restraining power over crime. Prof. John W. Draper, who is very guarded in his statements, positively asserts in his treatise on Physiology, that our common Education has rather the reverse tendency. The same position has been taken by Herbert Spencer and other investigators.

\section{DOES EVERY EDUCATION PREVENT PAUPERISM?}

It has equally been established beyond a doubt, that a common school Education is not proof against pauperism. Thus, the counties lying between London and the south coast of England are by far less illiterate than the North Midland counties, and have yet a great deal more of pauperism.

Only an Education that develops from early infancy all the powers of body and mind, fosters good habits, imparts practical information and trains men to active and skilled industry, is a preventive against pauperism and crime; and, in fact, against every other deviation from the normal type of humanity. 
It is time the sham of our illiteracy statistics be made clear to the comprehension of everybody. The fact that most of paupers and criminals cannot read and write is used as a conclusive argument, that all Education has to do to diminish pauperism and crime is to teach people how to read and write. In truth, however, illiteracy is not the cause of pauperism and crime; but, like pauperism and crime, it is a symptom of want, misery and a general deterioration and degradation, which are the real causes of illiteracy as well as of crime.

The detection of this fallacy is of vast importance, for it teaches us that to impart a knowledge of reading and writing does not touch the cause of pauperism and crime. To effect this, we must remove want, misery and congenital deterioration, which can only be brought about by the prevention of the development of inherited evil tendencies through correct early training in infant schools and the cherishing of active habits in the industrial school, developing skill and capacity, promoting well-being, health and comfort, where degraded tendencies, left to themselves, would have produced want, miscry and degradation.

\section{INTELLECTUAL PLEASURES.}

An increascd outlay and effort for educating the masses is our greatest security for the future. It 
has long ago been observed by prominent economists, whenever intellectual pleasures are in the ascendant, civilization progresses, and when sensual pleasures predominate, civilization is on the wane. It certainly shows in our favor that we spend a hundred and fifty millions per annum for the culture of the young, and, besides this, vast sums taken out of the fund of material gratification, lessen by so much luxury, ruinous by its effeminating tendency, and add so much to the virtue, force, intelligence and efficiency of the next generation.

Water, air and earth make the wheat and cotton plant, which, in their turn, are made into food and clothing. So does under the process of an advancing civilization matter enter into the production of mind. Our spiritual wants increase daily, and their satisfaction is attended with least waste. One loaf can feed but one stomach, and one coat can cover but one back; but one idea may feed a thousand minds. The production of mind is, therefore, the most profitable investment, and the progress of the race, of manufactures and of values lead all to it, and, hence, our increased educational efforts.

\section{EDUCATION AND THE STATE.}

Lycurgus has already said, the business of the legislator resolves itself into the bringing up of youth. 
Plato has said, man cannot propose a higher and holier object for his study than Education and all that appertains to it.

Nothing, says Auguste Comte, can give stability to a government but a great principle, to which under every change or revolution of opinion all the people will hold and around which they will rally; and an Education that will teach them the submission of their desires to the will of all.

Race Education, or the subordination of the individual in each and every act to the race, gives us the principle and the Education, which of all others trains for this wholesome subordination.

"It is most natural for the individual," says Aristotle, "to be educated for the nation, of which he is but a part, as the limb is of the body and for the body." We admit the criticism, that antiquity sunk the individual in the state. But do we not fall in the opposite vice, and err on the side of meanness, as the ancients did on the side of nobleness, by running individuality into consummate selfishness? Race Education decpens and unites both elements in educating the individual for the race.

EDUCATION AND OUR FINANCIAL CRISIS.

Too dull and listless to learn in the school of thought, nature's laws will make themselves heard 
at last by speaking to us in pinching want, ruin, misery and bitter disappointment attending the upheaval of commercial crashes, and, at last, in revolutions and national ruin.

Witness our present crisis, aggravated by our false Education. War has demoralized the industrial habits of the land; the late discontent of labor has materially lessened its results, and production was thus doubly cut short; still mislead by an inflated currency, the people were sure of getting rich, and spent more than ever. How could we but get poor, losing at both ends by a decreased production, and an increased consumption when labor and saving are the only sources of wealth? From the firing of the first gun at Sumter we got poorer as a nation, as we produced less, or what we produced were not means for further production, but destruction. We were piling up fences, farm implements and the wealth of cities and states, and made of it a great and fearful conflagration. And even this is not all; we destroyed a million of producers, made the living worthless through habits contracted in the camp or the extravagance and the gambling spirit at home. What a strange way of getting rich! From Adam Smith down to Mill, McLoid, Jevons and Cary, economists have taught us differently.

When we felt flush, the crash was coming; for we were indulging in a dangerous delusion. 
Our future will never be secure until our children are trained from their fourth to their seventh year to be active, skilful and creative, and thus a lasting foundation for industrious and moral habits be laid; then to their twelfth or thirteenth year they must be intellectually trained and instructed, and after that to their eighteenth ycar industrial employment must be combined with the highest technical and scientific instruction.

We are wofully deficient in industrial and moral habits, as also in the knowledge of the plainest principles of economy. We have to overcome the financial fiction of honestly getting something out of nothing, when, in fact, labor and saving are the only factors in the production of wealth.

If we bring up our children for work, we bring them up for the country and for the production and the cheapening of the first necessaries of life, the increase of which increases the well-being of the masses. If we raise them for idleness, we raise them for the city and for chance stakes, which tend to unprincipled transactions. It is the lack of the element of work in the popular Education that swells the movement of the population toward the great cities, where everybody fishes for his prize, and one wins while a hundred sink beneath the wave.

Our Education is at best a hunt for charming 
The School the Miniature of the World. 269

information, but the power of producing our necessaries to sustain life must precede the delightful.

Our defeats as our victories come from the schoolmaster, and the school is at the bottom of our financial disasters. "Nonsense," says my critic, "it is the time." But, pray, who makes the time but we, and who made us but the school?

\section{- ERAS OF CIVILIZATION.}

Our present development of the understanding must be followed by the reign of reason, as it has been preceded by the dominion of the imagination.

The creation of language and the fine arts formed the dawn of civilization; now science absorbs the age. Only the perfect state is the consummation of the highest reason.

THE SCHOOL THE MINIATURE OF THE WORLD.

It need not be repeated that to instruct is not to educate. But it is not enough realized that knowledge is not always saving, and that the downfall of empires has mostly been attended by subtlety of intellect and universal skepticism.

To educate the young is to make them live long enough the life we wish them to live, that they may continue it from habit. It is not to show them at a distance the way they are to walk in, but to train them in it. The school must be a 
miniature of the world with all its work and duties, in which the young must be exercised. And this simultaneous training of every part of man's nature is the more necessary as each has its modifying influence on the other, and none can be cultivated to advantage separately.

THE PERIOD OF CRIME AND OF EDUCATION.

The greater amount of crime is committed between the ages of twenty and thirty years. By increasing the industrial usefulness of Education, which enables scholars to support themselves, parents are more induced to send their children early, long and continuously to school than by compulsory school laws, and thus prolonged school attendance influencing those years of vicious tendencies, will lessen crime by one-half.

THE HALF-TIME SCHOOL SYSTEM.

Race Education divides the scholar's time between instruction and industrial training, which is acknowledged to yield better results than the long hours of our common schools, in which, however much talking the teacher may do, the jaded scholar receives but little.

The half-time system, not interfering with the acquisition of a trade; enables the student to prolong his period of Education, to become acquainted 
with the theoretical acquirements of his especial trade and their use; and having for years combined work with study, his success as an artisan and inventor is assured.

The leading educators of England agree with Mr. Chadwick in pronouncing short school hours a success; that prolonged attention is impossible for a young child; that school hours are wasted because they make impossible demands upon a child's immature powers; that short lessons, with bodily work, produce better intellectual results than lessons twice as long, without the relief bodily exercise gives to the mind.

Dr. Norris says, before the British Association, he has confronted this subject on all its sides, and found that children who studied half the school hours, and worked the other half of the day, studied and worked more efficiently than children who worked or studied all the time.

OUR WORDY EDUCATION.

Let our scholars have less to do with words, the shadows of things, and more with the things themselves, and they will prove as energetic and successful as our self-made men. Teachers and parents often think that children must learn all the words Johnson, Walker, Richardson, Worcester and Webster did not know how to spell and pronounce; 
that they must know by heart every third and fourth rate river in Africa, soon to be forgotten; and that their heads must be filled with Rs, Xs and Ys until they are turned themselves -into unknown quantities.

Who will deliver us from the yoke of the letter, and permit us once more to have a soul and to act an honest part in the world!

Our schools teach too much, educate not enough and train men for labor not at all.

Our information is too general, which means especial ignorance as far as accomplishing anything in particular is concerned. We want science adoing, as life and nature are. The word must become flesh, and not the flesh word, says Richter.

\section{EDUCATION AND INDUSTRIAL LABOR.}

Locke treats what the schools call learning in comparison with physical, mental and moral habits with a most hearty contempt. How strenuously this philosopher, eminent above all others for his great good sense, insisted upon combining one or several mechanical pursuits with intellectual Education even in the highest classes of society, of which practice he cites many examples among the ancients. Cato and Cincinnatus were but illustrations of what was most common among the great men of Rome. Spinoza does not stand alone in 
modern time. Luther made a good hand in several trades, so did the great Lord Brougham, and so did other men of like eminence.

Industrial universities, receiving their pupils from industrial common schools, would be of infinite more advantage to the country than our present colleges with their Latin and Greek pretences. It is the Central College of Arts and Manufactures at Paris, the pupils of which are in great demand among the manufacturers of France.

But not only Locke, the father of the modern sensational school, but as we have seen Leibnitz, the author of the monadology, and Fichte, the transcendentalist, all equally insisted upon the necessity of joining handicraft to mental culture. Froude, the realistic historian, instills the same lesson. And our own great dead of but yesterday, was not his parting tragic enough, that we so soon forget his life and his teachings? The destruction of slave labor was but half of Mr. Greeley's lesson. The union of Education with free labor was the other and more important half; and half the utterances of his life we should have to cite were we to repeat all he so forcibly said upon this score.

Solon made labor binding upon all men; our Puritan fathers legislated it; philosophers of all schools enforced it ; Germany, and all Europe, more or less, introduced it in its schools more than a $12 *$ 
hundred years ago. We may turn a deaf ear to the teachings of lawgivers and philosophers of other nations and our own, but the ruin of our industries, labor failing to feed the peoplc, and giving way to dishonesty, corruption and anarchy will at last force us to concede to labor its place in the Education of the people.

Labor, says De Gerando, is the great educator. Labor mcans wcalth, power and civilization. Labor means character, duty and nobleness. Labor prevents disorder, ennui and dissipation; it inures to action and usefulness. It is a school of sobriety, cultivates attention, perseverance, precision and method. It allays the passions and brings inward peace and health to the soul. Labor gives vigor, a sense of dignity and the power of self-restraint. It restrains inordinate ambition, and accustoms us to estimate reality above empty applause.

All honest work, says John Mill, is for the universal good, and as honorable as any public function; and by doing perfectly whatever we do we perfect our character.

Froude sets handwork before headwork. The first business of Education, he says, is to assist us in honestly supporting ourselves. A man must work, steal or beg. The practical necessities preeede the intellectual. As long as society does not mind the common wants of humanity and 
give this sort of Education, it has no right to condemn the rogue or mendicant.

Miss Nightingale has well said, that without industrial training the three Rs are most likely ending in a fourth $\mathrm{R}$-Rascaldom.

Mr. Pearson, in his report before the House of Lords, says: I am satisfied that the cause of juvenile crime is not the absence of Education, and that any Education of the children of the Iaboring masses unaccompanied by industrial training and actual employment in manual and useful labor, will entirely fail in checking the growth of crime.

And what opportunities have the people for engaging in profitable trades? says another well-informed authority. Owing to a variety of circumstances it has become almost impossible to procure for children such educational training as will make them skilful artisans. The public school must fit for work: European nations are competing in establishing schools of art, and we must shape our public schools in the same direction or fall behind the civilized world in our industries. European countries swarm with schools for drawing and technical training. Little Wurtemberg alone has four hundred drawing schools. The United Kingdom has eight hundred schools of art. Every country and every great city in Europe has a grand school of arts and industries. Whatever time and expense has been 
devoted of late in England to drawing has richly been repaid by the improved industries.

New York, Boston, Philadelphia and a few more citics have a few such schools as any German province is swarming with.

The Superintendent of Education of the State of Rhode Island says, our motto should be "the best Education to the largest number." The present course of study is arranged for those who intend to complete the whole course in the high school and not for the masses, who are growing up in ignorance, vice and youthful crimes, which multiply in a geometrical ratio.

Hundreds of orphan asylums, industrial schools and reformatories, in which many industries have for years been successfully taught, prove the practicability and utility of teaching and training the masses in skilled labor. Massachusetts has the honor of having passed an act in 1872 providing that the city council of any city or town may establish and maintain industrial schools and raise the money necessary to render them efficient, and prescribe the arts, trades and occupations to be taught.

The Cooper Institute of New York City, founded by the munificence of the eminently good and wise Peter Cooper, with more than two thousand students, mostly mechanics, crowding its courses in engineering, mining, metallurgy, analytical and syn- 
thetical chemistry, architectural drawing and practical building, schools of telegraphy, wood-engraving, photography, design and painting, proves the eagerness of the public to benefit by schools of art and industry, and is a reproach to public remissness in not following the lead of this great benefactor in giving the masses in similar institutions opportunities for combining labor with study, that they may rise from their unprofitable drudgery to remunerative technic art.

The Institute of Technology at Boston, the Worcester Institute of Industrial Science and Cornell University, under the able lead of President White, are all hopeful illustrations of the combination of labor and study.

It is pleasant to mention the noble beginnings made by the Women's Educational and Industrial Society of New. York City, who train and instruct thousands of women in a variety of occupations. Long Island has a Printers' training school. The Hebrew Orphan Asylum of New York and the Episcopal Orphan Home of Brooklyn teach several trades, and so does the Wilson Industrial School of New York to girls, the Brooklyn.Female Employment Society and the Young Ladies' Branch of the Women's Christian Association completing the list. A model for future institutions of healthful labor, is presented to us by Girard College, 
with its extensive arrangements for type-setting, printing, book-binding, type-casting, stereotyping, turning, carpentering, photographing, clectroplating, telegraphing and shoemaking.

By refusing labor a place in the Education of the masses, we practically tell them "we will not teach you anything useful, but even that will make you paupers, criminals and orphans, and soon cnough bring you to our industrial pauper schools, reformatories and orphan asylums where you shall be taught some trade or other." But must we burn down the house to roast the pig? Must the people pass through pauperism, crime and orphanage to get into industrial schools? Would it not be more sage to engraft industry upon our public school system, and rather prevent pauperism, crime and premature orphanage than make them the bridge to industry?

Women suffering nearly twice as much from poverty than men prove by the consequent deterioration of the race the failure of our present Education.

As long as in the absence of a great national system of Kindergartens women are not employed in what is peculiarly their work-the Education of the race-only a varied industrial Education can save them from being crushed by a competition they are bound to meet with in a few overcrowded employments open to them. By giving women a 
reasonably extended industrial Education, we curtail by one-half prostitution, crime, woman's slavery to man, widowed misery, the idiocy of orphans starving with their pining mothers and other innumerable evils, all flowing from woman's helplessness.

A proper industrial training would enable woman to provide for herself and for those depending on her whenever she should be thrown upon her own resources.

In 1859 women in New York City made and pressed stylish caps for two shillings per dozen. In London about the same time fifty thousand females were working for under sixpence per day, and above one hundred thousand for under one shilling a day. Shirt-makers made a dozen shirts for two shillings. Waistcoat-makers earned only from three to four shillings a week; workers for the army clothiers received eight cents a piece for jackets and trousers, earning thereby two shillings a week. Shoe-binders worked eighteen hours a day, and earned one shilling and sixpence a week. The mantilla-maker, working from nine in the morning till eleven at night; made four shillings and sixpence a week in the busy season.

At a meeting of one thousand female slop workers in England the curious result was obtained, that none of that number had earned more than five 
shillings a week. Ninety-nine had earned only one shilling, and two hundred and thirty-three had had no work at all during the whole of the week.

In 1867 , the New York World informs us, there: were in the metropolis 70,000 women and girls. beside domestics, who worked for their living, of whom 7,000 lived in cellars, and 20,000 were in a constant fight with starvation and pauperism. Since r 860 establishments doubled employing these haggard creatures at the top of princely merchant houses.

The New York Times in December, 1867 , informs us of thousands of women in the city working from seven in the morning to midnight getting seventytwo cents for the making of a dozen of shirts. Six cents for a shirt! And pay for drawers, undershirts and blouses in proportion. But flannel shirts carefully made brought $12 \mathrm{I} / 2$ cents a piece, best white shirts $87 \mathrm{r} / 2$ cents, a dozen best drawers $\$ 1.25$ a dozen. A soldier's widow, with four children to support was getting $\$ 4.50$ for embroidering a cloak, two weeks of toiling! the cloak selling at $\$ 50$ to $\$ 75$, the woman being told, if she will not do it plenty others will do it.

The average labor for I 866 was for

Cloak makers . . . . . . \$8.0o per week.

Shirt

Cuff and collar makers . $\$ \$ 8.00$ to 9.00 Umbrella 
Button hole makers . . . 3.00 per week.

Fur-sewers ..... \$4.00 to 7.00 "

Machine operators . . 4.00 to 8.00 "

In Boston we read there were in $1868,20,000$ women working at starvation rates, 8,000 workers at 20 to 25 cents per day, 12,000 workers for less than 50 cents, and even at these rates there was little work. These women lived at times on one cracker a day for breakfast, dinner and supper. American wives and mothers work in Boston from dawn to dawn to get one mouthful of food, making shirts at eight cents a day! Some women take shirts at 50 cents a dozen, and operate sewingmachines at $\$ 2.50$ a week. Dr. Dio Lewis says: "These operating girls run the machine from one and a half to two years, and their backs give out, and their spines give way. When they give out they are pretty well spoiled, and are then thrown out to pick up what they can get, until God in his mercy shall take them hence."

In 1868 one of the best informed journals reports, 30,000 girls struggled in New York City with starvation and cold, six cents for the making of a shirt and furnishing the thread!

In 1869 the New York Hcrald writes: "The working women live in nasty tenement houses, in cellars unfit for human habitation, in pools of foulness, where every impurity is matured, and every vice 
flourishes, with no air, no light, a rickety bed, a broken-down stove and second-hand cooking utensils. Such is the condition of 75,000 working women in New York City."

A room of 12 by 14 feet, ceiling 8 feet high, paying $\$ 8$ a month and earning $\$ 6$ a week, working on an average 12 hours a day.

The Economist, in 1869, said: "The maximum average of female labor was $\$ 5$ per week. The surgeons of Bellevue and other hospitals, who investigated the subject, assert that much of the sickness and mortality of females in the city of New York results from insufficient food and clothing, exposure and cold. The ranks of shame and death are re. cruited by thousands of unfortunates, who would never have strayed from the path of rectitude if they had obtained honest employment."

Does all this not loudly call for an industrial Education? Is it a wonder that with such mothers the race deteriorates? Who is there but takes good care of a valuable mare, and have we become so debased that we do not value our mothers and our race as much as a farmer does his stock?

Woman in her great misery, involving the ruin of the race-in more than one way-is the condemnation of our impracticable system of Education, which does nothing for the preservation of the race or for the individual, and the stolid indiffer- 
ence of which for human weal or woe betrays an appalling degree of barbarity.

The answer of Agesilaus, the Spartan king, upon the question, what was best for boys to learn? "What they will practice when they will be grown to be men," is as sensible to-day as it was then.

The masses of the people must be skilled in industrial labor; they must be used to the application of knowledge to work and must be industrious, and, hence, the importance of training them early to these requirements of their mature years.

Nervousness leading to a variety of affections, ending often in insanity, is one of the most serious symptoms of the general degeneracy of our age; and all great physicians pronounce moderate labor the most remedial agent in cases of insanity. Cabanis fully proves that muscular activity lessens nervous excitement; hence, physical labor is most wholesome in this our age of nervous affections.

The fostering of honest work would certainly have a good effect on the insanity of mammon worship or the madness of speculation.

The life and motion of the stars is kept up by the opposing centripetal and centrifugal forces; the adjustment of the inner and outer conditions is maintained in organic life by assimilation and dispersion, and social life consists in progressive adaptation and conservative institutions. 
The conservatism of China is known, so is its intellectual culture. The code of the Jews is "study the law and observe it," which includes research and steady adherence. And both these nations have outlived all others. The Romans were warring and progressive tribes; but, as we have already seen, the mothers grown up under the shade of domestic habits, had charge of-the Education of the children, and supplied it with the conservative element. The Greeks conbined the culture of the physical and intellectual element as no other nation, and, hence, their perfect health and beauty of mind and body.

The hard toiler is slow, patient and conservative, while the student is progressive, as thought will impatiently outrun the slow march of stubborn reality. By joining study with labor, we combine the spirit of progress, development and adaptation with the spirit of conservatism, both so necessary for the historic development of a nation.

Nothing but the union of intellectual Education with physical labor can save us from corruption of every sort and bring us back to the perfect culture and natural simplicity of the Greeks. Or, is there any reason to contradict the statement, that with culture, honest labor and simple living the simplicity of the Greeks is more likely to come than with musty Greek grammars and dictionaries? 
Our schools, instead of developing in us a taste for technical pursuits equal to that by which England, Germany, and, above all, France excel, force us to speculate on each other's hide. If, of a hundred scholars leaving school, ninety-five engaged in useful work, and five scrambled for the profits of their labor, that might do; but of the hundred, ninety-five scramble for the questionable profits of the unwilling labor of five, and, hence, the murderous competition, which leaves the five and ninetyfive dead on the field.

The clergy have started our Latin schools, the commercial classes have organized our grammar schools. The laboring masses of to-day call for industrial schools.

The famous Dean of St. Paul says, before the British Association: "Whether we have advanced as far as we wisely may, in blending the useful with the ordinary Education, may well occupy the thoughts of the reflective and practical men. I am at a loss to see, why exercise of the faculties may not be combined with what will be applicable to the future employment."

Dr. Fitch, one of the foremost educators of England, says, before the same Association, the children of the masses want more than reading, writing and arithmetic; they want to be put in possession of the mechanic arts; they want right habits; they 
want to be taught to think about their work, to feel an interest in inquiring and observing for themselves, and to know how knowledge is acquired and applied.

We badly want schools and appreciate them; but they must not devote themselvès exclusively to teaching us how to talk about things, but to do the things and do them rightly.

We appreciate the teacher's difficulty. He tries to make the pupil what he is; and as he is an everlasting talker, talkers he will make. But the world is getting tired of words. What it wants is doing, and to this the school must make some sort of an approach or the world will stay away from it.

The State of New York has a right to expect a better return from thirty millions school property than five hours spelling and geography five times a week. The school must form the home and the shop as well as the school of the youth of the land during eight or nine hours of the day. A nutritious but simple meal, not costing over five cents, a simple dress, earnest work and a generous conduct upon the playground alone can educate the nation to simplicity, industry and universal good-will. Moral teachings, enforced by such habits, must regenerate the nation that, though young, has already entered upon its period of decadence.

As we have already quoted, learning forms our 
speeches, but habit our inclinations, after which our actions take. Learning is not the end of man, for we can but little know at best; character and achievement, or what we are and what we accomplish, are much more important; and, hence, the organization of the school must develop our nature in infancy, and not dismiss us until we are ready to do our work in the world intelligently. The science of life and the art of living are the main object of Education, as leading to the preservation and improvement of the race.

Once the phenomena of nature have been deemed unworthy the attention of the schoolmen, and the fancies of men have been dignified with the name of philosophy. To-day learned men have but half parted with their conceit, and despise the knowledge of the common things of the world. But who can take an intelligent survey of the international exhibitions of the world without being struck with the amazing variety and grandeur of the works of common men when compared with the smallness and paltriness of the most elegant words of literature.

What is Homer, Virgil, Horace, Dante, Milton or Shakespeare in comparison with half a million of intricate mechanisms, each doing the work of dozens of men, and one hundred million articles of use and beauty? Well may Herbert Spencer say, 
what is stored up in books is but the smallest part of the knowledge of mankind.

We disavow every intention of disparaging science, but as emphatically declare that practical work, which has furnished science with the great facts underlying it, must be taken again into the service of science and must be treated more graciously by the new mistress.

Our abstruse scientific treatises may be excellent for scientists; the masses who must work must be initiated into the principles of science by studying and working them out in their application to industry. We need no more be ashamed of affiliating the school with the workshop than with old dame nature. To be plain, the school must become considerably a workshop, in spite of literary fops and word-mongers. Science and life will be gainers by the change.

A person of a practical turn of mind may not care about electricity, caloric or the common properties of matter, but will. take interest in electroplating, the steam engine and the strength of building materials.

Let every school district have a library not of the battles of England or the wars of Rome, but of every treatise on every branch of industry carried on in the said locality, with a museum containing every article manufactured in different countries 
and ages of the same nature and the tools used in the process, and the saloons will be less visited, and inebriety and pauperism will receive a check, and every industry flourish as never before.

From our primary and secondary departments of instruction to the college and university all is verbal, culminating in Latin and Greek, which is a very fraud, not one in ten scholars going through them ever being able to read these languages, save the few text books, parrot-like got by rote. Every town ought to have its industrial schools, every county its industrial college, every State its industrial university, and the whole country its national academy of the industrial arts and sciences.

The whole land must become a bee-hive, in which each works for all, and all work for each. Then, and only then, will all be sound in body and sound in mind, sound in government, sound in finance and sound all over.

Education must not begin and end in generalities, but must branch out in different industrial institutions, in keeping with the pursuits of the different sections of the country, to which they must give a higher impetus.

Since religion has ceased to be a state power, binding men's consciences and hands, too, a rational discipline must school men from very childhood up in useful activity and severe simplicity. 
The industrial training of a long line of generations must become an instinct with the race. Production is characteristic of civilized, as destructiveness is of savage life, and our social instincts make daily more the preservation of the race as dear to us as the preservation of our own life. Only when the world will be all work, will vice, fraud and war, and every other species of wrong and oppression, disappear from among men.

Let any one judge in the light of the recognized principle, that Education should enable us to avail ourselves of all our powers to our best advantage, and teach us how to learn and improve through life-if our schools are serving this double purpose -teaching and training, as they do, the people in nothing that bears directly on their future vocation, which is mostly industrial.

"The circle of knowledge through which every man in his own place becomes blessed, begins immediately around him from his own being, and from his own relations." Such are Pestalozzi's words. Instruction, foreign to a man's pursuit, is soon forgotten, while the science that discovers to a man the philosophy of his daily work, renders it to him an opportunity for constant mental growth and satisfaction, besides the practical advantage he derives from the thorough understanding of his business. 
To fit men for duty and the labor of life is the paramount work of public schools. Do they either?

We are beginning to feel the effects of crowding even upon this continent, especially in the larger towns; and nothing but Race Education, insisting with equal stringency upon physical, mental, moral and industrial training from earliest infancy to full maturity, can bar the door to pauperism, and prepare for us a future in which none will be so poor as to suffer want; none so vicious as to inflict wantonly an injury upon his neighbor; none so ignorant as not to know his duty and none so unmanly as not to practice it.

\section{RACE EDUCATION DESCRIBED.}

After we had penned down these our thoughts on Education, Dr. E. Seguin's masterly contribution to physiological Education came to our hand. Our standpoint is the practical forced upon us by the study of the unspeakable misery of the masses and their deterioration, leading us to Race Education, or Hereditary Culture, which at every step is an ethical as well as a physical problem.

The principle of Race Education, or Hereditary Culture, combines physical, mental, moral and industrial elements; it satisfies the highest requirements of science, answers the common ends of human life and society, recognizes the claims of the 
individual, the nation and the race; the ends of life and the means for attaining them evolve from it. It warns us against every possible mistake, and commends itself the more as the common degeneracy of mankind is studied. Practical necessity leads to it ; the general demand for universal Education finds its fullest expression in it; the latest biological results are formulated in it. It is highly realistic and idealistic, or a complete synthesis of both; and, finally, history shows us our ideal system of Race Education in execution with results, the most exalted imagination could not equal as far as the realization of the beautiful in man is concerned.

\section{THE EDUCATION OF THE OLD GREEKS.}

The ancient Greeks, who were but small in numbers, have furnished the nations of the earth ideals in every manner of greatness, unsurpassed, yea, unapproached. It is not the sky, it is not the race-for these still exist-but the great men have not come again since the Education of that race has changed. Lay it not to the age, sky, race or God; give us the Education of the Greeks, and God, nature and the race will give us Greeks again.

We take issue with the absurd method of the schoolmen, who think we can model after the 
Greeks by turning the pages of musty Greek grammars and lexicons. If we are to excel as the Greeks excelled, we must adopt the same training and spirit of Education, only improved by the experience of later ages.

While we protest against forcing Greek grammar upon a hundred thousand youths of the land for the sake of one hundred, who will make a successful.study of the noble literature of that language; we insist, however, upon the propriety, the possibility and the necessity of giving every child in the land the same Education the Greeks gave their children. It matters little if we read Greek, especially as it is commonly read, or not. What we want is to excel in action as the Greeks did, and this the like training alone can give.

All branches of Education were comprised by the Greeks under the terms of gymnastics and music, wonderfully expressing thereby that like these, they must all be practiced in a manner as to produce strength and beauty of body and soul.

A perfect life is a work of art, and is not attained by reading about it ${ }_{2}$ but by acting, by living, exercise and steady training, and in this we must model after the Greeks, if we are to equal them in beauty and harmony or rhythm of action. 
THE EDUCATION OF MASSACHUSETTS.

Massachusetts more than any other state has made our system of common schools what it is. We love study and admire that state for the tenacity with which it labors on its historical institutions and develops and improves them. But if we oppose the common school system of Massachusetts of to-day, we point with preference to Massachusetts two hundred years ago-the stand it took then on industrial training; and if we insist on early Education, it is Boston fifty years ago that gives us our argument.

Mr. Phillips, one of Massachusetts' most favored sons, said: "The fact is that many young people, graduates of our public schools, are not capable of doing any work for which any one should pay a dollar, nor can they write a decent letter at fifteen, nor even read a newspaper well. The old New England system, which made a boy work six months by his father's side on the farm or in the workshop, after he had been six months at school, was better than the present one. From such a system it was possible to get such a man as Theodore Parker. Now the public school hands a child to its parents with no means of earning its bread."

Mr. E. Washburn, another favored son of Massachusetts, admits that the Education the mother 
must give the child is a thousand times more important for society and the state than the Education our schools give. This admits our whole position so far as the indispensableness of national infant schools are concerned. If to watch over and nurse a baby every hour and minute night and day, to cook, wash, mend and keep a home neat and clean, and attend to a hundred other household duties, if all this is as much as one unaided young mother can attend to, the state must give us infant schools to attend to that Education of the heart and character of young children, which Mr. Washburn admits to be a thousand times as important to society and the state than the later Education, but which hardly one mother in ten is situated to afford her young children.

\section{THE DEMANDS OF RACE EDUCATION.}

The demands of Race Education are not unreasonable. It condemns the present system, which is purely intellectual, and gives rise to an intellectual strife and to a remorseless competition in life, which sends millions to insane asylums, poor-houses, jails and early graves.

Race Education simply insists that the intellectual culture of the present common school system be preceded by the still more important culture of the character, morals and faculties of the young 
children in national infant schools, and be followed by industrial training indispensable for self-support, general usefulness and the development of national wealth and the prevention of pauperism-the pest of modern states.

We may sum up the practical points of our system as follows :

I. Education must aim at the preservation and improvement of the race.

2. Many causes at work contribute to a race deterioration, which manifests itself as

a. An excessive infant as well as adult mortality;

$b$. Nervous derangement and frequent insani $y$;

c. Habitual criminality ;

d. An inactive pauper temperament, and a variety;

e. Of congenital defectiveness, weakness or deformity.

3. To lessen human deterioration in all possible forms is the great aim of Education.

4. The development of low hereditary tendencies must be counteracted by the formation of opposite habits in its very infancy, and thus the foundation must be laid for desirable hereditary tendencies, and, hence, the all-importance of infant training schools.

5. Information must be spread among the people about the hereditary nature of morbid tenden- 
cies, and the duty of parents to their children in whom their own passions, drunkenness or weakness, assume the shape of madness, homicide or idiocy, blindness or deaf-mutism.

6. A knowledge and observance of the laws of hygiene by the parents will lessen in the children weakness, the cause of every sort of defectiveness and an excessive infant mortality.

7. Race preservation being the end of Education, no woman's Education is finished until she has acquired practically the art of raising children in the infant training school.

8. The laws of health, domestic economy and moral government are woman's first studies, as upon them depend the life and health, the economical success and the moral tone of the family.

9. As the masses must live by their physical exertions, and as rude labor cannot successfully compete with machinery, men must be trained to industry and art in childhood by infant training schools.

IO. The tendency to nervous derangement and insanity, so prevalent in our age, can only bc corrected by inuring men to physical labor.

II. The spreading of technical industry alone can infuse into our age a spirit of simplicity, moderation and honest dealing, and thus counteract the present extravagance and fraud ending in ruin. 
298 Race Education and a Rational Idealism.

I2. The school, science and Education must be brought in closer relationship with the factory, and lessen the dangers accruing to life from deleterious processes.

13. In the people's school technical skill and proficiency must form the acme of man's Education, as domestic proficiency must be the end of woman's Education; and the school must provide for each, and dismiss neither the one nor the other until this is accomplished.

14. Education must, above all, prevent pauperism, which through want and misery leads to every form of moral as well as physical depravity, by fostering chiefly what is useful, and making man an efficient and self-supporting producer.

15. Every part of Education must practically as well as theoretically be based upon the devotion of the individual to the race. Our present Education is neither practical nor moral. It is all literary foppery, and too trifling to be borne with in an age of hard common sense.

\section{RACE EDUCATION AND A RATIONAL IDEALISM.}

The preservation and improvement of the race are the plummet line of every part of our system of Education. The hygienic and economic relations of the individual are ever present to us, as morbid juices lead to morbid desires, and an empty 
Race Education and a Rational Idealism. 299

stomach is dull of moral comprehension, and health and bread are important factors of virtue, and are both secured by labor wisely and moderately performed. But, though our aim is tangible, it is comprehensive, and by no means excludes the ideal ends of all schools, which we only use as means for the improvement of the race, which to us is the highest goal of Education.

It has been most truly said before us, Education must help us to help ourselves, not so much impart as draw out. It must train us to learn from our own observation, or to get our knowledge at first hand from nature. It must inure us to freedom without license, for chains are as galling to the mind as to the body, and lawlessness is debasing.

The whole of Education must be a process of unfolding, a gradual revelation of what is in man. Education, in developing the faculties and capacities of the human mind, always commences with what is nearest to us, and leads us gradually by our own exertions to do and to comprehend by our own power and energy what seemed but shortly beyond our capacity. It begins by naming to the child the external parts of the body, and leads it gradually to the knowledge of the most complex functions of the human system and the laws we must observe if we wish to live a healthy and happy active life.

Education, beginning with the simple relation 


\section{Race Education and a Rational Idealism.}

of the child to its parents, leads it on to the knowledge and obedience of the laws which govern men and states, and selfishness gives way as the child feels its dependence upon its mother, father, brothers, sisters, the community and humanity.

Education makes the child feel and act in unison with nature, humanity and the infinite. While it cultivates individuality, it develops the consciousness, that it is but part of the great whole, in harmony with which it must seek its own growth.

Education must embrace the activities of the body, which give energy to the mind. It must assist us in giving shape and form to our ideas with our own hands. It must make us creative as well as intelligent. We must realize our thoughts in the world without us as well as form correct ideas in our minds of things external. In man the ideal and the real blend and take coloring from one another, and, standing as mediators between the two, we are at peace with all.

Education must ever work under the inspiration that the child it directs is part of nature, humanity and the infinite, for which it must be educated fully as well as for itself.

We must be educated for intelligent work, for virtue, for freedom, for progress and for humanity.

The development of the capacities of man secures his highest usefulness, and the bringing his passions 
Race Education and a Rational Idealism. 30 I

under the rule of reason, bestows the truest happiness-peace of mind.

Education embraces the cultivation of the heart as well as the development of the intellectual powers, and the science of the duties and responsibilities of human life is the paramount knowledge of mankind and must form a part of his instruction, adapted to the various stages of Education.

Education must train us to the highest activity in the service of humanity, truth, justice and goodness. It must train us to take the right for our guide and to be content, and have internal peace when we have done our best.

Education must train the body, enlarge the understanding, develop the affections, give clearness to our perceptions and energy to our thoughts. It must free us from narrow-mindedness and lead us to reason and justice, to the infinite and the absolute, in which alone there is rest.

Education, by properly watching over and developing every faculty, physical, mental and moral, assists in the revelation of our God-likeness, which consists in living not in and for ourselves, but in. and for all things. It cultivates thoughtfulness, kindliness and industry, a hand ready in execution, a quick eye, an inventive imagination and whatever else renders man effective, is in its scope.

While Education works up to the general ideal 
of a universal humanity, it fosters with particular care what is original in every single man, and constitutes his individuality.

Education leads us to know ourselves and to comprehend the times we live in, to move with it and to live not for the present, but for the future, not in the narrow limit of our own self, but in the whole. It trains us to subordinate selfish desire to universal principles and the good of all. The noble passions must be inflamed by examples of nobleness, patriotism and self-sacrifice studiously held up to them, as fire kindles on fire.

Education brings the child up to the ideal of the educator and fits it for the world it is to live and act in; showing man his destiny, it assists him in fulfilling it. It is the lever by which we act upon the future of the race.

Education trains man to submission to the infinite, to the love of man and to a self-determined activity in the service of the true, the good and the beautiful, in all his relations to man, nature and the infinite. It imparts to him true human culture and a character, as far as possible, independent of external influences and in full accordance with reason.

Education trains us to be true to the relations. of things, and to act upon general principles, so as to earn the approval of our own conscience as well 
as that of an impartial world. It cultivates the æsthetic faculty and renders the will effective, promoting thereby the good and the beautiful, and making us perfect.

Let us hold up the sacredness of childhood, humanity and the eternal laws of mind and its relationships, as reflected from this rapid sketch of the nature and work of Education, and compare with it the dead materialism or aimless routine work of our schools. What wonder that the generation it brings up is as indifferent as men brought up according to the mandates of eternal reason would be glorious. Mankind ought to resemble a blissful family, a haven full of rest; but, alas! it is all a pandemonium full of unrest, in which every one is at war with everybody else and with all that is good in himself.

THE CLAIMS OF CLASSICAL AND SCIENTIFIC EDUCATION.

More than one battle has to be fought before a great cause is forever won. For upward of two hundred years the contest between the Old and the New Education has been going on ; and only induced by repeated recent attempts to introduce Latin into the highest grades of our common schools, do we enter upon an argument that we should have considered settled long ago by the popular verdict. 


\section{Classical and Scientific Education.}

We combat the introduction of Latin as the adoption of a false principle, which vitiates our whole system of popular Education.

Once, when Popery and Cæsarism swayed the world, institutions had to take the line of authority, the rule of life and the norm of their culture from Rome; and the effects of this conspiracy still blight our system of Education. Latin and Greek grammar, we are seriously told, are better suited for the formation and development of the human mind and its faculties than God's infinite universe. Latin and Greek grammar usurp, therefore, the place of science, which alone gives us power over nature for our own good and the benefit of mankind.

Even our purely English Education is vitiated by putting grammatical pedantries and verbal trash before the practical knowledge of things real and useful.

It is comparatively a short time when Latin was the only written language of modern Europe; next, an English book was hardly thought decent without being interspersed with crumbs of Latin; and even to-day the sciences useful to the common people are inaccessible to them by barbarous Greek and Latin names without number. Scholars naturally over-estimate their little Latin and Greek, but this magnifying of a deceitful sort of half-knowledge is hardly decent or honest. 
Already Comenius, born 1592, clearly saw that nature and industry are more properly instruments of mental development, observation, comparison and judgment than mere words and phrases are.

John Locke, born 1632, insisted upon the same principle, and, hence, laid stress upon drawing and the principle of utility, deprecating the loss of time bestowed upon a miserable little Latin and Greek.

Herman Francke, born $16 \sigma_{3}$, the founder of the celebrated Orphan House and many other public institutions at Halle, was equally eager to give to the common course of instruction a more realistic tendency.

J. J. Hecker organized as early as 1747 the first real, or high and technical school, at Berlin upon practical and scientific principles. Men of common sense have since opposed the senseless routine of Latin and Greek grammar ; until to-day, in Germany, the land of thorough scholarship, the old seminaries are fast giving way to real schools, teaching drawing, mathematics, science, technology and modern languages instead of the old Latin and Greek jargon.

The national budget necessitates the government to favor real or industrial and technical high schools, which are building up the industry, commerce and financial condition of the country.

But science and industry are not only to be rec- 


\section{6}

\section{Classical and Scientific Education.}

ommended on the ground of their utility, they are every way superior as instruments of thought or educationally than Latin and Greek.

The school must make men think. How is this end best to be attained? The new method answers, by early acquainting men with nature as a system of thought, law, and spiritual relations; so that, wherever men may be, the air they breathe, the water they drink, the sky they see, minerals, plants, or whatever may meet their view, may bring to their mind the physical, mathematical, chemical or physiological relations underlying them, and thus exercise their thoughts and keep their minds active.

Next to nature, industry occupies men's thoughts, which, therefore, combined with science, is of great educational value through life.

But as the individual is rooted in the nation in which it finds his spiritual home, the national literature forms another important element in the Education of the individual.

Thus the new Education builds its system upon nature, industry and nationality, to which the old Education opposes its miserable pittance of Greek and Latin.

Undoubtedly Petrarcha, Reuchlin, Erasmus and the like men, who penetrated into the genius of Greek civilization and its realism, or perfect union 
of spirit and matter, which they opposed to the revilings of nature by the old Church, were highly favorable to modern advance; but, alas! our fourth and fifth rate classical scholars know nothing of the old Greeks, and their miserable little Greek grammar and parrot-like learned few detached pieces of Greek or Latin stupefy them, and make them intolerable through the ill-founded conceit with which it fills them.

Emerson says, that he has not met in all his travels in America with half a dozen of men who could read Plato profitably. This whole Greek and Latin scholarship is an imposture, the writing of miserable verses in these languages included. There is not one teacher in ten who has sufficient knowledge of these languages to derive from them a higher culturc. The learned apparatus requisite for their thorough understanding requires the study of a lifetime. Must hundreds of thousands of students in the land throw away their years and opportunitics for the sake of a few hundred Latin and Greek roots, which can be learned by any English student with the help of an etymological handbook in a few weeks, if not days?

And, as for the historic value of Greek and Roman civilization, a few parrot-like learned detached pieces of Latin and Greek, forming a classic course, have nothing whatsoever to do with this sort of 
study; and any English reader can find most competent information about it in the great writers on the subject; and as to an original familiarity with antiquity, not a half a dozen of men ever attain it in any country.

A noted Oxonian scholar, in his address before the British Association, says that educators complain of the indifference of all classes for educational opportunities offered them in all sorts of higher and lower institutions. And true it is, he continues, university professors would lecture to benches literally empty, were it not that the pensions attached to scholarships attracted students to the universities. But educationalists forget that, though parents esteem Education, their chief care is to bring up their children that they shall be able to provide for themselves; and, hence, if schools will not teach and train scholars for their future vocation, but insist upon making the critical, grammatical and literary feature of the old schools the ruling tendency of our present Education, the hardworking, matter-of-fact world of to-day will entirely turn its back upon them.

Classical students pretend to be a privileged class of scholars, and use Latin and Greek as the badge of the aristocratic order, when, in fact, their Latin and Greek amounts to little more than nothing. 
Would we pardon the arrogance of a German or Italian, who maintained that we cannot be men of culture without studying his literature? And is it less stupid in a Latin or Greek scholar to maintain that we cannot be men of the finest culture without going to school to Rome or Greece?

Is the book of nature written by the hand of infinite power and wisdom, and is our own history and literature not instructive, refining and suggestive enough for us, and every way more useful and full of great issues, than the half-understood crudities of Greek and Latin books?

Has our modern civilization developed no new ideas and principles to which the ancients were strangers?

Is humanity so poor that it cannot develop itself on nature, industry and nationality, but is utterly lost without Latin and Greek? And still men will boast upon the superiority of Christian civilization!

Is it not enough that we are denationalized by a constant stream of men of all nations flowing in upon us? Must the school, too, tear us from our own soil and take us to Rome and Greece to make of us anything but what we are by our own past history? Should not our public schools deepen our national feeling and nurse our souls with the life, work and words of our own poets, authors and statesmen? 
Or are we so poor that we have none good enough in our own history and nation who could serve as models to our children? People, of course, will study Sanscrit, Zend and Arabic, and so they may Latin and Greek; but the imposition is to force any of these languages upon our children as a thing indispensable to culture, and deprive them of the study of science, industry and their own, perhaps equally excellent, if not superior, literature. By introducing Latin into our high schools we exclude practically from them the industrial classes, who have neither leisure nor taste for such studies.

Latin has for ages, like an impenetrable barrier, separated the educated class from the common people. Do we want to build up this wall again? Is it not more in keeping with our civilization to make our own tongue the sole medium of science and literature, that it may be the harbinger of culture and refinement to the lowliest hut in the land as to the proudest palace?

That the Greeks had a monopoly of ideal culture, which is only to be acquired by the study of their literature, is simply preposterous. Ideal men had never any more an existence than ideal trees or animals.

Only science, or the knowledge of the laws of nature and of common things and the literature 
of the land, can reach all and be the means of universal culture and prosperity; and, hence, the importance of schools of science and industry, which are nurseries of national intelligence and greatness.

Mere grammar schools will never avert from the nation the dangers threatening it from the growing power of Romanism. Only science schools accustoming people to reason from the observation of solid things, can secure us from the perils arising from a priesthood that, under the guise of spiritual rule, has owned and controlled the thoughtless of all ages.

General principles and philosophy are also a very unsafe guide, and even a dangerous one, if they do not rest upon the safe basis of scientific knowledge and practical observation.

Beside, we cannot understand the spirit of our own time nor choose the right means for achieving our own purposes without a knowledge of the elements of science, industry and social philosophy.

The Church fashioned our old institutions, and as she is the only road to heaven and the saints lived in her early days, so is Latin the only way to human culture and only the ancients were perfect. The modern culture, with its new elements of freedom, industry and commerce, is.the mother of our new schools of science and industry for the masses, 
and their deliverance from ignorance and its thraldom.

It ill becomes the realistic Greek student to charge science with materialistic tendencies. It is through matter the spirit manifests itself. Material elements have often a great moral significance.

What would become of modern civilization if it were deprived of coal, cotton or iron? Industry is to culture and civilization what the body is to the soul.

Industry, far from materializing us, forces us to the study of the laws and relations of nature, her products, the methods of gaining, treating and preparing them for the wants of men, and fosters the knowledge of the laws and conditions of nations with whom we are brought in contact.

There is not an occupation-and if it were breaking stones on the road-but affects ultimately the state and the very constitution of society.

Industry, through the creation of wealth and the distribution of property, becomes the mother of civilization.

Industry is progressive, promotes peace, favors labor-the condition of order-and science-the basis of its progress-as well as the higher arts, which alone satisfy increased wealth.

Schools of science educate us for life and industry. It is hard to say what Latin and Greek edu- 
cate us for. Or are we to take this very uselessness for ideality?

The achievements of science and industry are countless. Every day is marked by some new discovery, be it the compass, the telescope, the spectroscope, the telephone, the power-loom, the steam engine, the locomotive, the sewing machine or the mower and reaper. Chemistry opens the way to the very heart of nature and leads to every profitable manufacture; its elements are the alphabet by which we may read every page in the book of nature. Geology discloses to us the past, as astronomy does the future. What has Latin and Greek to put beside all this? We admit that the very remains of the ancient life of man are imbedded in old linguistic strata, and that the history and development of language are the history of the race and of the human mind. But what has the miserable Latin and Greek of the schools to do with the science of language and its history?

Almost seventy years ago Sidney Smith scourged classical pedants with his caustic wit, and said, they bring us up as if we were all to become village school teachers and spend our lives in declinating nouns and conjugating verbs. They despise the science of things and the knowlcdge of human affairs, and dignify their Latin and Grcek stuff with the name of erudition. 
The learning of a language, beside the vernacular, may bring clearly and distinctly before the mind every idea expressed in human language, assist in clear, exact and vigorous thinking, and develops the highly important power of abstract thought. But all this may be achieved just as well by learning a living language, and even much better than by a dead one.

Once the privileged few sought in school a sort of diplomatic shrewdness; and the impenetrable Latin fog made them appear to the masses like demi-gods. To-day, when the people rule, and private as well as public expenditure is large, something more than mere shrewdness, make-believe and grand phrase-science, that increases and improves production, is looked for in schools.

The masses cannot bend over books. The general fine taste of the Greeks was due to the element of culture in their public institutions; and universal culture among us is only possible if the industries in which we all are engaged assume the character of art and science, and become thereby a school of culture for us all, as public-life was for the Greeks.

Once life was monotonous and the imagination needed a stimulation word-culture afforded. Today life is only too exciting, and nothing but sober science can bestow what is wanted-prosperity, the basis of universal civilization. 
We, too, had for many years neither eyes nor ears for anything but the poetry of the ages and the dreams of philosophy. Arabic and Sanskrit trifles, like Latin, Greek and other literary trash came all in for their share of our attention. And to-day we freely confess, had we less indulged in idle curiosity and literary vanity, but by washing and combing a few forlorn boys, made of them decent members of society, the world would have been the gainer, and we should have lost nothing by it.

Men seem to escape one error only to fall into another. We have no more faith in the jargon of the creeds, but put our trust in the jargon of the schools, and men neglecting to do the good work at their door think to lay the world and civilization under obligation by talking about Arabic and Sanskrit.

Our classical students have much to say about a formal ideal culture and the beautiful. But are these grammatical pedants not notoriously awkward in their taste? And is the genius for art and the beautiful not rather an inspiration than a scholastic acquisition?

Is not the flood of grammatical, archæological, mythological and literary notices accompanying every line of the classics sufficient to destroy all poetic charm? And what can a tyro in the ancient 
languages know of the beauties of an author of whom he has read but a few scraps?

We leave it to the judgment of anybody, what is more apt to develop formal ideal culture, a heap of arbitrary grammatical observations or the study of nature, which is a systematic series of interdependent relations and an organic whole, every part of which is the embodiment of a beautiful law.

Or does the formation of the root, branch, leaf, bud and flower in a plant and its contemplation not contribute as much to the ideal and formal culture of the student as the memorizing of the prefixes and suffixes of declensions and conjugations?

How utterly false is the assertion that the study of the material world is less rich and suggestive than the so-called humanistic studies.

The simplest mineral, beside its physical properties and uses, leads us to the contemplation of its chemical composition and geological relations, and thus carries us back to the past history of the globe.

But when we consider that nothing in the state, religion or life of the ancients; their slavery, gladiators, unmentionable vices, cruel tyrannies, etc. comport with our taste and civilization, can it be wholesome for the heart and mind of the student to attach himself to the classic phrase which, whatever its form may be, is substantially ignoble?

How infinite, rich and real are the laws and ob- 
jects of nature and its kingdoms and their relations to man. What a study, and what an opportunity for culture, for observation, reflection and self-improvement!

Science and industrial schools use nature and the living present as educational means, as the Greeks made use of their own day, who, verily, did not trouble themselves with the grammars and literary remains of a still more remote antiquity.

Mathematics, astronomy, physics and chemistry are said to deal in definite quantities and relations, and the process of reasoning in these branches is too much in a straight line, while in human affairs we must be on the outlook in every direction. But does not the past history of the globe and the formation or upheaval of mountain chains, the formation of seas and rivers, the change of climes, the migration of plants and animals-does not meteorology, does not political economy, the philosophy of history and a host of other highly useful sciences afford infinitely superior instruments for the development and culture of general reasoning than musty Latin and Greek grammars and vocables?

Physical nature is not a stranger to moral relations. Columbus, Copernicus and Newton have by their physical discoveries revolutionized the world of human relations. And Humboldt, Oersted and Darwin have changed the whole tenor of human 
thought in our own day. Watts, Stephenson, Arkwright and Morse have by their discoveries of steam, the railroad, the jenny and the telegraph thrown humanity into an -altogether different mould and created a world of new moral relations.

Science and industry are not by any means purely materialistic, but rather highly humanistic in many of their relations and tendencies.

The wealth and prosperity of nations depend upon their exploring the laws of nature; and the knowledge of the true, beautiful and sublime in nature is wonderfully linked with the useful, aptly remarks Humboldt.

Nothing, says Oersted, is more elevating than the knowledge of the ever-constant laws of nature. Science, says the same savant, a help to industry, leads to work, while a fanciful culture leads man away from his work.

That the classical studies, which are hardly anything else than grammar, cultivate the moral feelings, hardly deserves a refutation; while, certainly, the study and contemplation of the physical universe in more than one way cultivate the finer feelings of man.

Everything, says Guyot, is order and harmony in the universe, because it is the thought of God. This sublime unity in the infinite variety of things is one of the many voices of nature audible to a susceptible heart. 
The collegian may melt into ecstasy at the beauty of a landscape; the scientific student is led by the observation of a pebble or a piece of chalk to a thousand facts and relations past and present, from which he construes a landscape, or an order of things that existed millions of ages ago.

The observation of nature is a school for the senses, which the linguistic student uses but very poorly, so that he can hardly be said to see, hear or smell with correctness.

What stupidity to maintain that we can better form our minds by reading the words of Homer or Sophocles than by reading the eternal thoughts of the infinite Spirit written in flowers, rocks, trees and milky ways! The Iliad is but a syllable-if as much-in the great book of existence.

Not languages, but science, was the password to Plato's academy, over the entrance of which we read the inscription: "Let none ignorant of geometry enter here."

The utter dissimilarity of antiquity has been made an argument in favor of its study by us moderns. We have learned to be surprised at no sophistry. How much nearer the truth is the argument that antiquity being entirely dissimilar to our own world, whatever we learn about it is, for want of analogy or association of ideas, forgotten as soon as we lay the Latin and Greek books aside and enter upon this new, modern world. 
Man is but part of nature, and to know himself and the laws which govern him, he must know nature. To know nature is to know himself.

Prof. Youmans says very significantly, the simplicity in the structural elements and the complexity of the whole in nature as well as in the brain, are such as to make the phenomena of the one the fittest instrument for the development and culture of the other.

What wonder that, as Matthew Arnold confesses, young men at the university exhibit a slackness, a sleep of the mind, a torpor of intellectual life, a dearth of ideas, an indifference to fine culture, a disbelief in its necessity, spreading through the bulk of our highest society and influencing its rising generation.

Train our young men in the love of the race, and teach them what appertains to our own life, culture and happiness and not fragments about Greece and Rome, and their attention will be at tiptoe.

It is too absurd to study Latin and Greek for the sake of understanding English; for, then, we should have to study the Sanskrit and the Zend also, and, with still more reason, the Anglo-Saxon, Old English, the French and the Provençal. But where have we the guarantee for living to an old age sufficiently advanced in which we might perchance get at our own mother tongue? 
Did the Grèeks so study their language? Why, then, should we ours? To know a language is one thing, to know its philology is quite another thing, and as a rule men who know the one are ignorant of the other. The greatest grammarians are the poorest writers, and Homer, Sophocles, Dante, and Shakespeare have written before a grammar or dictionary of their respective languages was in existence.

Political culture, parliamentary eloquence and patriotism, we certainly can derive as well from our own countrymen as from the Greeks and the Romans, who are hardly intelligible to us at a distance of more than two thousand years; and modern nations, like France and England, so much nearer and comprehensible to us, are more instructive because more applicable to our condition, which is not unlike theirs. Or must we go to Greece and Rome to learn to be Americans?

There is unquestionably beauty in the severe simplicity of the works of art of the Greeks, but the immaculate nature of the Greek ideal and its inapproachable excellence and perfection are dogmas akin to those of the old Church and the infallible Pope. The Greeks were no more ideal men than we or any other can be. We all are one or another thing, we are Greeks, French, Germans, English, Americans, etc., and ideal men exist only in the imagination. 
The world has not stood still in art no more than in any other thing, and poetry, sculpture, painting. and architecture have advanced beyond what they were in ancient Greece, nothwithstanding the assurance of men who would make us believe the ancients were infallible and immaculate in art and in matters of church and religion.

But let us look a little closer at this would-be ideal world of the ancients, to which we so anxiously send our sons and daughters for examples. Let us look at Athens with its narrow, filthy streets, mean dwellings, public halls and temples. Slaves meet us at every step, the temples are reeking with the blood of victims, the state is filled with party strife, revolutions follow as fast upon one another as thick clouds in stormy weather; the great patriots are rewarded with ingratitude; the party that wins murders the party that loses, and plunders it ; the sweetness and sacredness of quiet family life is hardly known, neither the amenities of modern life ; newspapers, picture galleries, or our quiet places of amusements are not known; boxing, prizefighting and the like pleasures, are national; war is almost incessant, and the taxes are very high. In Rome the abominable combats with wild beasts or men in the arena of the colosseum are the great delight. Education is left to the slaves; public information is at a low ebb; industry supplies but poorly the 
wants of men; a well-regulated state or religion is not known; superstition reigns supreme, and the flight of birds and the mutterings of an epileptic priest decide the most important political events involving the existence of the state.

It is hard for us to emancipate ourselves from the old Catholic superstition, that there is no soundness in us, and that truth and beauty lived and died with the ancients, though the masses were slaves and women were treated not much better, and infants worse. Strangers were called barbarians, and on all possible occasions sold into slavery. There was but little humanity in the general arrangements at Athens and Rome. National pride and barbarity exen rose to the bloody infamy of human sacrifices. Passion and ambition did not recoil from civil war and oppression, and rich as well as poor were corrupt and venal. And from the literature of such nations our sons and daughters are to learn humanity and ideal culture?

If there is any such ideal in their literature, the tyro, bewildered with the ten thousand difficulties besetting the reading of a language dead for two thousand years, cannot find it.

Does any one seriously contemplate that nature, painting, lithographs, and drawing cannot develop our asthetic powers and fill the place of heathen mythology? If the gods of Olympus were really 
so potent, we ought to recall them by all means, and become pagans again.

Modern nations need not go for patriots and statesmen to Rome, with its bloody Cæsars, or to Athens, with its demagogues.

But even if antiquity had unequalled politicians and historians, they would naturally be beyond the comprehension of youngsters, and would, therefore, be without educational value to us.

Homer, Sophocles, Thucydides, Cicero, Virgil, Horace and Tacitus have not written for youths, who, not penetrating them, cannot be improved by excellencies which are beyond their mental reach.

As far as composition is concerned, our modern languages, so easily learned and so useful in mapy regards-at least the French, Italian, German and English-are as grand and spirited, and certainly as logical and perspicuous as Latin or Greek.

The shallow cosmopolitan indifference that underates national pride and honor is the forerunner of national corruption and decay. One of the great duties of public Education is to strengthen and elevate the national feeling and love of country, and to foster the better genius of the nation.

A thorough acquaintance with the English language, its poets, historians and philosophers, would far more benefit us than the present Latin and Greek pretense. 
Modern nations have poets equal to any of antiquity, and, certainly, historians and philosophers; but their scientific writers and thinkers are unquestionably more exact and solid than any Greece or Rome had produced, and these modern languages and literatures are infinitely richer in productions and are more applicable to educational purposes than the languages of antiquity.

The antique state was despotic, whatever its form was. With modern nations freedom of the individual and organic development are foundation principles of civilization, and these we best promote by the study of great modern authors.

The great Vico deprecates the influence of the ancient poets on the passions. Their heroes are not only without humanity, but even without manliness. Agamemnon pierces his unfortunate suppliant with his spear, and setting his foot upon his body pulled it out. Hector drags through the dust dead Patrocles, as Achilles does Hector; and the Greeks are represented, one after another, stabbing the dead remains of the latter hero. Sovereigns are massacred and their bodies left a prey to dogs and vultures; sucking infants are dashed against the pavement, and ladies of highest rank are made to perform the lowest acts of slavery. Blood, fraud and meanest cowardice are the features of Homer's brutal heroes. Murder is no sin with Homer, 
neither fraud degrading, nor cowardly skulking before superior strength unbefitting his heroes, who, being cruel and inhuman, are not truly heroic, though eminent for savagery.

Hecuba, in Euripides, is chained like a dog to Agamemnon's gate. Prometheus, in Aschylus, is fastened by a chain, nailed one end to a rock, and the other end to his breast bone. In the Electra of Sophocles a woman is represented murdered by her children. In the tragedy of Alcestis, Admetus insists upon his beloved wife to die for him, and scolds his father indecently to do the same thing.

With such brutal and cowardly acts these writers are teeming, and they are held up to us as our models. What wonder, then, that there is so little moral progress among us!

We do not like to lift the veil from what is most reprehensible in the life and writings of the ancients. Their bordering on the brute state of man may be taken for an apology for that; but they must not be forced upon us as patterns. We may cut out all the passages in which that animalism appears in all its nudity; still, should we clear the classics of all that springs from that spirit, little would be left, and, hence, we protest against the idolatry made of the classics.

So coarse and indelicate were the Romans that 
whipping was a punishment inflicted on even high officers in the army.

To live by plunder was held honorable among the Greeks; for it was their opinion that the rules of justice are not intended for the restriction of the powerful. The policy of the Greeks and Romans in war was to weaken a state by plundering its territory and destroying its people.

The Romans eternally warred upon other nations. Let us take Lucullus' behavior toward Cauca, a city he attacked, for it is but an illustration of other similar acts. They surrendered upon his promise to garrison them for their own protection. Instead of which he enriched himself by plundering the city, leaving 20,000 dead upon the spot. Cæsar, Pompey, Crassus, and all the other Romans were men of rapacity and lust; and as their deeds are learned by our youths in an old and difficult tongue they fall deep into the soul and form their hearts and minds upon these execrable models, and, hence, our cruel disregard for the victims of our greed.

When we consider men, such as Sir Robert Peel, Lord Brougham or Ashley, and their life-long labors in the British Parliament in behalf of the working people, does it not seem as if the genius of humanity and industry presides over us to-day, and that under its inspirations the rising generation would make better men, than under the influence 
of rapacious Rome or cruel Greece? It may be well for the man to know what was practiced at Greece, Rome or somewhere else; but must we, therefore, make the minds of our susceptible youths the sinks of execrable wickedness?

We belie, degrade and render weak and inefficient our modern standard of moral excellency, which is a pure spiritualism, by making our models in Education the ancients, the life and soul of whom are rapacity, power, lust, deep dissimulation-as bloody Cæsar playing democrat or Cicero augur, consulting mice and chickens on mighty affairs of state-and a sensuousness bordering on pure animalism.

Let none think that the intellectual culture, generally derived from the study of the classics, outweighs the moral disadvantages; for, if we take the results of the inquiry of the Royal Commission on Education of Great Britain, a most insignificant minority of the students of the best colleges of England are at all profited by their Latin and Greek. "The number of well taught classical scholars at the university notoriously form a small proportion." "Very few coming from Christ Church, Oxford, to the university can construe accurately in Latin or Greek a piece from an author they have studied. It would be useless to try them with a new passage, a test they could not stand at all." 
Dr. Fitch says before the British Association for Social Science: "Of the many who have studied Latin, how many of them ever open a Latin book? How many have caught the spirit of ancient Roman life or polity, or acquired an insight into Roman literature, or have a trace of their schoolLatin left on their minds and opinions?

"The study of the classics usually ceases before the student begins to profit by it, and is, therefore, utterly useless. It is like mounting up a steep hill, and then stop outside the temple on the summit."

"The study of the classics comes in far too many cases to absolutely nothing; that it rather deadens than awakens thought; that it stimulates no literary appetite, and that it is not even indirectly helpful in enabling the pupil to write his own language with fluency and grace." Mr. Fitch, speaking before the British Association in this manner, is recognized by this most learned body as a man of great authority and experience in Education, having been the principal of eminent training colleges and holding the position of one of Her Majesty's Inspectors of Schools.

Dr. Hey gives his testimony as to the many hopeless youths sacrificed in the Latin schools to the hopeful few for the sake of making a good verse maker.

The royal commission and the witnesses brought 
before them, though all classical men, admit " The public Latin schools send out the ablest scholars and also the idlest and most ignorant men." "Of the time spent at the Latin schools by the generality of boys much is absolutely thrown away, etc." "With a great mass of men it takes them to twenty or twenty-one to construe a Latin and Greek book they have studied already at school, to master three books in Euclid and to solve a quadratic equation."

But, notwithstanding these unwilling confessions, the very able men of the Royal Commission on Education are statesmen, and as long as the domineering spirit and the diplomatic ability of prelates, nobles and kings are to be trained, for such work the schools of the Cæsars and of the Athenian oligarchs are by their nature most fit, and, hence, their high encomiums upon Latin and Greek for the high classes in society.

We see the impediment to progress in so many symbols as there are words in the Chinese language, which the scholar has to learn before he can give himself up to the acquisition of valuable knowledge. But is our devoting years to Greek and Latin grammar any less retarding us in our progress?

The question has often been propounded before, why do men so rarely continue their Education 
and self-improvement on leaving school? Our answer is, because during their school years their brain powers or molecules have been absorbed by the impressions of useless things forced upon their attention, and on their entering the world things can make but a dull impression on minds scribbled all over. Teach children what has a bearing on their future occupation, and it will turn up in their mind with freshness; it will shed light on and deepen similar impressions and ideas, and form between them all possible interconnections of cause and effect, setting them thus to think and improve and educate them through life.

Admitting the Greeks and Romans were the first in civilization in the order of time; must we, on that account, waste our years on them? Must we ride on a $\log$ because this was the shape and nature of the original wagon before the wheel-not to speak of steam-was invented?

Much of what we advance has been said before us by Locke, Vico, Lord Kames, Korner and others, but is not less true for that, and will be repeated after us until it is profitably applied by the schools.

Has there no progress been made in civilization, or the art of thinking and writing? If the hundred generations of philosophers since the days of Greece and Rome-for every generation has its philoso- 
phers-have not sufficiently improved upon one another in that long stretch of time so as to lose out of sight in the gloom of the past Greece and Rome, pity man and his poor capacity. He better give up at once the futile attempt of ever learning or knowing anything and set about eating grass like any other.ox.

Hosanna! it resounds from all over the land, great is the goddess Diana! Let pedagogues moderate their shoutings and their fears, our railings will injure neither the goddess nor their trade, for, if peradventure we have said anything sensible, the crowd will be sure not to mind it.

THE PROPER EMPLOYMENT OF TIME.

We do not trust business transactions to the unaided memory; why, then, should the golden sands of life be allowed to run down without a daily and hourly account? Time, says our immortal Franklin, is not short, but poorly managed. The relations of life are too multifarious to be properly attended to if left at loose ends. Self-knowledge, so material to self-improvement, requires an exact account with ourselves, and the sages of all ages, down to Bacon, Montaigne and our own Franklin, have all insisted upon managing our time and keeping a systematic journal, in which we render account of our hours and very minutes. 
Such an account will keep us in mind that our life is not wholly our own, but belongs to the race. Our cash account does not add to our cash-the account of our inner life is a most valuable addition to our spiritual capital. We keep strict account of our means and let the power that creates them float away unheeded. A continual watch over our thoughts, desires and actions will grow into a spontaneous self-control, until, in the course of ages, action, reflection and self-control will be one and inseparable in the race.

A strict training to a steady and regular employment of time is an excellent means for the formation of habits which, growing functionally and organic, become in the end unmistakable features of the race.

Only through the close observation of the selfrecorded thoughts and feelings of ages will we attain a veritable mental science, which is alike indispensable for a correct Education, the treatment of criminals and the insane, the government of men by laws, and for a proper conduct in life.

To record honestly, therefore, our inner life, is to lay a foundation, without which every science of man, his life, actions and happiness is impossible.

The slow moral progress is a sad riddle to many. But does improvement in morals not mean improvement in self-government? And how can we 
improve in this, if we do not improve in self-knowledge by kecping a steady watch over the employment of our time, life and actions.

\section{MEN, WOMEN AND THEIR SPHERES.}

The preservation of the race being the end of Education, man, as the natural provider of the family, must be industrially educated; and woman, the mother of the race and the guardian of the family, must be brought up with a view to these her natural functions, which are to-day sacrificed in a most pernicious manner-both in school as well as in the factory-to the most material injury of the race. Life is much shorter in districts with textile industries, where women work, as a rule, in factories; and our daughters, who are put through the higher course of studies in our seminaries and high schools, do not, as a rule, enjoy the good health their mothers did.

Forgetting that language is as often the medium of error or falsehood as of truth, we make reading, writing and speaking the whole of Education. We ought to remember that the art of reading and writing is not culture, it is the mere opportunity for it, and is often unused and forgotten by the masses after they have acquired it. The aim of popular Education must be something higher and more substantial. Next to the preservation and 
improvement of the race, the chiefest care of Education must be industry, which alone can lead to universal culture and the reign of eternal truth and justice, or the kingdom of God upon earth.

INDUSTRY, HEALTH, COMFORT AND HAPPINESS.

Industry must take the place of sloth and idleness-the fountain head of pauperism and all the hellish brood at its heel-and the satisfaction arising from an intelligent and well-ordered activity must banish the unhealthy craving after low pleasures with their demoralizing effects upon individuals and communities.

The preservation of the race being the true end of Education, the comfort, health and happiness of the individual must be all secured, and, hence, the science of life must take the place of the empty formalism of word teaching. Food; fabrics, houses, windows, stoves, and the bearings of the like things upon human health and happiness, are matters falling under the observation of the senses, plain to the young understanding, and are best suited to prepare for further scientific knowledge and practical work.

\section{THE SCIENCE OF THINGS.}

The science of things and common sense must be brought to bear upon the health and comfort of 
the individual, and our elementary course of instruction must be made as full of things as it has hitherto been full of words.

The effort scientific England is making to lift up the masses to a higher level of culture and wellbeing through spreading among them the rudiments of a scientific knowledge of the things of life, art and industry, industrial training, cheap publications, art, industrial and economical museums, command our attention, and exhort us to enter with like earnestness upon the same work.

French, piano, dancing-masters, and the semibarbarous, haughty and disgusting airs of ridiculous vanity notwithstanding, as far as solid excellency is concerned and the things leading to usefulness, efficiency, health, comfort, goodness and happiness, not the first step has as yet been taken in raising man rightly; and yet this is the highest work of the state as well as of the family.

We grow, of course, by the law of nature and by necessity; but man ought to be his own maker, and the state ought to ba a providence shaping man to a noble purpose. There is nothing greater nor more divinely beautiful than a noble man or woman, and the time will come and is even near at hand, when a child from the cradle to full maturity will be physically, morally, intellectually and industrially the tender care of the state as well as of the family. 
If the system we propose is utilitarian, our principle of utility is of the highest order, referring, as it does, to the preservation and improvement of the race. To-day, alas! we make money, and unmake man; but we shall soon find out that even in the material order of things the making of man must precede the making of money. An efficient industry requires health and science, and a prosperous commerce is impossible without confidence and honesty, which rest upon a universal moral consciousness.

\section{THE CULTIVATION OF ALTRUISM.}

We may daily hear in the shops or read in the works of philosophers that old prejudices are dying away and new ideas are acquired, but society is not improved. Still, John Stuart Mill adds in his memoirs, this cannot be due to the unalterable disposition or nature of man. For just as well as Education, habit and public opinion make men willing to fight and die for the state, they can also be disposed to work for the good of society.

Race Education as a whole and a system replacing selfish individualism by an altruistic disposition rendered hereditary by the training of generations, will ultimately save humanity from the miseries and troubles of the present fratricial struggle, and mitigates the want and the sufferings 
338 Laborers Must Make their Own Market.

of the masses of to-day by insisting upon a varied industrial training as one of the chief elements in the Education of the people.

LABORERS MUST MAKE THEIR OWN MARKET.

The connection between ever-recurring stagnations of trade and the uncertainties of foreign commerce has long been noticed, but the deeper and more universal cause of the restriction of the home market, and its possible removal, have hitherto escaped economists. The producing masses living in large cities have no means left for purchasing manufactured articles, rent and provisions consuming their wages. With our present powers of locomotion, this difficulty can be surmounted, and the excess of the mischief of city life in every other direction, as life, health and Education, will soon force us to seek relief from these and other troubles in suburban residence.

The reader may suspect us of forgetting that we are writing about Education, as we obviously lose sight altogether of Latin, Greek, grammar, stumpspeaking and the like school accomplishments of the present day, considering, as we do, mainly the housing, clothing and feeding of the people, their health and decent living, all of which being achieved not so much by each striving for himself as for humanity, we leave refinement and culture to take 
care of themselves. To this we plead guilty, but hope for an honorable acquittal at the bar of the future.

The present movement of the population toward large cities gives ascendency to deteriorating tendencies, and is an important question of civilization.

For, if the people are not sound in body, neither can they be sound in mind, government, or politics. Corrupt blood necessarily produces corrupt morals and institutions. The hectic flush of a consumptive people is apt to repeat itself in the appearance of the state and government, as private madness is apt to end in public folly, and private suicides in civil war, in which a nation ends its own life.

All great statesmen, writers and economists agree that nothing is more apt to lay a firm foundation for social order and conservative interests in a society of democratic tendencies than a multitude of small property owners, in whom the state is always certain to find the element of order and the spirit of industry and peace. This system of small properties, introduced by Napoleon in France and wherever his arms proved victorious, has been long on trial; and the economy, the prudence, the industry, the order it spreads, have everywhere brought it in favor. The wildest revolutionary elements of the large cities of France have been 


\section{$340^{\circ}$ Laborers Must Make their Own Market.}

unavailing against it; and in this republic, too, nothing but a solid wall of small industrial property owners will secure the peace of society.

Capitalists will find it as well to their advantage as to the advantage of the laborers to locate in the country. And how vastly preferable is to the young the companionship of nature with her sublimities and beauties to the dense city with its crowded lanes and squalid abodes-nurseries of meanness, vice and crime.

Capital, labor, human life, government and civilization would not only be great gainers by the industrial classes domiciling themselves on the lands surrounding our large cities, but their very existence imperatively demands it, as the moral poison engendered where great masses of population concentrate, is positively destructive to the social health of society.

The city breeds moral, social, economical and political pests and is the hearth of general disorder. Vice, crime and corruption among high and low are at home there. Close contact between the rich and opulent and the poor and the miserable, fills the latter with bitterness, which ends in strikes and agrarian disorders. Matrimonial bonds, recklessly formed by the hopeless laborer, swell the population beyond reason. Then come the pests, crowding breeds, which are more destructive, be- 
cause more constant than the pests of the Middle Ages. In three generations the city laborers are swept away with nothing left behind them but plenty of graves, showing by their small size that their occupants had but few days here, and these full of misery. The country population fills the gap, to be soon swept away like those of whom they took the place. And thus the moloch of the city devours the children of the land, until all health is gone. In the moral confusion attending such social corruption the turbulent and the ambitious soon find their account, and the government proves as short-lived as the people.

The country gives the laborer a home; it gives him plenty of heaven's pure air, light, pleasure, sensibility, happiness, contentment, health, energy. and peace and good-will. It gives him stability, character and efficiency, and personal consideration. In the city he dies from want of all this. His heart fills, therefore, with bitterness. He is a houseless, forlorn vagabond, full of unrest and unstable, without property, a home or anything to live for or to' look forward to and hope for. He feels as an outcast, an Ishmael, with everybody's hand against him, and his hand is, therefore, against everybody.

An intelligent and industrious people, with our vast country for our home, under the sweet influences of green fields and the smiles of the wide 


\section{Laborers Must Make their Own Market.}

heavens upon us, our future might be as long as God's own years; but double our tenement population and we perish. Still, how is it with London, Paris, Berlin, Vienna and the like cities? Well, they are hotbeds of revolution, burning craters watched by half a million of soldiers, whose organizations can only be kept up by an occasional war costing the trifle of a half a milliard.

But what has all this to do with Education? Simply this, that with a tenement population the Education of the heart, mind and morals is absolutely impossible.

A healthy community is impossible without the union of the schoolhouse, the home and the workshop, symbolical of the head, heart and stomach of which they have respectively to take care.

The sacredness of human life is the ethical aspect of Education, the natural function of which we have shown to be self-preservation.

The bloody strife has but been transferred from the battle-field to the exchange, but the victims are as vitally affected in the one case as in the other. If common laborers are not sure of their to-morrow's bread, capitalists are no more safe nor spared; though with them it may be a matter of months or of a few years. According to mercantile statistics but 5 merchants in 100 in Boston, 4 in 100 in New York City and 3 in 100 in Philadelphia succeed in business. 
The fact iș, modern life has not as yet accommodated itself to the great revolution of our grand industry working with steam and machinery.

The new system requires manufacturing on the largest scale for the largest market. Cheap manufacturing alone does not answer; for, when wages are very low, the masses cannot be consumers of articles of manufacture; business comes, therefore, to a standstill and a deadly stagnation follows.

As international commerce has taught us that the prosperity of neighboring nations is indispensable to our own national success, so does the necessity of a home market teach us the necessity of caring for the prosperity of our own people.

Nothing but a thorough industrial Education and understanding of the economical interests of society can lead to the necessary union between labor and capital, and give peace and prosperity to the present. disturbed and suffering industrial world.

As machinery is expensive, rapidly wearing out and liable to be superseded by mechanical improvements, it must be used to its full power, especially as the additional cost is not at all in proportion to the increased production, and, hence, the tendency to over-production, over-trading, financial crises, business stagnations and want of employment. But even in times of prosperity the usual trades cannot afford to pay for the labor of one man wages suf- 


\section{Laborers Must Make their Own Market.}

ficient to buy for his family bread, meat, lard, butter, milk, vegetables, clothing, to pay his house rent, incidental house expenses and insure him against sickness and death. It is evident a man must have all this ; still his claim upon it is not a question of right, but of fact. Docs he produce it? he certainly does not. Communism, socialism or co-operation do not solve this problem, which becomes more troublesome daily with the increase of improved machinery, the increase of population and the decrease of real wages. To our mind there is but one solution of the social question arising from the new condition of things, which is, in proportion as the increase of improved machinery supersedes human exertions, man must employ his labor more upon the soil, in which rooted, he will like a firm tree weather every storm. Every workman must have his house and his acre, he must raise his meat, his milk, his butter, his vegetables, live rent free, and with his factory labor he must provide for all other family wants. There is hope and encouragement in the acquisition of a homestead. A man should not be paralyzed by the fear of houseless misery, neither should all his wants be secured to him without the full display of his energies in his daily labor. The rendition of man to the soil removes a thousand complications.

Unscrupulous demagogues incite the masses to 
claim the share due to capital. Thoughtless capitalists propose no remedy, and call upon the armed power to put down the strikers who, of course, have no right to disturb the public peace. But hunger does not stand upon right, it asks for bread. Meanwhile riot upon riot demoralizes the people, class is arrayed against class, and anarchy and despotism are growing upon us until at last we cannot sleep in peace without an- army standing watch over us, and industry is ground between the upper stone or a standing army and the nether stone or the starving masses, and the expenses in which they involve the state in a thousand ways. To some there may be no problem in our present social condition; bayonets and starvation will mellow down the work-people to work at half starvation wages. But if the masses are half starved, who are to be our customers? and a system of labor which converted the people into a herd of vicious criminals and incendiaries is dear at any rate. We must improve the condition of the masses, for with them we live or sink in the end. Whatever assists the people in moving from the city to the country and aids them in acquiring homes there, contributes to the health, peace and prosperity of society, and spreads a healthy civilization.

We have been driven to the conclusion, as machinery supersedes human hands, labor must employ I 5 * 
346 Laborers Must Make their Own Market.

itself on the soil ; but this is but half and perhaps the lesser half of the truth, the more important part is, as the production of our material wants needs less labor, more labor will be bestowed upon man himself and upon his Education, and as this will be better understood, the blessings of machinery will be more appreciated. The fewer hands are needed for the production of articles of comfort, the more and the longer can children be left to the school and its humanizing influences, and the more can woman devote herself in the school and the family to the work of Education, fitting humanity for peace, for order, for love and for happiness; and the more can be shortened the hours of labor and manly toil mingle with study and contemplation.

We dwell here only upon physical deterioration and its effect upon morals. But the action of every mental and moral power and faculty oscillates between extremes, and, hence, the constant tendency toward aberration from the perfect and the danger of mental and moral deterioration.

At one phase of civilization the reason and conscience of the age are all in a torpor; at another, the one is all subtlety and the other sensitive to morbidity. And even at the same age all phases of civilization are simultaneously produced in people living in different conditions. 
Laborers Must Make their Own Market. 347

One end of society living in want of everything inclines to brutality, while the other end living in luxury runs into effeminacy leading to corruption of another sort.

The animalism of the masses must be corrected by the application of science to the common occupations of life, and the effeminacy of the over-refined must be overcome by the association of physical labor and exercise with intellectual culture; for reason and the senses are correctives of one another, and must prevent the brutality of barbarism and the corruption of over-refinement; and, hence, we see the necessity of combining science and industrial pursuits with the customary branches of Education as the correctives of the respective vices of the classes which occupy the opposite extremes in society.

Disparaging these opposite vicious tendencies, and favoring science and genuine culture, we discard but scholastic verbalism, as out of time and place in the industrial world of to-day.

The struggle for existence is as inexorable a factor in society as it is in nature, and that Education is, therefore, the best which, increasing the bread-winning capacity of the masses, sustains them in that struggle and gives them a chance under the law of the survival of the fittest: and that, Industrial Education alone can accomplish. 


\section{PART SIXTH.}

THE PEOPLE AND THEIR HOMES.

As the homes are so are the people, is an adage Race Education cannot afford to overlook. The shell is no more part of the oyster than the home is part of the man, who is more made by his home than his home by him. What light and heat are to the plant, home is to man. As climatic influences modify organic forms, so does home, the climate of man, ever modify man and his faculties.

The plant is no more rooted in the soil than man is. Myriads of ages man has wandered in the forests and green fields under the sweet influences of the azure sky, and their presence is to him health and strength. This ocean of light and beauty streaming into the eye is the quickening power of the life and activity of the brain and the nervous system, to which it is what the vivifying air is to the blood. Death and disease, like vice and crime and every other poison, ripen in the shade, and are in very deed the work of darkness. Place man in his correct relation to nature, and every possible (348) 
discord disappears from the individual and collective life of man.

The country is man's natural home. In the city his health deteriorates and his intellect degenerates by lack or excess of mental exercise; luxury or want debases his morals; politically he is made the dupe of demagogues or is enslaved by tyrants; his life is shortened, his very type is lowered, until within a few generations the stock itself becomes extinct.

What disadvantages attach to the homes, or rather barracks, of the masses in the city, which are insalubrious in respect to light, heat, air, dampness, soil, construction and surroundings, besides the effect of fearful crowding, deadly competition, temptations to vice and crime, evil associations, causes and opportunities for envy, hate and strife, while in the country all the elements and surroundings contribute to strengthen and invigorate man for his work and his duties, everything calming his passions and supporting his reason.

We hold with the old tradition that man is not made to become Godlike in knowledge, but to work the ground; and this command to cultivate the earth of which we are taken-which nurses us and to which we return-is binding alike upon princes, poets, tailors or presidents. We are all better off by complying with it, and invariably suffer for disobeying it. 
Every school should cultivate a taste for agriculture as well as for the mechanic arts. An hour or two daily devoted to the cultivation of a garden patch will add to our effectiveness in our calling by improving our health of body and soul, by enlivening us through change of labor or exercise, and by bringing us into a more living sympathy with nature, and the great masses, whose whole life is devoted to the cultivation of the ground.

It has been well observed that as development in the organic world depends, according to Darwin, on variability and permanency in the genesis of forms, so is social improvement conditioned by legality and progress or conservatism and reformwhich are in the political world, what the centripetal and centrifugal forces are in the cosmos, and of which the one would end in the rigidity of death while the other would bring infinite division and atomic isolation.

The city represents change and reform. The individual is driven from position to position by a mass of events he cannot control. -We are changed and carried away by a whirlwind of events. We hardly can collect ourselves or assimilate facts and experience into elements of internal growth, character and a harmonious individuality.

The country is conservative. There man can master the impressions which rush in upon him 
with less impetuosity; and as they are coming less from the heated strife of an artificial world and more from objects of nature, their effect upon man is invigorating and less apt to incline him to feverish activity.

Organization, stability and law were of the greatest necessity, when in the infancy of the race communities were forming, and, hence, the agricultural state in which the legal and conservative spirit predominates was then most conducive to human civilization. After men have become orderloving, cities best serve the cause of civilization, by bringing life, motion and progress into human affairs. The present system of manufacture causes a steady rush into already populous cities, and disturbs the balance between the two principles of permanence and reform, represented by country and city, the union of which our means of communication render feasible, as the space our dwellings spread over becomes daily a matter of less importance, as we annihilate it by the power of steam. By associating the conditions of city and country life, we unite the progressive tendencies of the one with the conservative of the other, and thus keep up a healthy social development, while the country alone leads to death through stagnation, and the city through revolution to anarchy and dissolution.

Freedom is the chief element of man's moral 
nature. But freedom is a fiction without power which property of some sort or other bestows. There is hardly manhood or dignity without as much property as will give a man standing room in the world. Property is, therefore, a moral necessity. In the Middle Ages, when the feudal lords owned the land, the industries in the cities gave the people a moral existence by giving them an opportunity to achieve property. To-day, when the manufacturing interests in the cities are owned by our industrial lords, the people must acquire homes and property in the country or become again penniless vagabonds without moral or political existence, the slaves of a regime more powerful than any of the past.

Manufacturing in large cities must give way to manufacturing all over the country, or the deterioration arising from trade diseases, combined with the deterioration peculiar to crowded cities, will degenerate humanity. And this putting side by side the manufacturer and the agriculturist, or the cotton and wool raiser with the spinner and weaver, is the solution of many a troublesome problem in social philosophy. For it decreases the machinery of transporting raw material and manufactured goods and turns men and capital engaged in the carrying trade into manufacturing, which is enlarged, while commerce, speculation, bank operations, panics- 
always springing up from the latter or sudden calling in of credit-business stagnations and public distress will be lessened.

Land without men and men without land are equally valueless. Combined they enhance each other's value. In proportion as men crowd into small areas, the land reaches a fabulous figure and a man's worth falls below that of the brute.

Let men spread all over the land, and the value of both will be equally enhanced. Henry C. Carey says with much truth, by this law alone we can escape the miseries and not far-off revolutions of England, the civilization of which is the last an honest republic would try to install. Not foreign commerce, but home trade and manufacture we must enlarge; the first is full of danger and uncertainties, the latter is safe and reliable. A country with resources sufficient for the support of $200 \mathrm{mil}$ lions population can grandly prosper-on the internal trade and manufacture of an industrial population of fifty millions.

England, not as large as many a one of our forty states, and with colonies all over the globe, seeks above all, foreign commerce; and its economists pretend to favor this course upon scientific principles. But a glance at the condition of England shows that foreign commerce carried on to excess is a curse to any nation. 
According to a late competent observer the elite of skilled mechanics in England, by rigid economy, may manage to subsist in tolerable comfort, though not without the wolf growling audibly at the door.

Next rank the wages of the skilled craftsman. After supplying him with clothes and shelter, they leave him about half enough to eat. Half-starved clerks may be ranked with this class.

Farm laborers, porters and the regular employees of commerce, systematically famish upon their wages.

Next comes the job laborer, who fasts when he can get work, and starves when he is without it.

Lower yet is the shop girl, on duty fifteen hours a day, for a pittance inadequate to the supply of her necessary wants-the seamstress earning four shillings a week, slowly dying of over-work and privation-and the servant girl to whom is doled out a shilling a week and one hour recreation once a fortnight.

Lower still are millions without regular work, or home, or food, hopeless, starving, dying-literally dying upon doorsteps, where they have crowded for shelter under hedges, where they have lain down from the wind; upon heaps of ordure, where they have groveled for the warmth derived from the reeking exhalations. The cities of England are crowded with this unhappy class of beings. They 
meet the eye upon every street-too numerous to attract attention or sympathy.

Thus the very élite of labor in England is faminepinched and hunger-driven. Millions pine, hopeless, joyless, slowly famishing upon wages insufficient for subsistence, and the homeless outcasts of the cities perish for want of employment.

With such a certificate from the famishing masses of England, we must be excused if, without giving here any further reasons, we prefer our American system to the commercial system of England, in which there is no more science than in the lion on the British flag.

We dwell on the economical aspects of homes and dwellings, for whatever produces wealth produces health and strength and civilization, and whatever destroys wealth destroys life and health, and spreads all the evils attending barbarism.

There is no more powerful agency than home. Schools and compulsory laws are of no effect without it, and whatever undermines it must be put down as most hostile to the cause of civilization.

Expensiveness of living in large towns makes pregnant mothers overwork themselves to the very hour of delivery, the result of which in the newlyborn child is marasmus - constitutional weaknessthe natural disease of the higher stages of old age. The same cause necessitates them to work in fac- 
torics and to deprive their infants of their most natural food-the mother's milk-through which they fall tenfold a prey to disease and death.

The same expensiveness of living in large towns forces mothers to go out to work and leave their little ones locked up in an empty room where brutal isolation trains them to idiocy.

This same expensiveness of living in large towns which has forced the mothers to leave their home for the factory, forces children to leave the school for the same place, and thus deprives the masses of their Education and the means of bettering their condition. Worse than all this, a home without a wife, without children, without any attractiveness, in which hardly anything but misery, death and - disease are bred, make the family burdensome to men and women who, shunning such a state, avoid marriage and live in all sorts of vicious indulgences, ending in crime and corruption and the dissolution of society. All this may be of no moment to some men, but the expensiveness of living in large towns absorbs all the earnings of the work-people for bare bread and shelter, and leaves them no means for procuring articles of manufacture. This, too, may be of no importance to some. But when the masses do not buy, the small traders do not sell. This looks a little more serious and assumes its full importance when we consider that, if the retailers do 
not sell, neither can they buy, nor can the wholesale man sell or the factory manufacture, and, hence, misery and stagnation overtake all classes.

The masses may be the lowest and least noticeable portion of the community, but it is also the foundation of the whole structure and the pyramid of society, which tumbles into the dust when its broad basis is withdrawn.

There is not a consideration of health, life or death, of Education, morals, government or economics but is in favor of workmen's homes in the country. But facts speak louder than arguments, and we shall turn our attention to them, as we are convinced that we serve best the cause of Education by urging homes for the people. For, if the people have good homes-if they have schools or not-they have the best part of a good Education anyhow; while, if they have no homes, the best schools are but whited sepulchres full of dead bones.

To illustrate the condition of the people and their dwellings in populous factory towns, we need not cross the ocean. Writing in the midst of a city of over half a million of tenement population we are surrounded by misery appalling in degree and frightful in extent; but as our responsibility for what of this sort is happening right at our door is blinding us to the condition of the homes of our people, we shall at first transfer our social studies to 
a more remote scene, where we can afford to be more impartial witnesses of events-to France and England-countries ahead of all others in manufacturing, and which may serve us as a warning, as in proportion as we adopt their system the same results will follow, and which, perhaps, has already transpired to an extent we are unwilling to admit.

A study of the industrial classes in France shows them in the smaller towns pleasantly located in neat houses, with savings in proportion to wages. In large cities, where the houses are unpleasant and the family is anything but attractive, higher wages bring only dissipation. Of 12 to 15 children, 3 to 4 survive. In Rouen, of 3,000 children, 1,100 die before the expiration of the first year. Most of the children of the factory people are farmed out, and 83 of 100 are left to die from starvation. Expensiveness of living forces the mother to go to the factory as well as the father, where they both work long and hard; the children, neglected and suffering, die, leaving but few, and they are crippled and puny, to the dissatisfaction of the grumbling conscription officer, who feels himself cheated out of his recruits. Here, as in all great centres of industry, dwellings are poor, and, consequently, drunkenness, misery and the ravages of licentiousness eat up the people.

The alleys, houses, rooms and furniture are filthy 
and miserable beyond description, left most of the time to the neglected little savages, the mother having neither time nor strength left to clean, wash or sweep, cook, or feed her little ones. She can do nothing for her family, neither can she take an interest in it nor be a companion to her husband, who, coming home, finds nothing but filth most repulsive, insufficient and poor food, children he hardly knows, and a woman work and misery have reduced to a veritable slave. And what of the children during all the day? There is not an hour of affection or joyous childhood for them. The dingy home, the factory, the hospital and the grave are all of life, and the last is the best.

The child of six is kept home partly from weakness and partly to take care of two, three or four little crying children. The school may keep some of the children five to six hours, but, of course, the parents stay away twice as long. The women can neither sew, mend, knit or do any housework. Not half the work-people, when their children are sickwhich is only too often the case-have moncy for bedding, food, medicine, or even fire. The physicians say in half of the cases good food is all that is needed, but they dare not tell it to the family who have not the means.

And yet all this misery is as nothing. This want of bread, these rags, these dingy, dark and damp, 
chilly, miserable chambers and cellars or garretrooms, and even loathsome diseases and burning fevers, they are as nothing compared to the souldevouring poison that grows in such foulness. Hardened by misery they are used to and know not how to escape, fathers spend their nights in drinking places, while their children die with hunger, mothers become indifferent to the vices of their daughters and act as their confidants and counsellors in prostitution, and neither father nor mother incline to save their children from the perdition which threatens them.

The mortality of Rouen-as in other industrial centres-is simply murderous. Devilliers shows that of 100 children the best situated citizens lose 10 under the age of I year, the work people lose 35 ! Of the children farmed out by the factory people, 90 in 100 die in the first year in most of the departments of France. In Eure-de-Loire 95 of 100 die. Of 27,219 children in this department 8,037 died within one year. There were 1,389 illegitimate children, of whom I,333 died after one year (I862). In the asylum of Loire-Inférieure 90.50 per cent., and in Seine-Inférieure 87.36 per cent. of the children died under one year.

Hunger-driven mothers work to the hour of delivery, and, hence, this mortality among their feeble children, who have not the strength to overcome 
the additional misery that is put upon them. Poor mothers! all day at work and nursing all night with empty breasts, children starving all day, this is killing game for mother and child.

What a city home! father and mother gone; an empty room; no fire in the stove; a baby in the crib; a girl of six doing the work of a mother. Or little dirty, ragged children fighting in the filthy lane about a dirty thing, hard to say what it is and which is beneath the notice of dogs, they are locked out, and vagabondage is forced upon them. If the children live to cight or ten years, their days of factory slavery begin. The working people in the large cities of France are worse housed than prisoners. No jailer would keep prisoners with so little air, light or food. Their dwellings are simply murderous. No room for anything, for attending to anything or even for turning around. No separation of sexes or decency possible. Men, women and children sleep all in the same bed. The room is often in the cellar or under the garret, exposed to wind or rain; everything rots, and the inhabitants are constant victims of rheumatism and skin diseases. There is no accommodation for anything; everything has to be bought in smallest quantities and in the most expensive way. The chimneys are often poor and the smoke blinding. In most contagious diseases, so common in such quarters, isola16 
tion is impossible. Coming from his labor to such a dark, damp, uncomfortable hole, the poor man is repelled and almost driven to the public house, which completes his ruin.

Villerme showed under these conditions in the industrial cities of France the average life of the factory people to be just nineteen years, while that of people in a normal condition is forty-three! The mortality among the children of the factory he showed to be a veritable extermination. The misery of the parents forces children of six to seven years into the factory. Of course, children so young are made to work by compulsory means. The parents soon lose all influence with these young factory hands, among whom a fearful demoralization prevails, and who at the age of twelve years smoke, drink, visit saloons and have their girls. So Villermé found it thirty years ago and so Jules Simon finds the condition of the factory people in the populous centres of industry to-day.

The physical and moral ruin of the people in the great manufacturing towns of France is beyond description.

The family, with all its saving influences, has given way to universal vagabondage, misery and depravity, which can hardly end otherwise for France than in the desolation of its large cities lighted up by maddened petrolleuses. Let this 
lesson written over the lurid sky be read and noticed all over the world.

Far from having overdrawn the picture of the working classes in the large cities of France, we dared not half tell the truth, which is too shocking for a straightforward recital.

Men, women, boys and girls being everywhere thrown together in the factory and upon the litter like brutes, decency and cleanliness of body become impossible, and this looseness ends in the complete destruction of all principle and character and in the ruin of society.

The working girls in their want and desolation abandon themselves and become mothers before they reach maturity of age, at sixteen to fourteen and earlier. Men fear the responsibility of a family; seeing as they do the misery of their fellows in the bonds of wedlock, they will not marry. Poor women are forsaken when their greatest need has come, the poor children are farmed out, and from eighty to ninety-five of a hundred die in less than a year. The men shift from woman to woman and the women from man to man, and abominations, best left unmentioned, fill the land and destroy the nation.

The same corruption we find everywhere in proportion as the people are crowded into tenement houses of a low order. Little Bavaria has an an- 
nual crop of 35,083 illegitimate births; Wurtemberg, 12,2 16; Prussia, 47,96I, and Saxony, 12,057.

A digression may not be out of place here in reference to Sweden, which seems to contradict every principle of social philosophy; for, while its population is almost entirely agricultural, well schooled and religiously trained; crime abounds to a degree found nowhere else. Laing found one in one hundred and thirty-four of the population in the country and one in forty-six in the towns convicted of crime, while in Ireland the proportion was in the same year one in seven hundred and twentythree. Stockholm had annually (I85I-55) 1,788 legitimate births and $\mathrm{r}, 477$ illegitimate ones! The fact is, though the country inclines us to virtue and the manufacturing town with its attendants to vice, none exerts such a power as may not be overcome by other influences. The nobility of Sweden, though but one in three hundred of the entire population, possesses more than one-eighth of the land, taxation presses hard upon the poor and their industries, who beside earn scanty wages and can hardly work six months in the year on account of the severity of the climate; half the people, therefore, live worse than English paupers. Add to this that nine-tenths of the population are peasants, treated by all classes with the uttermost contempt and whose degradation is completed by a most de- 
basing penal code, and we certainly cannot wonder that a people whose sensibilities are blunted by daily misery, and despised by all lost its self-regard, is not improved in its marals by the schoolmaster, the Church or the country. Sweden, thus, of all the countries, confirms our rule that the school is powerless where the people are kept in a pauperized condition that blunts their better feelings; and that the bringing together in our large cities the very rich and the very poor-robbing the latter of all self-regard, the safest defense against vice, immorality and crime-destroys them.

As to the condition of the working people and their dwellings in England, let Joseph Kay's pages answer. Fathers, mothers, sons and daughters crowd together in a state of filthy indecency, and are much worse off than the horses in an ordinary stable. Sometimes a man is found sleeping with one woman, sometimes with two, and sometimes with young girls; sometimes brothers and sisters of the ages of eighteen, nineteen and twenty are found in one bed together..... Men and women, three and four found sleeping together, are not ashamed, but answer remonstrances by laughter or sneer.....

In 1844,20 per cent. of the working classes of Liverpool, I $13 / 4$ per cent. of those of Manchester and 8 per cent. of those of Salford lived in cellars. 
And so it is all over England, and the farming hands in the rural cottages don't fare any better. The population is denser to-day and time has brought no relief. Look beneath all the display of objects of literature, science and art, and what is there but a pauperized and suffering people. To maintain show we have degraded the masses, until we have created an evil so vast that we now despair of ever finding the remedy.

A committee appointed by the statistical society to investigate the condition of dwellings and the people, say: "Your committee has given a picture in detail of human wretchedness, filth and brutal degradation, the chief features of which are a disgrace to a civilized country and which is but the type of the miserable condition of the masses of the community, whether located in small, ill-ventilated rooms of manufacturing towns or in many of the cottages of the agricultural peasantry. In these wretched dwellings all ages and all sexes, fathers and daughters, mothers and sons, grownup brothers and sisters, stranger adult males and females and swarms of children-the sick, the dying and the dead, are herded together with a proximity and mutual pressure which brutes would resist ; where it is physically impossible to preserve the ordinary decency of life; where all sense of propriety and self-respect must be lost, to be re- 
placed only by a recklessness of demeanor which necessarily results from vitiated minds."

Officials, clergymen and surgeons from all over England, give a description of the condition of the people in their crowded dwellings too shocking for recital. The promiscuous mingling of the sexes in the bedrooms has been increasing and producing year after year worse consequences, until it has become so common among the poor as to destroy all modesty and virtue among women, and threatens to annihilate the foundations on which are based all the national and domestic virtues, and to make want of chastity before marriage and want of delicacy and purity after marriage common characteristics of the mothers and wives of our working people.

We shall conclude these statements of Joseph Kay, which we could follow up by others of equál authority, with the significant statistical figures of 60,000 illegitimate births per annum in good Old England.

We are at a loss where to begin and where to end, or how to press into a few brief lines all the miseries of the poor arising from crowded dwellings as sketched by John E. Morgan. The poor are huddled together in a manner that health and strength for their daily work is fairly impossible. Their dwellings are forcing-beds of disease, where 
the plague originates. Here lies the very canker at the root of our social system. The day's work of our laborers, so wearing on the nervous system as well as on the muscles, is in their insalubrious dwellings followed by loss of appetite and loss of sleep.

What harvests of preventable deaths! Fifteen or sixteen deaths in a thousand is the normal deathrate. In sixty of the worst streets of Salford the rate of mortality for a number of years ranged from 36 to 91 in 1,000 , the average of the whole being 51 ! And Salford is no exception. Vauxhall district in Liverpool showed in 1864 a deathrate of 49 in 1,000 , and St. Paul's Exchange 48and that is not the worst.

How narrow is the life-span of our poor, and how full of physical ailments and misery is that little! Bad air and too little of it, kills the pcople. Thousands around us are annually dying, starving for want of a breathable air.

In Salford 25,000 people suffer intensely from air-poisoning ; in Manchester 80,000; in Liverpool and Glasgow are an equal number of sufferers from pestilential quarters, and London has fully a half a million of inhabitants, who suffer enfeebled health from the bad state of their crowded, stifling dwellings. Without naming the towns, upon a thorough knowledge of which the statement is based, of the 
I2,000,000 of the town population of England and Scotland, fully $2,000,000$ suffer from want of proper dwellings.

Dr. Hunter positively states that the dwellings are more crowded by ro per cent. to-day than they were 25 years ago, as the population has increased $5 \frac{1}{3}$ per cent., and the dwellings have at the same time decreased $4 \frac{1}{2}$ per cent., as many buildings have been appropriated for other purposes. Typhus, measles, scarlet fever, smallpox and other diseases come and go; there are signs of a widespread physical deterioration; chronic ailments are the rule ; dyspepsia, bronchitis, scrofula and consumption are common, and the thread of life is deplorably fine spun, and many seem to cower around the open mouth of the grave.

From these crowded poor one million of paupers gains its recruits; prisons and reformatories look to them for their largest supply; and it is among them that diseases originate that revenge themselves on society at large. So far Dr. Morgan, a public officer in 1869 , than whom none is better informed upon the condition of the laboring masses and their dwellings.

THE TENEMENT HOUSES OF NEW YORK CITY.

We beg the reader to notice that we closely follow the Official Reports of the Board of Health, $16^{*}$ 
published for the last ten and more years, by which every one of our statements may be verified.

The majority of tenement houses in this city are old structures built for other purposes; partitioned off within so as to give each family a living room Io by 12 feet and a bedroom 6 by 4 feet, while no regard is paid to ventilation or domestic conveniences; twenty, thirty, forty to one hundred and fifty such apartments are constructed, and into each a family of from three to five persons is crowded. The danger from crowding in these tenement houses is a hundred-fold increased by their being packed together in blocks. Rear tenement houses aggravate the evil beyond measure. They are built upon the rear of the yard, close to the rear tenement of the opposite lot, leaving a small cold and damp space between the front and rear houses, not inappropriately called the zuell hole. Not only are fresh air and sunlight thus effectually excluded from the living and sleeping apartments of most of the inmates, but the buildings become damp and cold, and in time saturated with the poisonous and filthy excretions of the inmates.

The result of this effective overcrowding in badly constructed dwellings is shown by the fact that this half of the population of New York yields 75 per cent. of the total sickness and mortality. Tenement houses of a capacity for ten families were 
found by the Board of Health, in which, beside other diseases, typhus prevailed, and in six months twenty persons were stricken down by this terrible malady. In other buildings a mortality of 55 in $I, \infty 00$, or $I$ in $I 8$, died! which is 40 more deaths to every $\mathrm{I}, 000$ population than there is absolute necessity for.

Tenements, with two houses on the same lot, suffer also from the super-added nuisance of privies located in the middle space. The air in these areas is always impure from the noxious gases arising from the privies, and even without these necessary nuisances the air is too confined for the proper supply of human beings. Tenements have been examined by the Board in which the apartments consisted of one living room of 14 by 8 feet and a dark bedroom of 7 by 8 feet, with no means for ventilation and full of filth, furnishing constant work for the undertaker, the ambulance and the hospitals. The privy vaults and everything else, of course, was in a most loathsome and killing condition.

A description of the kind of homes work-people at times find in tenement houses may interest. The roof leaky as a sieve, affecting the comfort of the inmates down to the second floor; the walls, ceilings and woodwork of the whole house shaky with age and bad usage and rotten with filth; the fire- 
places destroyed and dangerous; the partition walls thin, ill-fitting planks, covered with foul and ragged paper. The alleyway dark, extremely filthy and dangerous in every respect. The basement walls crumbling; the ceiling below the level of the street; no light, except through the door, and occupied by four beds; the steps decayed and dangerous. While the wood and other materials of such structures undergo the process of dry rot, the wretched tenants waste and die from a disease expressively termed the "tenement house rot."

The debasing effects of such houses have never been overdrawn. Mr. N. P. Willis gave the following vivid description of the tenement class of people immediately after the riot of 1863: "The high brick blocks and closely packed houses in this neighborhood seemed to be literally hives of sickness and vice. Curiosity to look on at the fire raging so near them brought every inhabitant to the porch or window, or assembled them in ragged and dirty groups on the sidewalks in front. Probably not a creature who could move was left indoors at that hour. And it is wonderful to see and difficult to believe that so much misery and disease and wretchedness could be huddled together and hidden by high walls unvisited and unthought of so near our own abodes. The lewd, but pale and sickly young women, scarce decent in 
their ragged attire, were impudent and scattered everywhere in the crowd. But what numbers of these poor classes are deformed; what numbers are made hideous by self-neglect and infirmity, and what numbers are paralytics, drunkards, imbecile or idiotic, forlorn in their poverty-stricken abandonment for the world! Alas! human faces look so hideous with hope and vanity all gone! And female form and features are made so frightful by sin, squalor and debasement."

The degree of overcrowding in the tenements of New York City exceeds that of any of the large cities of the civilized world.

The density of population was to each acre in 1870:

NEW YORK. LONDON. I1th Ward . . . . 328 Strand . . . . . 307 I $3_{\text {th }}$ “ . . . . 311 St. Luke's . . . . 259 I $4_{\text {th }}$ ". . . . 275 East London . . . 266 17th “. . . . 289 Holborn. . . . 229

The highest allowable population is 80 to 100 persons to the acre. The effect of this excessive crowding in badly constructed dwellings upon the death rate is that double as many of these tenement inmates die as of the people living in the country. Sickness and death are, however, but a fraction of the sum total of damage which overcrowding and defective house accommodations do 
to the poor. The gross immorality, the huddling up of all sexes and ages, leads them on to a total self-abandonment and every species of vice and crime.

Gotham Court may be taken as a representative of tenement houses, their character, accommodations and influence on the population. Two barrack-buildings furnish tenements to 146 families or 584 individuals. At times it has been packed with nearly double that number. The roof is a general playground for children and a place of deposit for ashes, garbage and to a large extent used as a privy by the tenants. The plaster and woodwork of the hallways is out of repair and extremely filthy; the stairs are dangerous; the cellars are dark, horribly foul and filled with mud, rubbish and human excrements. They are not used for storage of wood or coal, as neither property nor life are safe in these cellars on account of rowdyism rampant around this court. The privies are horrible breeding tanks of disease; the horrible odors rising from this immense receptacle of filth spread between the two piles of buildings-each five stories high-which are separated only by a distance of nine feet wide. The poison thus concentrated is very directly applied to each and every apartment in the buildings. Added to the filth of the privies is the filth of the yard, into which much rubbish and garbage is 
thrown. For a long time this court has been the nightly resort of a crowd of loafers, bummers and roughs, who kept the tenants in a complete state of terrorism. On Sunday especially this is the playground of these rascals-boys and half-grown men - who fight among themselves and pick quarrels with the tenants. Women of the street are dragged in, under the back-stairs and into the cellars by these miserable youngsters, and vice, drunkenness and terror reign rampant. The police will not follow them into these dark cellars and recesses. The agent and housekeeper dare not interfere; and the police, I fear, are content to leave the court pretty much to itself. Ventilation is impossible, and even if it was not, the air is already poisoned before it would enter the rooms. This was the condition of Gotham in 1870. In 1865 the Health Officer found the mortality in these buildings 30 per cent. of the children born, 7 per cent. of the entire population, which is three and four times as great a mortality than there is an absolute necessity for. Of 504 inmates 146 were more or less sick, some with smallpox, some with typhus, some with scarlatina, dysentery, chronic diarrhœa, etc.

All zymotic, epidemic and contagious diseases make especial havoc in our tenement houses, as they are usually overcrowded, badly ventilated, damp and filthy; the relapsing fever, however, is peculiarly 
a disease resulting from overcrowding and destitution, while typhus is a disease which finds its cause in overcrowding alone. Miserable living and sleep. ing in damp, filthy cellars and unventilated apartments produce this epidemy, by which thousands of the inhabitants of the tenement houses have bcen attacked in I870. This epidemy has been for the last few years raging all over the civilized (?) world among the destitute laborers, who are living in unwholesome and crowded apartments.

The cholera of I 866 left the inhabitants of the clean and well-to-do sections of the city of New York unvisited, even while this terrible pest has slain hundreds of victims in the overcrowded, badly ventilated, damp and filthy tenement houses. In I 867 the mortality of children of one year of age amounted from week to week one-fourth to onehalf of the entire death rate. In some of the crowded tenement neighborhoods 80 per cent. of the mortality occurred among the infant population. The unhealthfulness of the dwellings is most telling upon the delicate constitution of infants; and, hence, the slaughter among them. In many cases it was observed, though death was imminent, removal to the country and its pure atmosphere terminated the disease as if by magic. The filth and foul air of tenement houses furnish the ferment for contagious and miasmatic diseases, and fresh 
air, pure water and plenty of sunlight are the best preventatives of zymotic as well as of other diseases.

In the report of 1874 , we read that large numbers of cellars in the lower wards of the city were occupied as dwellings and lodging-places, which were totally unfit for such occupancy; many of them nests of crime, and all in a condition to become on the slightest appearance of pestilence the centres of disease. In most cellars the walls and ceilings were found damp; the floors resting on damp earth were rotting away or were resting upon stagnant water, which would be forced up below the boards at the slightest pressure of the foot upon the floor. Many of the lodging-cellars were found to be long rooms divided into small apartments by pieces of curtain, while in others the beds were arranged alongside of each other without such partition and occupied indiscriminately by lodgers of both sexes. In the second sanitary inspection district 315 persons were found living in damp, unventilated cellars. They suffered from alcoholism, and rheumatism in all its stages.

In the Fourth Ward i 76 cellars were found in a deplorably filthy state, and radical measures were recommended for closing them and redeeming the wretched occupants of those cellars from early graves, lives of drunkenness and prostitution. In numerous instances damp, dark, filthy cellars were 
rented from $\$ 25$ to $\$ 75$ per month. "The system of tenement dwellings is so radically wrong that to suggest improvements would end in a suggestion that the present houses be all torn down. Cleanliness in them is impossible without light and air, and this cannot be had with front and rear buildings. Volumes of air vitiated by the disagreeable smells of cookery of the lower stories are always sent up through the halls and narrow courtyards, also the exhalations of decaying vegetable matter and the like. The walls and ceilings of the halls become soon covered with a coating of animal matter deposited upon them, and the floors become soaked with moisture, filth and dirt, which is never removed."

We might have presented more sensational pictures-we have preferred to describe the homes of the working people in the very words of our noble sanitary inspectors, and the misery of their occupants can be easily inferred upon the principle of Mr. Godwin : "As the homes, so the people."

Our sanitary inspectors are doing their best to improve the condition of the tenement houses. But as the population increases and the business houses encroach and narrow the field of the tenement houses, and the proportion of the inhabitants to the area is already three times as large as health permits it, all their measures cannot bring 
permanent relief. Besides, their powers are too restricted to do all the good they would like to do.

Is it in Boston, the Athens of American intelligence, any better? The State Board of Health of Massachusetts tells us that the homes of the laboring classes in Boston are overcrowded and unwholesome, abodes of misery, affecting injuriously the health, the morals and the political purity of the community; they are disgracefully unfit for human habitations, and nothing can be added to a true notion of their badness, as their character for squalidness and unwholesomeness is known to all.

The State Board is tired of telling over the story of the miserable abodes of the people, and we shall follow the description of the Rev. Edward E. Hale in his "How the People Live in Boston, and How They Die There."

The mortality of the infants in Bethlehem, which has made every Christian mother curse the name of Herod, is more than equalled in the terrible sufferings of the children in Boston. Seventy-five deaths among the children of the poor happening just from cholera infantum alone in twenty-four hours! And almost all under one year of age, and coming out of all proportion from the tenements of the poor. Not a child on the dead-list from Beacon, Chestnut or Pinkney Strects, nor deaths in Union Park, Worcester or Springfield Streets, or from Chester 
Square; in short, not one death from the very nice streets. The largest part come from two neighborhoods-the quarters of the dingy homes of the poor. But let us glance inside these hells, called by a misnomer homes. Well, here we are in the room of Mrs. K-, who lost a boy-it was her only child. The air was damp, chilly and dark, because the sun never kissed it. The floor of the entry was wet from the overrunning of the water-faucet, which supplied the house, and all the region was damp, as the cellar is apt to be, which is much below the tide-level. Just seven people lived in four rooms, which put together would have made one of twenty feet square.

One of the deaths happened in the house opposite, in which thirty-one persons lived (?) in fourteen so-called rooms. What had been the yard of this house had been taken up by another tenement building.

Another one of the deaths occurred in a fourstory tenement, in which forty families are packed, and which looks very much like a menagerie cage.

I3 E- street is another such feeder of the cemetery. Two tenement houses adjoining each other, with thirteen families in the one and ten in the other. The water pipes are put up in the most shameful manner. They must of necessity freeze up at the very first frost. There are but two fau- 
cets for twenty-three families to draw from, and no way to get to them without wading through dirty water. Two of the most filthy privies, entirely open for these twenty-three families, are so much out of repair as to be dangerous to enter. The apartments are miserable places, out of repair, the plastering of the walls and ceilings give little chance to whitewash, as it is broken off to a large extent.

One of the poor innocents was sent to its rest from one of the tenements in Phœnix Place. There is a melancholy uniformity in this class of buildings. They are lightly built of wood, all on the same plan. Think of it, sixty adults and sixty-five children packed away in sixty rooms, each of which was about twelve feet square. The summer atmosphere of these places is odious, but the winter atmosphere is worse. The lots are so small that all privy arrangements and deposits of offal are horribly near the open windows. It was wretched to hear the woman talk, as if the child died of course, and she never ought to have expected that it would live. The poor feel they are doomed and become reckless.

It would be a sad and endless repetition to say more in detail about this matter, as the dwellings assigned for homes to the laboring poor in Boston all are pretty much of the same description.

In 1865 , a thousand children died in less than a 
hundred days from an epidemy that raged among the dear little ones. The Bostonians, who live in comfortable circumstances and neat homes, are surprised to hear it. It did not touch them-it raged among the poor.

But the worst of all is that it is not only New York City, Boston, Baltimore, Cincinnati, St. Louis, Louisville, New Orleans, in short, the very large cities; it is fully as bad in the smaller manufacturing towns everywhere. Take, for instance, the tenement house called "Buffum's Block," in Linn, Mass. It is eighty feet long, thirty feet wide, containing a basement, two stories and an attic. In the basement, below the level of the street, three families live, and the house contains not less than forty-six persons. The privies are foul and beyond approach by a decent person. Additional complaint was caused by the privies of the neighboring tenements which, being on higher ground and faulty in construction, were overflowing into this yard. Here is a sample, and we take the first-there is not much choice-from Salem, in the same State, at No. 18 Congress Street. At the time of the inspection by the health officer, this house stood in the midst of a pond of stagnant water. In the same watery lot was an overflowing privy-vault, and a piggery added its contribution to the general filth. Sixteen persons occupied the house, which was in 
a condition to poison the atmosphere of the whole neighborhood. All the tenements of the laboring classes in this district, says the State Report, should be condemned as nuisances.

Here, as an illustration-and we take again the first at hand-from Springfield, T- Block. The house, when inspected, was greatly out of repair-its windows broken, its stairs dangerous, its roof leaking. The vaults of the privy were brick receptacles, entirely above ground, and as one of them was broken, the abundant contents had settled away, a filthy mass of excrement overflowing. Most of the tenants declined to use these privies, and resorted to expedients which can only be hinted at.

This is not impracticable fault-finding. Quick transit opens a highway that leads out of these and a thousand other abominations equally destructive to the people, who are to-day unreasonably herded in miserable tenement houses.

Quick transit gives the working people the means to live out in the country in their own cottages, where God Almighty's untampered sweet influences will keep them sound in body and soul, sound in principle and in action, and in all the relations of the individual to himself, his family and the state.

A home in the country with a garden patch attached to it, owned by every working-man, is the 
only possible solution of a thousand problems which press for an answer.

Once every mechanic looked forward to the time when he would be master and have his own shop. To-day, once a factory employee, means always one; he is a hopeless vagrant; he cannot invest and does not economize, and ever remains without a home, hope or property. In unemployed spells, a general crisis, or a change or cessation of his trade through the invention of new machinery, in sickness or old age, he becomes homeless, breadless and penniless.

Must not such uncertainty be unbearable to intelligent laborers, spread discontent among them and dispose them to anything that threatens the overthrow of the present order of society? This terrible uncertainty must give way to something more reasonable, just and better. Our workmen are perishing body and soul in our city slaughter-pens, called tenement houses.

The population living in private houses in New York City number a half a million, and their mortality was in $1872,11,097$, or about 22 in 1,000 ; the other half a million of tenement population had in the same year 21,550 deaths! or more than 10,000 . above their proper share. And as there are fourteen cases of sickness to every one case of death, the workmen of this city had I40,000 more cases of sickness 
in their families than they would have had in more wholesome dwellings. What loss of human life, what sufferings, what expense and what loss of labor are implied in these preventable deaths and diseases, the latter of which, again, by enfeebling the bodies and minds of the people multiply pauperism, drunkenness, premature orphanage and widowhood, prostitution, crime, retributive violence and consequent prison life and suffering.

Most unfortunate for the people they are the children of God, for were they horses they would not be left to perish for want of a little more stable room.

This social murder could be stopped by the double measure of quick transit and strict sanitary regulations in reference to tenement buildings. "Houses that produce death cease to be property. If a man sells unwholesome meat, the law interferes; if he sells the use of a room with fever in it, the public do not complain. Officers of health point out such places, but the public still refuse to destroy them, and great numbers are slain annually by this indirect and legal method, while the strictest measures are taken to prevent a few annually being killed by arsenic. The time must come, and the sooner the better, when it shall be enacted, that no land shall contain more people per acre than can live healthily thereon. The same thing must 
be said regarding houses, though this is more difficult to attain."

At Muhlhausen, in Elsace, a workmen-town was built, giving laborers facilities for acquiring property, and what a change it worked! what a revolution! a blessed revolution that destroyed vice and misery, and led from the improvement of material conditions to a moral regeneration.

At Lille, in France, houses have been built for the workmen with gardens attached to them, and are sold to the laborers on easy terms. At Rouen the same system is attended with the same blessed results.

To illustrate this system, we may add a word more about Muhlhausen, the first great success of a workmen-town. One hundred houses were built in 1853 , an additional 428 were built in 1859, and 560 in 1863. Of these, 700 belonged to the workmen in 1866. They paid $\$ 4.60$ per month, and in I4 years each house held at $\$ 600$ was paid up, interest and capital, having paid but little more than a high rent. Each home has a garden of 30 by 36 feet attached to it. The government has voted $\$ 2,000,000$, a loan to building societies under the following conditions: I. The properties must be sold to the workmen at cost price. 2. No purchaser to be allowed to sell his property before ten years, so as to prevent specu- 
lation. 3. The building company not to charge the workmen more than 4 per cent. for capital until it is paid up. 4. A public building, uniting a reading-room, restaurant, bathing and washhouse and a bazar, where all articles of common consumption are sold to the workmen at wholesale prices, must be built in the centre of the town.

The Industrial Building Society at Muhlhausen has complied with these conditions, and received from the government in addition to their original capital of $\$ 25,000$ a loan of $\$ 80,000$. In this comparatively small manufacturing place 700 toiling families were changed from hand-to-mouth living renters into provident and independent citizens and property holders, each living in his own comfortable home undisturbed by the often unwelcome company of drunkards and other incongruous and even infamous characters thrust upon decent men in tenement houses, living in cheerful quarters, and as if it were under his own fig-tree. No more driven from cheerless and filthy rooms to the debauchery of the public house. What moments he can save he bestows upon his garden, and the boys and the mother are happy to second him with the hoe as he goes ahead of them with the spade, now and then stopping and blending his solid reflections and well-meant counsel to his family with his labor of love. They make arbors for shade and plan im- 
provements, beautifying the homestead. When old, he need not blush to live from the earnings of his sons, for he has done his duty to them and all the family. And father and mother, after a life of toil, but which was not without its blessings, die on the homestead with the children, leaving them not only property, but a good name and a model life. Not only property is thus made, but character is built up and kept like a jewel.

What a difference between such workmen and those who are driving about like vagabonds and semi-savages. Jean Dolfus, who started this noble work at Muhlhausen, deserves well of the human race for this illustrious example given to manufacturers and workmen.

At Guebwiller, also in Elsace, a hundred cottages with gardens attached to them, were built in 1866 .

Beaucourt had in 1864,97 cottages. Colmar built in 1864,50 houses. At Sedan, the workmen own their houses and gardens, and are as respected for their character as they are useful by their labor.

What touching stories could be told about many a workingman who, under the old system, became dissolute and was daily nearing a drunkard's grave, but who has been redeemed at the first opportunity of acquiring a piece of property, a home for his family and old age.

At the Ashton colony of workmen, in England, 
none have yet applied for charity; in 35 years hardly a breach of law has occurred, and illegitimate births are becoming scarce. The people look healthy, and even those who work in an atmosphere of $80^{\circ}$ Fahrenheit are. strong and vigorous, having but one-half day of sickness in a whole year. The intercourse between employers and employed is marked by regard and confidence.

Get railroad advantages, give us opportunities for cheap country homes, and societies will spring up which will enable the poorest laborer to live in his own house.

England has over 2,000 such building societies with 800,000 members and $\$ 80,000,000$ loaned on buildings. London alone has over 700 societies with over $\$ 20,000,000$ advanced on property to its members. Scotland has over 88 building societies with over $\$ 65,000,000$ advanced to its members. These building societies afford manufacturers the best opportunity for providing their workmen with homes, and have been used for that purpose by the noble Arkroyd, Crossley, and others. Belgium, Germany and other countries have been benefited by the opportunities building societies offer to the poor for owning homes, and there is no reason why building societies should not prove a success in New York and other cities in the Union as well as in Philadelphia. 
We consider that this step must be taken of all others first, if the great and momentous questions of civilization, which crowd around labor, are to find a peaceable solution.

The massing of the people in a few centres is productive of a thousand mischievous consequences, which thrcaten capital as well as labor and every other element of civilization-yea, the body and soul of man with utter destruction. Avoiding general argument and steering toward convincing facts, we refrain from entering upon the moral, political, social and economical tendencies of the present movement of population toward the great cities, and will strengthen our position of the importance of the workingmen acquiring homes, with an authority like that of Le Play, a most thoughtful and competent writer, who has devoted a lifetime to the study of the condition of the industrial classes, and who sees the only means of preserving society and the prevention of the dissolution and the relapse of society into barbarism through a variety of corrupting influences, undermining the family first and society next, in restoring the ancient custom-the family owning their hearth. Only by this means good habits and wholesome customs are preserved and revered, parental authority honored, woman's influence a blessing, economy fostered to acquire the home, character developed, reliability 
and trustworthiness gained and roving and indifference overcome.

In regard to the workmen reaching their homes in the country and their places of work in the city, we agree with Dr. S. Smith's sanitary report of $187 \mathrm{I}$, from which the following page is taken:

"The workmen must depend upon the railroad, which has not and probably will not give him cheap fares without compulsory legislation, and such legislation we believe should be at once obtained. As a slight return for the privilege which railroad companies enjoy within this city, especially in the monopoly of large areas of valuable land, they should be compelled to provide cheap transit for the poor and laboring classes. Such legislation in England long since compelled all new railroads entering London to provide penny trains at suitable hours. These cheap trains proved a marked success. The Legislature of Massachusetts recently passed a law compelling the railroads to provide cheap trains morning and evening, and charging one cent a mile for yearly tickets, and this law has been there in force since 1862 . The same kind of legislation should be obtained in this State in regard to all railroads entering New York City."

Homes for workmen out of the city is nothing but what is just and proper; it is in the interest of all parties, the capitalist as well as the laborer, and 
the family as well as the state. It is approved by philosophers and statesmen, and has been put into practice with success by manufacturers on a sufficiently large scale to judge its success.

Sir Robert Peel, whom nobody will accuse of impracticable radicalism, says: "Our large cities offer the workman only opportunities for continuous labor and gross and degrading pleasures. Give them small properties in the vicinity of the manufacturing districts, this will wean them from drunkenness and improve their moral character." He further says: "It must be confessed that the condition of our workmen is not what it ought to be, and that the mere production of wealth is not the highest aim of government, which ought to care for the happiness and well-being of the people."

Sir J. Coleridge, a member of the Gladstone ministry, said: "Our laborers live hardly, work very long, and have at the end of life nothing to hope for."

Neither religion, Education, nor temperance, nor courts of justice can elevate a people living huddled up like pigs, says the good and learned Dr. Blakie. The same great authority continues: Typhus, consumption, scrofula, etc., are wasting away the laboring people in the densely populated tenement houses, and the victims of typhus alone among workmen in the prime of life, number 
annually doubly the fallen on the battle-field of Waterloo. Love of home, says this same philanthropic divine, is associated with regard for father and mother and their precepts. Filthy tenements are no home, and, hence, no lesson to the heart; all the purer feelings even of a mother and sister are deadened by them. The cleanest can be but untidy, dirty, wretched, discontented and disorderly in such hovels, and the preference for the public house to such quarters become a necessity. The vice and filth in the crowded dwellings of the poor counteract all the lessons of religion and humanity. A miserable hovel destroys all home feeling and family ties, and plants atrocity, barbarity and crime in their place. The only remedy are small, neat homes out of the city the laboring man can even become proprietor of; he is stimulated by this method to saving, and, being provident and accumulating property, becomes a useful citizen every way. There are 8,000 to 10,000 such workingmen who have got their own homes about Birmingham. Happy homes are the chief cause of the prosperity of a country. Such are the thoughts and the experience of the learned Blakic.

Purity, affection, thrift and industry are lessons of a clean, neat and attractive home. "Lille in France," says the thoughtful Fix, "with a most dense population, is also the most miserable, most 
drunken, obscene place, with nothing but dirt, misery and vice."

The same author says: "Love of labor, of order and economy will always be found in a home that attaches the workman to his family; there he sacrifices low desire and studies thrift for the sake of the children and a home that is attractive."

Self-respect, regard for himself and his place in society, is one of the mainsprings of keeping aloof from every degrading vice, be it drunkenness or any other moral defilement. But can any one reared in the horrid filth of the tenements of crowded cities be conscious of human dignity? Or is it not rather a mockery to speak to such men of the high dignity of their being? Provident thrift or care for the future has no room in a man who is suffering from a thousand present ills. The poor everywhere suffer partly from want of intelligence, sobriety, thrift and self-respect, and their surroundings foster these very defects. And yet, regard for ourselves is intimately connected with regard for our fellows, for human nature, and, therefore, for the rights of other men. Regard for human nature leads to trusting in it and believing in its upward tendencies, which lead to hope, exertion, improvement and elevation. Vagrancy is one of the chief causes of crime, and miserable hovels lead to it by destroying all home attachment. Let all who study 
the sources of crime notice this connection between the homes of the people and vagrancy and crime.

Clean homes certainly should be made possible to the honest laborer, a privilege not even denied to crime (Hill). When the prisons are in better order than the homes of laborers, crime is encouraged.

So killing are the crowded dwellings of the poor that the English Commissioners officially report that the laboring population of large cities would soon be gone, if the influx from the country would not make up for the slaughter. Dundee, with its once proverbially splendid Scotch population, alas! what a spectacle it offers to-day!

What haggard looks the spinners of Lyons or those of Spitalfields in London present! And yet, the moral debasement of which the physical degradation is the cause as well as the index, is the worst feature of the whole.

These squalid homes, says Buret, drive children from 4 to 8 years into horribly dirty streets, where they already young contract vagrant habits.

Rev. Canon Girdleston, of the English Episcopal Church, said in a meeting of his brothers in the ministry: The laborers live in hovels without ventilation or the surroundings necessary for ordinary decency. Not one of those present would consent to stable their horses in these hovels; hovels 
which bred a race of men who, from want of domestic comfort, spent their lives in the pothouse, and who had nothing to look forward to but to be buried in a pauper's grave; hovels which bred a race of women whose maidenly blushes were blutched in consequence of the scenes they were obliged to witness through want of proper sleeping accommodations. The clergy might keep aloof from the labor question because it might be supposed that social questions were not within their province. He was bound to acknowledge that the clergy could not consider themselves free from blame, and that a great weight of responsibility lay at their doors. They ought from the pulpit deliver themselves more frequently from this responsibility. He solemnly declared that the man he should fear most to meet at the last great day was the poor laborer, who, perhaps, if he himself had exercised his ministry more faithfully and more fearlessly in denouncing social abuses, might have been spared a life of misery and penury and a pauper's grave.

A voice as clear, powerful and bold, that once thrilled the people of Boston from the pulpit in Music Hall, said: "Look at the houses the poor live in, without comfort or convenience, without sun, air or water; damp, cold, filthy and crowded to excess. In one section of the city there are 
thirty-seven persons on an average in each house. Consider the rents paid by this class of our brothers. It is they who pay the highest rate for their dwellings, paying often 30 per cent. on valuation. If your bills of mortality were made out so as to show deaths in each ward of the city, I think all would be astonished at the results. Of one hundred children of poor working people in Boston only thirty-eight live five years, only eleven become fifty! The mortality among the poor is greater in Boston than in any city in Europe, and the death rate among their children is increasing." So far Theodore Parker.

Another friend of the race, the great and gifted Channing, speaking of the influence of the poor man's dwelling on his domestic affection, says: "The delicate sentiments find much to chill them in the abodes of indigence. A family crowded into a single and often narrow apartment, which must answer at once the ends of parlor, kitchen, bedroom, nursery and hospital, must, without great energy and self-respect, want neatness, order and comfort. Its members are perpetually exposed to annoying petty impertinence. The decencies of life - can be with difficulty observed. Woman a drudge and in dirt loses her attractions. The young grow up without the modest reserve and delicacy of feeling in which purity finds so much of 
its defense. Coarseness of manner and language, too sure a consequence of a mode of life which allows no seclusion, becomes the habit almost of childhood, and hardens the mind for vicious intercourse in future years. The want of a neat, orderly home is among the chief evils of the poor. Crowded in filth, they cease to respect one another. The social affections wither amid perpetual noise, confusion and clashing interests. The poor often fare worse than the uncivilized savage in his ruder hut, which he can leave for the bright light and pure air of heaven. The poor man in the city must choose between his close room and the narrow street. He has a home without the comfort of a home."

There is hardly a faculty or virtue in man but it is fostered by a home that is deserving of the name. Franklin's motto, "Do everything in its proper time, in its proper place, use everything in its proper use," or orderliness, industry, thrift, taste or a sense of beauty, delicacy of feeling, kindliness, self-regard, culture, purity, serenity, joy and happiness, contentment, meditation upon our past conduct and forethought as to the future, family discipline and regard to the duties and relations between parents and children or wife and husband -nothing of all this is possible in an unclean den, in which all persons and functions are mixed up in 
one general confusion and disorder, and everything is out of time, place and joint.

Orderly homes among the working people are the best means for the spreading of a higher civilization through the moral elevation of the masses, and the preservation of the family in all its elevating influences. Facilities for the acquisition of these homes cannot fail to reconcile labor to capital and to attach the workmen to our present state of society. There is no other means by which pauperism as well as crime can be destroyed, and the individual, the state and the race can be saved but by the home and the family, the school and nursery of the civilization of the race.

Aside from moral considerations and economical reasons, sanitary facts of the gravest sort demand the formation of workmen settlements in the country.

We shall shift our studies to Prussia, that we may have the double advantage of observing the effects of crowding under other skies and through other eyes, which cannot but correct or confirm our observations made in France, England and the United States.

The efficient statistics of Prussia show that while in Westphalia the proportion of occupants to each house was, in $1855-1858,6.91$ to 1 , and in the Rhenish Province, 6.04 to $I$; the proportion in the 
district of Gumbinnen was at the end of $1855,8.97$ to $\mathrm{I}$, and at the end of $1858,9.19$ to $\mathrm{I}$, and here it was that typhus became epidemic and raged like a pest.

Dr. L. Muller writes: "I was soon convinced that the time, locality and origin of the disease, as also its gradual spread, was the effect of human or animal perspiration accumulating in close places, and that it thence spread to other places and became epidemic."

Dr. C. Canzow, the medical inspector of the Gumbinnen district, in his account of the origin of the typhus epidemy in the overcrowded dwellings of the laboring people, says: "It is not saying too much that spotted fever has become endemic among the permanently suffering workmen of this district."

Dr. Pappenheimer, the celebrated sanitarian and medical adviser, says in his publication on Sanitary Police: "The study of typhus in lodginghouses, in certain town quarters, hospitals, workhouses, ships and prisons leads always to the same result. Every epidemic typhus, which is not the effect of hunger and want, is the result of overcrowded and filthy localities. Filth and overcrowding produce typhus, very often becoming epidemic, and affecting impoverished nations or such as are in a suffering condition in consequence of a commercial crisis, war or the failure of crops. We physicians 
cannot cure such national sufferings. We have no medicine against hunger, nor can we prevent the overcrowding of houses, the home and origin of typhus." "Such is the medical experience in reference to crowded dwellings in Prussia.

The greater part of 60,000 illegitimate births, and of probably 20,000 annual infanticides in England, are traced, in the Transactions of Social Science, to the disgusting conditions in which the masses are forced to live. The London Times says: "If we wish to prevent infanticide, we must guard a woman against the cruel conditions in which the crime is usually perpetrated. Is everything really done by us which ought to be done? Most assuredly it is not done. As long as the poor have to live in a manner, which makes the separation of the sexes impossible and renders impracticable the observance of common decency, these crimes will be perpetrated. .... . Let us make a real, earnest exertion to improve the dwellings of the poor, and with the dwellings the morals of the inhabitants will mend."

Dr. Farr says: "The children of that idolatrous nation that passed its children through the fire, an offering to Moloch, were hardly more in danger of losing their lives than those born in our large cities."

Of a hundred children born, live to the age of five years, in 
Norwegia . . 83 Prussia . . . . 68

Sweden . . . 80 Holland . . . 67

England . . . 74 Austria. . . . 64

Belgium . . . 73 Russia . . . . 62

France . . . 7I Italy. . . . . 6I

But the very low mortality rates of the well situated lower the average mortality of the whole, and hide the real state of the case, which is ugly, indeed, as the mortality among the laborers crowded into the tenements of large cities rises to the fearful proportion of $50,60,70$ and even more in 100 !

Villermé showed that the mortality was in French arrondissements :

With 7 per cent poor dwellings. . I person in 72

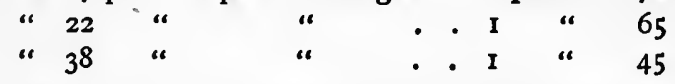

In England, sanitary investigations show a mortality in dwellings of

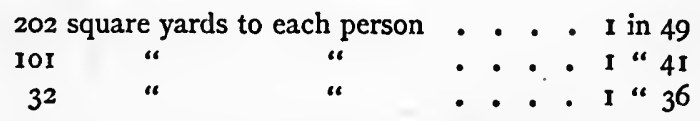

Of all the deaths from cholera in London, in I 849 , belonged to the

Higher classes. . . . . . 26 in 1,000

Middle " . . . . . . . 1 157 “ 1,000

Laboring " . . . . . . . 817 " 1,000

This, of course, is entirely out of proportion to the number of the various classes.

In Brussels, die 
In the quarter, with the best dwellings . . I in 53 persons. “ " poorest " . . I " 29

In Zurich, in Switzerland, the average life in the best quarters is 40 years, in the poorest it is 28.3 .

Dr. Lankester shows the mortality in one of the best localities of London to be II in 1,000 , in another one, among the laborers, it is 25 in 1,000 . The same sanitarian shows the loss of England from insalubrious dwellings to be 100,000 lives per annum; and as, where so many die, many more are sick, a simple calculation will show that 100,000 preventable deaths imply a national annual loss of $\$ 50,000,000$ ! And fully as much, and more, do the United States suffer, as our mortality rates are much higher, and human labor is worth more here than in England. We doubt not the interest on our whole war debt could be paid with what we lose by the annual slaughter of our working population.

In proportion to the density of population, rent, and with it pauperism, increase, the morality of the people is lowered and their death rate of mortality rises. Let the reader reflect upon the contents of the following table:

\begin{tabular}{|c|c|c|c|c|}
\hline Town. & $\begin{array}{l}\text { Occupants } \\
\text { to each } \\
\text { house. }\end{array}$ & $\begin{array}{l}\text { Proportion of } \\
\text { rent to in- } \\
\text { come. }\end{array}$ & $\begin{array}{l}\text { Illegitimate } \\
\text { births. }\end{array}$ & $\begin{array}{l}\text { Mortality } \\
\text { in } \mathrm{x}, \mathrm{oo0} \\
\text { population. }\end{array}$ \\
\hline London & 8 & $\frac{1}{10}-1 / 8$ to $I$ & 4 pr. ct. & 24 \\
\hline Berlin . & 32 & $\frac{1}{5}-1 / 4$ to $I$ & 164 & 25 \\
\hline Paris . . & 35 & $1 / 4$ to I & 20 & 28 \\
\hline Petersburg & 52 & $\ldots \ldots$ & 26 & $4 I$ \\
\hline Vienna. . & 55 & $1 / 4-1 / 3$ to 1 & 51 & 47 \\
\hline
\end{tabular}


Minute statistical investigations show that in the same country where no other influences modify the result, crime is in proportion to the density of population and the suddenness of its increase, and, hence, so nuch of crime at the present movement of population from the country to the cities. Drunkenness, prostitution, scrofula, phthisis, zymotic diseases, insanity, suicide, and, at last, death, perhaps the only possible medicine against all this and other unmentionable corruption, are all in proportion to the density of population, the breeder of all that is unwholesome for the body as well as for the soul, and for the state as well as for the individual.

The rapid increase of dense city populations, says Beale, and the unchecked advance of huge masses of human misery and destitution-mental, moral and corporeal-exhibited in every country of Christian Europe must end in barbarism and despotism, if the right sort of Education does not come to the rescue.

We have already referred to the barrenness of statistics in which extremes of all sorts thrown together produce insipid averages, which hide the true condition of things. Let our sanitary authorities give us the mortality of different sections by themselves, and not throw the pestilential and the salubrious together and produce the false impres- 
sion that things are just tolerable, when, in fact, this medium condition exists only on the paper where the best and the worst are thrown together, while in reality only extremes are met with. We talk of a rate of mortality of 36 in 1,000 , when the fact is that in the best houses the mortality is 15 to 20 in 1,000 , and in the worst it is 40 to 50 in I,, 00 .

Mr. Michael, the Mayor of Swansea, in England, read before the Association of Social Science a paper in which he divides his town, according to the density of its districts, into three divisions :

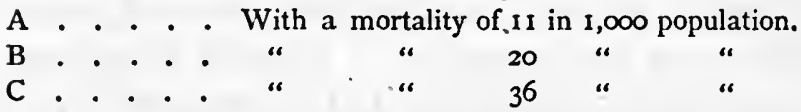

Or, taking the percentage of the houses in which deaths occurred, and taking groups of five houses and the deaths occurring in them during a series of five years, he found of the buildings in district
A, 21-29 pr. ct. had deaths, or I death in 5 houses in 5 years. B, up to 50
C, $90-117$

“ 12 “ 2 “
“"

Out of 127 population, 29 died in 5 years in the poorest district, which gives 58 in 1,000 , while the mortality of the whole district is 24 in 1,000 , and that of the best portion by itself is 11.6 in 1,000 .

Dr. Grunhow, an authority well known in the sanitary world, in an elaborate paper before the 
Association of Social Science, shows, while the mortality of Glendale, a healthy rural district of England, for a number of years was 15.09 per 1,000, that of Liverpool was 36.35 per 1,000! And while the average annual deaths in Glendale from pulmonary diseases were 216 to 100,000 population, the average annual mortality from the same cause to the same number of population was, in Liverpool, I,000.

The death rate of children from nervous diseases is at Glendale 40 in 100,000 population. In Manchester it is 393 !

Infantile deaths from diarrhœal diseases at Glendale were for a number of years 57 in 100,000 population, at Manchester 1,945 in 100,000!

Deaths from all causes of male children under 5 years, were at Glendale, 1848-1854, 3,499 in 100,000, in Manchester there were during the same time, 13,539 !

It is not the location or country that makes so striking a difference, for, as we have already had opportunity to observe, the best buildings in the cities have as low a mortality as the best rural districts have. Unwholesome employment, crowding, intemperance, want, misery and profligacy, all unite to make cities a pest. The low stature and narrow chests of the artisans in cities are proverbial.

Dr. Farr shows that the mortality of towns is in 
direct numeral proportion to the density of population.

But not only does the mortality of a district increase with the density of its population, but the fecundity of a population falls with the rise in its number.

In nine of twenty towns in England, which numbered over 40,000 population, the deaths outnumbered the births, and the increase of the population in all was due to the movement of the population from the country. In Stockholm, Petersburg, Moscow, Venice, Rouen, and many other cities, the population would soon dwindle down to nothing without this emigration from the country. In no city is the proportion of births to deaths as large as in the surrounding country.

In the country districts of Scotland the annual surplus of births over deaths amounts to 1.55 per cent. of the population. In the city districts it amounts to I.33 per cent, and in Glasgow, Edinburgh, Dundee, Aberdeen and others, the excess of births over deaths is reduced to 1.13 per cent.

It was calculated in 1857 that of the inhabitants of England and Wales 8,250,000 persons living on 2,150,000 acres, constituting the city population, the annual death rate was 25 per 1,000 . The remaining 9,750,000 persons living on 350,000,000 acres, constituting the country population, show an 
annual death rate of 17 per 1,000 , a difference of 8 deaths for every 1,000 persons, or 8,000 for every million of population. Of course, as our mortality has not as yet been reduced to that which it is in England, the annual slaughter of our working population is much larger. We are very nice about many little things, and cultivate social murder as one of the fine arts. We strain at a gnat and swallow a camel.

Low rates of life lessen the working ability of the masses eight to ten years.

The population born in large cities under the influence of noxious physical agencies is inferior in physical organization, tending to become shortlived, reckless, intemperate and little susceptible. of moral improvement.

Dr. Baly showed that the mortality from cholera in England and Wales was, in 1854, in

134 districts with 915 population to the square mile, 65 to 10,000 404
85

Dr. Stockton-Hough has carefully collected the most reliable statistics bearing upon the healthfulness of city and country, and finds the old adage verified that the city is but another name for the grave. London has yearly 10,000 more deaths than births. Humanity, if living entirely in such large cities, would be obliterated in less than 200 years. 
Crowding, want, misery, luxury, effeminacy, vice, corruption and crime in high and low places destroy mankind in large cities.

The mortality among children from I to 5 years in one hundred born is, in New York city, 50 per cent., in the country 38 per cent.

The average life in the state of Rhode Island is 31.45 per cent; in Providence, the largest town in the state, it was but 27.9 during 15 years ending 1870.

In the country districts of England 202 out of $1, \infty 00$ deaths occur over 70 years of age, in Liverpool but 90 . In the country the average age is 38 years, in Liverpool it is 27 years. In the agricultural districts of England 20.7 in every 100 persons attain 45 years; in the four great cities of the kingdom only 17.5 reach that age. The average life in the eastern district of London is 25 to 30 years; in the agricultural regions it is 40 to 50 years. General Walker gives the average life in the United States for 1870 as 39.25 years; in New York city and Philadelphia it is only 25 years. 


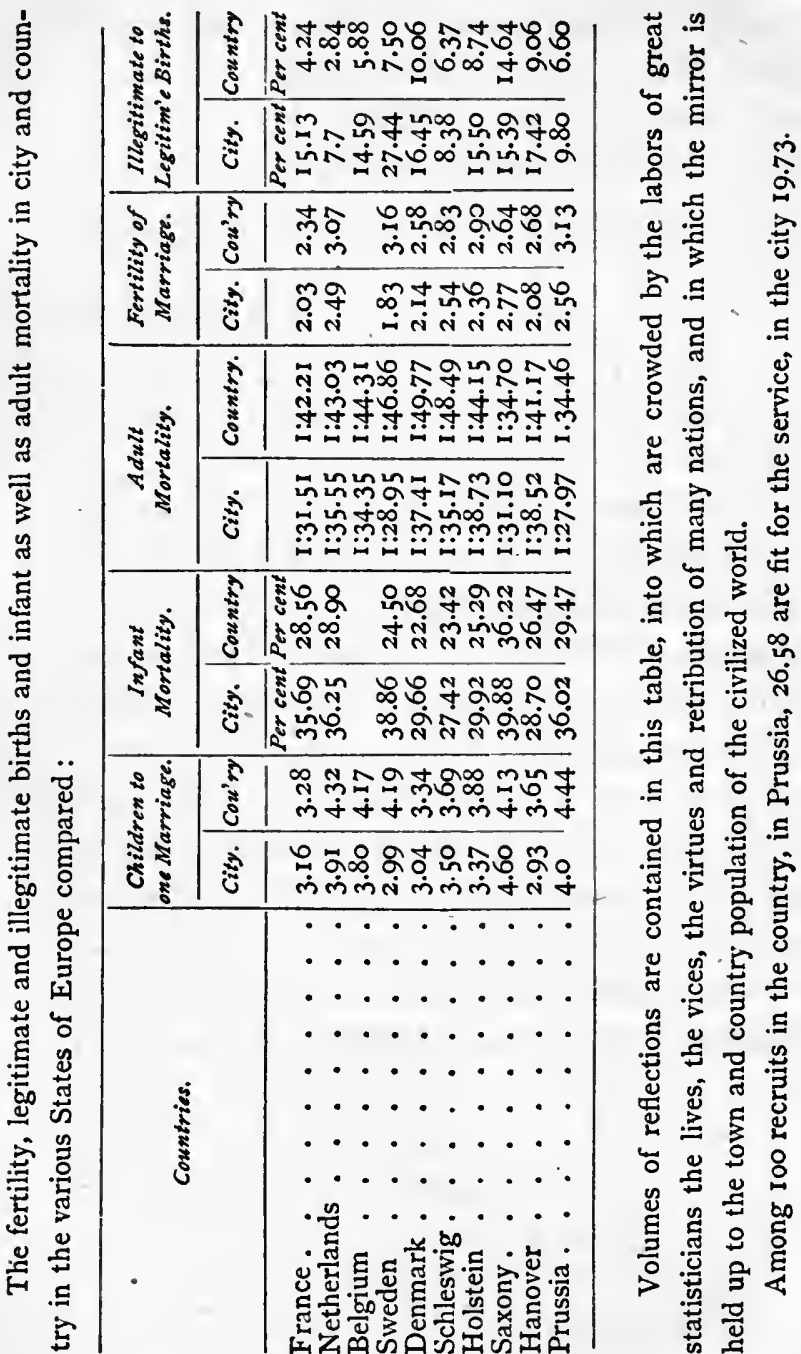


The average life in the cities of France is 35 years, in the country it is 55 years!

According to the Registrar-General of England the mortality in districts with

I or less persons to I acre, is 168 to 10,000 population. I00 to 250 " " " 262 "

In large cities the mortality to each 10,000 is, for London, with 50,000 persons to the square mile, 251 . Leeds “ 87,256 " “ " " 272. Manch'ter “ 100,000 " “ " “ 337. Liverpool " 138,000 " $\quad$ " 3438 .

For more than half a century the rush of population has been more than what is wholesome from the country into the cities, as the following table will show at a glance as far as the United States are concerned:

City population.

I790 . . 3.4 per cent.

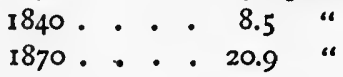

Country population.

94.6 per cent.

91.5 . “

79.1 “

This same movement of population modern industry brought about in England, where the proportion was, in

City population.

$$
\begin{aligned}
& 1690 \text {. . . } 26 \text { per cent. } \\
& 1861 \text {. . . } 56 \text { “ }
\end{aligned}
$$

Country population.

74 per cent.

44 . “

To realize still more the movement of population from the country into the cities, let us consider the 
growth of cities in the United States within this century, which is for

\begin{tabular}{|c|c|c|c|c|}
\hline & 1790. & 1820. & 1850. & 1870. \\
\hline $\begin{array}{l}\text { 13oston } \\
\text { New York }\end{array}$ & $\begin{array}{r}18,038 \\
\end{array}$ & $\begin{array}{r}43,290 \\
123,706\end{array}$ & 130,001 & 250,520 \\
\hline Philadelphia & . 42,520 & 112,772 & 340,045 & 674,022 \\
\hline Baltimore . & . 13,503 & $62,73^{8}$ & 169,054 & 267,354 \\
\hline New Orleans & 6,693 & 27,176 & I16,375 & 191,418 \\
\hline Cincinnati . & ... & 9,642 & I I 5,436 & 216,239 \\
\hline St. Louis . & $\ldots$ & 4,528 & 77,860 & 310,864 \\
\hline Chicago & $\ldots$ & & $\begin{array}{r}29,963 \\
4,853 \\
(1840)\end{array}$ & 298,977 \\
\hline
\end{tabular}

This movement of the population toward the cities is not by any means peculiar to America; it is our modern system of manufacturing, and the people flocking to the cities to make their fortunes. The increase of the population in England between the census of 1850 and 1860 was for cities 17 per cent. and for the country 3.9 per cent.

For the study of race deterioration and its prevention, this movement of population from the country to the city is the more important, as the city combines all the various causes of deterioration, and must the more tell upon the population.

There the air is vitiated by a lessened percentage of ozone and an increase of ammonia, carbonic acid and other impurities and the temperature is altered; it is there we find insalubrious buildings and occupations, epidemics, syphilis, luxury, effem- 
inacy and all sorts of extravagance, pauperism, drunkenness, insanity and crime.

The city mortality is high enough compared with the mortality in the country, and yet the worst is only realized when we consider that the rate of mortality is excessive among infant's, the cities, however, receive a great influx of adult population from the country which bore the risk. So, for instance, are of the 942,292 population of the city of New York of the census of $1870,419,091$ born somewhere else, and there the greater risk of their early mortality was born. The same is the case with I I I, I 74 out of 250,000 population of Boston. In London, of the population under 20 years of age, 26 per cent., and of those over 20 years, 53 per cent. were born outside of London. And the same is true of all growing cities, and gives them a much better sanitary aspect than they are entitled to. For many of their healthy citizens have been reared in the country, and, receiving all the time additions of adult citizens, their proportion of infant population is smaller than it is in the country, and their rate of mortality should, therefore, be much smaller, while, in fact, it is much larger than in the country.

London boasts very much upon its low rate of mortality, but 600,000 of its enterprising adult citizens are the picked men of all England, and it requires just an annual influx of 18,000 men and a 
national nursery of $2,000,000$ rural population, that sends the supply and bears the heavy mortality incidental to the bringing up of such a number of adults, and then London and the like growing cities boast upon their healthy population and their small mortality rates.

Infants being delicate, the unhealthfulness of city life shows itself first, but not by any means exclusively, upon them. Though marriages are more frequent in the city, births are less numerous than in the country; and though adults are more numerous in the city, the proportion of men over forty-five years is there smaller than in the country.

Just as fallacious is the comparison of mortality rates of different cities and states, without taking into account the proportion of immigration received by both and their proportion of infant population. So, for instance, have Massachusetts, Maine and Connecticut but 10,000 infants under 5 years in every 100,000 , while some of the states, like Mis- . souri, Nebraska and West Virginia, have over 15,000 infants under 5 years of age in every 100,000 , and, consequently, though in the latter states the rate of mortality may be greater, their sanitary condition may be vastly better.

Typhus fever, the disease of the prime of life, has, as we have already repeatedly had occasion to see, its origin in such impurity of air as is produced by 
overcrowding, and is a constant cause of death, misery and pauperism. If death does not result, a low state of health becomes the rule. Bad air takes away appetite, depresses the spirits, lessens the vital power, predisposes to disease, and a relief is sought in alcoholism. The children lose all sense of decency, propriety and order, and go to recruit the dangerous classes. It would be cheaper to send children thus situated to a first-class boarding school and put them in a way to become fair, healthy and wise, than to educate them downward into thieves, prostitutes and convicts, and keep up an expensive police force, courts and jails, and lose beside $\$ 25,000,000$ property per annum.

A man must not be allowed to crowd his family into less than necessary breathing space; but he is poor. Do we on that account permit him to poison or knock on the head those depending upon him? Neither should he be allowed to kill them with bad air. Instruct the people in the science of health, which has well been said, is the science of taking plenty of good air, improve what houses we have, build better ones, and protect the rising generation by positive enactments.

We protect property-that is right. But life is left unprotected-that is wrong. Herein the age is erring. Everything is allowable within legal forms that leads to wealth, however much human 


\section{The People and their Homes.}

life may suffer by it. Englishmen send out armed piratical crafts to force their poisonous wares or opium cargoes upon unwilling nations; and England itself, a Christian nation, goes to war to force $z$ hundred thousand chests of opium per annum upon hundreds of millions of men in Asia, spreading thereby misery, death and madness, and bringing ruin of body and soul upon countless people. But then, this makes commerce.

This must cease, or we shall all perish, for a lie cannot stand, prop it up as much as we may. Life must be sacred or property will soon cease to be sacred. The law of life and its sacredness must underlie every other law and institution. Hygiene must become a religion extending its influence in every direction. And the homes of the people must, above all, be brought under the influence of the law of life and hygiene.

Already three hundred years ago, under Queen Elizabeth, the following law was passed: "No owner or occupier of any cottage shall suffer more than one family to cohabit therein under fine of ten shillings."

The London Times and other influential papers, agree that the legislature has a right for the protection of innocent victims to fix a suitable minimum of breathing space, and to give greater power to inspecting officers. 
Sir George Strickland says: "Wherever you have an overcrowded population you will observe impaired health and morals, and, in consequence, lack of energy and self-respect. Sanitary improvement is the first step toward the elevation of their habits and tastes."

Mr. Rawlinson says: "In my large experience I have found overcrowding everywhere attended by misery, disease and crime. The people can no more help it than they can roll back the sun in his course. Healthy people may go into abominable overcrowded tenements, but nothing but disease and misery can come out of them. The formation of suburban villages for the working people, with cheap and rapid communication with the cities, would be one of the greatest blessings conferred upon the laboring population of the country."

Dr. Markham says: "It is the duty of the employer, and he should be bound by law to attend to it, that work-people-while engaged at work by him-should have proper accommodations, so that they may not have their health injured by overcrowding. People do not know that overcrowding undermines their health, and the first epidemic, be it typhus, smallpox or cholera, destroys them by thousands."

The community has a right to legislate how much of a lot must be left free by the owner for 18* 
giving scope to the atmosphere and free access of light.

We cannot legislate work, but by a consistent sanitary legislation we can protect the people in their health; and when they will have this, they will find every other desirable thing.

We own we have but one idea-in Education, in science, in industry, in government, in civilization and in religion-we know no higher and no more sacred principle than even this regard for human life, which includes everything else that is of solid worth.

There is an ancient people whose religion and legislation are chiefly founded on hygiene, and what spectacle does this nation present? It has furnished the world with a code of morals and the spirit to live up in a measure to the standard placed before them. This ancient people-hardly necessary to name-is preserved to this day in spite of the ravages of time and the persecutions of men, and though its dietary code dates back thirty-five hundred years, when nature's laws were but little understood, its effects on the Jewish people are better told by the comprehensive figures of statistics than by long discussions.

The most exact statistics of Prussia show the following death rates at the various ages of a population of 100,000 : 


\begin{tabular}{|c|c|c|c|}
\hline Still births & . & $\begin{array}{l}\text { Christians. } \\
. \quad 1433\end{array}$ & $\begin{array}{c}\text { Ferws. } \\
89\end{array}$ \\
\hline o-I year. & . & . 697 & 453 \\
\hline I-5 years. & . & 477 & 386 \\
\hline $5-14 "$. & . & $202^{\circ}$ & I5I \\
\hline $14-25$ “ & . & 155 & 123 \\
\hline $25-45$ “ & . & 334 & $23 I$ \\
\hline $45-70$ “ & . & 614 & 392 \\
\hline 70 and over & . . & 339 & $33^{\circ}$ \\
\hline
\end{tabular}

The pest in 1346 hardly touched the Jews, as the old historian Tschudi vouches. They enjoyed the same immunity in 1505 , according to Fracastor. They were spared from the intermittent fever which raged at Rome in I69I, as Rammazini states. The epidemic dysentery at Nimêque, according to Degner, spared them. The Christian sufferers from the pest were, therefore, declared the victims of wells poisoned by the Jews, who, in fact, owed their immunity to their conformity to the laws of hygiene.

Human life is not altogether a physical process, it is the basis of all our social and moral relations; whatever touches it assumes a peculiar importance.

Whatever shortens the life of man degenerates his race, and by lowering his energy and powers lessens the number of great men, and strikes thereby a blow against the Bacons, Newtons and Washingtons; it makes us a scrofulous and cretin-like race, unfit to govern ourselves or the state, and renders us slaves to passions within and tyrants without. 
Shorten the life of man, and knowledge and experience are not put to half their use; inventions go prematurely to the grave; and the proportion of the young, and, therefore, of the unproductive, of the criminal, of the inexperienced and the foolish, of the turbulent, of births and funerals, of widowhood and orphanage, of vagabondism, of pauperism and of vice and crime, is increased.

Shorten the life of man, and with the shortened generations thought, action, government, institutions and systems become feverish, the constant, silent action of time-which alone leads to healthy maturity-is broken; everything is hurried through as if hardly worth doing and comes into the world with the thought of leaving it in its mind, with paleness on its cheek, wrinkles on its brow and a coffin on its back, for when man is short-lived his work can be but fleeting.

Shorten the life of man, and principle, character, moderation, good habits and wisdom-all the work of many years-lose their power and influence, for young people incline to change for better or worse, just as age is conservative and preserves the state.

Shorten the life of man, and with the fulness of years disappears the sweetest charity, the broadest toleration, the most imperturbable justice, the most consummate skill in the management of great affairs, 
and the steady building and developing spirit which produces in science, life and government positive and permanent results, as Socrates, Newton and Humboldt did.

Shorten the life of man, and you deprive the workshop of the strong laborer, commerce of the honest and trusted merchant, and the government of the wise patriot. Industry will, therefore, languish, commerce dwindle and the nation decay.

Shorten the life of man, and you strike infancy and ripe age; the one destroys love in the family and the other veneration in the community, and both destroy man's motive for exertion; for, while man naturally works for his children and his own old age, an excessive mortality destroys both.

Shorten the life of man, and the strong though silent influences even upon rough men by sweet and holy childhood disappear; the invigorating presence of men in their best estate vanishes with their health, and the earnestness of life gives way to levity when venerable age is taken from us. Every age as every sex has its own peculiar qualities and virtues, and men and institutions are only perfected by the silent mutual Education of all the integral parts of a complete humanity.

But the disastrous bearings of an excessive mor- 
tality or a puny humanity shriveled in body and mind, in thought, motive and action, are beyond numbering; and we will only add that the wanton slaughter of our young children as well as of our prematurely dying parents, cannot but breed in us such an indifference and carelessness about life as will crop out in a thousand ways as social murder, and stamp us a fratricidal race. Love, goodness, beauty and truth are the highest functions of man, and require him to be in the healthiest condition; an excessive mortality is of necessity accompanied by feebleness, cunning, treachery, lying and lowmindedness. A long-lived race is a healthy, freedom-loving and defending race; a short-lived race is a cowardly race, one that neither loves freedom nor dares defend it-it is a race of tyrants and slaves. It is a race without truth, bravery or magnanimity. A race hardly worth the short existence allotted to it. It is bankrupt in body and soul, and held in derision by God, man and nature; and the best it can do is to perish and wipe out the blackest spot of creation - a race that has cast away the noblest heritage, a God-like humanity.

Do we lose sight of the great subject of our essay, Education? Surely not. But we mean to impress the all-important fact, that the miserable abodes of the people, breeding disease, vice, drunkenness and crime, render all true Education im- 
possible. Schools supported by dog-kennels may manufacture ciphering rascals, but to educate men and women they must have the co-operation of well-regulated homes.

We dwell upon physical comforts for the masses as the lowest round which must be passed before the highest can be reached. Destutt De Tracy, the well-known scholar and statesman, says, "Neither a legion of school teachers nor the professors of logic of all Europe can assist as much the civilization of a people, as an additional degree of well-being, which gives them leisure," the very thing without which the school is a name without a meaning.

We do not under-value the treasures of the mind. With Prof. Jos. Henry, Rénan and Prof. John W. Draper, we assign to perfect knowledge the highest place in the State. But we distinguish philosophical, practical and verbal knowledge or vague opinion; the first, like the hidden forces of nature, is a life power, and all-penetrating; the second, substantial like matter, is the very foundation of society; and the third, like shadows vast and running before the things which cast them, spreads darkness and works confusion; and, hence, as philosophy is attainable but by few of rare talents and leisure, we are, in the interest of truth, peace, order and prosperity, in favor of practical knowledge and industrial training for the masses. 


\section{PART SEVENTH.}

THE SCOURGES OF HUMANITY.

IN a treatise on Race Education, of which the prevention of human deterioration by forestalling bad habits or hereditary evil tendencies through correct early training and teaching, forms a not unimportant part, drunkenness, often hereditary and more frequently the child than the parent of poverty, but often the parent of insanity, of suicide and of crime, claims our attention.

Morell, who has made human deterioration a specialty, mentions in his pathological studies the case of $\mathrm{F}$ - who was the son of an excellent workman early given to hard drinking. $\mathrm{He}$ inherited the tendency to strong drink, and had seven children. The first two died in infancy of convulsions, a nervous affection. The third attained some skill in handicraft, but fell away into a state of idiocy at twenty-two years of age. The fourth attained a certain amount of intelligence, and relapsed into profound melancholy with a tendency to suicide, which terminated in harmless imbecility. The fifth is of a peculiarly irritable tem- 
per, and has broken all relations with the family. The sixth was a daughter, with the strongest hysteric tendencies, and has been repeatedly and seriously troubled in her reason.

Here is another pathological study of a gentleman of distinction and an inveterate inebriate. Four of his children perished in infancy, as the children of such men usually do; the fifth, a son, in spite of every precaution taken by Education, was at nineteen the heir of his father's vice in an insane asylum ; as a child he was extremely cruel, as many children of inebriate parents are-the terror of their playmates and of innocent little animals.

Morell cites many cases of children of inebriates cursed in later years with the hereditary bent of excessive alcoholism, leaving one insane asylum for the other, and ending in marasmus, general paralysis, in a perfect brutal condition, and the utter extinction of reason and conscience.

The same great author and physician gives the following analysis of a family under his treatment. In the first generation : immorality, depravity, excessive alcoholism and moral torpor. In the second generation : hereditary drunkenness, mania and gencral paralysis. In the third gencration: sobriety, hypochondria, monomania of being persecuted. In the fourth generation : little intellect and homicidal tendencies; at the age of sixteen, fits of mania, 
stupidity, transition to idiocy and extinction of the race.

Morell further says: "I constantly find the children of drunkards in the asylums for the insane, in prisons and houses of correction. The deviation from the normal type of humanity shows itself in these victims by the arrest of the development of their constitutional system as well as by a vicious intellectual disposition and cruel instincts."

Dr. Elam justly remarks, the children of the poor, where this evil tendency remains uncorrected by a good physical and moral Education, the surroundings are vicious, and want and misery irritate a weakened constitution, the consequences of drunkenness in the parent are aggravated, and, hence, the frightful amount of insanity among the poor.

The intellectual and moral nature of man is his very essence, and its total degradation betokens a morbidity or deviation from the normal type, which cannot be but hereditary.

A system of Education that aims at the preservation of the human race, cannot lose sight of drunkenness and its prevention, the means of which are many and decided, and form the natural elements of a practical Education, as we shall have further opportunity to show. The characteristic mental features found by Morell in the children of inebriates and which demand attention, are 
an irresistible wandering from place to place, a want of purpose, indecision, lawlessness, moral obtuseness and a taste for ardent spirits. What a heritage! the very genius of pauperism and the high road to crime to which vagabondage unfailingly leads. The desire for stealing and the taste for the lowest and most vicious associations, as also a spirit refractory to all regulations, accompany the morbid appetite for strong drink in the victim of hereditary dipsomania.

Maudsley says, drunkenness in the parent is a cause of idiocy, suicide or insanity in the offspring, as also insanity in the parent may occasion dipsomania in the offspring, which conclusively proves the deep-seated deterioration of the nervous system arising from drunkenness, the close attendant of pauperism.

Delirium tremens is not the worst nor is it the end of drunkenness, which weighs down humanity with a leaden curse, convulsing it through generations, until, at last, the spirit in man succumbs to the demon, and every trace of divine intelligence and power has been crushed out in the long and painful struggle.

Alcoholism is attended by great weakness, cramps, convulsions, partial paralysis, horrid pains, sleepless nights, restlessness, delirium, haggardness, a complete abolition of the intellectual and moral pow- 
ers, a perfect obliteration of the will and excited desires, which make the drunkard a brute, lost in indifference to all, and moving like an automaton, without motive or end, but drink, with the heart, lung and liver suffering, and ending in marasmus, dropsy, diarrhœa or delirium tremens.

Among 1,000 paralytic insane, studied by Morell, 200 were reduced to that condition by hard drinking, and of 200 inebriates, who found their way into the insane asylum, 35 were obviously hereditary cases.

Four brothers inherited the passion for drink, in which they all indulged to excess. The oldest drowned himself, the second hung himself, the third cut his throat, and the fourth threw himself out of an upper window. And there is, in fact, no end to the sad stories of whole generations of drunkards. The drinking habit of the parent is in most cases an irresistible impulse or disease in the child, uncontrolled by any motive whatsoever. Men are treated by the law as criminals, when they are in fact maniacs.

When the duty on spirits was removed in Norway in 1825 , between that time and 1835 insanity increased 50 per cent., but the increase in idiocy was 150 per cent.!

Out of 300 idiots, examined by Dr. Howe in the State of Massachusetts, 145 were the children of intemperate parents. 
Sweden consumes $25,000,000$ gallons of spirits though it has but $3,000,000$ population-of whom but half are of an age to drink-and the consequence is that insanity, suicide and crime are fearfully common among them, notwithstanding every one of them has what passes commonly for an Education.

In two hospitals at Copenhagen, of 1,000 male patients among mechanics, 34, and among day laborers, 80, suffered from delirium tremens; among the first class $6 \mathrm{I}$, and among the latter 104 cases of deaths were the result of liquor. Of 100 deaths among saloon keepers and bar tenders, 13.4 per cent. are caused by liquor.

Neison, the great English statistician, established from extended observations made on 6, I I I drunkards, that at the ages of $2 \mathrm{I}-30$ the mortality among them is five times, and at $30-50$ four times as high as among temperate people; and while of 6, I I I common people, 100 should have died at all ages, the drunkards lost 357 .

The expectation of life is at

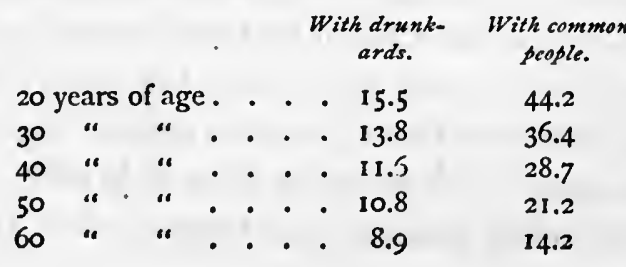


While at 20 years of age a common man has an expectation of living 44 years, a drunkard has but an expectation of 15 years, which cuts his life short 35 years!

Drunkenness is the bridging over from pauperism to insanity, and the three together represent the complete destruction of humanity.

The statistics of England are noted for their reliability. The following table will, therefore, show the exact increase of insanity among the English poor. The population of England and Wales was in $1861,20,061,725$.

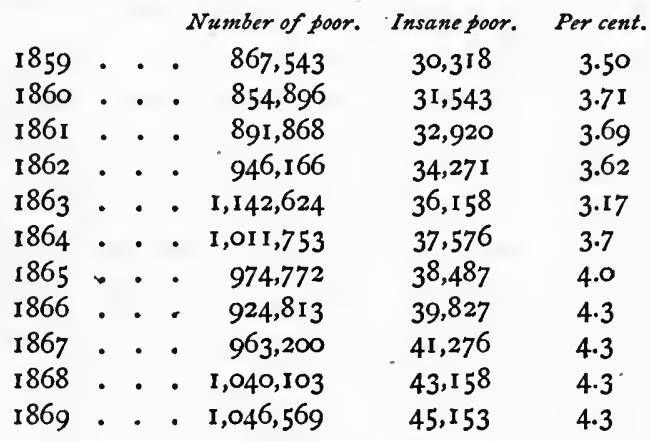

Whosoever can read this table intelligently and his heart does not ache for his brother, need not mistake his own quality any more. Let him set down himself for all future a heartless villain. 45,153 insane among $I, 046,569$ paupers, or 44 in every $I, 000$, in 1869; while England and Wales had 21,158 in- 
sane paupers, or 23 in every 1,000 , in 1852 , which gives an increase of $9 \mathrm{I}$ per cent. of these unfortunates in seventeen years! Think for a moment, the city of New York had 50,000 maniacs and the United States 2,000,000; well, the proportion of the insane among the very poor-we may call them paupers, they are men and our brothers still-is just the same. Is this not a degenerating humanity? And ought Education not to meet it with different weapons than grammar, spelling and geography?

A State Report of 1855 , of Massachusetts, shows that the picture is as dark here as it is in England, and that insanity afflicts the poor sixty-six times as much as the independent classes.

What we have said sufficiently establishes that drunkenness most fearfully deteriorates the race, and should be met by Education, which must look to the preservation of the race. But the subject is too important to be dismissed without further remark.

George Combe maintains overwork and underfeeding to be among the chief causes which induce the craving for stimulus. The school, therefore, by spreading technical knowledge must relieve the laborer of his poorly-paying drudgery, which means much work for little pay, that leads him to the gin shop. 
Prof. Fawcett traces drunkenness greatly to excessive toil and ignorance. The toiling masses are reared in_such ignorance, squalor and misery, that life to them is dreary and nature without beauty, and moral beauty exists for them no more than the beauty of the physical world, for society and the laws of government oppress them, and wife and children sadden them in proportion to their love for them.

Rev. Alexander Macloid strenuously insists, that drunkenness is not a voluntary evil. The polluted atmosphere in which the poor live, the poor dwellings, the bad food, the want of temperate refreshments and of a sensible Education, which is a check on low desires, are all causes of drunkenness. The most unwholesome and exhausting trades, as the mining and iron industries, count the hardest drinkers.

To the causes of drunkenness already stated, we may add over-excitement as well as depression, chagrin of all sorts, anger, etc., need we say, hunger, cold, hopelessness, self-abandonment and shiftlessness?

In many trades an irritating animal, vegetable and mineral dust produces a continual dryness and irritation in the respiratory organs and throat, and, hence, a desire for drink.

Want of employment and a mind not finding 
sufficient mental excitement in its occupation, lead also many to drunkenness.

The cultivation of higher tastes and pleasures, delight in flowers, music, song, paintings and gardening, science, literature, and whatever raises the condition and dignity of workingmen, will remove them above the low and degrading vice of drunkenness. An Education that will raise the work-people from mere routine drudges to the rank of thinking mechanics, will lift them above all temptation of drunkenness, for as skilled artisans they will cease to be poor, to want food for the body or food for the mind; as men of thought they will, as a rule, be neither over-excited nor depressed, as thinking cultivates equanimity; they will not be debarred from the higher and purer delights of the mind, and if they enter the company of the low it will not be to fall into their vices, but to raise them who are low; careful men and trained in the scientific principles of their trades, they will soon rid their work of every element that may tempt them to drink.

The Westminster Review says: "While men are permitted to breathe pestilential air all their life, how can we expect the love of strong drink to perish? Shorten work, or the drooping frame will infallibly have recourse to stimulants. Give the workingmen libraries, amusements, lectures and 
leisure for attendance; good and cheap newspapers have already done much to elevate the workpeople, and will do much more; park excursions, woods and fields, sky and open air, all elevate and improve man's better nature."

Taine, the philosopher and historian, says: "The depression of the workingman and his whole condition drive him to the cup and drunkenness."

The workingman, whose wages must be supplemented by those of his wife working out of the house, is driven, by the cheerless, unprovided doghole of a home he enters coming from his day's labor, to the more inviting public house.

The squalor of the poor separates them like a gulf from better society; it is crushing and degrading and destroys all self-regard, with which all else is lost.

The unceasing toil of men, women and children renders all culture and virtue impossible among the poor.

A practical school that uses more collections of objects of nature, art and industry than text books, will form a taste for zoological gardens, picture galleries and industrial museums.

Let us clean out our own hearts and join the company of the poor. He who had their welfare at heart did not disdain to mingle with wine bib- 
bers. The paying out of wages at long intervals gives rise to sudden excesses and long depressions, which both favor drunkenness.

Misery leads to drunkenness and is intensified by it. Ireland drinks more than England, because it is more miserable.

Many laborers suffering ill health induced by over-exertion take refuge from exhaustion in stimulants. Many suffer from indigestion brought on by protracted in-door labor, and the appetite failing early in the morning they take a glass, and soon another one, and so on.

The London Times, very guarded in its statements, says : "Many workmen could not get through the work by which they gain their own and their children's bread without liquor." Of course, a man ought not to draw to-day upon his vital powers of to-morrow.

The same great journal continues in the same article: "That to many of the poor people, living in over-crowded, ill-ventilated, ill-lighted rooms, the public house is the only place in which they can enjoy a quiet evening in pleasant and perhaps instructive intercourse with their neighbors after a hard day's work, cannot be denied."

The vice of drunkenness was a hundred years ago universal; with wealth the well-to-do classes gained in refinement; as we spread by our human- 
ity comfort among the masses, grace will also adorn their manners.

Careful statistics prove that in proportion that a more thorough Education and well-being spread among the working-people everywhere, in England, France, Germany and among us, in the same proportion is drunkenness lessened.

The vast capital that is wasted in poisonous liquors, the army of men engaged in this nefarious manufacture and trade, the pauperism that is made and intensified by it, the crimes that are committed under its influence, the families that are broken up by it, the brutality that is nursed by it; the idleness and loss of industry and the consequent want of which it is the cause, the army of court officers, police, jail and penitentiary officials it makes necessary, the broken-hearted widows and deserted orphans it fills the country with, the prostitutes it makes-all this, and more than all this, the low, vicious state in which we all more or less must sink living in such a community, render it difficult for us to suppress facts and thoughts calculated to throw light on a subject exercising the hearts and minds of the good men and women of this land. But our space commands us to break off-and we can only appeal to teachers to believe us or to consult perplexed boards of charities and correction and burdened tax payers, and they will find 
that pauperism, drunkenness, insanity and crime are not accidents, but evils of a steady and gigantic growth, defying all palliatives, and threatening the life of modern communities, which Education alone can prevent by practical training and measures all taken in view of this great purpose during the long years of the formation of men and women at school.

John Brown consents to keep John Smith at school in his early years that he may not have to keep him at a later day in jail, the poor house or insane asylum, but he positively refuses to pay a hundred dollars school tax, and deprive himself of so much comfort that John Smith may learn the name of every river in Africa, or spell at school every word between the lids of Webster's unabridged quarto dictionary.

Educators, whose horizon does not widen beyond declensions and conjugations, have long since laid aside this volume, and men interested in the race and its preservation will not shrink from the study of evils, which no amount of prudery will wink out of existence.

The virus of syphilis spreads noiselessly, and destroys the race in its very germ, poisoning the blood, disorganizing nerve and bone, and inflicting. scrofula, phthisis, insanity and many other forms of disease upon the innocent, a fearful heritage of 
shame and woe that fills them with thoughts of self-destruction.

Neither the extent nor depth of this evil is sufficiently understood. Through hereditary transmission syphilis appears after one or two generations as scrofula, which, like the parent evil, attacks the mucous membranes, the flesh and the bones, is hereditary and amenable to the same treatment.

It is equally the opinion of weighty medical authorities that phthisis, of all deadly diseases the most common, robbing the young and the fair so often of life and hope, and the very scourge of mankind, is, to a great extent, the taint of syphilis in the blood, spread at the end of the fifteenth century, when the licentiousness of princes and prelates had reached its height, and, as Buckle says, from the Pope in the Vatican to the chambermaid, this terrible malady had afflicted all classes.

In Rome, we are informed by cotemporary writers, the disease broke out in March, 1494, and spread before the year 1495 all over France, Italy, Dalmatia, all the parts of Macedonia and Greece, Germany, Mecklenburg, Westphalia, upon the coasts of the Baltic and Roumania, and did not spend its force until the end of the sixteenth century, after every twentieth person all over Europe became a victim of this loathsome pest. This universal plague was followed by more partial ones at the 
end of the eighteenth century in all parts of Norwegia, where it was brought by Russian soldiers; in Sweden, where Norwegian soldiers introduced it ; in East Gothland, where soldiers coming from Pomerania brought it in 1762 ; in Norrtige, brought by soldiers in 1790 ; in Courland, introduced in 1757 by the soldiers of the Seven Years' War; in Lithuania, brought in 1800 by the Russian soldiers. In 1760 , it raged on the banks of Lake Huron, and made great ravages on the shores of St. Paul's Bay among the Ottawa Indians. In I785, 5,800 were afflicted with this poison in the then sparsely populated Canada. It ravaged in I79I, and for many years in Illyria, and as late as I84I in certain localities in France. In Sweden and Norway it often commits ravages; it is remarkably frequent and extended in England, in large towns or where the military are located, who make more havoc at home by the spread of this most loathsome and deteriorating disease, than they ever do among the enemy with cannon or bayonet. Such is the history of the introduction of the virus of syphilis into the blood of the living generation, and which enforces upon us its tribute paid by scrofula, which appears in a variety of skin and other diseases, in the different forms of defectiveness, and, above all, as phthisis, in which form it makes the greatest ravages; it certainly is of all the deteriorating agents 
the most fearful, and demands the attention of every friend of humanity.

The virus of syphilis in the blood does not only, as Dr. Sanger says, entail upon children a mental and physical unfitness for action in the active pursuits of life, but feeds low desires, stimulates the appetite for strong drink, produces a cynical state of mind and an obliquity in the mental and moral nature of man, which renders him mendacious, hypocritical, cunning and selfish, poisoning Church and state, and answering for much that is reprehensible in both.

The insidious nature of this fearful poison calls for exact information based upon statistics which cannot be questioned.

From 1804 to $1842,129,809$ venereal patients have been treated in the hospitals of Paris, the number increasing with every year, so that while it was 2,212 in 1804 , it was 5,059 in 1842 , and to this day this number must have more than quadrupled. What a deterioration of the nervous system, epilepsy, insanity and suicides such an amount of syphilis must produce!

The Report of Guy's Hospital in London states 43 per cent. of all external diseases treated there are venereal. Mr. Caspar Foster states 174 cases of 285 in surgery, in 1867 , were venereal cases. The Royal Free Hospital in London has daily 1 I 7 new con- 
sultations in venereal cases, or 3 in every 8 cases of a surgical nature. At the hospitals of King's and University Colleges, St. Mary's, Westminster, London, Middlesex and Metropolitan Hospitals, one-third of the surgical cases are venereal. In the hospitals for the sailors, 50 cases are daily brought in. In the Eye Hospital for Children onefifth of the cases are syphilitic. Dr. William Remond states that in the Children's Hospital 93 boys and 105 girls, or I in every 5 children, were affected with syphilis. In hospitals for skin diseases one-eighth to four-fifths of the cases are syphilitic eruptions.

From 1844 to 1851 the British army, numbering 44,6 I I men, had annually 8,032 , and the navy during the same years annually of 28,800 men, 2,880 venereal cases. From 1859 to 1860 , of 1,000 soldiers in London, 422 were treated in the hospitals for venereal affections.

Recruits examined for the service in 1853 showed 250 in 1,000 the symptoms of syphilis. In 1860 , the British army numbered 306 cases of syphilis in every 1,000 men, and each man averaged 8.69 days yearly loss in the hospital.

At Vienna were treated in the hospital in

Men. Women. Girls. Children. Total.

\begin{tabular}{|c|c|c|c|c|c|c|c|}
\hline 1860 & - & - & 3.550 & 62 & 1,440 & I & $5,4^{6} 3$ \\
\hline 1861 & . & . & 3,375 & 73 & 1,753 & 5 & 5,206 \\
\hline 1862 & - & & $4, \infty 00$ & 77 & 2,019 & 5 & 6,901 \\
\hline 1863 & . & & 5.808 & 90 & 2,224 & 6 & 8,128 \\
\hline
\end{tabular}


Under private treatment there must have been three or four times as many.

Among 42,000 artisans in Berlin in 1856 and 3 I,000 sick at the hospital, were I,800 cases of venereal, or 4.3 per cent. of the artizan population, and 6 per cent. of the hospital cases.

Syphilitic cases under hospital treatment have doubled in little Bavaria, as everywhere else. In the hospitals there were in 1859,974 cases; 1861 , I,32 I cases; I865, I,834 cases.

At the end of the last century the inhabitants of several districts in Denmark were obliged to submit to an official medical examination on account of the frequency of syphilis among the people.

Syphilitic children die mostly in their first infancy; still, in the hospital of Bordeaux, I856-1861, 77 children among 2,719, or about 3 per cent., show plainly symptoms of syphilis, and 66 of this number died before their sixth year.

The following facts, gathered from the work of Dr. Sanger, show the increase of venereal poison in New York City. Blackwell's Island Hospital treated in

$$
\begin{aligned}
& 1854 \text {. . . . I,54I venereal cases. } \\
& 1855 \text {. . . . 1,549 “ } \\
& 1856 \text {. . . . . 1,639 “ } \\
& 1857 \text {. . . . 2,090 “ }
\end{aligned}
$$


The following table contains the venereal cases in the various public institutions of the metropolis in the year 1857 :

Penitentiary Hospita, Blackwell's Island . . 2,090

Almshouse, Blackwell's Island . . . . 52

Work-house " " . . . . . . 56

Penitentiary " . " . . . . 430

Bellevue Hospital . . . . . . . . 768

Nursery Hospital, Randall's Island . . . . 734

New York State Emigrants' Hospital, Ward's

Island . . . . . . . . 559

New York Hospital, Broadway . . . . 405

New York Dispensary, Centre Street . . . 1,580

Northern “ Waverley Place . . 327

Eastern “ “ Ludlow Street . . . 630

Demilt “ Second Avenue . . 803

Northwestern " Eighth “ . . 344

Medical Colleges . . . . . . . . 207

King's County Hospital, Flatbush, L. I. . . 3 II

Brooklyn City Hospital, Brooklyn, L. I. . . $\quad 186$

Seaman's Retreat, Staten Island . . . . . 365

Total . . . . . . . . . . . . $\overline{9,847}$

Cases in these Institutions unrecorded . . 4,923

Total . . . . . . . . . $\overline{14,770}$

Add to these hospital cases the number of persons treated all over the city, privately, which must be at least three and four times as many, and we may form a somewhat correct idea of the deterioration of the race from syphilis. This estimate may appear high, but as we have for every 5 per cent. adult males one prostitute spreading the virus of syphilis, the result can surprise no one. 
What a fearful amount of deterioration of the physical and moral nature of man must this poison effect! More than half of the seamen are its victims, 100 to 200 in every $I, 000$ soldiers suffer from it, 25 to 30 per cent. of all the sick in military hospitals are affected with it, 5 per cent. of the paticnts in all hospitals are sick with it, 4 per cent. of the poor and 2 per cent. of the entire population of large cities are tainted with it, I to 2 per cent. of innocent infants perish from it, and many more transmit it to coming generations as a fatal potency cropping out in deteriorating diseases without number.

It is the milliners, seamstresses, tailoresses, dressmakers and the like low-payed occupations, which force women into the path of vice. But one in five hundred cases was found by Dr. Sanger, in which a woman in the better remunerated trades followed this low life. "Working from early dawn till late at night, with trembling fingers, aching head and very often with an empty stomach, the poor seamstress ruins her health to obtain a spare and insufficient living."

Among I,224 of these miserable creatures the earnings of their honest trades yielded them per weck in

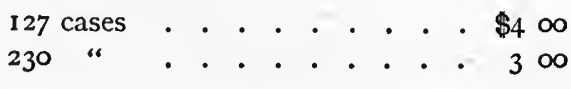


336 cases . . . . . . . . $\$ 2 \infty$

534

Whatever fosters prostitution by interfering with woman's making an honest livelihood, or encourages concubinage by rendering the maintenance of a family by the masses of the people impossible, or undermines the family by false teachings, is the indirect means of spreading syphilis, the fell-destroyęr of the race, who, unchecked, would exterminate it in the course of not many generations.

Let the school see to it, that woman on leaving it may be trained for maintaining herself honestly, and that man may be enabled to support a family with his labor, rendered effective by a practical and scientific Education.

We must banish, says a great sanitary authority, misery, educate men correctly, fill them with higher interests, make sanitary care a religion, put life under the authority of correct morals and a comprehensive hygienic legislation, restrain selfishness, and fill all with a spirit of love and mercy by a regenerated civil and penal code. Nothing so much as purity of morals and cleanliness oppose the genesis and spread of syphilis, but want and misery are hardly compatible with cleanliness and purity.

Let wisman be trusted with the holy office of training and educating the race in the national nurseries of the land, and she will cease to lead the 
fashion and induce extravagance; a man will then be able to support a family on a modest income, and prostitution will consequently become exceptional. Woman in her elevation will disdain to subserve to the pleasure of man or to live for her own vanity sake; her labors for the race will spread a noble spirit, and want will bring her no more to that lowest depth of infamy which disgraces to-day man more than her and most of all our Education, which makes us all what we are. The school is responsible for the prostitution it does not prevent, and the pest it does not arrest it spreads.

Our schools teach us many fine things, but leave such matters to jails and houses of correction, which in their turn deem it labor lost to attend to a field overgrown with weeds.

Shall we, then, correct this race-deteriorating evil by Race Education, which strengthens our hands and gives them cunning and inspires our heart to work for the race and its preservation, or shall we make a yearly contribution of 70,000 to 100,000 illegitimate births and half as many infantile deaths, and the day of judgment may reveal how many infanticides registered "still births"?

According to exact statistics 700,000 illegitimate children are annually born in Christian Europe, or one illegitimate child to every 13.5 legitimate. In 
some of the large cities every second or third man is a bastard.

In France the number of illegitimate children were in

$$
\begin{aligned}
& 1844 \text {. . . . . . . } 73,950 \\
& 1849 \text {. . . . . . . . } 75,395 \\
& 1857 \text {. . . . . . . 76,189 }
\end{aligned}
$$

Marbeau, in the Séance of the Academy of Moral Sciences, gave the following interesting social figures, expressive of the moral condition of France:

76,189 illegitimate children.

35,000 abortions.

34,000 abandoned children.

30,000 still births.

I68 infanticides.

The Medical Chirurgical Review calculates that at the very least, a million and a half of persons are yearly infected in Great Britain with this most terrible poison. How enormous, then, must be the number of children born with secondary syphilis! how immense the mortality among them! and how vast the amount of disease and misery transmitted to coming generations! It is this that fills our hospitals, insane asylums, asylums for the blind, the deaf and dumb, our poor-houses, jails and many an early grave.

And here, then, again the question urges itself upon our mind, can Education engage in a more important work than arresting this as well as other 
pests which deteriorate the race and dwarf the proportions of man?

Standing armies, these ulcers of modern states, the graves of liberty, consuming the earnings of the nations and heaping up monstrous public debts, causing rates of taxation that bear heavily on all enterprise, these evils require volumes to be shown up in all their bearings, but cannot be left unmentioned where the scourges of humanity are-numbered. They are sources of death and destruction in times of profoundest peace as well as in times of war, as we have shown by their rates of mortality and suicide and the propagation of the most loathsome and deteriorating disease among the nations. They are a public sanction of murder and robbery, and are a standing challenge to God and humanity.

Our prisons are another public scourge and a hotbed of human deterioration; and what else but our schools can we blame for the state the criminal is in, or for the worse laws and officials, who in the name of justice perpetrate the greatest injustice, malice and revenge, and render men's lives cheaper by their dealings than the criminal ever did in his lawlessness, creating nests breeding vice and crime of the deepest dye, which like a torrent sweep destructively over the land they were to protect, by reforming or making innocuous dangerous men.

The trades and pursuits of artisans which are 


\section{The Scourges of Humanity.}

sources of pleasure, delight and comfort to all are under our present system of Education scourges to the men, women and children who actively engage in them. A description of the deterioration of the masses, arising from the numerous trade diseases, would swell our volume beyond proportion; we can but hint at the skeleton, but dare not enter the charnel house.

An observing employer remarked: "The men drop off from work unperceived and disregarded. I am quite at a loss to know what becomes of them. When they leave off working, they go, and are seen no more. Some, perhaps, become applicants for charities; but so few have I known of the ages of sixty or seventy, that leaving work, they seem to leave the world as well, a solitary one appearing at intervals to claim some trifling pension or seek admission to the almshouse." This is as melancholy as correct a representation of the end of the artisan, still let our end be like his, rather, than to be among those who can read such a summing up of a hard workingman's days without a deep pity stirring in their heart for poor humanity.

Man after man dies of decay in the prime of life and no warning is taken by the survivors. Men are generally unwilling to admit the fact of the excessive mortality of their trade. They will hardly 
admit that they labor under a disorder until consumption is established, and its effects apparent to every observer. To the physician's inquiry all the workers in dusty trades will say, "We are all pretty healthy," and it is only by examining each workman that the physician finds the deception.

Here is the description of an eminent physician of the operatives of a cotton factory: "The children were almost universally ill-looking, small, sickly, etc. The men were almost as pallid and thin as the children. Among the women there was not a fresh or fine-looking individual. What a degenerate race, human beings stunted, enfeebled and depraved, men and women that were never to become aged, and children that were never to become healthy adults. It was a mournful spectacle."

The cotton dust or fibre tells on the lungs; the operative may continue at his work, but ails occasionally without being exactly ill; he has an occasional attack of sickness of his respiratory organs; he is weak and easily a prey to disease; may live on, neither well nor ill; is worn out at an early period, and sinks an old man at the age of 45 to 50. In a cotton establishment of $\mathrm{I}, 685$ spinners only 22 passed the age of 50 , and 8 the age of 55 !

The same authority inspecting a flax mill, declares, that of a personnel of $\mathrm{I}, 079,22$ reached 40 years, and but 9 lived to the age of 50 years. 
Fourteen men, taken indiscriminately from the flax mill, showed on examination great impairment of the respiratory organs. Drawn up in line, what a sight! pale, spare, emaciated, head declined, pulse feeble, subjects of disease advanced to a fatal issue, ripe for the hospital, working till they die from consumption!

Hatters, rather pale, complain of pains in the chest, are subject to asthma, and there are scarcely any old men among them.

Millers are generally pale and sickly, and often asthmatic at an early age.

Jewellers suffer in their chest, stomach, liver and head. An old jeweller is hardly to be found. In an establishment of 37 men, one had passed the age of 50 .

Brass founders suffer in their respiration, cough, have often pains in the stomach and are subject to morning vomiting. Few of them live to be old men.

Masons have the bronchital membrane often in a state of inflammation from the stone dust, die frequently of consumption, and hardly ever live to old age.

We might take up trade after trade and would find each, as carried on to-day, the destruction of the artisan engaged in it. But as the subject is almost endless, we must take a larger sweep.

Arsenic, as arsenite of coppcras or emerald green, 
is employed in the manufacture of paper hangings, tinted paper, artificial flowers; but it enters also into the manufacture of other pigments-in printing calico, in the manufacture of glass, rat poisoning paste, not to speak of arsenic ores. Ten thousand hands in this country are engaged in these trades, and Dr. Guy, in his able report, states that out of 25 persons he examined in the artificial flower trade, I I were considerably affected by this virulent poison, 22 were affected with a peculiar rash, sickness in the morning, weakness, feverishness, dimness of the eyes, drowsiness, trembling and convulsions. Dr. Guy gives a striking picture of the development of the miserable sickness until death steps in, and the post-mortem examination reveals fearful lesions in the mucous membrane of the stomach and in the liver. This is a sad end which is often quickly reached, but the worst is the steady deteriorating effect this virulent poison has on ten thousands engaged in these trades -but we must hurry on to still blacker trades.

Phosphorus, eating out the jawbones, makes of men engaged in manufactures using it such pitiful looking subjects, that we best turn from the sight.

More than forty thousand artisans are exposed in the United States to the deteriorating effects of lead, a metal most inimical to the system, causing the dropt hand, and other serious symptoms, 
among which is the painter's colic, often stubborn and convulsing the patient with the most excruciating pains ever suffered by man. Smelters, whitelead manufacturers, potters, painters, type founders, plumbers and many engaged in other trades, are deteriorated by constant contact with this metallic poison, which especially affects the nerves and the brain it paralyzes, and, like alcohol, is sure to tell on future generations.

Quicksilver is used in many trades, and is most fearful in its effects upon the system, and but few coming in daily contact with it escape chronic poisoning. The mucous membrane, especially of the gums, gets livid; the breath, as salivation advances, becomes more fetid, the pulse and respiration are retarded, and digestion becomes irregular. As the mucous membrane is destroyed and the teeth fall out, the patient is disfigured. Mercurial tremor comes on, the joints pain, trembling increases, arms, legs, the tongue, and, finally, the facial muscles, refuse service, and the man is but a grimace and a mockery of himself, a pitiful sight, helpless misery-he cannot chew his own food. Paralysis takes from the man the use of one limb after another. The teeth have gone long ago, hair and nails follow them; the man is all wounds, old ones opening, all bleeding profusely, and the poor invalid perishes under hectic developments a picture 
of the most horrid misery. And the worst feature about all this is, that it is but the delineation of the sufferings and unspeakable misery befalling men and women in the prime of life in the diseases of many other trades.

According to the latest observations of Hirsch, the average amount of phthisis was among the sick of

21 trades without dust . . . . Ir.r per cent.

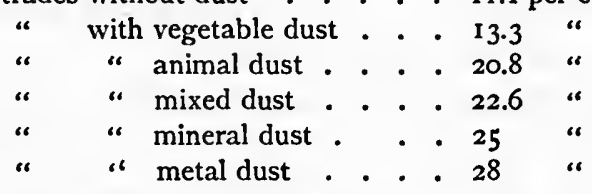

Dr. Holland reports 12 needle-grinders began to work at their trade between their $14^{\text {th }}$ and $27^{\text {th }}$ years, and died between their 27 th and $42 \mathrm{~d}$ yearsthe 12 men together had an average life of 30 years and 8 months. Of 102 scissor-grinders 60 died under 40 years. The fork-grinders die before their 35 th year, the razor-grinders between 40 and 50 . Among I00 sick file-cutters 62.2 per cent. are phthisical, I7.4 suffer from chronic bronchitis and 17.6 from pneumonia. Of I,000 glass-makers, Dr. Hanover found 349 at the hospital. Such is the state of health among them.

In Coster's factory, in Amsterdam, among the diamond setters,

23 per cent. suffered from bleeding from the nose.

36 " " " asthma. 
57 per cent. suffered from heart troubles and giddiness.

73.5 " of the men were pale and haggard.

Lead intoxication is common among the men; among 90 men subjected to medical examination, 30 showed symptoms of poisoning. These diamond workers are almost all sickly men, ailing with pulmonary complaints -9 of them were advanced consumptives.

Among the diamond grinders in the same factory,

8 per cent. suffered from heart complaints.

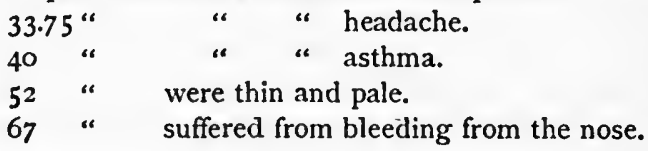

The average life of the diamond-polishers was, in the same factory, 33.5 years, and of the diamondsetters 26.5 years!

The Report of Registration of the State of Massachusetts shows that the average lives of the following trades and professions have been in the last thirty years as stated :

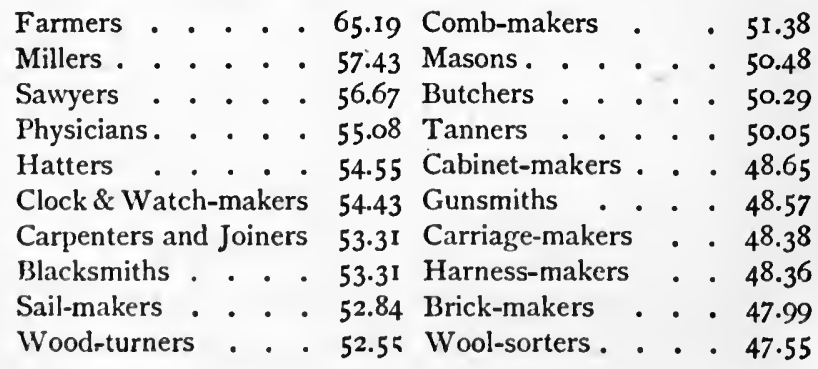


Leather-dressers . 47.4I Chair-makers. . . 41.59 Laborers . . . . 47.39 Engineers . . . . 41.57 Musical Instrument ma- Musicians . . . . 41.19 kers. . . . 47.32 Tinsmiths . . . 40.96 Tailors . . . . . 47.19 Expressmen . . . 40.94 Architects . . . 47.15 Nail-makers . . . 40.80 Bakers . . . . . 46.76 Machinists . . . 40.80 Dress-makers (women) 46.49 Jewelers . . . . 40.29 Seamen . . . 46.33 Servants (women) . 40.19 Stone-cutters . . . 46.30 Teamsters . . . 40.13 Coppersmiths . . . 46.07 Book-binders. . . 39.94 Silver and Goldsmiths . 45.46 Upholsterers . . . 39.78 Dyers . . . . . 45.35 Barbers . . . . 39.77 Mechanics . . - 45.13 Pail and Tub-makers . 39.50 Painters . . . 45.05 Cutlers . . . 39.23 Weavers . . . 44.65 Operatives . . . 38.92 Artists . . . . 44.56 Printers . . . 38.57 Shoe-makers . . . 44.45 Cigar-makers . . 38.31 Brush-makers . . 43.40 Engineers and Firemen 38.21 Furnace Men . . 43.05 Drivers . . . . 38.16 Founders . . . . 42.73 Milliners . . . 37.30 Shoe-cutters . . . 42.62 Glass-blowers . . 37.81 Pianoforte-makers . 4 42.50 Plumbers . . . . 35.43 Glass-cutters . . . 42.39 Carvers . . . : 33.84 Civil Engineers . . 42.34 Operatives (women) . 27.98

How important these figures! What losses to the nation and to their own families these short lives of the workmen of the land indicate! While farmers average 65 years, workmen die in some trades at 35 , in others at 38,45 , and hardly in any do they live to 55 years. It is time the public realize the ravages made among the most productive classes by the great scourge of preventable trade diseases, and stop the social slaughter that com- 
promises the strength of the nation and its moral soundness for the sake of a few silverlings in hand.

Lombard has more than forty years ago directed attention to these statistics, which ought not to be taken as fixed quantities, but should lead us to the removal of their causes. They are not the results of unalterable conditions. The injurious elements of the trades can in most cases be eliminated, and in others rendered innoxious by shorter hours, a more hygienic life of the workmen, and the choice of a trade suited in every case to the peculiar organic condition and degree of health and strength of the individual. But only a close union between the school and the factory enables the workman to realize the inappreciable but constant action of these injurious elements, and gives him the power to eliminate them from the trades. A more substantial and hygienic living, which increases the power of resistance, is expensive, and is only within reach of a laborer well-schooled and scientifically trained in his trade, whose work is highly productive; and, as for shorter hours, they, too, are only practicable with men, whose labor is highly productive and whose minds are stored with valuable practical knowledge, which will occupy them during the cessation of active employment; else their short hours prove detrimental to them in more than one way. 
The geat trouble is, the Education of to-day is not suited for the working masses. When the school gave only a clerical Education, only the clergy availed themselves of it; to-day, when it gives mostly a commercial and polished Education, merchants and people of leisure alone care for it.

Give us an Education profitable for the masses of the people, and they will be sure to avail themselves of it.

Bring the school to bear upon the factory, and we shall increase the productive years of the great mass of the people at least 20 per cent. What gain to the nation and to themselves! A longer life means more health, more strength, more energy, more thought, more virtue, more manhood, more labor, more wealth, more comfort, more culture, and more everything desirable in the family as well as in the state. A longer life means less sickness, less loss of time, less expense, less poverty, less orphans, less vagabondage, less crime, less police and jails, and less taxation and public burdens, and, hence, more general prosperity.

The employment of children in factories is one of the great scourges of modern times; we can only mention this plague without unburdening our mind. Four out of five children who are from early infancy up working in factories, die before they reach the age of twenty. 


\section{The Scourges of Humanity.}

The majority of children of factory people were found, by actual count, at schools attended by this class to be orphans, and by the show of the mortuary register of fifty-two deceased, forty-one only had attained the age of twenty-five.

These short lives mean volumes of misery to the laborer as well as to his family; they mean much sickness, loss of earnings, expense, impoverishment, pauperism and crime, and deserted orphans and sorrowing widowhood; they mean national loss and bankruptcy; yea, they mean injustice in a nation who is indifferent to such misery, and end in universal selfishness and dishonesty, and the consequent ruin of the country.

But the facts we have adduced speak for themselves, and the reader can make his own comments. To do justice to the subject of race detcrioration as resulting from the innumerable diseases which haunt the laborer to-day, space fails us. That this deterioration is inevitable, we emphatically deny. Unite the factory and the school, labor and science, the worker and the thinker, and the laws of the intellectual order of the universe will impress themselves upon labor and its relations, and every dissonance will disappear between the worker and his work and between labor and capital; every force will become a willing tool of man, and all matter will become pregnant with use and beauty, and 
460

The Scourges of Humanity.

man will be healthier, stronger and wiser, every one standing back to back to his brother, and rendering one another every help their situation may require.

\section{OUR RESOURCES AND OUR GREED.}

The revolution which gave birth to the nation, having lasted full seven years, thoroughly aroused the people's encrgies, employed since in exploring resources which have grown with the population, the progress in science, machinery, quick transport and inter-communication by steam and electricity, and this feverish activity has been still more intensified by the opportunities for amassing colossal fortunes during the late war, until, at last, every other motive or principle has been smothered by the one of acquiring wealth; and, natural enough, greed for gain ended in universal disloyalty and distrust, and a final stand-still of trade. This pause brings us to our senses.

The activities of the nation are too fully aroused

- to be repressed ; they must be directed into a channel as noble and generous as the former was ignoble and selfish. The nation must be made alive to the peril to which universal selfishness exposes its past greatness.

Or are we alarmists? and is the silent potency of the three R's sufficient to save the world with- 
out the concurrence of other social agencies? We hardly think so. Popular Education has been fostered everywhere the last hundred years, still the statistics of the steady increase of illegitimate births and abandoned children the world over, would fill a moderate volume. Offenses in France have increased from 110,593 in 1846 , to 171,35 in 1853. The liberal professions, composing 2.2 per cent. of the entire population, form 4 per cent. of the criminals of France. Whilst the farmers, who form 53 per cent. of the entire population, commit but 30 per cent. of the crimes, showing at once the decided influence of work, home and a competency, and the doubtful bearing of Education on crime.

In England offenses rose from 75,859, or 4 in 1,000 , in 1857 , to 105,310 , or 5 in 1,000 , in 1865 . Murders and attempts at murder in France numbered in 1830-1834 931 , and increased gradually to $\mathrm{I}, 850$ in $1855-1859$.

Enough has been said on the score of this universally-spread fiction or swindle of what is in the clap-trap of the day styled Education. Our present Education, by getting up a false pride discouraging manual labor and putting cunning in the place of physical and creative effort, aids the progress of crime.

We talk about pauperism in Europe, and shut our eyes to the extent of the evil in our own midst. 
Massachusetts, willing to probe the evil, gives us reliable statistics. It has with a population of I,65 I,912, 4,342 inmates in its poorhouses, and supports partially 65,988 outside poor. It counted in $1876,148,933$ tramps! and making full allowances for duplications, it has, at least, 5,000 of this dangerous element. Massachusetts has six or seven large State institutions, beside 342 town and city poorhouses, and thousands of private families in which, at public expense, individuals are maintained; and the poor cause to the State and private charities an annual outlay of $\$ 4,500$,oo0. The convicts number 4,340. Whilst the poor in England, $1,037,360$, are $I$ in 23 of the general population, and the convicts, 28,756 , I in 790 , our poor are $I$ in 22 of population, and our criminals $\mathbf{I}$ in 380 .

There were commitments in the State of Massachusetts in

$$
\begin{aligned}
& 1871-2 . . . . . . .160 \\
& 1872-3 . . . . . . . .174 \\
& 1873-4 \text {. . . . . . . } 246
\end{aligned}
$$

In 1865 there were in the common prisons of the State I0,000 individuals, and $48 \mathrm{I}$ convicts in the State prison. In $1875,20,000$ were detained in the common prisons, and 852 were in the State prison. Hardly a State or country, says the State Report before us, in the civilized world, where 
atrocious and flagrant crimes are so common as in educated Massachusetts. Of 4I5 convicts sentenced to the Charlestown State prison in 1874 and 1875, 53 per cent. are born in Massachusetts, and 25 per cent. of all the convicts of 1873 came from its reformatories. Only I i per cent. of the convicts of 1876 were illiterate, which, therefore, was not the cause of their criminality. One of every 364 natives of Massachusetts is a pauper, and $I$ in every 546 a convict ; whilst $\mathrm{I}$ in every 348 foreign born is a pauper, and $I$ in every 252 is a criminal. But here again we must direct the attention of the reader to the absurdity of all our statistics of pauperism. We are informed one of so many natives or foreigners is a pauper; in other words, is an insane, an idiot, a deserted woman, an orphan, of infirm mind, sick, a cripple, an old man, or a widow -a most meaningless assertion indeed.

According to a more just and simple classification-we shall soon make clearer-we should say $I$ in 100 of the population of Massachusetts is a defective; $I$ in 20 is partially depending and poor, $I$ in 10 is struggling against poverty, and $I$ in 5 is managing closely.

This is rather gloomy, but is a fact worth while knowing. Massachusetts has :

$$
\begin{aligned}
& \text { Blind . . . . . . 2,512 } \\
& \text { Deaf ....... 7,24I }
\end{aligned}
$$




$$
\begin{aligned}
& \text { Dumb . . . . . . . } 129 \\
& \text { Deaf-mutes . . . . } 654 \\
& \text { Idiots . . . . . . 1,340 } \\
& \text { Insane . . . . . . . 3,637 } \\
& \text { Total . . . . . 16,513 }
\end{aligned}
$$

In 359 cases out of 420 cases of idiots, one or both parents departed from the normal condition of health.

Epileptics, paralytics, cripples, feeble-minded and the like classes, will swell this sum to 25,000 ; and what must be the nature of the tree that bears the like fruits in such abundance?

The following table shows the steady increase of pauperism in the State of Massachusetts. Vagrants were relieved in

$$
\begin{aligned}
& 1873 \text {. . . . 45,653 times. } \\
& 1874 \text {. . . . . } 98,236 \text { “ }
\end{aligned}
$$

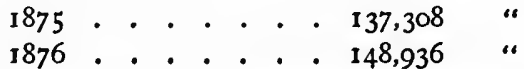

A glance at the population of the poorhouses of the State of New York will clearly prove our position, that widespread pauperism is evidence of physical deterioration, which has to be met by means both universal and efficient.

New York contained in its poorhouses in 1876

2,030 homeless children.

278 " women.

2,08I old and destitute.

795 permanently diseased. 463 temporarily diseased.
29 deaf-mutes. 4,047 insane. 580 idiots. 268 epileptics. 322 paralytics. 
240 crippled.

17 deformed.

303 blind.
394 feeble-minded.

767 vagrant and idle.

$$
\text { Total . . . 12,614. }
$$

The Report on Pauperism, by Charles S. Hoyt, Esq., throws further light on this subject, by showing that 4,273 of this number had each pauper relatives-some as far back as three generations. The number of pauper relatives of the paupers examined into amounted to 14,901 ; 4,968 of these relatives were known as insane, 844 were idiots and 8,863 inebriates.

What a widespread deterioration this condition indicates, and how vast must be the means that shall victoriously counteract it.

We often witness with indifference the development of a morbid formation, relying upon the remedial power of the means at our command, which, in truth, are almost invariably impotent.

We try to study the problem of pauperism; but systematization is the first requisite, to get at the nature of things, and we lump together under pauperism, a name that means. social leprosy, a pest and every other thing that is loathsome-the poor insane, the idiot boy, the orphan, the widow, the sick and the man of a hundred years.

These classes are all free from personal guilt, and our dealing in such a bungling manner makes the solution of the social problem impossible, and is as 20* 
much an insult to our own good sense as to humanity. The plain state of the case is, the wrecks in the poorhouses of Massachusetts, New York or any other State or country, are the flower and fruit; the outside helpless poor-call them tramps, vagrants or what you please-are the branch, and the struggling millions, who have not yet given up all hope, are the veritable tree sending forth those branches bearing the bitter fruit.

We must stop paying attention to the branches and attend to the roots of the tree. The hundred thousand outside the poorhouse must themselves be radically diseased, to yield the ten thousand physically and mentally ruined inmates of our poorhouses, and the millions-let us not be unjust - they mean as nearly right as they know. We are republicans; let us be just toward the masses, the people, the hope of the nation and of the future; perhaps the whole Education we give them is the wrong one, and we dare say this is fully half of the trouble.

An increased mortality rate may be the result of a food supply suddenly cut short by a failure of crops or a financial crisis. An increase in the rate of insanity is evidence of a deep degeneracy, the work of a long series of deteriorating causes. It is for this reason that insanity especially must occupy the attention of the social student. 
Dr. Charles A. Lee said before the Social Science Association: "Statistics abundantly show that both in this country and in Great Britain there is a progressively increasing ratio of lunatics to the whole population, and the estimate of 45 per cent. increase here, as in England, in the last ten years is very probable. We know that there is an enormous and constantly increasing accumulation of chronic lunacy in every State in the Union, and that in the States which have erected the most and largest asylums, as New York, the number of insane in the poorhouses has not diminished, and is constantly increasing. Especially is insanity increasing in the United States among the middle and lower classes."

Of course, the increase of the 45 per cent. of insanity in so short a period is partly due to the preservation of the lives of the insane under their improved treatment; still there is left a positively increased ratio of insanity sufficient to stagger the thoughtful student of social phenomena.

But whoever will read the reports of the Boards of Charities of the various States in the Union, and take into consideration the increasing numbers of the inmates of the poorhouses and the nature and composition of the latter, will of necessity come to the conclusion of Dr. Lee.

What wonder that the insane are in the most hu- 
mane States penned up in cages like wild beasts, only kept less clean. Are they not, according to our most stupid and inhuman nomenclature, paupers? And yet Dr. Edward Jarvis, like his predecessor, the great Pinel, says : "Most of these unfortunates need no double doors, no bolts, no locks, but confidence and the encouragement of their own selfrespect, the most important means of restoration."

The constantly diminishing yearly increase of population is another evidence either of physical deterioration or moral depravity. So, for instance, was the annual increase of population in Prussia:

$$
\begin{aligned}
& \text { 1817-1828 . . . . . I.7I per cent. } \\
& 1828-1840 \text {. . . . . . } 1.27 \text { “ } \\
& 1846-1855 \text {. . . . . . . } 0.86 \text { “ }
\end{aligned}
$$

The annual increase of population in England was, in

182 I-I 831 . I.46 per cent. I84I-I85I . I.35 per cent. $1831-1841$. 1.46 “ $1851-1861$. I.19 “

In France the increase of population was, in 1821-1831 * 0.67 per cent. $\quad 1841-1851$. 0.44 per cent. $1831-1841$. 0.50 " $1851-1861 \cdot 0.18$ “

And when we study our own country, the steady decline of the natural increase indicates a lamentable deterioration. The annual increase was, in

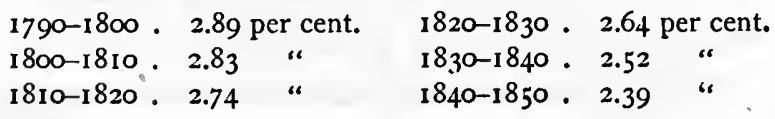


According to Dr. Allen's statement before the Social Science Association, yo per cent. of the marriages of Americans are childless; and whilst I birth upon 30 of population is the natural ratio, the ratio of births in Massachusetts is $I$ in 60 .

We cannot deteriorate without losing vitality and strength as a nation, and losing the chance of giving birth to thinkers and organizers and leaders in national greatness and goodness.

But the great misery of the masses is the plainest and most irrefutable proof of their deteriorating condition.

The following official items furnished by E. Crapsey, Esq., are well worth considering. There were in 1870 in.

Bellevue Hospital and Charity Hospital 17,190 patients. Hospital for Contagious Diseases . . 6,165 “ Bureau of Relief prescribed for outdoor poor . . . . . . . 16,850 “ The almshouse poor . . . . . 4,315 “ Relieved by private agencies . . . 50,000 “" Dependent upon public charities . . 61,971 “ Inmates of prisons and reformatories . 71,849 “ Total . . . . . . . 228,340 “

Reducing this number on account of duplications to 150,000 persons, what an army of dependents and what a problem for solution!

There is not a block of tenement houses where 
mothers may not be found putting the morsel of bread they covet into the hungry mouths of crying children; where strong men do not starve that the old people may be supported. Widows are chummed together, who are living illustrations of a sisterly spirit; they have for years worked and starved together; the strongest bank in the city may break, but their honor and honesty, so often tried, make them trusted for their rent during the winter months, when, also, their most modest furniture travels to the pawnbroker, to come back in the summer season and greet the presence of these, God's own dear children, who starve the year through with a never-faltering spirit. Does any one think that such stories, rising into the hearing of the Almighty Father, do not avenge the poor by confounding all in one great destruction, in order to assert, in the inexorable ways of Providence, the solidarity of the race, coldly denied by us in the cruel treatment of a brother?

The steady and stubborn growth of pauperism proves all present attempts at preventing it rather efforts at mitigating it, an enterprise laudable, but thankless, like carrying water from the sea in a sieve, as the millions brought up and living as they are, grind out paupers by the hundred thousand, and swallow up all private and public means, rendering all our efforts nugatory. 
We do not indulge in vagaries, and do not stand alone in what we blame or in what we advance. We insist upon work as well as study, and condemn the one-sided mental Education of the day, which ruins both the body as well as the mind, leading to want and misery.

The effects of our almost exclusive attention to study may be partly illustrated by the following facts. Blindness is a great source of loss of opportunity of self-support. The number of the blind in the United States is 25,000 and over. Congenital blindness is but as $I$ in Io compared to the whole class. Whatever weakens the eyes exposes them to succumb to the effects of disease or external injury, and the short-sightedness or weakened condition of the eyes, due to over application to study, has been fully established, and ranges from 5 per cent. in village schools, to not less than 68 per cent. in our highest institutions.

Of 73 I collegiate scholars 296 , or 40 per cent., suffered frequently headache. Of 3,564 scholars of public schools, 974, or 27.3 per cent., suffered more or less headache. In the highest class of a college not less than 80 per cent. were found sufferers from headache. Bleeding from the nose was found in 20 per cent. Spinal diseases were met with in 20 per cent., and of these 84-90 per cent. were females.

One hundred and forty-six physicians of Massa- 
chusetts have declared that our system of Education promotes consumption, and the writer in the Massachusetts Report adds to this testimony, "If this be not worthy of serious thought by our people I know of no question that can be."

"The state," says the School Commissioner of Ohio, " needs, for its material prosperity, a race of strong and healthy men and women. Widespread violations of hygienic laws as fostered by a vicious system of Education cannot be overlooked by the state."

"Education lays the foundation of a large part of the causes of mental disorders," says Dr. Jarvis.

"Insanity is the price of an imperfect civilization and an incomplete Education," says Rev. J. S. Goodman, School Superintendent in the State of Michigan.

"Our young men have a great indisposition to physical labor. We believe in that kind of compulsory Education that will fit a man for work and self-support. Of 220 convicts, in 1875, in Massachusetts, 177 were without a trade. A workman who labors and pays his way, though he is unable to read and write, is a better member of society than men educated who will not, or know not, how to earn their bread. We want more of the gospel of work." These words of Mr. Wright, the chief of the Bureau of Labor of Massachusetts, deserve consideration. 
Richard Vaux, in an able article on crime in the State Report of Pennsylvania, says: "A far larger number of convicts have attended school than who never went to schools. Does, perhaps; the association of youths in school create an influence which leads to depreciate labor? This certainly would have to be considered."

Nothing but the joining of industrial work with study secures the proper equilibrium between mental and physical action, and endows the future citizen with the power of providing honestly and honorably for himself and for those who have a claim upon his support. We insist, therefore, upon a more material Education, but we lay equal stress upon a more spiritual one than the present, and one founded upon the physical, moral, and industrial relations and nature of man.

The neglect of the physical and moral Education in our schools, and the perversion of the passions this double neglect leads to, are a great cause of race deterioration. Fashion, appearances and sham in Education, leaving the heart and the higher reason empty, take the place of the more practical culture of the will, good sense, and human kindness. The state, expending millions out of the public treasury, has a right to insist upon an Education that instills in the individual, educated by the contributions of all, kindliness toward all. The state 
and the government are no more interested in the scholarly accomplishments of the citizen than in his religious faith; in the eye of the law actions alone have an existence, and are culpable-or meritorious, and hence for action the public school must train us, that we may live a life useful for the state and for ourself.

When a German university celebrity, like Professor Ekhart, and a Professor Stuart, of Cambridge University, England, treat labor schools as a prime necessity of our present civilization, and such schools do prove a success, in France, Germany, Belgium, Holland, Denmark, Sweden, Austria, Italy and Switzerland, none is justified in saying, that however well such institutions may look on paper they are not reducible to practice. Reading questions from text-books, and seeing to it that the answers be exactly as printed, may be less troublesome in execution, still the world has got tired of words, and Education too must advance from words to work.

If men make leadership in the highest department of human life their business, let them be trained for it in institutions of the severest mental discipline. But we do not want schools dabbling just enough in Latin and Greek to spoil a boy born for the plow or the shop, without fitting him for anything else. 
Is the demand for a moral basis of Education, and the preservation of the race an insanity? Is the enlarging of the individual consciousness to a universal consciousness that identifies itself with all mankind, past and present, not the essential nature of human culture, and if we are to love Him whom we have never seen, are we mad for making the demand on Education to train man up for the love of a brother whom he has seen?

The realism of the Greeks must unite in our Education with the moral inspiration of the East; still, the latter must form the basis of the entire fabric of Education; for to confess our weakness, we give preference to the poor, the central figure in the civilization of Judea; for the element of beauty in the Greek world may exercise our admiration; the poor call forth our benevolence.

Education among the ancients was the business of slaves; in the middle ages it was left to the Church; in our day it is a trade. But the Education of the race must become a religion, and the state and the citizen must give it their best thoughts and warmest support.

We especially insist upon orderly homes, which are for men and women what schools are for children. For we hold that the Education the family provides for all through life is of a higher order than that of the school, which is but partially 
provided during a comparatively brief period of life.

Home, labor, property, health, the family and Education are secured to the masses, with the opportunity of acquiring suburban dwellings, and with these clements of civilization the peace of socicty and the stability of the government are guaranted.

The effects of crowding in large towns, says Charles Bray, are ill health, misery, drunkenness and degradation. Ups and downs natural to commerce, make the operative wreckless. Waste and lowest licentiousness, or starvation are the alternative. The disadvantages of the factory system may be avoided by uniting it with the culture of a garden patch, which a man can tend when he cannot sell his time to better advantage in the labor market.

Our industrial system, says Sir A. Alison, brings to-day to the masses weakness and debasement, national grandeur and private degradation. Whereever, as in the Jura, or the Val d'Arno, manufacturing employment is coupled with separate dwellings and rural residence, and the laborer can safely base his calculations upon something that is certain, there is industry and frugality, and beautiful little properties gratify the traveller in those delightful regions. On the other hand, there is not to be found among civilization a more dissolute or reck- 
less race than the silk weavers of Lyons or Spitalfields, the cotton manufacturers of Rouen or Manchester, or the muslin operatives of Glasgow or Paisley.

The national commerce bought at the price of the strength, health and moral soundness of the masses becomes the nation's curse. The man who could discover a mode of combining manufacturing skill with isolated labor and country residence, would do a greater service to humanity than the whole race of philosophers.

Dr. Elijah Harris stated most forcibly, before the committee on crime, appointed by the Legislature of New York, that crime in the different city wards was always in proportion to crowding. Sing Sing, the House of Refuge and the like State institutions trace their criminal inmates and juvenile offenders to the worst tenement houses. Nothing but healthful domiciles secured by a stringent sanitary legislation, can prevent wasting disease, pauperism and crime. Overcrowding, in dark and filthy tenements, wipes out all moral distinctions. Mine and thine lose their meaning, thieving becomes natural and crime habitual. Such is the statistically ascertained relation between crime and crowding the world over, and hence crime is fearfully on the increase among the densely packed populations of our growing citics. 


\section{PART EIGHTH.}

\section{THE NEED OF THE NATION.}

WANT of the proper means and conditions of life weakens and deteriorates the human system. It deepens misery by lowering energy and lessening the capacity for useful work until pauperism, crime, and insanity become hereditary.

Raise the productiveness of industry, and as men are supplied with the necessary means of subsistence their energies will be quickened, and with pauperism, crime and insanity will be lessened. Industrial Education is the great need of the nation. It would not only increase the army of usefully employed men, but would make us strong through work; it would train us to industry and order, make us provident, keep active our minds as well as our bodies; it would be a practical school of virtue, as vice springs from idleness, which is always accompanied by ignorance and want.

The noted philanthropist, Frederic Hill, says: "Bad training, drunkenness, and poverty are the chiefest causes of crime, against which the best 
remedies are the cultivation of habits of forethought, sobriety, and frugality; the promotion of habits of industry and self-reliance, and the adoption of all other practical means for raising every class of society beyond the sphere of destitution, and into that of comfort and moderate wealth."

The same great thinker insists upon the necessity of training the people in the various industries, which would decrease poverty by adding value to labor, and parents should be made responsible for the crimes of children they have not given those opportunities generously afforded by the State.

Crime results from want of home-training, which is hardly possible without a certain amount of comfort and order, and, hence, the morals of the community require that labor should be valuable, which it only can be where a general system of industrial Education prevails.

The increase of crime among high and low has everywhere prompted the investigation into the causes of crime, the prevention of which must occupy the minds of educators. Culture is too indefinite an aim for a public system of Education costing annually the tax-payers of the land \$80,$\infty \infty, \infty 00$. Next to the preservation of the race, the preservation of the State through a self-relying, law-abiding, and useful citizenship, or the prevention of pauperism and crime through the develop- 
ment of skill and virtue, must be the aim of Education.

"By Education," says further Mr. Hill, " is not meant the mere capability of reading and writing, but a systematic development of the different powcrs of the mind and body, the fostering of good feelings, the cultivation of good principles, and a regular training in good habits. Such an Education necessarily includes industrial occupations, and giving a taste and aptitude for useful employment, so as to prepare the scholar to earn a livelihood without that severe and constant labor by which alone the ignorant and clumsy workman can obtain an honest subsistence, and from which he too often recoils and flies to crime. A good carpenter, shoemaker, or blacksmith is seldom to be found in prison, and still less a good machinist or watchmaker."

An imperfect knowledge of a trade, or a poor trade, will keep the rising generation hovering over the verge of want and crime, into which every next generation will be sure to sink if the effort of rescuing it from its abandonment is not continually renewed. Give the rising generation a perfect knowledge of a remunerative trade, which shall lift it out of struggling poverty into competence and a well-ordered condition, and the next generation, growing up under the moral influences of normal 
homes, will not be in need of the social quackery of our charitable institutions.

A large, unskilled population, living in crowded tenements in bitter want, calls for a technical training in our schools which would soon rid us of the disease of pauperism, a degrading soup-kitchen charity only aggravates.

Technical training will, by its physical exercise, relieve the nervous system and cultivate simplicity, and thereby counteract the evil tendencies of our present civilization which decidedly increase insanity. Technical Education elevates labor and makes us more industrious, provident, self-supporting, and self-controlling. It prevents drunkenness, idleness, and bad company, and in many other ways prevents crime.

There is hardly an author treating on crime but considers work as its sure prevention. The Massachusetts Board of Charities say: "Exercise is the law of organic existence. Health can not be preserved without it. Work commenced early in life is one of the most effective preventions of dependence and want. Idleness and laziness beget povcrty, vice, and crimc. Habits thus formed bring the individual to the almshouse, the house of correction, the jail, or the prison. Exercise, industry, occupation of body and mind are powerful antidotes to pauperism, crime, disease, and insanity." 
Is it, then, right that we wait until the masses are eaten up by corruption of every sort, and are beyond recovery, before we apply the God-ordained preventative? When early neglect and a life of ill habits have destroyed body and soul, nothing will, and nothing can, help. We might just as well commence the work of reformation in the grave as in the prison; we must put every man to his work at school, and in early life, when habits are formed; and upon this, societies devoted to the prevention of crime must insist. Work comes equally too late with the pauper portion of the community, who come into the world with the laziness of three and four generations in their slender bones. The community at large, the masses, all our children, must be brought up in their school-days to physical as well as to mental work, which is the normal condition of man, and yet the verdict of all is, that our present system of Education cultivates a decided distaste for manual labor.

Reduce the figures of pauperism as much as we may, the poverty of the masses, and the tens of thousands who but shortly belonged to the rich, and to-day suffer want, call for a technical Education. A careful study of the causes of the various forms of defectiveness points to want of industrial Education with its attending poverty and want of 
hygienic conditions, as to the most common source of these social distempers.

Insanity and idiocy cost the United States today directly over $\$ 8, \infty 00, \infty 00$ per annum, and indirectly, more than double that - not to speak of the misery it inflicts-fully one-third of which could be prevented by the means of the hygienic conditions which would follow in the wake of industrial Education.

We have seen the cost of the depredations, detection, and detention of the State criminals of the various prisons in the United States amounts to fully $\$ 130,000,000$, and besides this sum we must bear in mind the vast expense and loss caused by the detection, detention, and pilferings of hundreds of thousands of arrests made annually by the police in the United States. How cheap we could get rid of a large part of all this cost and demoralization if we would bring up the people in our schools to work and industry, or must we wait until these evils eat into the very heart of the nation, and financial ruin and physical and moral decay force upon us the New Education? Is it wise to wait until it may be too late, and we lack the energy and the means to make the change?

A partially theocratic communism may have suited agricultural Judea, equally divided as it 
was among tribes and families; the Church organization of charities may have done in the Middle Ages, when almost all the wealth and all the land were in the possession of the Church. Old Rome tried to mitigate pauperism by the public distribution of corn, by which it only aggravated the evil, and England has done very much the same thing by its organized State relief. The present civilization demands that the public Education be in the main organized and conducted for the great work of the prevention of pauperism with all its deteriorating tendencies. This alone justifies taxation for educational purposes, pays richly back what is taken out of the public treasury, and bestows a tangible benefit upon the people. There will always be sporadic cases of want and misery for the exercise of public and private charity. But public Education must prevent pauperism from becoming a public danger, what it decidedly is to-day. One organization for a polite universal Education, and another one for taking fully and completely care of all the burdens of an unchecked pauperism, is more than any nation will, or perhaps can, stand.

Noble impulses are as old as the race; the cultivation of the intellect does not distinguish our age; industry has always been insisted upon by the Chinese; and, according to Herodotus, the 
Egyptians punished idleness with death. But the organization of a universal system of Education, based upon the moral, intellectual, and physical nature or wants of man, among which labor stands forth foremost in importance, must lay the foundation to a new civilization, which starts man rightly in the early period of his life, when he is properly enough put under conditions conducive to his development, that he may be least interfered with when he shall have reached his full growth and the age of moral freedom and responsibility.

We know that good taste stands aghast at our declaration, that the prevention of pauperism and crime is the next highest end of Education, the preservation of the race being the first. But we are all one and the same species, and the Education of us all must be based upon the same fundamental principles. The specified lists of thousands of defalcations, amounting to more than $\$ 40,000$,$\infty 00$, the annual crop of crime among the higher classes, the industrious metropolitan press brings us the first of the year-not to point to court proceedings-should dispel the notion that the aim of preventing pauperism and crime can be safely dispensed with in the Education of any class, and that work is vulgar, or that it is sufficient for the school to equip men for life with fine words. There never was said a truer word to point out the 
duty and responsibility of the higher classes than that of the Rev. Wm. Henry Channing: "It is the loafers who are rich that make the loafers who are poor." We do want culture, but such as is based upon work and performance, and not upon words and a puffed-up imagination.

Industrial Education is beginning to be felt as the great need of the nation, men of practical genius are giving it shape, and we hope men of generosity and faith will come forward and give it their support.

\section{NATIONAL TEACHERS' ASSOCIATION.}

Hon. A. Newell, the President of the late National Teachers' Association, said, in his admirable address before that distinguished body of educators: "Our public school system can not be regarded as complete until the department of manual labor is added. State Education must teach the children of the people to work, without which they can never become good citizens. Industrial Education will soon be an accomplished fact, like many other things which but shortly were considered 'impracticable.' The many must live by labor, and the school must help them so to live by turning them over to the city workshops, where they would learn to be workers."

The Hon. J. P. Wickersham, State Superintend- 
ent of Education of the State of Pennsylvania, said, on the same occasion: "I am not sure but that if half the money expended in the schools of our cities were expended in the erection of shops to teach boys and girls trades, it would be better."

President Runkle, of the Polytechnic Institute of Boston, remarked that young men who commence with learning their trade never come to school to learn the science which underlies their trade, while those who set out with the study of the science hardly ever learn the art or trade, and hence the necessity of combining practice and theory at school. Mr. Runkle explained that in the Russian System of Instruction the technical operations underlying a number of trades are studied as an elementary art and separate from those trades themselves. So, for instance, is vise-work an art important to the blacksmith, die-sinker, tool-maker, machinist, gun-smith, boss-finisher, iron mold-maker, jeweller, etc. And vise-work again divides into filing, sawing, tapping, chipping, reaming, thread-cutting, breast-drilling, etc.

Dr. Buchanan, of Ohio, showed the bearing of industrial training on character and intellectual energy, and on the dignity and productiveness of labor, the elevation of our population, the increase of general prosperity, and the solution of the great problem of capital and labor. "The mechanic 
arts," said he, " are to-day in the same degraded condition the medical profession would be in if instead of having schools, a literature, and public instruction, it blundered along nursing the sick."

\section{MASSACHUSETTS BOARD OF EDUCATION.}

The Massachusetts Board of Education shows the possibility of gaining technical and elementary school Education in its Forty-first Annual Report, where all the details of such a course are given, and from which we condense the following statement :

The progress in the mechanic arts, the disappearance of the old apprentice system, and the welfare of the masses, as well as the public peace and the safety of the Republic, demand that our common schools train the heads and hands of the people simultaneously.

President Runkle explains in the mentioned Report, that all existing mechanical operations can be taught as a system of art fundamental to the trades, and that this method forms the only true and philosophical key to all industrial Education. This system distinguishes Instruction Shops which teach exclusively general mechanical operations, or the use of tools, and Construction Shops which teach especial trades.

These ideas have been carried out in the "School 
of Mechanic Arts" at Boston in the following Art courses: In wood-I. Carpentry and joinery; II. Wood turning; III. Pattern-making. In iron-I. Vise-work; II. Forging ; III. Foundry-work; IV. Machine-tool work. In textiles-I. Designing; II. Pattern-weaving; III. Dyeing.

Twelve hours per week-three lessons of four hours each-of the student's time are devoted to shop-work, and the balance to drawing and other studies. We can not enter here upon the regulations of the shops, the course of studies or exercises, the methods of examining the work, etc.

The Whittling, or Carving School, at Boston, has been for a long while in successful operation, and so the Industrial School Association. The committee on Report of the Industrial School Association close their Report with the following words: "One such work-school as we have described might furnish four hours' instruction every week for one hundred and ninety-two boys; or, if evenings were added, for two hundred and eighty-eight boys. This is more than the number of pupils between the ages of thirteen and sixteen commonly found in any one Grammar School. We can not but believe that it would be easy to establish, in connection with all our Grammar Schools for boys, an annex for elementary instruction in the use of the half-dozen universal tools; $i$. $e$. , the hammer, 
saw, plane, chisel, file, and square. Three or four hours a week, for one year only, of the GrammarSchool course, would be enough to give the boys that intimacy with tools, and that encouragement to the inborn inclination to handicraft, and that guidance in its use, for want of which so many young men now drift into overcrowded and uncongenial occupations, or lapse into idleness or vice."

President Runkle thinks boys are best admitted to technical training at the age of 12-14 years. In cities mechanic art schools located in central parts might combine instruction in manual labor with mental study after a given age. These shops could also be open evenings for the purpose of the manual Education of large numbers who could by no possibility have any other opportunity.

In the district school, a single room fitted up to teach the use of the saw, plane, chisel, and auger, the common wood-working tools, or what seemed best adapted to the locality, would be all that need be done.

The Instruction Schools for the use of tools are the first step; the nature and condition of specific Trade Schools must be left to time and local conditions.

At an expense of a sum no larger than $\$ 20,000$ can be equipped for the instruction of seven hundred and sixty-eight students to be taken through 
in a three years' course, beside evening classes in wood shops for: I. Carpentry and joinery; II. Wood-turning; III. Pattern-making; in iron shops for: I. Vise-work; II. Forging; III. Foundrywork; IV. Machine-tool work. The annual expense for the industrial Education of each student does not exceed \$10. A shop teaching carpentry and joinery may be furnished-to commence-with $\$ 500$. The industrial Education of the entire youth of the United States need add no more than Io per cent. to the cost of our present school system, which breeds wild speculators and hungry communists. The cost of buildings, tools, and machinery, for the Industrial Education of the United States would be less than the capital invested in the school-buildings of the State of New York. But the addition to the public wealth by an annual accession of 200,000 trained men would make the investment the best the nation ever made.

THE WORCESTER FREE INSTITUTE.

The Worcester Free Institute has been on trial for nine years. The students in the Department of Mechanics practice in the school-shop 900 hours in the first, and 500 hours in each of the next three years. In this course the student practices chipping, filing, forging, planing, lathe-work, the use of 
the milling machine, etc., and is exercised in the fitting and finishing of machinery.

We give in brief the experience of this school. The shop is organized as if for manufacturing, and adapts itself to the school only so far as to give proper variety of work. Construction, perfected as far as possible, is made to serve the nobler purpose of instruction. Mechanical practice forms a constituent part of every week's work throughout the course, and is done in the atmosphere of real business, though without pecuniary return to the student for his labor. Study and work accompanying each other, the school inspires its intelligence into the work of the shop, which in its turn renders practical the learning of the school. The parallel study of science and handicraft gives labor its real dignity. The practice in the shop serves the double purpose of mechanical discipline and of physical exercise, and is a great economy of time and cost. The teaching of handicraft in connection with the school is thought necessary, as few would stop to learn the practical use of tools and machinery after leaving school, and besides, whatever mixes with the discipline of those plastic years from 16-20 years enters into the life and character of the man in a more intimate and organic sense than the contributions of maturer years. The object of the shop is to give a thorough working 
The Developing School and Manual Institute. 493

knowledge of the fundamental processes of mechanism as found in all -manufacturing machineshops. The annual salable product of the schoolshop is about $\$ 17,000$, falling short but $\$ 3,000$ of the actual expenses of the shop, and this deficit is gradually diminishing. While the school is teaching handicraft, it does not disassociate labor from its producing power. To spend time in learning mechanical processes which are not used, may add to his culture, but not much to his practical fitness for a mechanic's life. Excellence in construction, tested by the demands of the best judges, is an indispensable element in sound instruction in the mechanic arts. The country which commands the most energetic and intelligent labor, produces most for a given expenditure of labor. And intelligence in labor has in it the cure of all the ills which now attend labor and its relations to capital. The Worcester Institute has graduated annually about 20 students, and the average age of its entering apprentices is 17 years.

\section{THE DEVELOPING SCHOOL AND MANUAL INSTITUTE.}

The American Social Science Association recommends the plan suggested by Mr. S. P. Ruggles, which is universally endorsed by the press, in contradistinction to the former system of our fathers- 
that the youth, whenever he has completed his general education in any of our public or private schools, may enter what may be called a

\section{DEVELOPING SCHOOL,}

so established and arranged as to give all the pupils a good general idea of all the different trades, arts, or callings, in order that it may be ascertained by themselves or the superintendent for what kind of business they have the greatest natural genius. Imagine, if you please, one very large room, with a steam-engine and boiler in the middle of it, so that all pupils that have any taste for the management of steam, or steam-engines, could examine every point, and readily understand all about it. Then we would have a carpenter's bench, with a variety of tools used by carpenters, to show how that work was done; then, perhaps, turning-lathes, to show how the wood-turning business was performed; then, with the aid of blackboards, carving-tools, and jig-saws, it might be seen how drawing and carving and jig-sawing were done, by those that have any inclination for that business. We should also have the machine-shop represented by having planingmachines, lathes, upright drills, etc., to represent the machinist business. Foundry work should be shown by having the usual fixtures for sand, and two and three part flasks for moulding, etc.; the casting 
could be done in soft metals, as" "ead, zinc, or tin, which could be reused, as the whole art in foundry work consists in the different manner of moulding. We would have a printing-press, type, fixtures, etc., to represent the printing business; mason work, the laying of brick to some extent; stucco work, or the working and the moulding in plaster of Paris could be shown; the whole room being filled with educational problems of instruction, such as three different heights of barometers, the bellows-valve, the gyroscope, the ball on the top of a jet of water, the steam-injecter, etc., etc., all to bring out the thoughts of the youth, enabling the superintendent to ascertain the true bent or natural genius of the individual, so that he could be put to the right manual profession which he is best suited for.

As soon as it should be ascertained what kind of business the pupil is best fitted for by nature, he would be recommended to the Manual Institute where that trade should be taught, and be more thoroughly instructed in two years, and become a better mechanic, than in six or seven years under the old system of learning a trade.

We would here like to show the difference between Manual Institutes of all kinds that should be established to teach a trade, art, or calling, and the shops already established for doing work of that particular kind for profit. For example, we will 
speak of the machine-shop, which, as now arranged, is fitted up with the general tools and fixtures necessary to do a particular class of work, such as locomotive building, or steam-engine building of various sizes, or printing-press machinery, or factory machinery, or tool-making, etc., etc., neither of which would have every variety of tool or fixtures in any one shop for doing every kind of machine work. But when we fit up a machine-shop for the express purpose of teaching that trade or art, it should contain, not only planers, lathes, upright drills, gearcutting machines, etc., for doing work generally, but should contain every tool and appliance of every name and nature that is ever used in any machine-shop, so that the student would become acquainted with every manner of doing work and the management of every kind of tool or device ever used in shops doing any kind of machine work. Also, there should be a very particular selection of the kinds of work to be made at the Manual Institutes, consisting of lathes and planers and other tools that are always kept on sale, large and small work of different kinds, making as great a variety of work as possible for the pupil to practice upon in building, so that he would get a thorough knowledge of all and every part of the machine business ; and each pupil would be taught to make the whole, and put together every machine that was being constructed. 
In the Manual Institute the pupil would advance from a lower degree of instruction to a higher as rapidly as his thorough knowledge and good workmanship would justify. The instructor would be paid a satisfactory salary, and not be permitted to make merchandise of the time of the student. All machinery or articles made by the students could be disposed of by being put on sale, and the proceeds appropriated toward defraying the expenses of the "school-shops."

The great and rapid change in the division of labor and the introduction of machinery, and the great variety of appliances for doing all kinds of business, show plainly the importance of changing the system of instruction at the present time. We think it will be admitted that it will be of incalculable advantage to the youth, and would prove in the end to be very economical for the whole community.

It is well known there is no place at the present, nor has there been for some time past, where a boy could "learn a trade."

Every boy, rich or poor, is, we think, as much entitled to be taught a good trade as to have an Education in our public schools. We also believe the proposed plan would be self-supporting in a short time after being once put in successful operation. 
To recapitulate:

First. There would be great advantage gained by selecting the right youth (by the Developing School) for the right business.

Second. The boys would be taught the trade, instead of picking up their knowledge by mere chance, as was the case by the former plan; and not be kept on work which would be most profitable for the master, as it would be his whole object to teach the boys, instead of making profit on their work.

Third. The Manual Institute would be much more perfectly fitted up (as described) to teach the business than any shop to do work for profit, as all shops heretofore have only been fitted with such tools and appliances as were necessary to do their particular class of work.

Fourth. The kind of work selected to be made by the boys would be both large and small, embracing as great a variety as possible, in order to give them a perfect knowledge of every branch of the business.

Fifth. There would be good moral discipline in the Manual Institute, the boys not being mixed up with journeymen and all classes usually found in all shops as generally established.

Sixth. There would be no more expense to the boy while learning the trade and making him a 
producer, than there was while getting his publicschool Education.

Seventh. The worth of the work made by the boys would probably pay current expenses after a very short time.

Mr. Ruggles insists upon keeping entirely apart the school proper from the Developing School and the Manual Institute, into which the children are only to be received after a certain age, or after they have left the grammar school.

The Developing School of S. P. Ruggles is a new and far-reaching thought, with tendencies of remarkable interest to the social student. It is the natural accompaniment of public industrial Education, for a State, with almost infinite means at command, can not act blindly in doing the work of millions, as weak and isolated individuals are wont to do. Or shall the State lavish its resources in teaching men what they will never succeed in, and what will ever be a drag upon them as individuals, and upon the State as a whole? And, hence, we may safely assert, that industrial schools will ever be attended by Developing Schools, equipped for doing the work of a dynamometer, measuring the technical and professional powers and qualities of youth before they are put to what is to constitute their vocation in life.

Every man is an especial organ of society, and 
will best perform his own function. But who ever heard of an eye doing the work of the ear, or of an ear doing the work of the eye? As long as every man is not started rightly by the Developing School, and put to his own proper work, society will be out of gear, just as the body is when one or another of its organs is out of order.

Men enter trades without reference to taste, talent, means, climate, soil, natural production, local opportunities, demand, or their own physiological aptitudes and hereditary tendencies, and, hence, they make through life botches and failures, eke out a miserable existence, shift from one thing to another, betake themselves to drinking and gambling, and get into other pitfalls, -and into general apathy, and become vagrants and tramps, or get diseased and die prematurely. Upon the concourse of our occupation with the forces of nature within and without us, and with the facilities of time and place, our success and happiness in life depend. We must hitch the infinite forces of nature and society to our own car, and not rush into the battle of life like the general who, in his haste, left behind him the army which was to do the fighting.

Only the Developing School and Manual Institute will remove the ground for the timely complaint of the eminently practical divine, the Rev. 
Dr. Hall, of New York, that there is want of a settled purpose in life, a shallowness and lack of development in individual capacity, and an unwillingness among young men to become mechanics, laborers, and farmers.

It is a consideration not unimportant to the race, that we have hitherto counteracted, if not destroyed, the heredity of mechanical genius by the habitual exercise of opposite tendencies. Let the Developing School suit the employment of men to their native bent; and the natural tendencies, which are organic aptitudes, will be deepened by congenial habits of body and mind, and skill and talent will become more and more hereditary.

Drunkenness, vice, crime, pauperism, insanity, and every other deteriorating tendency are hereditary; let us suit men's trades to their talents, three, four, and more generations, in the Developing School, and foster congenial industrial habits in the Manual Institutes of the American system, and we shall thereby co-operate with the Creator, render the upward tendencies of our nature equally hereditary, and improve, with the progress of Art and Civilization, the physiological aptitudes which attend mechanical genius.

Adam Smith observed, already a hundred years ago, and every succeeding philosopher had more and more an opportunity for observing the mis- 
chievous tendency of a progressive division of labor, in narrowing the capacity of the individual. This same system of labor overrules to-day every occupation, and a boy has not the slightest chance for learning a trade. So, for instance, with 316,459 artisans and manufacturers in Massachusetts, there are but 1,206 apprentices in the State, or one apprentice to 262 artisans and manufacturers, and in Boston are 51,344 artisans and manufacturers and $37 \mathrm{I}$ apprentices, or $\mathrm{I} 38$ artisans and manufacturers to one apprentice. This vice, rooted in general conditions beyond the power of the individual, can only be corrected by the State.

But when an evil becomes unbearable, a higher order of things is ready to burst upon us; the travailing pains are the harbingers of the new birth, and what hitherto was mixed up with other functions, is, hence, performed by a new organ, and of course is much more perfectly done: such is the order of nature, and of the social organism.

When the means and conditions of learning a trade can no more be commanded by the individual, a new and separate public organ is shaped with such perfect adjustment to this end, that all haphazard is henceforth precluded, and the function is performed with an accuracy and perfection never anticipated. Everybody's trade or profession is henceforth no more a matter of chance, but the 
Developing School gives everybody the trade or profession that is his by nature, and the Manual Institute is fitted to make him a master of every part of his trade.

Only when what is now chance will be brought under the law of nature and reason, the principle of heredity will have its sway in Education. Children with the taint of dipsomania in their blood will not be put to trades which, by their environments, are sure to render this craving irresistible. Children with the taint of consumption in their blood will not be put to indoor trades, like tailoring, shoe-making, watch-making, and the like trades. Children with the homicidal taint will not be put to trades which naturally tend to brutality. And children with the taint of insanity and other nervous disorders will not be put to trades especially wearing upon the nerves. And thus crimc, disease, and death will be lessened, the vigor of the human system will be preserved, and its working capacity prolonged, the productive years of men increased, and the public burdens will be lessened, and the general wealth swell.

How many a boy had for want of opportunities for industrial Education to accept the first chance of a trade offered to him, and being misplaced, had his genius smothered, and could do but poorly his work through life. Place a man where he belongs, 
and drudgery will give way to art, beauty, and invention. Why do men shun work, and run mad with speculation ending in bankruptcy? Because work is no pleasure. And why not? Because men can feel but miserable in doing a kind of work God has not made them for. And this misery and unwillingness for work sharpens the conflict between labor and capital, while Ruggles' Developing School, or the American System, placing men where they belong, transforms mercenary labor into a natural function and pleasant exercise, as men like to do what they can do best. Neither will men hoard to relieve their children from the necessity of labor, when labor will be engaged in as the exercise of natural skill, and an opportunity for technical distinction in an art suited to the talents of the individual. Work will cease to be a slavish task, onerous and burdensome, and no amount of capital a man may become possessed of, will keep him from what is but the natural promptings of his own natural disposition, and the expression of his individuality, and therefore his most rational and enduring happiness.

The Developing School is the egg out of which will be born the future organization of society upon the basis of natural talent. It will put the child where it belongs in the starting of life, and like a plant in a congenial soil, every man will prosper. 


\section{Developing School.}

God's will, the elements of nature and of society, or the environments and man's freedom, will be made to conspire, and the natural result will be, that production will be doubled, and health of body and mind and, consequently, human happiness will be enhanced. Social problems, with which the world has hitherto grappled in vain, will find their solution in the Developing School originated by the Great American mechanician and inventor, S. P. Ruggles.

The financial crisis may put off, but can not put to rest the problem of technical Education. The old system of apprenticeship is dead, and we must replace it by something new, or we shall make tramps and paupers whose maintenance will cost us more than the mere expense of industrial training. It is certainly cheaper to teach men how they may take care of themselves than to support them through life.

The Hon. P. Emory Aldrich shows the folly of the cry against the expense of Education. Have we not expended thousands of millions on railroads to which the Government has freely given hundreds of millions of acres? The Commonwealth of Mássachusetts has expended nearly or quite $\$ 18,000,000$ to build four or five miles of railroad under and through one of the mountains of her western border. There are four buildings in the 
State of New York, which, before they will be completed, will cost in the aggregate $\$ 40,000,000$. The same lavishness we meet in every State, and shall we say we have not the means to set the youth of the nation carly to work that we may enhance the productiveness of the labor and capital of the land?

What folly, says the same gentleman, to expend millions from the public treasury upon the military and naval schools, wherein a limited number of young men may be instructed in the arts of war, and yet deny to other technical schools, wherein the arts of peaceful industry are taught, all State aid or Government support. Multiply the schools of peaceful industry, fill the land with their light and influence, and you will dispense, to a great extent, with the necessity of military schools and the arts of war.

As we have already remarked, the technical training of 400,000 youths in the United States would hardly add Io per cent. to the present cost of public Education, while half the product of their labor would soon add daily to the public wealth, at the lowest calculation, $\$ 200,000$, covering the entire expense of the public school system of the nation. Still, according to another view, the additional cost would be nothing at all, as ten thousand words, or three hours' teaching, being as much as children 


\section{Developing School.}

can daily bear without confusion of mind and injury to their physical system; the present number of teachers and school-buildings will suffice for double the number of pupils, and, hence, school instruction and industrial training combined need not cost more, and may even cost less, than our useless cramming system.

But even if the State is not ready for the universal introduction of industrial Education, the Developing School can be made to do its work with little extra expense, as one or two suffice for a city, the industrial museums of which contain sufficient machines, tools, and instruments, only poorly arranged, and hardly serving a reasonable end, all of which could be arranged in the manner proposed by S. P. Ruggles, so as to assist young men in finding out their peculiar bent and talent, that they may choose correctly their trade, business, or profession, and afford besides constant instruction through the suggestive arrangement of the various parts of the Developing School.

Universal industrial Education changes the whole order of civilization; it is the beginning of a new page in human history. It is a revelation. It sets up work as the equal of thought. It is the recognition of humanity at large, of its wants, its work, and its worth. It will infuse the spirit of humanity into all legislation touching the masses. The co- 
ordination of the workshop and the school-house is the emancipation of labor from present prejudices.

Instead of educating, drawing out, and developing men, and putting them in the way of developing themselves through life, by bringing them in contact with the means and conditions adapted to their natural disposition and talent, we smother and impede their natural growth by putting them to uncongenial work that constitutes their misery, and of which they try to rid themselves by wealth acquired without scrupling at means.

To force work upon men is communistic nonsense, and will never succeed. Put men to their proper work and nothing will keep them from it. Besides, we do best the work we are adapted to, while the work that is forced upon us is, as a rule, worthless. When means, climate, soil, talent, health, heredity, and natural bent, in short, when God, man, and nature will co-operate in every stroke of work that is done, and doing will become a pleasure, there will be such an abundance of the utilities of life that wealth will no more be an object of greed than air or water are to-day, and our pleasure will be in doing and not in having, and men will vie with each other in serving the world, as their work will be their happiness.

Not a new, arbitrary, and despotic organization of labor or society, but a new organization of Edu- 
The American Social Science Association. 509 cation upon the basis of life, labor, and the natural disposition or talent of man, is wanted, and men put to their own proper work in life may be left free, as their own desire for happiness will be a guarantee for universal order and justice:

Right-living is an art, and can no more be taught by words than any other art. We must go at it at once, and begin with its practice. Education today is all theory, but practice must precede theory, and the use of the brush is more apt to make a painter than Newton's theory of colors. Practice is more important than theory, as it will always lead to perfection in executing or art, while theory, in many things, may never rise to the dignity of science, and still less to the truth and reality of life.

THE AMERICAN SOCIAL SCIENCE ASSOCIATION.

Mr. Wendell Phillips, on the Committee on Industrial Education, appointed by the American Association on Social Science, says : "Seven out of ten who come out of our public schools will be obliged to make their living by the work of their hands. Hundreds leave school at fifteen years of age wholly unable to do anything for which any man would be willing or could afford to give them a dollar. The boy who is going to college has two or threc more years of Education given him to fit him 
5 10 The Amcrican Social Science Association.

for his future. Why should not the city extend to the children who prefer some mechanical trade equal favors, parallel advantages, the same amount of training for their future that the college boy has for his? The discrimination against those who prefer to work with their hands is very unjust. Our present school system does a boy rather a harm than a good, as it rather unfits him for the life of labor, which is to be his life."

Rev. Edward E. Hale says : "After intemperance untrained labor is the worst evil, and all our average boys are fit for on leaving the common schools, is to be news-boys, or cash-boys in the great retail shops, or to peddle lozenges."

The Hon. Elizur Wright says : "Our school system is set up wrong end foremost, because children should be taught the use of tools before they learn to read, write, and speak, which is the bottom idea of Froebel's Kindergarten, which is to educate children through work. Ruggles' Developing School gives a boy the mastery of many a tool, and the School Shop teaches him how to do almost everything connected with his trade, whilst, under the old system, he was put to the doing of one thingthe thing most profitable for the boss-over and over forever and forever."

Foremost among the men who have given their best thoughts to the elaboration and popularization 
of the American system originated by S. P. Ruggles, John Newell, Esq., of Boston, deserves most honorable mention. He made plain in his remarks before the American Association of Social Science, that President Runkle lays mostly stress upon the discipline his system gives, " not caring if the student never touches a tool after he leaves the school;" and naturally so, as the School of Technology was a place for the training of men of science to whom science and not a trade is the end. Mr. Ruggles' system is calculated for youth who wish to ascertain what trade they are most fit for, and want to learn it most perfectly and in the shortest time. The Developing School and Work-shop are intended to replace the old apprentice system, which is irrevocably gone, and will be a vast improvement upon it, as it will instruct a youth just as fast as his talent and progress will allow, and teach him every part of his trade, which, under the present division of labor, is more than he can learn in any single shop.

Mrs. Elizabeth Thompson says : "The best charity is to teach the people how to work most productively, and to elevate labor by placing it on a level with science and making it a part of Education."

THE PRESS ON INDUSTRIAL EDUCATION. The Boston Commercial Bulletin says : "Our exist- 
ing system does not supply the youths of our cities with the Education which will prepare them to earn a living. Nine-tenths of the failures in life come from the rarity of a man finding his calling. The Developing School provides for this difficulty, and Mr. Ruggles' long experience entitles his opinion as to the necessary change in our educational system to a serious consideration."

The Boston Post says: "The impression is almost universal that we must supplement our public school system by industrial training. Our boys today on leaving the common school are left for years a burden to their parents, listless seekers for vacant places in stores, or, at the worst, an idle class from which vice and crime are wont to recruit their strength through the always ready agency of temptation."

The Boston Saturday Evening Express says : "We have now in the State 300,000 persons who have no practical knowledge in any trade, art, calling, or profession by which to obtain a living, only being useful as a reserve from which a draft can be made for tramps, political bummers, thieves, jail-birds, candidates for all our penal institutions. Ninetenths of all our criminals arraigned and corrected, are persons who have no technical Education. Let the Developing School of S. P. Ruggles give our boys the chance to select their trade, and the 
school shop teach them thoroughly in the shortest time to master it, and all will be well."

The Philadelphia Times says: "What a tcrrible satire upon our boasted free school system, ninetenths of the young criminals sent to the penitentiary have enjoyed its advantages, but three-fourths of them have never learned to do an honest stroke of work.- Surely there must be something very wrong about a system which thus recruits the great army of idlers and criminals, and it is not wonderful that many thoughtful men believe, though they scarcely dare to speak it aloud, that our public schools are an evil rather than a good."

The Philadelphia Evening Telegraph says : "It is evident that to these young men, Education-that is, common and classical Education-is a curse rather than a blessing. Society has developed their mental powers to a point, that they are 'above' devoting themselves to occupations that they would be perfectly willing to follow were they uneducated ; . . . society, so far as it does anything, actually throws impediments in their way by educating them. Something must be done in the direction of giving technical instruction in all of the common schools, or they will, year after year, grow to be, instead of blessings, curses to us." 


\section{PUBLIC ACTION DEMANDED.}

The late Report of the Commissioner of Education informs us that the movement to secure indusstrial art training has made some progress in Philadelphia, and the day is not far distant when there will be engrafted upon the common school system a practical mode of technical study. Public art Education has now become such a necessity that if teachers do not lead in this matter, the manufacturers will soon take the initiation and insist upon drawing being taught in all schools.

The State Report of Rhode Island says: "The subject of class instruction in labor in the various trades and branches of applied arts, is in its infancy. What is feasible and what is not, is a question to be settled only by trial."

At a meeting of the School Commissioners at Utica, N. Y., Feb. 19, 1878, the following resolution was passed:

"Resolved, That we recommend study and experiment in the direction of physical labor to the end of devising for our schools some practical system of industrial art which shall stimulate mental action, and give skill in the arts which underlie the trades."

Governor Hartranft, in his message to the Legislature of Pennnsylvania, says: "A thorough system 
of industrial training must embrace the children, the workingmen, and the people. ..... In addition to the theory, it may be necessary for the State to afford practical training in the mechanical arts. It is not probable that the old system of apprenticeship, which has for various practical reasons fallen into disuse, can ever be generally restored. .... Believing that, under these circumstances, no remedy can be found, except through the direct agency of the State, I renew my recommendation contained in the message of 1875 , for the establishment of workshops in connection with industrial schools, and beg leave to refer you to the current report of the Superintendent of Public Instruction for the proofs he has collected of the feasibility and advantages of the plan."

“ THE SENATE OF THE UNITED STATES.

$$
\text { “April 9, } 1878 .
$$

“ Mr. Burnside asked and, by unanimous consent, obtained leave to bring in the following bill, which was read twice and referred to the Committee on Education and Labor:

"Be it enacted by the Senate and House of Representatives of the United States of America in Congress assembled, That the school-officers of the District of Columbia shall introduce and sustain industrial expositions of the pupils' handiwork in connection with each public school in their jurisdiction.

"SEC. 2. That these expositions shall consist of all kinds of 
useful articles made or invented by the pupils, including specimens of wood-work, iron-work, cooking, sewing, knitting, crocheting, and mending; also, farm, orchard, and garden products that are the result of their own industry.

"SEC. 3. That ornamental work be admitted when accompanied by something useful.

"SEC. 4 That the pupils be permitted and encouraged to explain the purpose of each article and the process of its culture or manufacture.

"SEC. 5. That these expositions shall occur as often as once a month during the school-year."

Peter Cooper, the venerable founder of a school. of art and industry, South as well as North, says in his open letter addressed to President Hayes: "Let us promote and instruct industry, all over the land, by founding, under national, State, and municipal encouragement, industrial schools of every kind that can advance skill in labor. The rich need the literary and professional school and colleges, and they should have them; but the poor need the industrial school of art and science; and it should be made the duty of the local governments to provide a practical Education for the mass of the people, as the best method of 'guaranteeing to every State a republican form of government.' "

We may study the history of industrial Education at home or abroad; we may listen to the discourse of the teachers of the land in council; the 
science and ability of the American Social Srience Association; the experiments of institutions, and. of practical mechanicians and philanthropists; the increasing poverty of the masses; the decay of public health; the decline of private and public virtue and simplicity; the warnings of the truest men and women in the nation, as well as public opinion expressed in our daily jourrals-all alike proclaim the necessity of educating together the head and hand, and that this is the great need of the nation.

It will not do to say children have no time to study and work at a trade, for the success of the half-time system is too well established, and the Hon. Mr. Newell is right in maintaining that the time given to the tricks of spelling, mental arithmetic, grammar, and geography could be applied to much better purposes. And as to the cost of industrial Education, is it not a noble investment by an annual outlay of fifteen dollars during two years, at most, on each young mechanic, to save him three precious years, enhance his skill and productiveness for life, spread industry, raise labor in intelligence and position, and strike a telling blow at pauperism, drunkenness, vice, crime, disease, insanity, and the whole sickening train of hostile causes which are only too fast undermining the life of this young nation? The quarter of a million it 
may cost to turn out annually ten thousand skillful mechanics would soon be saved on the police, courts, prisons, and asylums of all sorts, while their industry, at the rate of a dollar a day for each, would produce for the country ten thousand dollars every day. Is this not motive enough to stir us to action? In the name of God and humanity, and our own interests, and the country's future, let us act.

THE NEW ERA AND THE DIVINE LAW OF LABOR.

We are entering upon an epoch as distinct as any of those which mark the past; it comes in a workshop, and work it will until it transforms all; it comes to the masses and to the young, and as it transcends in humbleness, it will transcend in glory.

Slavery, with all its untold horrors, next brigandage, and lastly wholesale hanging, are stages of civilization belonging to the past; to-day a perfidious charity is killing the poor in ten thousand bastiles, covering the land the world over. America, with the practical wisdom and humanity peculiar to it, is ushering in a new era, by a revolution as thorough as it is quiet, by the union of the school and the workshop, which shall supersede poorhouses, jails, mad-houses, and the like institutions characteristic of the past civilization. Only by educating the children of the Republic through 
work and to work in the Manual Institutes of the nation can we hope to establish the reign of the Divine law of labor.

PAUPERISM EATING UP THE NATIONS.

There is no other way to prevent us from ending in a festering mass of pauperism, crime, disease, and insanity, but setting all sensibly, kindly, and practically to work in childhood. To house properly to-day our various pauper-classes and defectives, and provide accommodations-which we will have to do-for the tramps and vagrants in the United States, would, upon close calculation, require an outlay of $\$ 1,000,000,000$ on buildings, with $\$ 50,000,000$ for recurring annual expenses. How much cheaper would the industrial Education of the people be, and how much more would we have to show for our money. Are we not sufficiently taxridden to feel the force of this argument? Or are we to pass against pauperism laws of repression originated in ignorance, selfishness, and pride, attempting substantially to restore the expiring system of slavery? Everywhere in Europe, almost all severities, says a writer of unquestioned authority, have been inflicted upon the poor, except scalping. There is a revolting monotony, we read in the blue books of England of to-day, in the earlier history of this policy of repression in all civilized 
countries. Without referring to the barbarous legislation of earlier reigns, we read at the times of Queen Elizabeth, "all parts of the realm of England and Wales are at present exccedingly pestered with rogues, vagabonds, and sturdy beggars, by means whercof daily happeneth in the same realm horrible murders, thefts, and other great outrages. .... It is enacted that thesc rogues, and vagabonds, and sturdy beggars are, for the first offense, to be grievously whipped, and burned to the gristle of the right ear with a hot iron of the compass of an inch about; for the second, they are to be branded felons; for the third, to suffer death as felons, without benefit of clergy." In every county of England 300 to 400 vagrants lived by theft and rapine. Threescore and twelve thousand great and petty thieves and rogues were hanged in the reign of Henry VIII. And in the beginning of the reign of Elizabeth there was not a year wherein 300 to 400 vagabonds were not eaten up, in one or another county, by the gallows.

Spain lashed, banished, cropped the ears, enslaved, and put to death mendicants who solicited alms. France flogged them, put them in th 2 pillory, burned them with a hot iron on the forehead, and banished them, or made of them galley slaves. Even under the magnificent Louis XIV. female 
beggars were banished, and male beggars flogged, and next time consigned to the horrors of the galleys. Refined Dresden flogged and imprisoned beggars as late as I790. Hamburg and Switzerland had similar legislation, and Copenhagen condemned men asking charity to solitary confinement in the penitentiary. Such are, by necessity, the means by which the poor, the natural fruit of the old civilization, were kept out of sight.

The number of the poor, says a thoughtful author, is underestimated. It is put in England and Wales at $1,300,000$, because as many receive charity on a certain day; but when we count those who received public charity before or after that day, during that year, we shall find the number of the poor to be fully three times as large, taking out of the public treasury $\$ 100,000,000$ per annum, a figure which is doubled by what flows from private sources. And even this sum, enormous as it is, it is more than doubled by the cost of crime and police, waste, destruction, pilfering, incendiarism, and cost of intoxicating liquors; and this may give us a glimpse of the cost of pauperism which is due to the want of industrial Education.

Scotland, with a population of $3,100,000$, gives parochial assistance to 350,000 persons ; and London, with a population of $3 \frac{1}{4}$ millions, has 300,000 people receiving parochial relief. 
Let us look at the results the want of a universal system of industrial Education has produced in France, and the load of pauperism that beautiful country and great nation is staggering under. In 1866 the following classes got public assistance :

Men appealing to the Bureau of Relief, . I,303,08r

Sick in hospitals, . . . . . . 336,130

Lunatics, . . . . . . . . . . 12,589

Women in childbed, . . . . . . . 16,132

New-born infants, . . . . . . $13,58 \mathrm{I}$

Casuals, . . . . . . . . . . 27,155

Aged and incurables . . . . . . 52,781

Orphaned and abandoned children, . . 45,322

$\overline{1,806,771}$

But even this number has to be more than doubled, and Dean, in his "History of Civilization," states it, on official authority, as $4,000,000$, as the number given by us includes but the part relieved.

France expended in $186 \mathrm{I}$ 108,44I,828 francs upon its poor in 1,557 asylums and hospitals, and yet half the cities of France, and rather more, are unprovided for by public assistance, and according to the best French authorities, misery is hardly relieved, notwithstanding the large sum applied for its alleviation, and had 337,838 vagrant beggars. Paris expended in $1869,23,806,027$ francs for in- and out-door relief to 317,742 persons out of a population of $1,799,880$. Its charity department employed 4,349 officials, and I,989 physicians and surgeons; 
100,000 patients were in its hospitals, and 7,000 in . sane in its asylums, with a yearly increase of 2,500 cases. What an argument, then, France offers against the old Education.

The kingdom of Prussia has over 486, 79 paupers, and gives public relief to 4.89 per cent. of its entire population. In 60 of its largest towns, I8.12 per cent. of the population are recipients of public charity: in 238 towns next in rank, 7.38 per cent.; and in 672 of the smallest towns 4.91 per cent. are relieved.

Saxony, with $2,337,192$ population, has 2,540 poor-houses, and relieves $4 \mathrm{I}, 547$ poor. Bavaria, with $4,370,977$ population, relieves 79,863 poor, and swarms with tramps and beggars as hardly any other country does. Wurtemberg, with a population of $1,400,000$, has 1,842 poor-houses, and 16,734 recipients of public charity.

Austria, exclusive of Hungary, relieves 171,768 poor. It has 6,678 poor-houses. It has, besides, in its hospitals for the poor, 212,517 patients, takes care of 68,053 foundlings, 18,824 lying-in mothers, 4,749 insane, etc., etc.

Italy, exclusive of Rome and other districts, counts, in a population of $18,599,029$, I , I I 5,126 poor, upon whom large sums are expended. It has I 2,976 hospitals and asylums, in which $861,921,624$ francs are invested, and the current expenses of which are $14,945,02$ I francs. 
Let the reader once for all notice the poverty not relieved is not counted in the statistics of public records.

Belgium had in 1868550,000 poor. Of its $908,-$ , 0 families 446,000 are public paupers. It spends on its poor $\$ 10,673,792$, which, of course, scarcely at all relieves the vast pauperism which would be wiped out if industrial Education was universal and not merely a shred.

Sweden, with a population of 4,1 14, 14I, had in r 865 I 48,000 poor, at a cost of $\$ 1,100,000$. Denmark had $1,784,741$ population, and 74,324 poor relieved. Norway, with $1,720,500$ population, had I 80,$\infty 00$ poor relieved. Germany has 900,000 paupers. But these figures are all deceptive; they merely represent the crushed poor who are trodden under-foot as the abject recipients of public charity, while the poor who are nobly struggling against hard fate are fully four or five times as numerous.

And does the present Education yield different results in our country? The State of New York gave from $\mathrm{I} 868$ to $\mathrm{r} 874$ relief to $\mathrm{I}, 256,955$ individuals, which gives an average of 179,565 who received alms annually. In 1872 147,427 applications were made for lodgings at the various police stations of the city of New York. Add to this the tramps the State gave 200,000 lodgings in the same year.

The following table, taken from the official sta- 
tistics of the Board of State Charities of Massachusetts, shows the condition the people are drifting to in the Eastern States :

\begin{tabular}{|c|c|c|c|c|}
\hline & $\begin{array}{l}\text { Wholly and par- } \\
\text { tially supported. }\end{array}$ & $\mid \begin{array}{l}\text { Lodgings giv- } \\
\text { en at Boston } \\
\text { police stati'ns. }\end{array}$ & $\begin{array}{c}\text { Acts of relief } \\
\text { to tramps ex- } \\
\text { clusive of Bos- } \\
\text { ton. }\end{array}$ & $\begin{array}{c}\text { Total of State } \\
\text { expense. }\end{array}$ \\
\hline $\begin{array}{l}1872 \ldots \\
1873 \ldots \\
1874 \ldots \\
1875 \ldots \\
1876 \ldots \\
1877 \ldots\end{array}$ & $\begin{array}{r}29,066 \\
32,738 \\
41,130 \\
63,237 \\
73,737 \\
82,997\end{array}$ & $\begin{array}{l}35,667 \\
42,384 \\
57,014 \\
64,680 \\
60,803 \\
64,419\end{array}$ & $\begin{array}{r}33,230 \\
45,653 \\
99,083 \\
137,308 \\
148,936 \\
190,704\end{array}$ & $\begin{array}{r}\$ 906,819 \\
980,404 \\
1,009,688 \\
1,172,416 \\
1,321,011 \\
1,450,624\end{array}$ \\
\hline
\end{tabular}

Boston has already registered 16,2 I I families, or 56,738 individuals whose condition is such that one-half of them are reduced every year to the necessity of applying for public relief, and from observation and comparison we may say that before the count is completed it will embrace 20,000 families, or 70,000 individuals. This is the best test of the condition of the masses, to whom our means of improvement must be adapted, for the tramp and out-and-out pauper are but the last stage of the same disease, and beyond the reach of any remedy.

How absurd to judge the condition of the people by the comparatively few cripples and imbeciles inside our pauper institutions; or to take measures that meet the case of those who take outside public 
relief. An effectual prevention of public distress must take notice of, and be adapted to, the great masses which are ever hovering between want and a competency.

As the standard of living, general benevolence, and the disposition and constitution of state and government differ in various countries, the call for public relief will differ, and the statistics of pauperism do not tell the exact story of the condition of the people as they are educated to-day. We must take into consideration the cost of living in our cities, and make an exact study of the average incomes of the masses, and we will be amazed at their trials. We have already noticed the low incomes of the masses in other countries. In Massachusetts the average income in the trades is $\$ 482.72$; the average rent paid by a family is $\$ 109.07$, and the cost of living is $\$ 488.96$. Instead of an indispensable surplus for insurance against sickness, old age, death, and the thousand mishaps of life, we have here a deficit growing inevitably, as the years roll on, into pauperism.

How closely must the people border on pauperism, when statistics show us that the number of marriages, of births, of deaths, and of crimes, positively depend upon a few cents more or less in the price of a bushel of wheat or potatoes, or upon the reduction of a few cents in the daily wages of the 
people, upon a few weeks' stagnation of commerce, or upon a few degrees of difference in the temperature of the atmosphere, and the need of a little more or less fuel. Is not all this evidence that with general intelligence the school must develop in the people a higher and more remunerative skill, and the faculty and the knowledge and the habit of a wiser economy than they practice to-day? Let not the man of God say all that is needed is religious training. For as God worketh hitherto, only he that works too, has God on his side, and the right use of our powers and means is the fulfillment of the will of God.

It is often said, that what the schools call ignorance, threatens the perpetuity of our government. We maintain, general misery threatens it far more, as it includes every other vice or disorder. A republic with the extremes of wealth and poverty is a short-lived thing. But there is no reason why a nation educated to work and to intelligent exertion should perish, as all virtues flow from such an Education, which is, beside, most conservative in its tendencies.

The practical teachers of the early and happy days of Greece and Rome built up the State, the liater grammarians and sophists ruined it, and we are foolish enough to begin with what they ended, the spirit of negation that nibbles away every shred of 
morals, patriotism, or esteem for anything, until nothing is left for the nation to stand upon.

With scientific exactness we have studied and found everywhere the symptoms of a spreading deterioration of the race. We have studied the various causes of this deterioration, and found them all centered in pauperism, the parent of all possible unhygienic conditions of our physical as well as mental nature; and, finally, we have seen the fearful compass of pauperism under the old aimless Education, which must be overthrown by one of work and immediate useful results, which alone is sure to prevent pauperism, the source of the maladive deviation from the normal condition and from the very type of the race, among the imbruted stratas of society, whose fall, loss, and total degradation is the sin of the world, and must be wiped out by work, work, and again work, this incessant praying of the whole frame of man, and parent of every grace and blessing to each and to all.

LABOR AND THE MODERN STATE.

Life and nature are positive, and so are workers and observers. Books give us the shadows of things; they are discursive, mostly negations, rendering us hypercritical and revolutionary. Words can not save the people; give them bread, clothe them, house them, or make them honest. 
Labor, wealth, hygiene, and morality are inseparable. Labor, therefore, is the foundation of the modern State, and must be made the main object of public Education. Drawing, mechanics, natural history, technology, and, finally, the workshop, are paramount in educating the people.

Much is said about mental training. But the observation and study of the natural history of the place; the study of the pursuits of the locality; its history, character, and institutions, and the observation of the life of the simplest child, are all unequaled in their power of training us for life, by any text-book or set of school lessons.

Industrial work being the foundation of the modern State, to industrial work the children of the Republic must be reared in the schools of the nation. This was the secret of the success of the Greeks, whose educational motto was, the child is father to the man, and in what the citizen is to excel he must as a boy be excrcised, and, hence, the law of Solon made the maritime Greeks as well swim as read at the age of five.

The lack of adaptation of our schools to the wants of the masses would be without an excuse, were it not that they are without examples in the past. The upper ten thousand among the Greeks and Romans were taken care of by a half a million of slaves, and looked to the school but for words. B it then 
their real business was war, and military exercises formed the main part of their Education. Under feudalism the people did not go to school, neither had they to take care of themselves, as they were taken care of by the lords, of whom they took care. Next came the régime of the small masters, when every hearth was an industrial school. And, until but shortly, slight commercial attainments were a sufficient capital for self-support, and that the school afforded. With the accumulated capital and great industries of to-day, the very existence of the masses is threatened, and Education must become industrial, and save the people from the bitter alternative of starving, stealing, or begging.

But though the greatest and most illustrious men the world has seen, among whom St. Paul is not least, have lived by their trade, European princes are taught trades, and health of body and of soul and of the State, as well as of the individual, demands an Education through work and to work, there is an insuperable objection to it: it conflicts with the inalienable right of every born American, which is, to be brought up for political loafing. We answer, an honest man is the glory of his Maker, to which official honors can add little, but from which they often detract. Political ambition is the bane of the Republic. Work makes the man. Work means duty, and duty is 
the lesson we need, and Education should inculcate. Endless talk of rights has puffed us up until the bare acknowledgment of a power in the family, in the State, or even in Heaven, is considered an offense to our individual sovereignty; and this is the feeling of the times and the spirit of the young.

We are told it is the commercial profits that allure away from useful labor. Well, that is just why the children should all be brought up in the common school for work, which, though it relieves them of the temptation of looking after the emoluments, does not unfit them for the performance of the duties of any station, if they have the talent and there is a call for it:

\section{CHANNING ON MANUAL LABOR.}

"Manual labor," says Channing, "is a school in which men are placed to get energy of purpose and character, .... a vastly more important endowment than all the teaching of all other schools. Alas, for the man who has not learned to work!" "The universe in which we live was plainly meant by God to stir up thought. Every object, even the simplest in nature and society, every event of life, is made up of various elements, subtly bound together, so that to understand anything we must reduce it to its parts and principles, and examine their relations to one another. ... . The greatest 
men have not been book men. Washington, it has often been observed, was no great reader. The learning commonly gathered from books is of less worth than the truth we gain from observation or reflection. Indeed, most of the knowledge from reading is very much a vain show. . . . What a library is human life. . . . . Every human being is a volume worthy to be studied." "Manual labor . . . fosters a sounder judgment, a keener observation, a more creative imagination, and purer taste than any other vocation. . . . Not a few of the wisest, grandest spirits have toiled at the work-bench and the plough. A boy might be made, in an institution, a thorough farmer, both in theory and practice, and might, at the same time, learn a trade, and multiply his chances of a comfortable existence."

Almost fifty years ago these words were greeted as an inspiration by men of genius, who made public misery in Europe a study. And shall not we profit by the teachings of our great apostle of the sons of toil?

\section{THE DREAM OF PHILOSOPHERS.}

Huxley pronounces "as the sum and crown of what is to be done for technical Education, the provision of a machinery for winnowing out the capacities and giving them scope. Whatever that 
United States Looking to. Massachusetts. 533

might cost, depend upon it the investment would be a good one. I weigh my words when I say that if the nation could purchase a potential Watt, or Davy, or Faraday, at a cost of a hundred thousand pounds down, he would be dirt cheap at the money."

"A large allowance to each man," says Emerson, "to choose his work according to his facultyto live by his better hand-fills the State with useful and happy laborers."

"God," says Ruskin, " has made us for happiness as well as for work, only we must find, if unhappily our parents and masters have not done it for us, what we are fit for."

What has been but a dream with philosophers has become a reality under the hands of the inspired mechanician and practical and patient thinker, S. P. Ruggles. As Massachusetts has given the country what was in its day the best common school and the first Normal College, so let us hope it will give us to-day the first Developing School and Manual Institute.

THE UNITED STATES LOOKING TO MASSACHUSETTS.

What may we not expect, for the ushering in of the great new era of practical Education in which all the nations will ultimately be blessed, from the 


\section{United States Looking to Massachusetts.}

noble men and women of Massachusetts, who lead in every work that elevates the masses and builds up the State.

We hope the great women of the country will come forward, as Mrs. Elizabeth Thompson has already done, and take pride and pleasure in redeeming mankind by the establishment of a practical training in the place of the old fowerless method.

The United States look to-day to Massachusetts, and Massachusetts looks to Boston for the ushering in of a general system of manual Education which will foster private and public virtue and a moderation adding a thousand happy years to the life of the nation. Can Boston, can Massachusetts, falter and give up the lead in such a cause? Judging from the past, we believe it will not.

But our aspiration for Massachusetts, which has made the cause of Education her own, Boston is fast turning into prophecy by the Joint Committee on Public Instruction of the City, consisting of Aldermen Hayden, Slade, and Guild, and Councilmen Pope, Coe, and Wheeler, taking under advice the Developing School, upon the petition of Edward Everett Hale, Wendell Phillips, Thomas C. Amory, S. P. Ruggles, and John Newell.

The remarks of the petitioners were full of force, point, and suggestion, and like the names that graced the occasion, deserve to be made historic. 
Thomas C. Amory, Esq., supported the petition, - by reminding the Committee that the building and appropriation asked for, have been favorably reported upon by a previous committee. It implies no loss to the treasury. It leads to a diminishing of pauperism and crime, and the outlay is insignificant in comparison with the gain. There is no way to teach the young the useful arts. Apprenticeship has died out, and the workshops recognized in England and Germany as the appropriate substitute, have not yet taken its place. We must educate labor for the mechanic and useful arts, and train skill for its wage, as we do science for its salary. . . . Our plan matured embraces a council board composed of representatives of the City Council School Board, mechanics, technological, charitable and industrial, and a few other men particularly interested in the subject, workshops, etc. .... If diplomas or certificates of proficiency were bestowed on all entitled to be entrusted with work, it might help them, and help skilled labor. . . . . The council and several guilds would carefully scan the progress of invention, dearth, and abundancy of the markets, and the fluctuation of wages, and exert an influence to prevent over-stocking; to. build up new industries, to qualify men losing a trade, by substitution of mechanical contrivance, for another; schools for mariners and farm-work 


\section{Unitcd States Looking to Massachusetts.}

would be added. The large bequests would supply every want, and donations are already forthcoming; etc. There are few more precious commodities for a community to produce than men and women healthy, strong, and accomplished, to earn their own livelihood, support their dependents, and hive up wealth for the State.

The Rev. Edward Everett Hale said that pauperism was not a chronic necessity in this country, and could be prevented. .... The begging class was divided into only two parts-people who never knew anything, and people whose heads have been cultivated at the expense of their hands. If the city would throw the prestige of the system of public Education around the business of making skilled mechanics, it would be found that the number of these paupers would soon be decreased. Good mechanics were always in demand, and he doubted if any really good workmen had found it necessary to ask for relief.

Mr. S. P. Ruggles said it was not to the advantage of manufacturers now to take apprentices, and the great problem was, what are we to do with the army of youths now graduating from the public schools? Are they to become tramps, or what? Mr. Ruggles showed the mistake of supposing that machinery makes lack of work, when, in fact, it is giving more work to artisans, and first-class workmen are more than ever in demand. 
The Rev. C. A. Bartol made an earnest plea for the education of the mechanical functions of the brain suffering paralysis from lack of exercise, and interfering with the soundness of the rest by the law of sympathy. The training of the faculties through the hands was especially useful in preventing pauperism. Poverty resulted from the lack of employment for the faculties. The present system of Education was defective in many particulars. Instead of taking recreation in some productive employment, like gardening, students were given gymnasiums.

John Newell, Esq., showed the futility of sending to the great West men who have not learned to do anything worth doing.

Mr. Cole, of the Committee, said in corroboration of the dearth of skilled labor even in the New England States, that of the forty foremen in the mills with which he was connected, not more than five were native born.

Wendell Phillips said it was the duty of the State to see to it that character, knowledge, and skill were taught to the youth. Children were taken from parents to educate, and how were they returned? They were sent back without any knowledge which would yield them an income of ten cents. Our present system takes the backbone out of youth, and will never make men of the force 
538 United States Looking to Massachusctts.

of a Butler, Theodore Parker, Wade, and others. It is a wonder the American people did not deteriorate through our defective system of Education. The Education of half a century ago was combined with labor, and was superior to the Education of to-day.

Sheriff John M. Clark thought it more necessary to give the general youth of Boston a practical Education than a classical one, and he believed the city would derive benefit from it. It would be vastly better to dispense with a great deal of what is now taught in the public schools, and put in place of it handicraft, the basis of a true and honest life.

- Mr.S. F. Gates and Mr. I. M. Blood spoke each of the advantages of universal Industrial Education, and the Committee took under consideration the granting of the appropriation and the building asked for, as the first step toward introducing a system of manual Education, that shall save the children of the Commonwealth from the bitter necessity of starving, begging, or stealing.

These episodes in the new time coming are breaking in upon the logical order of our argument, still we invite them, and may Massachusetts grant to its noblest sons what they ask for her children, and again we shall sin with a gladsome heart by interrupting words by acts. It is not lit- 
erary work, but work, work for all, we crave, that God's kingdom may come, and never mind our literary $\sin$, but let the $\sin$ of the world, crime and pauperism and insanity, be stayèd.

The saving of the masses through the reorganization of Education upon the basis of labor, is the watchword of the modern State which rests upon universal production.

There are men, and there are women, who see the star rising in the West, and who, with faith in God, the good and humanity, work with head, heart, and hand to help the coming in of the better day.

\section{THE GREAT REFORMATION WE NEED.}

Only work can bring us back to the hardiness of our fathers, and to their stern virtue and simplicity. We all love ingenuity and mechanical invention; the traditions of the harvest-field are fresh in our memories; we all love and honor work; are thoroughly democratic, and love the public school. We have, therefore, every reason to believe that of all countries this will be the first where labor introduced as a universal means of Education will effect the great reformation of which we all feel the need.

Of course we should encourage agriculture and emigration to the West. But our masses come from the surplus populations of the large cities of 
Europe with native tendencies for aggregating in large communities. They are often unskilled men, not inclined to great exertion, and, therefore, poor, and, hence, the necessity of making our cities, in which they settle, schools for technical culture and Education, or they will become centers of pauperism, communism, and revolution, recruited from our present schools.

Great cities are the tendency of civilization, and we must turn them into blessings, and we can if we will. It is true we have immense agricultural facilities. Still, it is absurd that, therefore, we should be a purely agricultural people. A nation of fifty millions has men of every sort of talent, and requires opportunities for every sort of culture. Heterogeneity of pursuit is the law of our nature and of civilization. Industry and manufacture stimulate scientific research in every direction, and a thousand trades give scope to the development of every God-given talent which leads to wealth and happiness. Why should we not manufacture everything and be self-sufficient as a nation?

This tying down Education to generalities is against the law of differentiation, the law of God, nature, and society. Education, like everything else, must and will differentiate into specific lines, just as the trunk of a tree does into branches and bear fruit. The world can not always remain a 
nebulous mass, and it is time we get beyond the fog of general Education, and teach the people to do something specific.

We have a history, government, and a place, and opportunities peculiar to ourselves. So are our tastes and wants, which are best supplied by our own artisans, which keeps alive and develops our own individuality as a nation, which we think as rich and beautiful, to say the least, as any, and worth cultivating.

We have already developed, and will still more develop, new styles and tastes in every art and manufacture, and create new worlds of beauty in which our national spirit will reflect itself, and spread civilization by a thousand things of use and beauty, which shall cultivate the taste, mellow the heart, kindle emotion, call out reflection, and spread comfort, happiness, peace, and good-will among men.

The trifles of art, however, can not save us. Antiquity surpassed us in beauty of form and richness of color. It abounded in imaginings vast in sculpture, architecture, and poetry. It had masters in loftiness of mind and in action. One art it did not know, and all the others could not save it-the God-like love of our race, which discovers the divine nature of man under poverty's rags, and works without ceasing to save and elevate the masses, that none of the angels in disguise, we call brother 
or sister, may be lost. This art-of all arts the most enduring-must preserve the State, the nation, and the race.

We must rise from the idolatry of the senses to the worship of the heart, from the sensuous delight in the beautiful to the God-like exertion of active life, and rescue the masses from the billows which are rushing in upon them.

Antiquity, the Saracens, the Middle Ages, China, Japan, Persia, and other ages and nations may be our masters in many pretty things, but the art of saving men, women, and children, and making them stand forth in all the perfection of a divine humanity, more than Phidias ever could in marble, or Raphacl upon the canvas, this art must become peculiarly our own, and humanity must be, hence, the source of all inspiration and of all action, from the humble artisan to the mighty man of State. The devotion of each to all, and of all to each, and nothing else, can save us from the cruel barbarism with which we are threatened by a materialism as glittering and as cold as ice.

Greece and the materialism in which its sensuous art-culture ended, crumbled away before the moral power of Rome, the depraved empire of which waned before the spiritual dogma of the East. Neither will philosophy and art or political organization avail us, and our worm-eaten commercial 
States are bound to go down in revolution and anarchy unless they are regenerated by the preserving efforts of a consummate humanity. A mass of high and low corruption does not form a national unit; there is neither life nor power in it. It can not live, neither ought it.

The questionable idealism of the knowledge and culture of the schools has neither the power nor earnestness to grapple with materialism, the very power of which we must press into the service of humanity, and that we only do when we increase, through industrial training, the productiveness and power for consumption of the masses, which must eventuate in their moral elevation.

Nothing will free us from the low materialism of a shallow empiricism which does not see the things above it and in the far future on the one side, and from the impractical idealism which does not discern the things near and the present on the other hand, of which Buckle complains as the present malady or weakness of the human mind, and bring the millennium of good sense and higher wisdom, but the union of thinking and doing, or letters and industry at school.

\section{INDUSTRY AFFECTING THE CHARACTER.}

Industry not only supplies our wants, it develops our understanding, it is the school of mankind, and 


\section{Three Stages of Industrial Education.}

there is hardly a trait or virtue in human nature but was matured in this school, and the character of men, and ages, and countries, and nations differs as their trades and vocations differ. The hunter, the herdsman, the sailor, the plowman, the tailor, the shoemaker, the mason, the carpenter, the machinist-who does not see how they vary from each. other in character? And the technical Education that transforms them all is of a vast moral reach, and touches the very mould and character of whole classes of men who are the constituent parts of the nation.

Establish an industrial system of Education which shall single out for every talent its own proper work as the American system does, and intelligence will be added to strength, and taste to intelligence, and all trades will become arts, and every workman an artist. Beauty and harmony in the works of man will be followed by beauty and harmony in the character of man, and justice and goodness and truth will spread, and the country will be filled with peace and happiness.

\section{THREE STAGES OF INDUSTRIAL EDUCATION.}

Froebel, Runkle, and Ruggles indicate the different parts of a complete system of industrial Education. The first gives the child the mastery of the senses; the second, the mastery of the tools; and 
Three Stages of Industrial Education. 545

the third, the mastery of the right trade, which is the consummation of the whole. And this division, in fact, is applicable to the whole work of Education.

Stage first. Putting the child into the possession of his senses, æsthetic faculties, reason and moral nature by cultivating the physical powers, mechanical skill in the use of the hands, the sense of symmetry and harmony, a quick judgment of number, measure, and size, readiness of invention, and the social habits of polite life, in a natural, spontaneous, and methodical manner.

Stage second. Putting the boy or girl into the possession of the tools: which are, for the senses and their technical employment, the hammer, chisel, saw, file, etc.; for the æsthetic faculties, drawing, the theory of colors; for the reason, the theoretical studies or pure sciences; and finally, for the moral faculties, correct moral notions or ideas.

Stage third. Putting the youth into the possession of the concrete whole: which is, for the senses and their technical employment, a full and complete trade; for the esthetic faculties and their practical application, architectural and industrial design and technical ornamentation; for the intellect, the applied sciences; and for the moral faculties, practical ethics, domestic and public economy, politics, etc. 
546 Three Stages of Industrial Education.

And thus the work of the cultivator of men must be directed, first to the senses, next to the tools, and then to the concrete work of life, the most important and the end of all.

If the advocates of the Russian system mean that a child shall not go to school a year, a month, or a day without using a tool, but that neither shall he leave the school and the workshop until he is a complete workman and can produce something that will support him handsomely, this is all right; but if the public workshop is to set children merely to hammer or file and know nothing in particular, this is sure not to make one tramp less.

A lad wants a trade by which he can make an honest living, and such as Ruggles proposes and practical men declare feasible. A boy's ability in the use of a half-dozen of tools does not alter the fact that manufacturers will not be troubled with teaching him the particulars of twenty different operations in the make-up of an article, which is cheapest produced by so many individuals, though for the State and the workmen it would be best if the latter were skilled mechanics and commanded the highest wages. A boy that can use a half a dozen of tools, but is ignorant of a special trade, is exposed to want and to the danger of having to accept for his calling whatever chances, be he fit for it or not. 


\section{Our Education without a Foundation. 547}

Or must even stern industry, under the hands of our teachers, evaporate in hollow generalities in order to be considered educational? It is time we free ourselves from this shallow pedantry. Let the friends of industrial labor remember that the blows of the hammer are as windy as the blows of the tongue when the performance is no more marketable than words. Bread is the cry of the million, and how shall we rid ourselves of pauperism, crime, and crushing taxation?

But has not the teaching of trades great difficulties?

We answer, none which the American people can not overcome, when crime, pauperism, and insanity threaten to eat us up, and the saving of the multitude demands it.

We have industrial schools after a fashion, or say rather shoe-black brigades, technical institutions, and even excellent schools for particular trades, but they are not of a quality nor sufficiently universal to regenerate humanity, and save the masses, and with them the nation.

\section{OUR EDUCATION WITHOUT A FOUNDATION.}

We have schools for the diffusion of literary trifles to the neglect of the development of character and working capacity.

Wm. T. Harris, the Superintendent of the Public 


\section{Our Education without a Foundation.}

Schools of St. Louis, eminent as a thinker and educator, says kindergarten are peculiarly adapted for an industrial people. And as ours is an industrial age, kindergarten are the portals through which we must pass to a new and better condition of men and things. Our present Education is a building without a foundation. We neglect to train systematically the original activities of children from their third to their seventh year, and when the period for forming creative habits has passed, we stuff them for years with other men's brain labor, and thus we induce the morbid greed that makes them cry through life, "give, give!" though they no more know how to apply what they get, than how to originate it. Kindergarten may add to the present expense of Education, but they are cheap at any cost, as they will more than double and treble the creative capacity, the skill, and the talent, as well as the love of work of the people. Under the heat and burden of the day, the innate longing for a better day has grown into a restless passion, dangerous to the very existence of society. Better we plant kindergarten and organize industrial schools, and educate the young for work, than let them grow up in a manner as to be good for nothing else than to form Jacobin clubs and revolutionary brigades; which will be the beginning of the end of our greatness and prosperity, and of the Republic itself. Let 
the people see that something is done. We may make laws and constitutions on paper, but the kingdom of heaven is a growth; it calls the little children and prepares them for their future glorious citizenship.

We wonder at the grossness of men who mean to make a new society in a day; but are we, who bring up the rising generation, ever talk about Education and development, and have the child, a manifest growth under our hands, any wiser, when we crush the child under piles of books, instead of setting him to work, that he may grow and develop into what he is in future to do and to be?

We may make learned babblers and expert swindlers, but never men, such as the future is bound to have, and will have, under the new order of things-which God is ushering in, in spite of all our blundering-until we dismiss the old parrot style of teaching, and replace it by training through work to work. A cobbler's or tinsmith's useful improvements are more real and valuable than a confused mass of the dreams from Pythagoras down to Schoppenhauer.

We repeat it ; the German system, or Froebel's Kindergarten, educating children through work and to work, the Russian system, brought forward by President Runkle of the Technical Institute of Boston, teaching practically the use of a 


\section{Industrial Education and Ovcr-production.}

variety of tools, and the American system of Developing Schools and Manual Institutes, originated by S. P. Ruggles, in which the proper trade is chosen and quickly and perfectly taught, both theoretically as well as practically, far from conflicting with each other, form the successive steps of a complete industrial Education, beginning with the child, continued with the boy or girl, and completed with the youth.

INDUSTRIAL EDUCATION AND OVER-PRODUCTION.

But the increase of opportunities for industrial culture meets with a shrug from the general public, who believe that we suffer already to-day from over-production. There never was a more dangerous mistake afloat. At the close of the Napoleonic wars, and some time afterward, a situation similar to our own caused in England the same delusion, which James Mill dispelled, by showing that a great production and a great demand are inseparable, and to complain of the one is to complain of the other, as those who produce one thing want to exchange it for something else. Of course we may overstock the market with one thing, but the abundance of every sort of manufacture can never lead to want, no more than men who sit down to a table can suffer on account of the overflowing abundance of the good things set before 
them. Suffer from over-production! Strange, more than half of the community suffer from want of the bare necessities of life, and not one in ten is provided with the comforts of life, and we are -told that we are over-producing. But are not half of our mechanics out of work? We repeat, yes; because the other half of the people can not or will not do anything that could be given in exchange for what the other half would like to do.

\section{THE FUTURE.}

With the curse came labor and the exit from Eden. The Developing School, harmonizing labor with man's inclination and talent, removes that curse, and throws open to us again the gates of Paradise. When work was hard and slavish, and therefore shunned and despised, only high profits, rents, and interest were sufficient motives for industrious application and accumulation, and they form a necessary link in the history of labor. But when labor and inclination shall be wedded to each other in the Developing School, production will become immense; rents, profits, and interest will decline; neither will they be wanted as motive powers for exertion; men will labor for pleasure, and not for gain or from necessity.

With shoemakers doing the work of machinists, and machinists doing the work of tailors, and 
tailors doing the work of painters, the world is moving on to-day just as square pegs would in round holes, and hence the endless troubles of labor and capital.

Men will not employ to-day their capital productively, as they can get a high bank dividend, and the men who employ their bank credit, are often ruined by the high interest they pay; and this financial confusion keeps the State in a constant turmoil, and the masses who are to live by their hand, perish from want of industrial opportunities, for money on security as good as gold, and on demand, is an accommodation for capitalistic speculation, but not for the slow and solid industry of the country.

The Education of to-day schools the wits of men of opportunity, and fits them for the work of oppressing the masses, and thus impoverishes the country and initiates a war of classes, ending in anarchy and general ruin. The future Education must enhance the industrial capacity of the lowly millions, and thus lead to universal prosperity and peace.

Industry is fully as important as knowledge, and the opportunity for each should be given. Let the school cultivate our powers for creating and organizing, and the desire for doing and accomplishing will take the place of that for having and getting.

When the stimulus of hoarding will be replaced 
by the pleasure of exercising our ingenuity and invention, and thrift and industry will be universal, and all will be provident and reliable, and universal credit will be a general good, money will be at cost, and production will rise to a height never dreamed of. We will become creative like God and nature, every pulsation will leave behind it a monument, and the riches of the world will turn the wealth of to-day into poverty. It is a slander upon the name and the wisdom of God, aye, upon common sense and humanity, to believe that pauperism, insanity, and crime are the concomitants of a progressive civilization; they are the pains of our folly and ignorance, and warn us off the barren ground our schools occupy to-day; they are the chastening rod by which Providence educates us up to a higher level. Give the child, the boy and the girl, and the youth, the training the German, the Russian, and the American systems call for, and pauperism, drunkenness, crime, idiocy, insanity, vagrancy, prostitution, and kindred pests will cease to mar this country and nation. The Kingdom of God is not impossible. It does not call for Newtons, but simply for sensible and honest men. Educate the nation for work, for action, and for industry, and wealth, and health, and beauty, and goodness, and truth will cover the land as the waters cover the sea. 


\section{THE THREATENING DANGER.}

The future of the nation is imperiled by the almost universal degeneracy of the masses, who are sacrificed to pelf. The nation is in danger. The hand of Death is upon it. The enemy is among us. He is in the city and all over the land. Who is not aroused? Who has any other care but how to rid the country of the common enemy of us all?

Pauperism, crime, insanity and a general degeneracy are eating up the masses, while extravagance, general corruption and dishonesty are rendering worthless the upper ten thousand. Let us save the nation from this greatest of foes-degeneracy. Let us live for our children. Let us live for one another, and instead of each warring against all, and all against each, let each be for all, and all for each, and all will be well. How precious is the saving of but one life, how much more so the saving of a whole nation! No, it cannot be; we are not so corrupt as to be indifferent about the nation and all the generations to come.

\section{THE DUTY OF THE NATION.}

Not wealth, but the health, strength, virtue, intelligence and character of the nation must be the future care of the republic. The noble sentiments of the nation may be repressed for a while, but will 
assert themselves again; and then everybody will be brought up for the race and live for the race; and his motto will be like Fénélon's: "I prefer my family to myself, my country to my family, and humanity to my country."

\section{CONCLUSION.}

Education, like the circulation of the blood, is life and health, when it is directed to every point alike; rushing to one point it brings death to all.

Neglect physical training, and the frail framework of humanity breaks down under its manifold burdens. Neglect industrial training, and the economical relations of man and the very foundations of civilized life are destroyed. Fail to exercise reason, and the light of the world is put out. Neglect man's moral training, and he becomes a monster. Train him exclusively for industry, and he becomes a machine. Train exclusively his moral faculties, and he is made a slave of habit and a zealot. Train exclusively his intellect, and he is turned into an iceberg or heartless villain. Thus a onesided Education spoils man, and makes of the intended king of the cosmos a maniac, pauper, criminal or villain.

To train all faculties alike and combine general and industrial Education, to develop early through science and art judgment and imagination, and do 
this with ease, so as to make the exercise or instruction a pleasure, and thus cause it to be organically appropriated and to become spontaneous, automatic and hereditary, are some of the chiefest problems of Education.

Our main proposition that the individual must be brought up for the race is supported by reason, nature and authority. John W. Draper says in his Intellectual Development of Europe, "Let man cast off the clog of individuality, and remember that he has race connections. The appearance of isolation presented by the individual is altogether illusory. Each individual man drew his life from another, and to another man he gives rise, losing in point of fact his aspect of individuality, when his race connections are considered. One epoch in life is not all life. Man cannot be separated from his race." Again, in his Civil Policy in America, "We have not been introduced here and do not continue here for our own personal sake, but that we may share in the development of a result of a higher order."

The same high authority coincides with us in our estimate of ancient languages, in which he sees neither the depositories of human knowledge nor instruments for mental training: "This evil . . . . was imported from England .... a remnant of the sixteenth century, but obsolete in this. ... 
A mastery of the game of chess improves more the mind than the translating of all the Greek and Latin authors in the world."

Buckle says, the natural sciences are democratic in thought, the classics never took notice of the masses, upon whom they had, therefore, no influence, and, hence, their but partial and short-lived eivilizations.

The conviction is deepening that neither is the Pope, God, nor the king the state; we dare to add, neither is the kid-gloved Greek and Latin cotery the nation, an appellation it in vain seeks to rob of the great masses of the working people. And we are supported in this our sentiment by the great philosopher and statesman, John Locke, in his solid work on the Human Understanding, where he contrasts the artificial ignorance and learned gibberish of scholarly disputants and all-knowing doctors with the illiterate and condemned mechanic, whose name is thought a disgrace, but from whom we have received the improvements of the useful arts.

Infant schools are a main feature in Race Eucation, but are discarded in our public school system. Still, J. Willm, an educator of world-wide reputation, has said as many as thirty years ago: "The Education of the people will not be truly provided for until infant schools are established everywhere, 
and the success of primary instruction itself cannot be obtained without this sacrifice."

We insist upon country homes, and will add to the many authorities already quoted, that of the celebrated Isaac Taylor: "It is in the country, and there only, that the minds of children may be kept in a state of healthful activity and be made acquainted with nature without the impertinent gobetween of books. A full half and more of all that ought to be learned in early life may be learned out of door by country-bred children, and how incalculable is the advantage of such a method in respect both of the mind and the body."

We insist upon scientific and industrial Education, which sobers us down to work for bread, and raiment and a little to spare. The vast generalities of the indefinite word-culture of our literary schools stimulate limitless desires and make us strive for the impossible. The insanity of exaggeration renders us madmen all, and the Stock Exchange as well as Bedlam has to be cured of this disease, or we shall never return to a sound financial basis. When the nine millions of families in the country will try on an average to make a thousand dollars a year, all will be well again, but as long as each strives for ten times as much, all will burst and all will brcak.

Race Education is the most complete union be. 
tween private and public interests, from the contest between which offenses rise. Solon said: "Yourselves will so well be convinced that obedience to my laws is your interest, that you will not be tempted to break them."

Race Education training us to live and work for the race, trains us for virtue or the public good, and fostering in us devotion to the race nourishes in us a noble passion from which great deeds may spring.

The school, the government and public opinion must educate us to work for the good of all. The fragmentary, finite and unreal in each must be supplemented by our living for humanity, the infinite and the whole. Still each must remain arbiter of his will, and, like a statue, stand on his own pedestal. The straight-jacket of communism precludes all freedom and internal growth and individuality. It may, perchance, do for angels, for whom any system will do, because as we fancy them they can do without any. But it will not do for men, certainly not such as they are in our day-and we deal with the present.

The depth or compass of every power or function of the mind, be it that of judgment, reason, imagination or will, being but the sum of all former repetitions of the same act, is increased by continued exercise. Göethe's dramatic faculty was formed 
in the nursery by constant exercise. Lessing, when but a child, buried himself among a pile of books. And the great Linnæus, the first organizer of the vegetable kingdom, was quieted in the cradle by a rose put into his hand.

As energy is the one great virtue including all others, and man is not to be controlled by every fleeting fancy, but the will is to be king in him, Education must be as full of action as life is, and the young must be kept active, as action is the best school of energy.

Individuality, next in importance to energy, can. only be preserved, under a uniform system of public instruction, by the adaptation of schools to the variety of pursuits prevalent in the different sections of the country.

The industrial virtues, formerly contracted by the daily example of the father working at the family hearth, must be inculcated to-day by the school.

The prevention of human deterioration through the cultivation of health and strength, developing energy and individuality, does the best for that spontaneity so much vaunted by the ideal lovers of the good and the beautiful.

The well-being of the race is no low and materialistic aim; it is the concrete of every high and noble endeavor, and gives it reality. This our age better bow in submission to the law of love as the 
one embracing every other law and contingency of human progress and development.

A comprehensive. glance at the world of legal and moral offenses or at man's motives and desires, as hunger, thirst, gluttony, drunkenness, sensuality, lust, greed, rapacity, tyranny, corruption, servility, meanness, pride, vanity, arrogance, prejudice, zeal, fanaticism, malice, hate, revenge, cruelty and all the frightful host of human passions, which, like so many disenchained brutes, threaten to lay waste as if it was the world itself, what are they but in-dividual selfishness, monopolizing the world for itself?

What is all law and all government, all science and all religion for, but the one to restrain the individual in favor of the collective whole, and the other to enlighten us about our true position as a part in the great, stupendous whole, in which and through which alone we live and have our being.

Must we wait until every brute of a passion has grown strong and untamable, and law and government, the keeper, step in with the red-hot iron and keep us at bay? Race Education trains the individual early to live for and in harmony with the race. Education must do the work of the government in the nursery and in the school. This is the very alphabet of organizing society, and if the lesson has to be repeated, it is not our fault. 
It is time the individual be made secondary to the race; it is the reverse order that gave us Cyrus, Alexander, Cæsar, Attila, Charlemagne, Tamourlane, Charles XII., Bonaparte and the like scourges. It was the same order that called forth the wars of the Popes for universal domination, the crusades and religious persecutions. Even in philosophy this individual selfishness has stifled the knowledge of the truth through the pride of system. It was the same individual pride, selfishness and tyranny that put a yoke and reins on a brother and called him a slave, a word at which the heavens wrapt them-selves in mourning.

And to this day what is it that thwarts the intentions of the best-designed institutions, makes prisons hot-beds of scrofula, phthisis, madness, vice and crime, and insane asylums and poor-houses the scenes of shocking barbarity but even this same disregard for the race that stifles philanthropy?

We do not pity the sufferer, be he poor, insane or criminal, but even stoop to coin fortunes from the miseries of such men, which makes us the poorest of them all. Yes, only too often our charities are a mockery of the very miseries for the relief of which they are intended. Or does any one expect jailors and waiters to act up to human considerations to which legislators are strangers, as our penal legislation proves them to be? 
There is but one sovcreign law of human life and action, and this law, as is in the nature of the case, must be the sovereign law of Education, and the one great universal remedy, or rather preventive of every human ill, and this law and remedy is to live and act for the race. The Education of the race brings us daily nearer the fulfilment of this law, which is and must be the basis of the Education of the individual, as it is the basis of the Education of the race.

The Education of the individual and that of humanity in the great drama of the world's history -must become one in aim and purpose. Social science, hygiene and Education must become one and inseparable, and the redemption of the race can only be achieved through the combined work of them all.

Rousseau first taught the educator the necessity of studying the child ; may we say, it was our humble endeavor in this essay to show the necessity of making a thorough and faithful study of the normal and abnormal conditions of society, of which the child forms an integral part, and without a perfect knowledge of which the Education of a societory being is impossible?

A vigorous employment of the mind exercises all its faculties, and, hence, earnest students have in all ages made equal progress with all methods, as well as in the absence of any. The knowledge of 
the laws of the mind is as beautiful as that of the stars and as merely contemplative in many of its results. Still, psychology has its golden applications in Education.

But as the social relations of man are entirely artificial, arbitrary and depending on his will, he cannot, in the absence of the physiological and pathological knowledge of society, but blunder and suffer social deterioration, which ends in physical degeneracy and moral depravity; and thus an acquaintance of teachers and parents with the structure of society will appear, to men who have to deal with the many miseries of mankind, of vastly more practical significance than a theoretical mapping out of the faculties of the human mind.

Race Education, or Hereditary Culture, the highest induction of all past educational thought and experience, embracing the whole of humanity, increases the physical power and moral tone of the race, for where the highest, broadest and deepest humanity is, there is God, as devotion to mankind is devotion to God.

\author{
THE END.
}




\section{N D E X.}

\section{FOR THE CONTENTS OF PART VIII. SEE ADDENDA.}

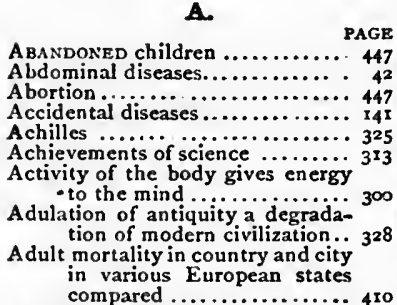

Advantage of early moral training. $14 \mathrm{I}$ Eschylus .................... 326 Asthetic system of Education.... r25 Agamemnon .............. 325

Age of the mechanic arts. ... I86, 187

Agesilaus, King of Sparta .......28

Agriculture. .............. 183,189

Agricultural colleges......... 166, 169

Productions .................... 204

Agnculturists and operatives, lung diseases among........... 42

Aim of Education ........ I2 $1,122,1_{5} 1$

Aim of the teacher........... I02, I03

Aimless routine ............... 303

Alabama, manual labor schools in. 180

Alcestis ...................... 326

Alcoholism. physical and moral effects of ............4,427,428

Algebra ...................... 194

Alison, Sir A..................476

Allen, Dr. . . ............... 469

Altruistic spirit .............. 87, r20

Altruism must become hereditary. $33^{8}$

America, deterioration in ....... 9, ro

American cities, growth of........ 412

Culture .................. 309

Ancient civilization too repugnant in substance to be admired.. 316

Ancients, Education among the .. 425

Andover Seminary, manual labor at $\mathbf{1 7 7}$

Anglo-Saxon.................. 32y

Apricots introduced ............. 197

Appropriation for primary instruction in France under the Restaura:ion, under the German rule in Elsace and in England in 1841 and $1872 \ldots \ldots .260$

Approval of our own conscience .. 302 Arabic and Sanscrit trifles.... 310, 315
Arago, François .............. P. $\frac{76}{76}$

Architects, average dife of. ......... $45^{6}$

A riosto ...................... 73

A risto phanes.................. 73

A ristocracy of France and England dying out ............... Irg

Aristotle $\ldots . .74,93,121,123,219,266$

Arkroid, the model em ployer ..... $3^{89}$

Arkwright, carding machinery of.. 20r

Arnold, Matthew ............. 320

Arrow and the bow, first implements................... 788

Arsenic, its effects upon artisans .. $42,451,452$

Artichoke introduced ........... 197

Art and industry, integral parts of a common Education ....... $8 x$

Artists, rate of unfitness for military service .............. asg

Ashton, a model workmen-town...

Assyria $\quad 3^{88,} 3^{89}$

Athens, number of hands engaged in grinding flour .......... 201

Augustus sentencing a Senator to death for engaging in manufacture .................. $2 r_{4}$

Austria, schools of art and industry in .................. I66

Suicides among the civilians and in the army of ...........226

Defeat at Sadowa of ............ 259

Average life of children working in weaveries ............. 230

Operatives in French cities ...... 360

The population of Rhode Island, and of Providence, its largest town...................409

Country and city $\ldots \ldots \ldots \ldots 4 \%, 411$

\section{B.}

BACH, a family of musictans ..... 73 Bacon, Francis ................... $12,94,353,198,211,332,4^{19}$

Roger ... ............... 198 Bakers, average life of ........... 456 Baldness, hereditary............. 70 Baltimore.. ….......... 382, 4ra Barbers, average life of ...........4 456 Battering-ram first used ........ r9 Bavarsa, infant mortality ......... Iq 
Bavaria, schools of art and industry in.................. 166

Illegitimate births............. 364

Hospital cases of syphilis on the increase.................442

Basedow, J. B.............. 96, 146

Beale, Dr. L. J............ 141, 404

Beaucourt, a workmen-town...... $3^{88}$

Beer-house collection, a former mode of school revenue....252

Belgium, increase of insanity in... 25 Industrial and technical schools in ............. $159,16 \mathrm{t}, 166$

Building societies in ............ $3^{89}$

Adult and infant mortality, marriage and fertility of illegitimate births in ............ 4 ro

Benefit of clergy................ 193

Benriston de Chateauneuf, consumption in the different trades...................

Berlin, increase of insanity in.....

Rate of cousumption among artisans

Mortality in the poorhouses .... 226

Increasing rate of suicide and a comparison of the same with that in rural districts ....... 233

First high school .......... .. $34^{2}$

Rate of venereal cases among artisans ................. 442

Bermudas, mortality of the troops. 225

Bernouilli, famous mathematician. 74

Besançon industrial school ....... I59

Berzelius, J. J................ 127

Birmingham, deterioration of the workmen....................

Schools of art $\ldots \ldots \ldots \ldots \ldots \ldots \ldots, 16_{3}$

Workmen's homes............. 393

Birth rate. general, and in Massachusetts......

Elaikie, Rev. Wm. G., the condition of the people and their homes............... 392-394

Blacksmiths, average life of....... 455

Blindness, causes of .............. 37

In Europe, Asia, and America.. 37

Source of poverty.............. $47^{3}$

Blood-poisoning at school .... 127, 128

Boeotians, thejr contempt for commerce................ 214

Books often a hindrance in Education................. 139

Their scarcity in former ages ... I9

Bookbinders, consumption ainong.

Average life of............... 456

Boots and shoes, value of, in the last census . .............. 204

Boston, increase of mortality rate in 20

Kindergarten.................. I 37

Infaut schools................. 1 139

Drawing in the common schools. 276

Rate of commercial success .... 342

Condition of tenements..... 379-382

Brace, Charles L................. 263

Growth of ................... 412
Brain growing to its habitual activity.................... 72

Diseases among criminals........ $3 x$

Bray, Charles .................. $47^{6}$

Bread, history of .............. rgo

Rarity of, in England........... 200

Brick makers, average life of..... 455

Bristol (England) trade school.... 164

College (Pennsylvania), manual labor at ................. 179

British army and navy, syphilis in the $\ldots \ldots \ldots \ldots \ldots \ldots \ldots \ldots$ 44 $\mathrm{r}$

Brooklyn, common schools ....... 128

Female Employment Society ... 277

Brougham, Lord, importance of infant schools ............... 135

"The schoolmaster is abroad". I49

Importance of economical information ................ 151

Dangers of public ignorance.... 254

Personally engaged in manual labor......

His life-long labors and character better calculated to influence our youths than Roman brigands $\ldots \ldots \ldots \ldots \ldots \ldots \ldots \ldots \ldots \ldots \ldots \ldots$

Bruce, Thompson, hereditary crime 29

Brunehaut, Queen, atrocity......243

Brush makers, average life of ..... 456

Buckle, Thomas, uncertain about hereditary mental faculties. 73

Effect of industry on the mind.. 216

Science democratic in thought ...481

Buret, E., influence of squalid homes un children......... 395

Burning the straw to get the wheat 189

Burns, Prof. J. W. of Philadel phia, on industrial Education..... 158

Butchers, average life of ........ 455

Byzantine empire............... 69

\section{c.}

Cabants, muscular activity lessens nervous excitement........ 283

Cabbage, carrot, turnip and other edible roots introduced ..... 200

Cabinet makers, rate of military unfitness $\ldots \ldots \ldots \ldots \ldots \ldots \ldots$ 229

Average life of .............. 455

Making, Lane Seminary........ 179

Cassar.............. . $324,327,328$

Calico printers, rate of consumption .....................

Camphell, Dr., examination of the brain of criminals............

Canzow, Dr., spotted fever among workmen ................. 400

Carpenters, average life........... 455

Carriage makers, a verage life ..... 456

Carey, Henry C. ................. 353

Carthage. ... $\quad \ldots \ldots \ldots \ldots \ldots \ldots . . .6 \%$

Carvers, average life. ................ $45^{6}$

Cashmere goat introduced........ 220

Cassini, the astronomer........... 74 
Cataract, hereditary

Cato ......................... 272

Cave fishes, structure growing to habit and surroundirigs .....

Cellars and their occupants ........ $365,377,37^{8}$

Central College of Arts and Manufactures in Paris........... 273

Cereals and civilization............ I95

Ceylon, mortality of the troops ... 225 Chadwick, diffusion of useful information ............. $15 \mathrm{r}$

Long school hours a useless tax upon children ............ $37 x$

Chair makers, average life......... 456

Chaldeans................... 195

Chalmers, Rev. Thomas, necessity of spreading economical knowledge ............... I5

Channing, Wm. E., the tenements of the poor........... 397, 398

Charlemagne, his illiteracy ........ 193

Chemical manjpulations ............ r 98

Cherry trees introduced ............ r97

Chicago...................... $4^{\mathrm{I}^{\mathrm{I}_{2}}}$

Childhood, fixing early the attention of ............. 14I, 142

Early arrest of its facultues ... .. 16

Its ages and phases of Education 66

Sacredness of................ 303

Chinese tradition of the invention of fire................. 188

Used for transporting freight like animals ................ 198

Symbols..................... 193

Their intellectual culture and conservatism ............ 284

Cholera in tenement and privat: houses ............ 243, 376

Proportion of, among the higher and lower classes......... 402

Deaths compared with density of population. ..........., 408

Cicero, how treated by Antonius' wife $\ldots \ldots \ldots \ldots \ldots \ldots \ldots \ldots \ldots \ldots$

Consulting mice and chickens .. 328

Cigar makers, average life ........ 456

Cincinnatus ................. 272

Ciphsrs, their invention.......... I94

Ciphering and spelling ho security against misery and crime ... 104

Cities breed moral, social, economical and political pests .. 340, 34I

Unite all elemerts of human deterioration ............... 349

City and country represent progress and stability ....... 350, 35

Civil engineers, average life...... 456

Civilians, their mortality rate ..... 224

Civilization of the Greeks........ I2

And insanity ............... 28

Stages of ..................... ro

Deterioration............ 119-124

Antedates religion, poetry and philosophy............... 186

And the cereals $. . . \ldots \ldots \ldots \ldots \ldots . . .189$
Civilization created and preserved by the mechanic arts ...... 158

Must protect us against deterio rating conditions .......... 229

Its definition ............... 237

Clock makers and watch makers, average life..... ......455

Clothaire, king of the Franks, his cruelty................4423

Clothing, its history . ....... Igo, Igr Clothiers' goods, value of.......... 204 Coaches introduced............... Ig6 Cock-fighting in the schoolroom for raising school funds..252, 253

Coffee introduced.............. Ig6

Colbert ..................... 47

Coleridge, Sir $\mathbf{j} .$, fate of the workmen.................. 392

Colligny $\ldots \ldots \ldots \ldots \ldots \ldots \ldots \ldots \ldots .74$

Colleges sending out men full of speechet. ...........136, 273

Collegiate teaching............. I40

Combe, George, causes of drunkenness.................. $43^{1}$

Comenius the forerunner of Pestalozzi .................. 96, 305

Commerce exploring the seas..... 203

Unscrupulous .............. 416

Competition and association alike necessary ............. 239 Compulsory industrial Education. I53 Common schools in the United States.................251

The property of ........... 251,252 Communism destructive of liberty

59,483

Does not solve the problem..... 344 Condition calling for industrial schools.................. 159

Congenital deformity. ......... 70

Consumption and deterioration ... 42

In different trades and gencrally

43,44

In country and city ......... 43, 44

Promoted in schools.......4 47 $47^{2}$

Cooper, Peter ................ 276

Institute $\ldots \ldots \ldots \ldots \ldots \ldots \ldots \ldots \ldots 277$

Copenhagen $\because \ldots \ldots \ldots \ldots \ldots \ldots .43,429$

Rate of suicide compared with rural districts........... 223

Coppersmiths, average life........ 456

Cornell University and industrial Education.............. 277

Corrupt blood produces corrupt morals and institutions ..... 339

Cost of crime ........... 26r, 262

Cost of technical Education....... 160

Cotton manufacture ......... 201-204

Operatives, their ailments and early decay.............. 450

Country and town population, proportion of..............411

Homes bring health, energy, peace and good-will.... 34I, 342

Surplus of births over deaths in and city...............407 
Country homes a security against lack of employment ........

Homes bring induxry and frugality, and are the great desideratum .................

Course of the Government School of Design at the Somerset House ................. 163

Cowardice, fraud, brutality and murder in Homer still a textbook............... 325, 326

Cramming system of Education... $125^{-135}$

Crassus .................... $3^{27}$

Cretins, where located and causes producing them ........... 66

Creusot Industrial School. ... ${ }^{159-r 6 r}$

Crime, past and present, habitual and incidental .... ........

Pauperism and insanity reverting into each other............

Increase of . . . . . . . . $35,36,46 \mathrm{x}-463$

Among scholars and farmers.... 461

And crowding ........... 404, 477

Legislative committee on....... 477

Criminals, mental condition .... $30,3 x$

Post-mortem examination.... 30, 33

Not lessened by common Education . ............46 $46 \mathrm{x}-46_{3}$

Critics, but not artists, are fostered by our system of Educatinn. 156

Crompton's mule introduced.. 201

Crowded schools $\ldots \ldots \ldots \ldots \ldots$ 127, 128

Cultivation of the heart and intellectual improvement....... zor

of the hand, eye and imagination $30 \mathrm{r}$

Of a garden plot promotes the well-being of the family .... 350

Culture ...................... 122

Of mind in infancy......... $14 x$, 145

Cumberland College, manual labor 177

- Currant shrub . .............. 197

Cutlers, average life ............. 456

Cutting grain with rib-bones...... 198

D.

Damask rose $\ldots \ldots \ldots \ldots \ldots \ldots \ldots . \ldots 97$

Darwin ................ $70-72,74$

Darwinian would be reformers. 24r, 242

Davy, Sir Humphrey ............ 127

Dante ................. 287, $32 x$

Day laborers, death rate from consumption . ............. 44

Dayton (O.) Manual Labor School 44

Deaf-mutism, causes of........ 37, $3^{8}$

Deceptiveness of averages of mor-

tality rates............404, 405

Defective teeth hereditary......... 70

Defectiveness......... 37, 38, 463-465

A public burden.......... $63-64$, ro3

In Massachusetts ........... $46_{3}, 464$

Defective nutrition and vicious sensations . ... ............. r26

De Fellenberg................... ${ }_{14}$

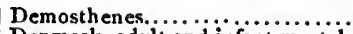

Denmark, adult and infant mortality, fertility and illegitimate births ..................... 4 ro

Delirium tremens.............. $4^{2} 7^{-429}$

Density of population of $\mathrm{New}$ York and London ................. 373

Of population, rent, illegitimate births and mortality of great cities ................... 373

of country and city, and their mortality ...........407,408

Descartes ...................... ${ }^{408}$

Despine, morbid psychology...... 70

Deterioration................... 14 $_{4}-\mathrm{r} 8$

Or rising mortality rates .......22-29

Or rising insanity rates........29-38

Or blindness and deaf-mutism. $3^{8}, 39$

And military unfituess ...... 39-4I

And consumption ............ 42-44

And Scrofula $. . \ldots \ldots \ldots \ldots \ldots \ldots, 45$

A picture of $\ldots \ldots \ldots \ldots \ldots \ldots \ldots, 45$

Of factory population. $4^{1}, 4^{2}, 228-231$

And paujerism............ 49-58

From wars and standing armies.

$222-226,44^{8}$

In public institutions and prisons $226,227,448,486$

And crowded dwellings..... $34^{8-423}$

And drunkenness............ 424 43r

And syphilis ............. 437-448

And trade diseases.......... $449-459$

And the national existence ......

And civilization ......459,469, 478

Only met by a race ameliorating

Education ............ rr9, $x 20$

Proceeding from mentai and moral causes........... 346, 347

And decreasing fertility ..... 346, 347

Deteriorated tribes........... 64,65

Diamond-setters and grinders. 454,455

Diseases, political aspect of $\ldots .236,237$

Division of labor ............. ryr, x12

Dix, Miss, insanity among convicts 34

Doing the right, and be at rest $\ldots$ 3or

Dolfos, Jean, the model employer. 388

Domestic duties of women......... rr5

Animals. ................. 188

Domestics, rates of military unfitness $\ldots \ldots \ldots \ldots \ldots \ldots \ldots . \ldots 229$

Donaldson Manual Labor School..

Draining .................... 182

School .......................... 166

Draper, John w. ............. 99,480

Drawing, geometric and science applied ................... ${ }_{5} 6$

Drunkenness, prostitution, scrofula, phthisis, zymotic diseases, insanity, suicide and death in proportion to population ................... 404

Hereditary, as dipsomania. idiocy, suicide, insanity or crime ............... 424-427

Its causes $\ldots \ldots \ldots \ldots \ldots \ldots \ldots .44^{1}-437$ 
Dust trades, rate of phthisis... ...454 Dry grinders .................. 44 Dryden..$\ldots \ldots \ldots \ldots \ldots \ldots \ldots \ldots$ r27 Dutch, the, in Amboyna ......... 244 Dyers, average life............. 456

\section{E.}

EARLY arrest of intellectual faculties of the deteriorated children of poor laborers ....... 16

Mental training ............. 142 Eastern Penitentiary of Pennsylvania................. 158

War, and its barbarity ........... 158

Eaton, John, Commissioner of Education.........158, 169,170

Education among the ancients....

Must become religion.......... 475

Different stand points ...........

And trade poisoning............ 42

A natural function.............. 64

The evolutions of ..............., 67

The three ages of..............., 67

And heredity.................. 60

The various forms of government 69

Hereditary tendencies .......... 73

The aim of ............... 75

Not Greek and Latin verses ..... 158

Functional, hereditary and national.................. 75

In the formative period........ 77,78

Heredity. ............... 78-80

Not a trade, but a worship...... 88

Defined ....................... 90

Systems of, and their defects....

$90-100,125$

And the ethics of science ....... ror

A social science ................ ro

The foundation and purposes... ro5

And individualism......... 121-124

And insanity .. .............. 129

And social science........ $146-152$

Civilizing through industry ..... 185

M ust affect the masses......... 206

Improvement of the industries

an important service ... 208, 209

In England ............... 254-256

In France................ 256, 257

Helping us to help ourselves... 299

A process of unfolding .....2 299, $23^{\circ}$

Must develop the ideal and real. 300

Fosters individuality and selfknowledge .............. 302

Must be brought under the in fluence of great moderns who represent the genius of industry and humanity... 327,328

Impossible in our tenement houses ................ 342

And homes ............... 422, 423

And drunkenness................ 424

And trade diseases................. $45^{8}$

And mental disorders.......... 472
Education must unite the realism of the Greeks and the moral inspiration of the East.....4 475

Among the ancients the business of slaves........... 475

Educators must study society. 487,488 Edict of Nantes............... 199 Edward III., king of England ..... rg8 Egypt.............69, 188, 193, 195

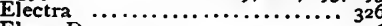
Elam, Dr................... 426 Elizabeth, queen of England.. $x 98,416$ Emerson, Kalph Waldo.......... 307 Emotions, fancy, and the passions. 84 Energy...................... 300 And individuality $\ldots \ldots \ldots \ldots \ldots 4^{84}$ Employment of children in factories a source of deterioration $\ldots \ldots \ldots \ldots \ldots \ldots, 45,48,49$

End of Education............... Engel. Dr., man the highest capital 18 England, abortion.............. 16 Deterioration of the work-people

16, 17

Mortality rates .............. 20

Insanity $\ldots \ldots \ldots \ldots \ldots \ldots \ldots \ldots \ldots, 24$

Increase of crime..........35, 36, $46 \mathrm{r}$

Deterioration of the factory people.................. 4I

Increase of pauperism and insane poor ............. $5 x, 430$

Infant schools...............

Technical training ............. 160

Parliamentary Committee and Normal School of Design 162,163

Civilization............ 196-204

Mortality in the Crimean war... 225

Foreign commerce and pauperism .... . . . ...... 353-355

See also.... …2ri3, $276,284,389,413$

Decreasing fertility............4 468 English Commissioners, terrible admissions .............. 395

Language, etymological study of, requires a life-long study.... 320

Epilepsy among the poor...... 52 Episcopal Orphan Home in Brooklyn.................. 277 Epochs of labor ............... 2 2rz Eras of civilization............... 269 Erasmus ....... ... ...... 196, 307 Eschylus................. 82, 326 Eternal laws of mind $\ldots \ldots \ldots \ldots \ldots, 303$ Euripides ........................ 326 Europe, defectives and criminals.. 49 General increase of suicide...... 233

Schools of industry .......... 275 Evening studies ............... I3 Evolution of Education...... 67, r 17 Exercise of the senses .......... 134 Excess of sensibility ............. r 34 Expensive governments call for industrial Education......... 160 Expensiveness of living in cities ... 
Eye diseases of operatives and the rural population............

\section{F.}

Factories ............ 112, 115, 119

Factory population........... 4I, 42

Laborers die out in three generations.............. 119, 395

Laws ................ 145, 237

Fallacy of our illiteracy statistics.. 264

Farmers exchanged labur for Education $\ldots \ldots \ldots \ldots \ldots \ldots$ 170, $17 \mathbf{1}$

Average life ............... 455

Rate of unfitness for military service $\ldots \ldots \ldots \ldots \ldots \ldots \ldots, 227$

Rate of suicide .............. 233

Female criminality and human deterioration ............. 37

Fénélon ................... 75, 479

Farr, Dr.................... 401

Fawcett, Prof................. 423

Ferocity of the slave system ...... 215

Fertility of marriage in country and city in various European states ................. 4ro

Fichte on Education ............ 37, 273

Financial fiction................. 268

Crisis, lesson of............ 266-269

File cutters, consumption......... 454

Fine arts . ................. 209

Fire, traditions of the first use.... 188

Fisk, Dr., President of the Wesleyan College, on union of manual labor and Education 175

First food ................. 188

School Superintendent in the State of New York ........ 25I

Parliamentary act for Education 254

Schools of design............255

Flax mill operatives and their decrepitude ........... 450, 451

Flanders................ 197, 207

Forentine republic............... 2 253

Foreign commerce and its dangers 353

Trade of the world ............. 205

Fork grinders, average life......... 454

Formalism................ 331, 398

Founders, average life . .......... 456

France, manufacturing population. ${ }_{17}$

Infant mortality................ 20

Insanity...................... 25

Increase of crime ............ 35,461

Unfituess for military service.. 39, 40

Condition of................. 48

Public misery ................ 54

Infants in public halls........... 137

Indust rial schools $\ldots \ldots \ldots \ldots \ldots \times 159$

School of Art and Industry. 16,166

Latin the official language...... I93

Greatness of, founded on indusry 213

Deterioration, following the $\mathrm{Na}-$ poleonic wars.............223

Mortality in Algeria of the sol-

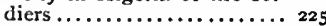

France, mortality in the great Russian campaign of the soldiers 225

Suicide increasing........... $23^{2}$

Rate of suicide ....... 233, 284,439

Education ................256, 257

Decreasing fertility.............4 468

Franke, Herrman........... 146, 305

Franklin, Benjamin .......... 75, 332

Frobbel moved by the misery of the masses .................... 136

Fröbel's games ................. 140 Freedom and manhood impossible without property $\ldots \ldots \ldots \ldots \ldots 5^{2}$

Fulvia, savagery of ............. 243

Furnace men, average life .......... $45^{6}$

Furniture ................... 199

G.

Gall, Dr., believed in hereditary improved aptitudes .........

Galton sees degenerating causes at work................ 23,70

Gauls, savage in war............ 243

General paralysis increasing....26, 27

Geneva, rate of suicide in, compared with that of the coun-

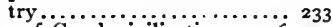

Genius of Greek civilization .. 306, 307

Georgia, manual labor school ..... I76

Gerando callsl abcr the great educator. . .............. 274

Germany cultivates gymnastics ... I $3^{2}$

Industrial schools .............. 159

Latin the official language... 193,196

Manufacture.............. 199, $2 \mathbf{1}_{3}$

Rate of suicide ................233

Geometry, science of color and form and technic knowledge our schools must spread.. 182-188

Gibbon, not made by the school .. 127

Extols the mechanic arts ....... 187

Girard College, a model industrial institution ........... 277, 278

Girdleston, Rev. Canon, duty of the clergy to the working masses............... 395, 396

Gladstone would see women withdrawn from the factory ..... 112

Glass and windows .......... 198, 199

Makers, average life ............. 454

Works in the United States. .... 204

Glascow, want of proper homes ... 368

Glaucos, of Chios, first smelter of iron ................. 196

Gloom and depression in childhood, niserable effect of.... $\mathbf{I}_{44}$

Goldsmith dull in his youth ....... 127

Gordian knot................ 192

Gotham Court a representative of the tenement house tribe 374,375

Goethe says, our educators make bags full of words. ....... 9x

His own training in childhood... $4^{8} 3$ 
Government of children by burdened mothers ............ ${ }^{3}{ }^{8}$

Governor of Pennsylvania in his message on manual labor schools................. 176

Of Gtorgia officially refers to the same subject $\ldots \ldots \ldots \ldots \ldots$ in 6

Graces and virtues fostered by neat homes................. 398

Grammar, spelling, arithmetic and a little geography too dearly paid for............. 182, $28_{3}$

Granville, manual labor school.... 178

Great educators are lovers of the race ................ $146,1_{47}$

Industries, disadvantages of ..... $206,476,477$

Greece, the decay of............. 69 Excelled in philosophy, still lacked in humanity. ....... 250

And Rome full of barbarity..... $3^{23}$

Greek grammar does not give us the Greek nature, this requires Greek training........ $292,293,307,308$

And Latin schools improved upon 167

Greeks............188, 219, 242, 284

Immaculate nature ........... $32 \mathrm{I}$

Greeley, Horace, on labor Education.................... 273

Graenhow, Dr. ............ 405, 406

Gregors, the mathematician ...... 74

Griesinger on insanity and misery 23

Growtl of scientific and industrial schools in America ......... I67

Gucbwiller, a workmen-town ..... 388

Guise, Dukes of ................ 74

Gunpowder and fircarms introduced .................. I98

Gustavus Adolphus.............. 74

Guyot....................... $3^{18}$

Guy, Dr. Wm. thirty years record of the Millbank Prison ..... 32

Gymnastics........... 81, 129, I3

B.

HAErT and heredity ........... 76

Habits and structure .......... 70 , $7 \mathbf{I}$

Haddenfield. manual labor school. 376

Hale, Rev. Edward, Boston, home

for the workman .......... 379

Half-time schools wanted ..... 270, 271

Hanley, school of art . ........... 363

Hanover, adult and infant mortality, fertility and illegitimate births............... 4 to

Jansa, the greatness of, purcly the work of industry ...207, 213

Hargreaves, spinning jenny introduced .................. 201

Harmonious development not expressive of the end of Education ................. 125

Harness makers, average life..... 455
Harris, Dr. Elisha, crime, pauperism, insanity congenital.. 34, 477

Prof,, of the Medical Institute of Philadelphia, on study and manual labor ............ 157

Hatters, condition and average life $45 x, 455$

Headache contracted in schools... $+7^{1}$ Health the first condition of success ................. I3I

Of young people in spinneries... $23^{\circ}$

And well-being, but not literature, the end............ 118

Hebrew Orphan Asylum, combining Education and industry. 277

Hecker, J. J., organizing the first real or high school........ 305

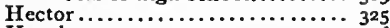

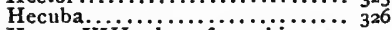

Henry viii, but few chimneys and $a \log$ for a pillow ... I97, 200

Henry the Great, king of France, founder of the industry of France................. I 99

Henry, Prof. Joseph............... 423

Hereditary affected criminals ..... 34

Consumption ............. 44

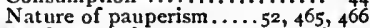

Malformation, nervousness and disease. .............6 $69-7^{2}$

Mental tendencies illinstrated. . $73-76$

Heredity limited ........... $7^{2}$

Must be made subservient to Education............... ro4

Herschel, Wm............... 74

Hieroglyphics.................. 192

Higher law of subordination....... I23

Hindostanee the inventors of our ciphers .................. 194

History of the world, is the Education of mankind. $185,221,470$

Hitchcock, Prof., of Amherst, in favor of manual labor schools 175

Holland, increase of crime in .... $3^{6}$

Provided London with vegetables................... 200

Holland, Jr., short-lived artisans. 454

Holstein, adult and infant mortality, fertility and illegitimate births................4 410

Home the first requisite of Education ............ 1 $5,116,34^{8}$

The school of life............ 475

Labor, property, health, the family and Education........ $47^{6}$

Homes of the operatives in large manufacturing to w $\mathrm{s}$ in France.............. 358-360

And wretchedness of the English workmen.......... 3 $3^{5-369}$

More crow ded than ever... ... 369

Of the working people in New York.............. 369-379

Of the workmen in Boston.. 379-382

Of the work-people in other towns............. $3^{82}, 3^{8} 3$ 
Ilomes with garden plots owned by the workmen out of the city. ........ $3^{8} 3,3^{8} 4,476,477$

Of the poor to-day induce them to vagrancy and crime...394, 395

Healthy and orderly indispensable for the elevation of the masses and the stability of government ......... 399, 476

Homer.. т93, 196, 287, 319, 321, 324, 325

Horace..................... 287

Hospitals, mortality rates........ 226

House of Representatives of Pennsylvania on manual labor schools ............ 172, 173

Howard, Dr., our present Education increases insanity..... 129

Huddersfield, school of art......... $16_{3}$

Huguenots carried industry to other countries........... 199

Human exertion superseded by machinery, must turn to the cultivation of the soil and the race itself ........ 343-346

Hume, industry and enterprise.... 216

Humboldt, Alex., union of labor and science $\ldots 158,219,229,421$

Howe, Dr., drunkards and an idiotic progeny ............ 428

Human life, not altogether a physical process........... 419-423

Hunger does not know right from wrong, neither can bayonets

Hunter, Dr. Thos. F... our public schools propagating disease. 127

Hunter, Dr., dwellings more than ever crowded to-day...... 369

Hunting, fishing, pastoral life..... 189

Hygiene the basis of Race Eudcation.................. $8 \mathrm{r}$

Determines the moral dispasition............... 298, 299

Hygienic nıanagement of factories 42

Legislation of the Jews ........ 4 I

\section{I.}

IDEAL culture $\ldots \ldots \ldots \ldots 3^{\text {ro, }} 3^{r} 5,3^{16}$

Ideality .................... $3^{12}$

Idleness, Education for, swells city population . ........... 268

Illegitimate births, crime and deaths, the harvest of.......

In the German states.......... $33^{37}$

In Fngland ............... 401

And legitimate in country and city of various European states compared... 4ro, 446, 449

Illyria, venereal plague. . . ........446 Imagination, undue cultivation of. 125 Importation, amount of. ........ r 68

Incendiarism, increase of ....... 35

India, men used as beasts of burden 189
Indiana, manual labor schools..... I77

Individual the mcans, the race tive end ................... ro

Happiness an unworthy end .... 22

Selfishness threatens the race. . 4 485

Usturpation and war ........... 486

Inductive philosophy and industry $185,215,216$

Industrial Education ........ $152^{2-161}$

Colleges in the United States.. $\times 53$

Education and pauperism...... r $6 \mathrm{r}$

Progress and technical schools..

Education in the United States I6r, I62 $170-184$

Spirit in normal colleges ....... 147

Education a question of life and death ................ r 84

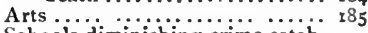

Schools diminishing crime established by Brace, Charles L. . $26_{3}$

Universitıes................ 273

Education and crime........ 275

Trainıng a bar to pauperism .... 291

And economical Ediscation and labor and capital ......... 343

Building societies ........... $3^{8} 7,3^{89}$

Industrials, rate of suicide of....233

Industry and materialism ......... 153

Degraded by association with pauper schools ............ I55

Raised to art .............. 168

And progress................ 205

Compared with science.... 209-211

The greatness of states ........ 213

And commerce............ $24 x$

And improvement and wealth and civilization.......216-218

Changing the face of the globe. 218-220

And the modern state..... 220, 221

And beredity............... 290 Industries and the Education of the people.......... 200, 207

Schooling the masses.......... $3^{15}$ Infant mortality in different states

$40 \mathrm{r}, 402$

In New York tenement homes.. 409

Among the operative classes....

$22,52,163,365,368$

From different diseases in city and country compared..... 404

In city and country in different European states compared.. 4 ro

Population, proportion of...... 414

Schools....... 85, 133-146, 358, 360

Infanticides................ 37,446

In England ............... 401

In France............... 447

Insane, their treatment. .. 467, 468, 486 Insanity, increase of, in various

European states........25, 26

In Massachusetts.............. 26

In the United States ....... 27,467

In New York.............. 27, 467

And civilization........... 48 
Insanity among criminals in England................... $33^{1}, 32$ In Scotland ................... 30, 31

In Ireland.................... $3^{2}$

Among the poor ..........431, $43^{2}$

And mortality in reference to deterioration ..............4 466 Instruction foreign to our pursuit. 290 Intellectual powers, all faculties to be subordinate to.......... 144

Iron, its history .. 195, 196, 200, 20x, 204 Italy, the venereal plague in......4 439

\section{$\boldsymbol{J}$.}

JAMAICA, niortality of the troops.. 225 Jarvis, Dr. Edward......... 468, 472 Jean, Cretien, hereditary crime ... 75 Jenner's great discovery ......... 47 Jewellers, death rate of, from consumption

A verage life of ............... 44

Jews, rate of mortality of...... 418,419 Juke's family, hereditary crime ....

Justice and devotion to the race $75,76,262$ to be developed

Juvenal aptly said, a healthy mind in a healthy body ........99

\section{K.}

KaMes, Lord, complains of the inattention to the heart... I05, 106

Kant on Education............96, 97 Kay, John, invention of the fyshuttle................. 201 Joseph, misery of the people $36_{3}-365$ Kentucky, manual labor schools .. 177 Kindergarten.....1 1 $7,118,133-146,278$ Knives in troduced.............., 196 Knight, Charles................ $15 x$ Knowledge usurping the place of humanity ........... 117,118

Philosophical, practical or ver-

bal........................
Krupp's eighty-ton gun and our civilization............ 227, 228

\section{I.}

LABOR debased by feudalism...... 199 And saving the only sources of wealth

The seed of ali that is good...... $2 G_{7}$

And study the conservative and progressive elements ... $288_{3}, 284$

Laborers, average life............ 456

Laboulaye, Education the solution of the problem.............

Lacedemonians................ $9_{92}$

Lace-making and hlindness..... .. 37

I.ake Huron, venereal plague at.... 439

Land without men, and men without land, cqually wort!less..
Lane Seminary, manual labor at... 178

Laing, Sam.................... $3^{64}$ Languages, the study of, and clear, exact and vigorous thinking. 314

Iapouchin, Mme., tortured... 245, 2m6

latin, introduction of, in our common schools ....... 303, 304, 310

And Greek, the educational value of .................203-232

Law of life and health........237-239

Lead, and its effects........ 452, 453

Leather, value of ............... 204

Dressers, average life .......... 456 Leckey, W. E. H. .......... 217, 218

Lee, Dr. Charles A.............. 467

Leeds, school of art.............. $16_{3}$

Leibnitz, teaching arts and trades. 95

Le Playe, the family must own their hearth .............. 390

Lessing, Socrates' wisdom and Plato's dreams ......... 12x, 483

Lewis, Dr. Dio .......... 281, 452, 453

Louisville (Kentucky) ... ....... $3^{82}$

Lexington (Kentucky) manual labor schools.............. 177

(Massachusetts) manual labor schools ................ 177

Lieber, Francis, compulsory industry. .............. 154, $16 \mathrm{r}$

Life must be sacred, or property will soon cease to be sacred. 416

Light, air and exercise.......... 145

Lighting houses at the time of Homer. ............. r r

Lille (France), fearful infant mortality ........... 223, 386, 393

Lindsley, President of Nashville University. in favor of manual labot schools........... 176

Linnzus' early impressions .......... 483

Literary schools and insanity ..... 129

Literature substituted in our schools for life ................ 128

Under obligation to industry ... 202 Lith wania .................... 439 Liverpool.............. 365, 368, 409 Locke, John..94, 105, 272, 273, 305, 482 Locks and keys................ 192 Locomotives, transperting power.. 195 Lombard, consumption among attisans.............. 43,457 London... $226,279,342,368,409,413$,

Times .............. 416,442 Long-lived persons less numcrous. 224 Loom .................... 195 Loss of life from preventable deaths 408 Louis XIV................... I97

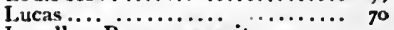
Lucullus, Roman rapacity .......... 327 Luther, the reformer of the school house. ................259

And manual labor ............... 273 Lycurgus. .............237, 265 Lydians coining gold and silver... 194 Lyons................ 16, 199,395 


\section{II.}

Mackdonia, venereal pest at..... 439

Machinery .................. 195

Machinists, consumption among.. 44 Average life .............. 456

Mackintosh on Education ........ 97

Macloid, Rev. Alexander, drunkenness not voluntary........ 432

Madison (Indiana), teachers' manual lahor seminary.. ....

Main proportion of infant population..$\ldots \ldots \ldots \ldots \ldots \ldots$ 4r4

Man, and not.scholarship, the end of Education ... ........ 76

Mann, Horace...................... 30 , 150

Manchester, infant mortality...... $22,163,365,3^{68}$

Manual labor schools in the United States ............. 170-184

Labor Academy ............. 171

Manufacturing in rural districts ... 352

Marietta (Ohio), manual labor schools ................ 178

Marion College (Indiana), manual labor ................. 177

Marius................... 246

Masons, consumption among, and average life .........45t, 455

Massachusetts statute laws rendering industrial Education obligatory ................. 16

Manual labor schools........... 177

Mortality rates in its workhouses 226

Technical Education in....... 276

Industrial Education in, two hundred years ago . ... 294, 295

Late industrial school act passed 276

State Board of Health on the dwellings of the working people $\ldots \ldots \ldots \ldots \ldots \ldots \ldots$

Cheap trains for work-people provided by the laws ...... 39r

Proportion of infant population. 414

Increase of crime............4 462

Defectives ............. 46 $3,46_{4}$

Increase of pauperism .......... 464

Fertility in ............... 469

Maudsley, Henry .................... 99,427

Mat:-ice of Nassau............ 74

Mechanics, average life............ 456

Mecklenburg (Germany), venereal pest in . ................

Memory developing into imagina-

Men can not be talked into virtue.

Mental fowers, cumulative growth

of............................
economy and philosophy of history, cultivate more a general outlook of the mind than Greek and Latin....... 113

Mexicans, shocking treatment by

$\begin{array}{rr}\text { Spaniards .............. } & 244 \\ \text { Mrichigan, manual labor schools... } & \text { r8o }\end{array}$
Middle Ages, religious spirit of.... 250

MLilitary deficiency...............

$39,40,223,228,229,410$

Mill, John Stuart.......... 274, 337

Millers, consumption among, and average life .........44,455

Milling, the produce of, in Athens and Rome and to-day ...... 20r

Milliners, average life........... 456

Mills introduced................ 196

Mining products.................. 204

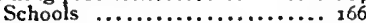

Milton, John ............. 94, 287

Miseries of the poor ...........469,470

Of operatives in towns...... 476, 477

Missouri, manual labor schools.... 177

Modern and ancient literature .... $3^{25}$

Money, its introduction and effects 194

-Mont aigne ... .......... 94,332

Montesquieu, Education and government................. 95

Monumental buildings............. 220

Morality, gall z or state ........... 107

Morbid tendencies and their prevention ...............

Morel $\ldots \ldots \ldots \ldots, 17,424,425,426,428$

Morgan, Dr. John E. . ........ 367

Mortality rates rusing.......... 18-22

From consumption in different trades ............... 42-44

Effected, among other causes, by Jenner's invention ........ 47

Of the poor and favored classes. 57

In the standing armies..... 224-226

In workhouses, hospitals and prisons. ............ 226, 227

Among factory children in France $3_{22}$

In the large manufacturing towns of England. ............. 368

In the tenements of $\mathrm{N}$ ew York City ............ 371, 384, 385

Under five years (see infant mortality).

In poor and wealthy districts ...

In more and less crowded $\mathrm{lo}_{0}, 403$ calities.............402, 405

In country and city. .......... 406

Compared with number of population to the acre....... 4 II

of large cities compared with density of population ....... 4 II

Of Christians and Jews at all ages $\ldots \ldots \ldots \ldots \ldots \ldots \ldots$ 4 19

Of drunkards and temperate people at different ages .... 429, 430

Moses....................... 237

Mulberry trees introduced ....... 216

Muhlhausen, infant mortality..... 20

Indust rial schools ............. I59

Workmen-town .......... 386-38

Muller, Dr. L. ............... 400

Muscles and nerves left without an Education................ 174

Muscular system, exercise of ..... I 31

Museums of art and industry ... 163,289 
Musical instrument makers and musicians, average life of....456

\section{N.}

NAIL makers, average life

National Bureau of Education and its service................ 169

Infant schools............... 79

Infant schools developing a hereditary national character.

Industrial University.. $182,183,11 \mathrm{r}$ Nature, humanity. and the Infinite the goal of Education........ 300

Nature and industry instruments of mental culture............325

Nebraska, infant population...... 414

Needle grinders, short life........ 454

Needles introduced............ 200

Neglect of physical Education..... 775

Neison, mortality of drunkards.... 429

Nervous diseases, prevalence of, and their prevention....... $\mathbf{r}_{32}$

Netherlands, adult and infant mortality, fertility and illegitimate births............... 4to

Newcastle, schools of art and industry .................. $\times 6_{3}$

New Education based upon nature, industry, and nationality... 306

New Hampshire, manual labor schools................. 277

New Jersey, manual labor schools. 177

New Orleans, growth of ......... 412

New York, school property....... 59

Pauperism and poorhouses..... $6 \mathrm{x}, 62,464,465,469$

Cost of charities and capital invested ................ $6_{3}, 6_{4}$

Society for promotion of manual labor in literary institutions. 173

Manual labor schools.. 177, 276, 277

Starving women... 279, 280, 444, 445

Success of merchants..... .... 342

1enements............... $360-378$

Growth ...................4 412

Influx of population............ 413

Syphilis ..............442,443

Nightingale, $\mathbf{M}$ iss ............... 275

Nobles of Venice dying out........ r r

Normal school at Constance and its popular tone........... ${ }_{447}$

Normal Schools of Design........ I63

In the United States and their increase ............. 25

Norwegia, increase of crime... $3^{6,} 4_{28}$

Venercal epidemy ............ 439

Norwich School of Art........... I6 3

North Carolina Legislature, manua

labor schools........ 176, 178

Nottingham School of Art........ 163

Numa ..................... 237

Nutrition determining our passions and actions........... 86,87 o.

OberLin................. 146,179 Object teaching worked out by Pestalozzi................ 96 Octavius. . . . . .................... 276

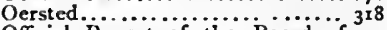

Official Report of the Board of Health of New York... 369, 370

Ohio, manual labor schools....... 178

Old Testameot............... 92

Operatives, rate of unfiness for military service........... 229

Opium trade................ 415,416

Ottawa Indians............... 439

Overcrowding impairs health, cnergy, and morals..........4 4I7

Over-production, and art and industry ................... 155

Over-worked brains induce indigestion................ 143

\section{P.}

Painters, death from consump-

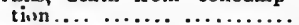

Suffering from lead poison... $45^{2}, 453$

Average life of...............456

Paisley. ...................... $16_{3}$

Paper introduced ............. 197

Pappenheimer, Dr.............. 400

Parents chiefeare the self-supporting capacity of their children. 308

Pariahs rising amid our civilization. 85

Paris.......... 166, 232, 233, 342, 440

Parker, Theodore....... 294, 396, 397

Parliamentary investigation of the national industry....... 162,163

Grant for Education............ $25^{6}$

Pauperism and its tendencies...... ${ }^{4}$

Its producing cause and treatment................4 49-5r

In France, Germany, Ëngland and Belgium, in London, Paris, Lille and Marseilles. 53, 54

And Education............... 57

In the State of New York and Massachusetts increasing... $6 x, 62,45_{4}, 463$

Made the passport to industry.. $155,27^{8}$

Only to be barred out by industrial training.............291

And insanity .............. 430, 43I

The threatening danger.................. 478

And crime of England and Massachusetts............. $4^{52}$

Cost of in Massachusetts......... 462

Classification, cause and treatment ................464,465

Paupers and their blood relations. 46.5 Peaches ripened but imperfectly, formerly in Greece........ 219 Pcel, Sir Kobert. ... ....... 327,392 Penn's exhortation, Fducate and labor................ 91, $15^{8}$ 
Penny traias at suitable hours for the work-people of London. 39x

Pennsylvania leads in manual labor schools......... 171-173, 179

First iron works in ............ 204

Perception deepens into memory as sensation deepens into perception and memory into imagination ...............

Period of crime reached by prolonged school attendance... 270

Persians...................... 188

Peruvians, their numerals......... r 193

Infected with smallpox by the Portuguese.............. 244

Pestalozzi, the lover of the race, the schoolmaster of Europe, and founder of the developmental system of Education. $96,146,182,259,290,294$

Peterboro, manual labor schools... 178

Petrarcha .................... 306

Philadelphia.... I28, I7x, 276, 409, 4I2

Philanthropy the mark of the great educators.................. ron

Phillips, Wendell, says, our schools turn out the children without the means of earning bread. 29

Philips on scrofula...............

Phonicians.................... 88

Phosphorus, its effect on artisans..

Physical labor a fundamental condition of human existence... 181

Wholesome in an age of nervous affections................... 283

Physical energy ............... 89

The loss of, attended by loss of success.................. 14 I

Labor, indisposition to............. 472,473

Pianoforte makers, average life... 456

Pinel, diseases and political institutions............... $23^{6,}{ }_{4} 68$

Plato........ $92, x 21,123,153,256,379$

Pliny ........................ 229

Plow and canibalism ........... xgr, I95

Plowing with horns............. 189

Plistarch ..................... 93

Plumbers, average life............. 456

Pocket watches................. 196

Political economy, dangers from want of instruction..... 150, 153

Political culture better derived from modern authors ............ 321

Polytechnic schools ............... 166

Polytechnic Institute of France... 26r

Pompey ..................... 327

Popery and Casarism.............. 304

Poorhouses and their mortality.... 58

Practical scientific instruction and industrial Education wanted. 182

Population, decreasing ratio of increase............... 468,469

Practicability of industrial schools established $\ldots \ldots \ldots \ldots 2_{276-27} 8$

P.:edisposition alone hereditary .. 72
Prevention of human deterioration no mean aim............. 484

Pride, cultivation of, in the vicious scholar................... 120

Primary Education, secondary and collegiate Education all verbal.................... 289 Department in France........... 256

In Paris ..................... 256

In Belgium.,.................. 257

In Prussia............... . 260

Princeton, manual iabor schools.. 177

Printers' training school in Long Island................... 277

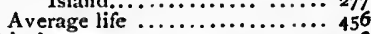

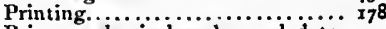

Prisons, physical and moral deterioration. - $\ldots \ldots \ldots \ldots 148,486$

Progress, importance of the elements of, in Education..... I 19

Of kindergarten.............. 137

Of industrial Education...... 161-170

Of civilization. ............ $155^{-250}$

Provençal... .................. $3^{20}$

Providence (Rhode Island), average life.................. 409

Prussia, rate of mortality.......... I9

Suicide among its troops......... 226

Increase of rate of suicide...... 232

Mortality of infants and adults, rate of fertility and illegitimate births............... 4 40

Public charities................. 59

Education ill provided for by private means and efforts...... 257

Education must train us for action $\ldots \ldots \ldots \ldots \ldots \ldots \ldots \ldots \ldots+45$

Institutions must promote the national feeling. .......... 324

Pursuit of wealth, effect of, on human deterioration.......... 28

\section{QUERN Elizabeth's reception-} room.................. $x g^{8}$ Quick transit, the antidote to tenoment houses.............. $39 x$

Quicksilver, effects on work-people ................ 453, 454

\section{R.}

RACE ameliorating Education..... 34

Deterioration and factories....... 14

Deterioration and crime...... 29-34

Education and pauperism........ 80

Education and hereditary defectiveness and hygiene....... 80

Education and scholastic Educir tion..................... $8 \mathbf{r}$

Education and race amelioration. 89

Education defined ........ ... 90

Education and individual Education.................... so, 
- Race Education and physical conformation................. 106 Education, its double purpose... 108 Education fitting woman for her duties................... 115

Education elevating the masses. Ir6

Education impresses parents with responsibility $. \ldots \ldots \ldots \ldots \ldots, 122$

Education and hygiene..... 124-132

Education studies temperament and hereditary tendencies..

142,143

Education answers all ends. 291, $29^{2}$

Education condemns our exclusively intellectual culture : health, habits, industry and the prevention of pauperism are in its scope. ..... 295-298

Education for living in harmony with the race............ 485

Improvement requires industrial Education............... $\mathbf{r}_{52}$

Railroads in the United States.... 205

Rawlinson, crowding and suburban villages ............... 4r

Ray, Dr., our future mothers. .... 129

Reading and writing prevents neither crime nor pauperism...

263,264

Recommittals of prisoners...... 3I, 37

Recruits, physical condition of, in

city and conntry.........4, $4^{\text {ro }}$

Reforms must be content with small beginnings... ... 258, 259

Religion thrown away on med perishing in pestilential homes. 392

Religious men, dissatisfaction of, with men of science........ Iro

Rénan on Education.......... 9r, 423

Reuchlin ................. 306

Revolution becoming unavoidable, Ix4

Not put down with the bayonet.

Rhode Island, average life in town and city............... 409

Richter, Friedrich........... 272

Rochelle, schools of art......... I66

Romanism, how to be met ...... 31

Romans had model mothers.. 113,284

Rome... 69, 201, 202, 243, 246, 250, 438

Routen, Schools of Art .......... 66

Roumania, venereal epidemy..... 439

Rousseau, the study of the child by the educator.............. g6

Civilization the mother of our woes ................... 120

Royal Commission on Education un classical Education.. 328-330

Philanthropy............. . ${ }_{5} 6$

F.udolphus, the Emperor ......... 193

Rush, Dr.. on work and study . 175

Russian soldiers spreading venereal diseases.................4 439

Army, mortality of, in peace and the camp. s.

SACREDNESS of childhood.........303

Sail makers................... 455

Salford, cellar population and mortality ................ $3^{6}{ }_{5}, 3^{68}$

Sanctity of human life....... 248, 249

Sanger, Dr.............. 442, 444

Sanitary legislation must stop human poisoning ............ 385

Sanscrit ............... 310, 315, 320

Saracens, experimental seience.... ry 3

Saxony, schools of art and industry 166

Increasing unfitness for the service in, and suicide among the civilians and in the army ... 226

Adult and infant mortality, and fertility and illegitimate births ............. 364,410

Scarlatina and blindness......... 37

Scholastic Education . ............ 82

Tat tooing ............... $8_{5}$

School property of $\mathrm{New}$ York and Massachusetts............

Histories and Metropolitan $\overline{G a}$ gette ................ 18

Libraries in France. ........... 257

And our financial disasters...... 269

A miniature of the world ........ 270

Floggings.. ............ 253, 254

To develop taste for agriculture as well as industry........ 350

Impotent without homes... 115, 116

Unhygienic condition of $\ldots .126$

Must relieve us of jails and poorhouses, or have no right to exist............. 62, 437

Must increase productiveness and cultivate justice ....... 123

Must change in scope with classes at tending them........... 156

Schools of art in England..... 162-165

In France.............. 165, 166

For watch making, design for textile arts, lace, wall paper, furniture, etc. ........... r66

Of industry................. 167

Have in the past little done for industry. ..............207

In cellars and garrets. . ...... 255

Responsible for prostitution and the consequent spread of the pest of syphilis and human deterioration .......... $444-446$

Spoiling boys born for the plow. 474 Science most truly religious... ... II

Ameliorating power of ..... $18_{3}, 18_{4}$

Mingling with the trade, civilız ing the world. ........... r86

Raises by the increased productiveness of the masses their consumption .............207

Owes much to industry..... 209, 22 r The means of universal culture and prosperity............ $3^{11}$ 
Science and industry deal with the present............... 317 Leads to work................. 318 Of life and the domestic dutie; of woman ........... 334, 335

Scissor grinders, average life ...... 454 Scotland, mental condition of criminals.............. $30,3 \mathrm{I}$

Serofula and blindness............ 37

Scrofula and deterioration ........ 42

Among recruits................ 45

Among the poor $\ldots \ldots \ldots \ldots \ldots \ldots .45$

Reverting into consumption .... 45

In the industrial departments of France................... 228

And syphilis............. 437, $43^{8}$

Scylla ....................... ${ }_{246}$

Scythians, savagery ........... 243

Seamen, average life ............ $45^{6}$

Seamstresses starved into prostitution .....................

Seguin, Dr. E., physiological Education................. 291

Sedentary invalids and manual labor sehools............... 180

Self-command and love of order, how cultivated in children

Culture a duty to others 142,144

Pollution, how prevented....... 124

Observation the foundation of the knowledge of self and of mankind and all moral science and government... 332-334

Servants, average life.............4 456

Seven years' war, deteriorating effect upon the next generation ...................223

Spread of syphilis by soldiers... 439

Shaftesbury, Earl of ............. $3^{27}$

Shakespeare............. 127, 287, 321

Sheffield, schools of art .......... r63

Sheridan ...................... 126

Ships, gradual improvement ...... 19x

Shirt makers' wages...... 279, 280, $28 \mathrm{r}$

Shirts came in to use............ 192

Shoe cutters, average life ........... 456

Binders wages............... 279

Short lives, private and public misery indicated by it.....459,460

Sightedness promoted by schools $47 \mathrm{I}$

Silk, its in troduetion in England.. 199

Manufacture............. 198, rg9

Workers, death from consumption................. 44

Silver and goldsmiths, average life ${ }_{456}^{44}$

Slaves teachers among the ancients 475

Slavery the basis of ancient civilization.............. 214, 215

Slavonic nations, rate of insanity and suicides. ........ 28.233

Small Antilles, mortality rates of the troops.................225

Smith, Adam, Industry pith of his

Wealth of Nations......... 2r

Gerritt, manual labor schools ... 178
Smith, Stephen, compulsory legislation providing cheap trains for the work-people....... 391

Social science............ $116, \mathbf{r}^{3}$

Socrates, practical wisdom silenced by Plato's dreams and Aristotle's sophistry ... 12I, 2II, 42 I

Socratic method ................ 82

Soldiers, rate of mortality and suicide................. 224-226

Solidarity of mankind........... $3,4,470$

Solon .................. 160, 273

Sophocles......... 73, 319, 321, 324

South Carolina, manual labor schools...$\ldots \ldots \ldots \ldots \ldots$. 180

Hanover College, manual labor. 177 Spain, rate of insanity and suicide.28, 233 Sparta's periodic slave hunt....... 242 Special industrial schools .......... 182 Spectacles .................. 200 Spencer, Herbert, functions becom-

ing structural and hereditary:, $\quad 7^{2}$

Ciphering and spelling alone is not bettering the world..... 104

Book knowledge the smallest part of human experierce...

287,288

Spitalfields, weavers......... 16, 395

Spoons and forks .............. rgx Spotted fever and crowded dwell-

ings............... 399,400

Spurzheim ..................

Spinoza .................... $27^{2}$

St. Helena, vegetation .......... 2 rg

Mortality of the troops .... . . 225

St. Louis, Kindergarten... 137, 382, 4 12

State prisons and tenement houses........... $\quad$. 477

St. Paul Bay, venereal epidemy.... 439

Statistics of defectiveness. ...... 64

Steel ....................... r 195

Still births ................... 446,447

Stockbridge Academy, manual labor .................. I77

Stockholm, illegitimate births...... $3^{64}$

Stockton, Hugh, health of city and country ............4 408

Stoke, schools of art.............. $16_{3}$

Stone bridges................. 198

Cutters and masons. consumption, and average life. $6 \mathrm{r}, 45 \mathrm{I}, 45^{6}$

Struggle for existence, law of, and

industrial Education ......
Stuart, Prof., of Cambridge University, in favor of industrial sehools ...............

Submission to the Infinite, the love of $m=n$, the true, the good and the beautiful..... 302

Subordination of desire to principle ................. 302

Suffield (Connecticut), manual labor schools.............. 176

Suicide in the armies of different states ................ 226

Proportion and increase of, 
among the different classes in city and country ....... 233

Sully. Marshal ................ 199 Swansea, mortality in the different portions..................405

Sweden, the effects of the thirty years' war ........ 223, 224, 234

Suicides among the army ...... 226

Pauperism, crime and Education flourishing together ....3 364,365

Switzerland, infant mortality..... 19

Condition of recruits. ........ 40

Consumption among different classes.............. 43, 44

Schools of art and industry .... 166

Syphilis deteriorating mankind and leading to scrofula and phthisis ............... 437,438 Spreading as an epidemy ... $43^{8-440}$

Ir. London, Paris, Vienna and Berlin, in the British army, etc. ............. 440-442

In New York City ........ 442, 443

In the different classes of society 444

The work of woman's starvation wages and the want of industrial Education. 444-446, 447

\section{T.}

TAcirus.............. 215, 324

Tailors, death from consumption..

Average life............... 456

Taine, misery driving men to the cup .................. 434

Tanners, average life ......... 455

Tasmanilians fed to the dogs.... . 244

Tasso................... 73

Taxes, to find relief from grinding, we shall have to adopt a proper Education of the masses.......... 10, 63, 64, 103

Taylor, Isaac, unhappy childhood makes a wrong life. ........ 144

Country life the best school for children................ $48_{2}$

Teachers' chief study and work... to

Teachers drawing pauper rates.... 253

Better make use of social and physiologlogical studies or jailors will have to......... 108

Teaching, there is too much-not enough Education and no training at all to work. . 271, 272

Teamsters, average life .........4 456

Technical Education hereditary.. I60

Gymnastics .............. 182

Pursuits a general benefit, the philosophy of schools often $a$ harm .............. 21r, 212

Temperance and exercise of body and mind in children....... 144

Tene nent houses and blindness... 37 Tenements of New York City and their miserics......... $369-378$

Of Boston................... 376
Tennessee, manual labor schools.. 180

Text-books, stuffing the young with. ................ 82

Thornton on mental culture...... 82

Thought, sensations the elements of, and, hence, their importance................... I34

Thucydides ..................... $3^{24}$

Town, county, state and national industrial schools.......... $\approx 89$

Towns, births falling short of deaths in great. .............. 407

Tracy, Destutt De.............423

Trade, want of a, among convicts. I08, $47^{2}$

Diseases and their effects.... 4 $4^{x, 42}$

Diseases preventible through Education...........457, $45^{8}$

Contempt of, in 'Greece and Rome................ 2 r $3_{3}$

Trades and blindness........... 37

Tradesmen founded towns and liberty. ............... $2 \mathrm{I}_{3}$

Traditional and scientific culture..

$\mathbf{x 5}, \mathbf{x} 56$

Training for life's work the best' Education............... 283

Schools and their importance in infancy. ............... $x_{34}$

Tropical America, its flora........ 2 rg

Plants..................... arg

Tuberculosis, scrofula, etc., generated in school rooms ..... $128,47 x, 472$

Tylor, E. B., every tool a volume. I 30 Tyndall, Prof., work and study.... $13^{2}$ Type founders, rate of consumption................. 44 Typhoid fever and blindness..... 37 Typhus, hunger and crowding, predisposing causes....... 399, 400

\section{U.}

UMbRELRAS. . ................200 Unfitness for military service...... $39,40,223$

In city and country and among different classes....... 227, 228

Union of social science and Education................... 199

Between the school and indus try..........221, 222, 473, 474

United States, mortality from old age................ 2x

Loss of capital through preventable deaths and sickness.. 21, 22

Crime and its incrcase...... 36,462

Progress of kindergarten ....... 137

Lack of trades among criminals .. 153

Educational activity ....... $x 69,170$

Manufacture.............. 199,204

Operatives, steam engines, water-power and great industries ................. 204

Increase of insanity............ 467 
United States, increase of fertility

The blind in the....... 468,469

Universal culture alone hereditary. 259 Consciousness and human cult-

ure.................... 475

Universities formerly the exclusive care of governments ........ I33

Usctul and tine arts............... r94

Utensils ..................... 197

Utilitarian philosophy the offspring of industry........... 185,216

\section{V.}

VEHRLI, the founder of the model normal school at Constance. $\mathbf{r}_{47}$

Vendée, its victims in the revolutionary madness...........246

Venereal epidemics.......... 138,439

In the hospitals of Paris and London, British army and navy............... 440, 44 r

In the hospitals of Vienna and Berlin.............. 44I, 442

In the hospitals of New York. $44^{2}, 443$

Among different classes......... 444

Agency our schools have in it....

Amount of in England 446

Amount of, in England.......... 447
Vica....................... 325

Vienna, epilepsy among the poor..

Vild, Secretary of the New York Manual Labor Society....... $x 73$

Virgil

............................

\section{W.}

WАBASH College, manual labor ... 77

War means barbarism........... 222

Sanctions homicide............ 228

Of the masses imminent ........ 238

Implements ............... 191

Histories substituted by treaties on the industries .......... 288

Washburn, E., importance of infant Education......... 294, 295

Washington................ 91, $4 \mathbf{I 9}$

Watts' steam engine.............. 201

Wealth, production of, not the aim of the government ........ 392

Weavers, condition and average life ................ 16, $45^{6}$

Well-being more civilizing than legions of teachers........ 423

West Virginia, proportion of infant population .............. 4 II $_{4}$

Western Reserve College, manual labor.................. 179

Westiminster Reviez, drunkenness and its prevention ..... 433

Westphalia, venereal epidemy .... 439
Wheat ................ 1s9, 190

White, President, of Cornell University ................ 277

White-lead workers (pain:ers) .... $42,44,452,453,456$

Wichern, Heinrich ............. 146

Wife and children, treat $\mathrm{ment}$ among the ancients........ 215

Willm, J., insufficiency of common schools in the absence of infant trairing schools ........ 48t

Wilson, Dr., examination........... 460

Heads of criminals............. 33

Windows, rare articles of furniture 199

Wines, Dr., mental condition of criminals................ 34

Winslow, Edward, of Boston...... 158

Woman, a slave, a toy and next an educator..$\ldots \ldots \ldots \ldots \ldots \ldots \mathbf{r r}_{3}$

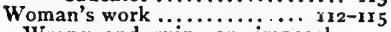

Wrong and ruin, an impeachment of our system of Education. ....... 278,282, 444, 445

Wages in London, New York and Boston................ 279-282

Wood turners and wool sorters, average life............... 455

Woolen goods ..................... 204

Worcester (England) trade schools 164

(Connecticut), manual labor.... ${ }_{7} 6$

(Massachusetts), Institution of Industrial Science. ....... 277

Work the co-ordination of all pow ers .................... Ir

And Education........60, 197,198

And nat knowledge the end .... $273,287,288$

Freedom, progress and virtue important elements in life and Education .................

Workhouses, mortality......... 226,227 Workmen-towns, rise and success.

Work-people's country homes de$3^{86-392}$ manded alike by all interests 357

Living in cellars ...... 365, 366, 377 Workshops, the vestibule to real knowledge ............... r 53

Writing, history of ............. 192,193

Wurtemberg, infant mortality.. 19, 275

Illegitimate births............. 364

$\mathbf{Y}$.

Youmans, Prof. Edward L.... 118, 320

\section{Z.}

Zумотіс diseases decimate the tenement house population.

375,376 


\section{A D D E N D .}

A.

Agriculture............. 539,540

Aldrich, Hon. P. Emory, on the folly of refusing public help to Industrial Education. 505-506

American Social Science Association ............ 509-51x

System of Industrial Education.

Amory, Hon. Thomas C., on 550,552 dustrial Education. 534, 535, 536

Antiquity $\ldots \ldots \ldots \ldots \ldots \ldots \ldots . \ldots \ldots$ 54, 542

Apprentice system, the old, has passed away... 497, 50r-502, 505,

Art, the only, that can preserve 515,535 the State is that of saving the perishing masses.... 541,542

Art-courses in the School of Mechanic Arts at Boston.. 488-489

Cost of .............. 490-491

Austria, pauperism in............ 523

\section{B.}

BARometer................... 495

Bartol, Rev. C. A., on Industrial Education................ 537

Bavaria, pauperism in ............ 523

Belgium, pauperism in ........... 524

Bellows-valve.................. 495

Bent, the natural, and avocation ascertained in the Developing School............ 494-495

Bequests, men would encourage their own trades with...... 536

Blood, M., on Industrial Education...................... $53^{8}$

Book-men and learning. $531-532,528$ Boston, School of the Mechanic Arts at .................489

Apprentices in. $\ldots \ldots \ldots \ldots \ldots \ldots 502$

The Press on Industrial Education.

Pauperism in $\cdots \cdots \cdots \cdots \cdots \cdot 5^{11-513}$

Massachuset ts looking to. ..... 534

Can - give up the lead in Education ?................. 534

Joint Committee on Public Instruction of the city of - on Industrial Education.... 534-539

The youth of - want more a practical than classical Education.
Buchanan, Dr., of Ohio, on the degraded condition of the mechanic arts.......... $487-488$

Buckle, Henry T., the extremes of empiricism and idealism... 543

Butler, Benjamin F............. $53^{8}$

C.

Carpenter's bench............. 494

Carving tools ................. 494

Channing, W. E., on manual labor

Character, knowledge, and 531, 532 duty of the State to train youth in................ 537

China.......................... $54^{2}$

Civilization, its stages of slavery, brigandage, wholesale hanging. killing in poorhouses, and final reign of the divine law of labor...........

Clark, Sheriff John, handicrafe ought to replace useless studies.....

Cole, Mr., on the dearth of skilled labor................. 537

Commissioner of Education, $\mathrm{Re}$ port of the............ 514

Cooper, Peter, letter to the President of the United States concerning Industrial Education $\ldots \ldots \ldots \ldots \ldots \ldots \ldots, 516$

Copenhagen, laws of repression of pauperism in............ 52r

Crime, cost of, in the United States $\ldots \ldots \ldots \ldots \ldots \ldots{ }_{4} 8_{3}$

Culture too indefinite an aim for public Education.......... 479

D.

Developing School, The.... 493-509

Its arrangement........... 494-495

Its advantages $\ldots \ldots \ldots \ldots \ldots \ldots \ldots . . .498$

Inscparable from public industrial Education ... . . ....4 499

Assigns to every man lis proper function in society.... 499-500

Prevents man's failure in life.... 500

Favors heredity of mechanical genius.$\ldots \ldots \ldots \ldots \ldots \ldots$ sor

Performs with exaceness an important work formerly left to chance... ......... 502-503 
Suits the trade to the hereditary condition of the blood... . 503

Leads to improvement in art and makes work a pleasure.. 503-504

Contains the solution of the great social problem... . . . 504-505

Doubles production.... 505, 55I, $55^{2}$

Can be introduced without hardly any extra expense...... 507

Putting man to his proper work leads lim to educate himself through life........... 508

Replaces the pleasure of having and getting by that of doing................. 508

And Manual Institute replacing the old apprentice system... 5 II

Realizes the dream of philosophers and philanchropists

Harmonizes labor with inclination regenerates society. ... 55

[C The Developing School takes the choice of a man's avocation out of the range of chance and makes it a matter of trial, observation, and judgment. Not a parent but is to-day perplexed as to what to put his boy to with the certainty that he does not shut upon him forever the door to success by mistaking his calling.]

[Ners The Developing School by harmonizing work, capacity, and inclination, modifies, directly or indirectly, every generalization in political economy, and corrects the conflicting elements of labor, capital, and competition.]

Dresden, Saxony, laws of repression against pauperism in...

Dream, The, of philosophers.. 532-533 E.

Education, a new organization of - and not of labor and society wanted.......... 508-509

To-day not as good as fifty years ago $\ldots \ldots \ldots \ldots \ldots \ldots \ldots \ldots \ldots \ldots \ldots 3^{8}$

Must differentiate in to specific lines ............... 540-54I

Our - without a foundation $547-550$

Our - instead of improving the industrial capacity of the many, schools the wits of the few.............. 551, $55^{2}$

Elizabeth,Queen of England, vagabonds hanged under....... 520

Emerson, Ralph Waldo, clioosing the right work........... 533

England, laws of repression of pail-

perism in ............. $519-520$

Era, The new - we are entering upon........ 518, 533-534, 551-553
F.

FOUNDRY-WORK... ............ 494

France, laws of repression of pauperism in................ 520

Pauperism in. . ........... 522-523

Froebel's Kindergarten.. 510, 544,

Future, the. ............ $55^{54-553}$

G.

Gates, G, F., on Industrial Education...$\ldots \ldots \ldots \ldots \ldots \ldots \ldots 3^{8}$

German system of developing capacity........... 549, $55^{2}$

Germany, pauperism in ............ 524

Grammarians and sophists, Greece and Rome ended with them, we ill-advisedly begin with them ............... 527-528

Greece, the materialism of, crumbled before the moral power of Rome .............. 542

Greeks and Romans had no need of industrial Education..... 530

Gyroscope ................... 495

\section{H.}

Hale, Rev. Edward E., on Industrial Education.... 510, 534, 536

Half-time schools......... 506,507

Hall, Rev. Dr., complaining of want of purpose and individual capacity .......... 500-50z

Hamburg, laws of repression of pauperism in ............ 52x

Handicraft ought to take the place of useless studies......... $53^{8}$

Hill, Frederic, Industrial Ëucation and skill as preventives of crime..............478,480

Huxley, Thomas $H$., on ascertaining capacity $. . \ldots \ldots \ldots \ldots, 53^{2}$

\section{I.}

INDIviduAL sovereignty takes offense at a power in the family, state, or heaven... 530-53 Industrial Education........ 478-553 The need of ................. $47^{8}$ Paying for itself.... 499, 506-507,

Frederic Hill on $51-518$

Frederic Hill on .......... 479, 480

Opens a new order of civilization $504-505_{2} 5 I^{8-5}$ I $9,551-553$

Lack of - the prime cause of most forms of defectiveness $4^{8} \mathrm{r}-4^{8} 3$

Considerations in favor of... $5 \times 6-517$

Its effect upon courts, prisons, and asylums of all sorts..... $5^{18}$ 
Channiag on ........... 53r, $53^{2}$

Lessens pauperism and crime... 535

Without - large cities become centers of pauperism and communism.......... 539-540

Stages of ....... . $544-545,545-550$

School Association of Boston, Report of ... ....... 489-490

Expositions, monthly, for the encouragement of labor and invention .............. 5r5-516

Industry, comfort, and orderly homes preventives of crime. 479

Stimulates science and gives scope to the development of a variety of talent ........ 540

The school of the natioaal character............... 543-544

Insanity, its cost to the Üuited States................. $48_{3}$

Invertions, useful, more valuable than philosophical fancies... 549

Italy, pauperism in .......... 523

\section{J.}

JACOBin clubs and revolutionary brigades recruited by our schools................... $54^{8}$

Japan....................... 542

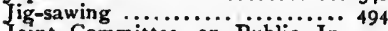

Joint Committee on Public Instruction of the city of Boston...$\ldots \ldots \ldots \ldots \ldots$........ 534-539

\section{K.}

KindergïRten.. 510, 544, 545, 547-550

Develop love and capacity for work, and are cheap at any cost.. .................... 548

\section{I.}

LABOR the foundation of the modern State................. 529 Conflicting with republican aspirations............... $53^{\circ}$

Skilled - encouraged by the diploma of the iadustrial school.................... 535

Dearth of skilled - in New Eagland

Disjointed from capacity and inclination leads to the confusion of all interests....... $55 \mathrm{x}$

London, pauperism in .......... 55

\section{M.}

Machine-shop................. 494

Machinery does not injure labor, but lack of Industrial Education does.................. 536
Manual labor the best school for taste and character.... 531-532

Manual Institutes ........ 495-497 Arrange work for teaching and not for profit.......... 495-496

Teach every part of a trade. $49^{6}-497$

Their advantages.............. 498

Mason-work.................... 495

Massachusetts, apprentices in...... 502

Not too poor for training industrially her children... .. 505

Pauperism in ............... 525

Average income and cost of living in .............. 526

The United States looking to. $333-539$

The noble men and women of...

Can - give up the lead in Education ?..................

Massachusetts Board of Charities and Correction on crime and ind ustry $\ldots \ldots \ldots \ldots \ldots \ldots 4^{8} \mathrm{r}$

On the increase of pauperism... 525

Board of Education on Industrial Education.......... 488-493

Masses, precarious condition of the................ 526-527

Our schools not adapted to the wants of the ............ 529-530

The saving of the - through the organization of Education upon the basis of labor...... 539

Materialism crumbling before moral power......... $\quad \ldots 42-543$

Mechanic arts, sound instruction in the, impussible without excellence in construction.. 493

Mechanical functions, lack of the, paralyzes a part of the brain and weakens the whole.... 537

Mechanics, good, hardly ever seek relief................... 536

Men and women, healthy, the most precious commodities of a community............. 536

Middle Ages................... 530, 542

Misery more dangerous to the perpetuity of the government than scholastic ignorance... 527

Misplaced, men are, in aine out of ten cases, and consequently fail in life..$\ldots \ldots \ldots \ldots \mathbf{5 1 2}^{2}$

Moral discipline in Magual Institutes................ 498

\section{N.}

Natronal Teachers' Association, - on Industrial Education. 486-488

Native industry best satisfies and develops the national taste and genius................. $54 \mathrm{r}$

New England, dearth of skilied labor in.............. 537

New York State, pauperism in.... $5^{24}$ 
Newell, Hon. A., on Industrial Education............486,517 Newell, John, Esq., on Industrial Education........ 511, 534, 537

Norway, pauperism in.......... 524

\section{o.}

Observation of the natural and artificial medium we live in affords the best mental training............. 529, 531-532

Over-production a dangerous misconception.............. $55^{\circ}$

Over-stocking in one or another line preventable by Boards of Industrial Education....... 533

\section{P.}

Parls, pauperism in........ 522-523 Parker, Theodore............. 538 Pauperism, its treatment in different ages and countries.. 483-484

Prevention of - and crime the next highest aim of Education ................ $485^{8-486}$

Prospective cost............. 519

Laws of repression of - in various ages and countries.. 519-521

Three times as large as the official figure ............. 521

The statistics of the - of the world ................ 52x-525

The comparative - of States not indicated by their statistics. 526

Preventable and lessened by Industrial Education. 535, 536, $537,552-553$

Often caused by cultivating the head at the expense of the hand.... ...............5 $53^{6}$

Pennsylvania, Gov. Hartranft's Message to the Legislature of - concerning Industrial Education................ $5 \mathbf{I}_{5}$

Persia ..................... 542 Phillips, Wendell, on Industrial Education..... 509, 534, 537-538

Planing-machines . ............ 494 Press, the, on Industrial Education................. 511-513

Printing-press $\ldots \ldots \ldots \ldots \ldots \ldots \ldots . . \ldots 495$

Prussia, pauperism in............ 523

Pythagoras................... 549

R.

Reformation, the great, needed 539 Rhode Island, State Report of, on Industrial Education........ 514

Right living is an art and can only be learned by practice...... 509

Rights, endless talk of, makes anarchists .............. 530-531
Rome, the moral power of, crushed Greece with its material-

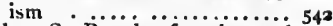

Ruggles $_{1}$ S. P., the founder and originator of the Developingschool and Manual Institute, or the American system of manual instruction 493,499 , $505,507,511,533,534,536$,

Runkle, President of the $544,546,550$ technic Institute of Boston, on the Russian system of technical training .. 487,488 $491,511,544,549$

Ruskin, John, on fitness for our work.............. 533

Russian system of technical training... $487,488-491,546,549,55^{2}$

\section{s.}

SARAcens.................. 542

Saxony, pauperism in. $\ldots \ldots \ldots \ldots \ldots . . .6523$

School, the union of, and shop corrects the extremes of idealism and of empiricism.. 543

Our present system discriminates against the laborer......... 5 ro

Schools, our, recruit crime..... 5 512-513

Return the children helpless to the parents.............. 537

Fail to form men of force.... $537-53^{8}$

Tend to deteriorate the American people... ....... $\quad \ldots \quad 53^{8}$

Not adapted to the wants of the masses... ........... $529-530$

Schoppenhauer . ............ 549

Scotland, patperism in .......... $52 \mathrm{5}$

Senate of the United States, motions of, concerning Industrial Education......... 515-516

Senses, the mastery of the $\ldots 544,546$ Spain, laws of repression of pauperism in ............... 520

Spelling, grammar, arithmetic, etc., tricks of............. 5 I7 Stages of Industrial Education $544-545$ Steam-engine and boiler......... 494 Steam injector................. 495

Stucco-work. ................. 495

Study and work correcting each other. ................492

Sweden, pauperism in $\ldots \ldots \ldots \ldots \ldots . . . \cdots{ }^{24}$

Switzerland, laws of repression of pauperism in.............. 52x

T.

Technical training and not soupkitchen charity wanted....4 48x

Thompson, Mrs. Elizabeth, insists upon the elevation of labor through the school......... 511 
Her position in reference to the New Education

Tinsmith.................... 549

Tools and their uses, instruction in .................... 489-490

The mastery of $\ldots \ldots \ldots \ldots . . \ldots, 544,545,546$

Trade, every boy entitled to a.... 497

The mastery of the right - the consummation of Industrial Education............545, 546

A boy may learn a - at schnol and farming too, says Channing.................... $53^{2}$

Trades, especially when they are remunerative, build up normal homes and prevent lapsing into pauperism........... 480

For children with one or another taint in the blood. ......... 503

Mechanical elements fundamental to all ............487,488

Learned in Manual Institutes or picked up in the old shops..

Tramps, prospective cost of....... 519

Turning-lathes................. 494

v.

UNITED States, cust of insanity to the.................... $4^{83}$

Cost of crime to the .........483

Motion on Industrial Education in the Senate of the... 515-516

Looking to Massachusetts.. 533-534

Unskilled labor lapsing into crime. 480

Lapsing into pauperism......... 480
Useful work, variety of, the best gymnasium............. 537

Utica, N. Y., School Commissioners at, concerning Industrial Education............... 54

\section{W.}

Wade, Benjamin............. $53^{8}$

Wages, fluctuation of, preventable by Boards of Industrial Education ............... 535

Want or misery not indicated by the figures of pauperism....

$522,524,525$

Ascertained by the average income and cost of living.... 526

Leads to hereditary defectiveness 478 Whittling or Carving-school at Boston ................ $4^{89}$

Wickersham, Hon. $J$. $\mathrm{P}_{\text {., }}$ on Industrial Education........ $\quad 487$

Wood-turning................. 494

Work a preventive of pauperism, crime, disease, and insanity,

$48 \mathrm{r}-482,591$

Comes too late with criminals and paupers ............. 482

Is positive while books are negative. ........... $528,531-53^{2}$

Means duty, the lesson most needed............. 53 $53^{1-53^{2}}$

Makes us hardy and virtuous.... 539

Worcester Free Institute..... 49 49 -493

Its annual salable products...... 493

Wright, Hon. Elizur, on Industrial Education and the Kindergarten................... 5 5 10

Wurtemberg, pauperism in........ $5^{23}$ 

Deterioration and Race Education, with practical Application to the People and Industry. By Samuel Royce. 586 pages. Price, \$2.50. Boston: Lee \&o Shepard, Publishers.

New York: Charles T. Dillingham.

\section{RECOMMENDATIONS.}

\section{From the New York School fournal.}

"Deterioration and Race Education" has been in preparation for several years, and begins to attract attention. This work is strong in facts, arguments, and erudition, etc., etc.

\section{From the Popular Science Monthly.}

.... In this book Education is considered from a broad, humanitarian pcint of view, and in connection with the great causes of decay and deterioration. The author has collected a great deal of interesting material, interspersed with valuable observations and reflections, and the volume is pervaded by a reformatory and progressive spirit.

\section{From the Library Table, Feb. 16.}

The author displays a thorough knowledge of his subject, and his conclusions, no less than the startling array of his facts, deserve the most serious consideration of all who are in any way connected with the promotion or administration of public interests. We recommend the volume for careful perusal as one of the most valuable recent contributions to social and educational science.

From the Reformer, Jan. Ir.

"Deterioration" is replete with erudition and practical wisdom, bearing testimony of the author's genuine philanthropy, and will make its mark-as none can read it without being thoroughly aroused as to the present appalling condition of the masses; and what is proposed is moderate and sustained by other social thinkers.

\section{From the Boston Evening Transcript.}

.... The range of this work is comprehensive, and the various topics which incidentally arise in connection with the main subject are ably discussed. 


\section{From the $N . Y$. Daily Sun.}

A valuable contribution to the materials of social science, "Detcrioration" is a remarkably painstaking and useful work. It is singularly thorough and effective, and such is the range of the book and so important its topics, that parents, teachers, and social students should welcome it.

\section{From the Christian Union.}

.... Fact follows fact in this book with appalling demonstration. . . . We can not in any degree do justice to the importance of Mr. Royce's book, but bespeak for it from earnest minds a careful and serious perusal.

SIR: I know of no publication that so thoroughly shows the injury, the general neglect of early industrial training does to the masses, as the work on "Deterioration and Race Education." I have, therefore, determined to make the effort to bring this subjeet, so vital to the welfare of the people and the stability of our Government, to public attention, by presenting a copy of said work, with my compliments, to the President of the Board of Education of every large city of our Union for the use and consideration of the Board.

\section{Yours respectfully,}

Peter Cooper.

"Deterioration" deserves the fine reception it meets with from the philanthropists and active men of the community. It is a useful and noble book, timely, too, in its appearance. May it accomplish the work whereunto it is sent.

O. B. Frothingham.

S1R:-I have taken some interest in religious, charitable, and educational movements, and hold to-day, labor is worship. There is a majestic grandeur in work. It is the only panacea against all evils and God's great blessing to man. If life is work, work alone is life; it is full of dignity as it is of power, and an honest laboring man is the crown of the Almighty; let us then all work, trust, and hope. The joy of life is love, the religion of life is justice, the glory of life is work, and the summing up of life is death, and with it our judgment comes. With such a creed you will not wonder that I hailed your publication with a hearty "God bless it and its author," and determined to do my part in scattering the seed, trusting the harvest to the Power above.

Elizabeth Thompson.

SIR: The necessity of preventing pauperism, misery, and crime becomes daily more urgent with the increase of population. . . . I I hope, therefore, to do my country some good in spreading the valuable information contained in a late publication entitled "Deterioration and Race Education," by sending a copy of the latter to the Governor and other high functionaries of each State in the Union, who are interested in knowing the condition of the people, and the means proper for their elevation.

Very respectfully,

Elizabeth Thompson. 


\title{
STATE OF FLORIDA, Executive Department.
}

I sincerely trust that much good will result from the work of "Deterioration and Race Education," and that its suggestions may prove beneficial to our whole nation.

Grorge H. Drew, Governor of State of Florida.

Executive Department, W. Virginia.

I have read "Deterioration and Race Education." This work has been . prepared with care and ability, and I think will accomplish much good.

Henry M. Mathews,

Governor of W. Virginia.

State of Wisconsin,

Executive DepaktMent.

I am directed by the Governor to express .... his great interest in the subject discussed in the volume of "Deterioration and Race Education," and of his appreciation of the same. ....

George W. Burchard,

Private Secretary.

A general knowledge of the subject resulting from the dissemination of the views of the author of "Deterioration," as expressed in this volume, can not fail to have a beneficial influence, and must necessarily tend to the amelioration of the condition of the masses.

$$
\text { W. K. ROGERS, }
$$

Sec. to the President of the U.S.

I have examined "Deterioration and Race Education" with much interest. It is impossible not to honor the earnest and sincere spirit in which this book has been written. It is full of needful truths bravely spoken, and I am glad to have had the privilege of perusing it.

\author{
Henry C. Potter, D.D., \\ Of Grace Church, N. Y. City.
}

"Deterioration and Race Education" is interesting to educated persons, and very valuable to the mass of society. I have read it wich pleasure and profit, and wish it success.

John W. DRaPER, M.D., LL.D.,

Prof, in the University of New York.

"Deterioration and Race Education" is an able and thoughtful work, evincing erudition, earnestness, and a conscientious desire to advance the cause of public education; I would recommend my fellow-teachers to study the facts and principles set forth in Prof. Royce's work.

Thos. Hunter, Ph.D.,

President of the Normal College of New York City. 
I have read "Deterioration" with interest. There is no oubt about its fasts. We must revise our system of public education, and better adapt it to the wants of the times.

J. D. RunkLe,

President Boston Institute of Tethnology.

"Deterioration" is one of those books well worth the time required to read it carefully. It is a very, very useful book, and one the knowledge of which should be spread.

\section{Coleman Sellers,}

President Franklin Institute, Phila.

"Deterioration" should be carefully read, not only by teachers, but by all who are interested in the education and the welfare of humanity.

Ben Hyde Benton,

President Polytechnic Institute, New Market, Va.

"Deterioration" follows a line of argument greatly needed at the present time in educational affairs, and is an especially useful book.

Hon. John Eaton,

Commissioner of Education.

"Deterioration" is full of curious and interesting information, and I sympathize with the philanthropic desires of the author.

George William Curtis.

I have read "Deterioration" with just admiration for its depth, breadth, and vigor. This book is like a hundred-pounder loaded to the muzzle. . . . . I am now nearly seventy-four years old, and perhaps the most encouraging thing I have seen done is this plain-spoken, earnest book; for touly an evil must be demonstrated before it can be cured. Another thing is encouraging it comes with its sharp thunder-claps, etc., etc.

ElizUR Wright

"Deterioration and Race Education" is of rare value, full of suggestion, and opening up views that can not fail to attract and interest deeply every student of the social questions of the day. Its contribution toward solving these is of great value, and no one can follow snch guidance without placing himself in a position to serve humanity efficiently in most important interests.

Wendel. Phillips.

The studies pursued by the author of "Deterioration " are in a direction very generally neglected, and the information given is just in the lines where it is most needed.

Rev. Edward E. Hale.

"Deterioration and Race Education" is of great value and importance, diffusing knowledge upon subjects on the due consideration of which depends the welfare, if not the very existence, of our social organization.

O. Wendell Holmes. 



DATE DUE

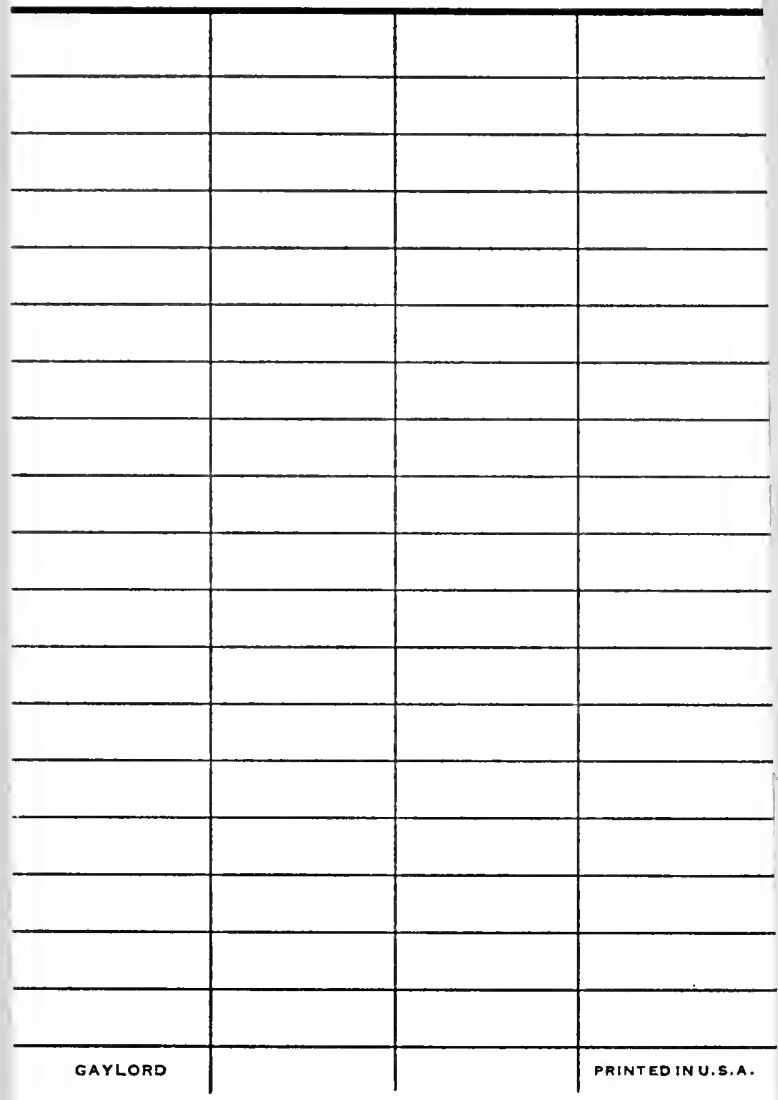




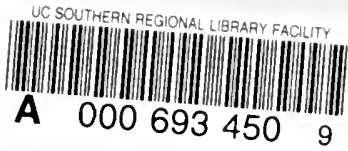



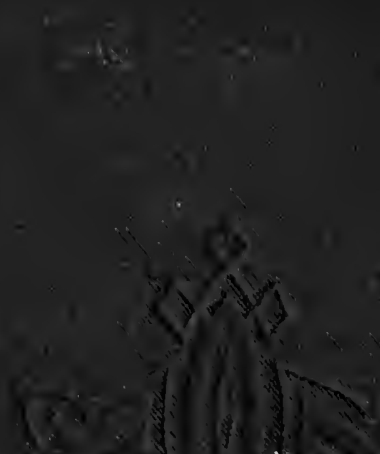

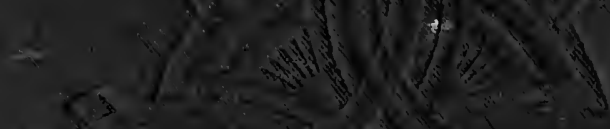

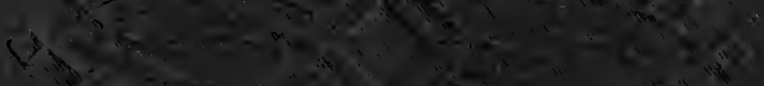

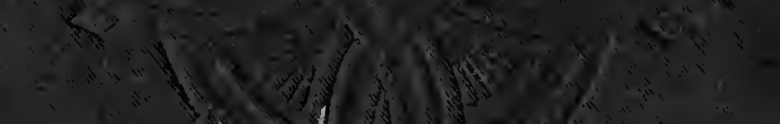
$\rightarrow x+y$ s.

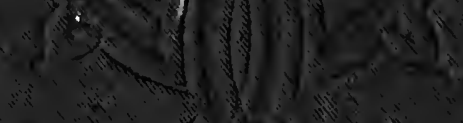

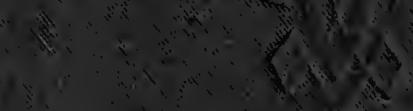

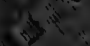

